\title{
Simulated Coal-Gas-Fueled Molten Carbonate Fuel Cell Development Program
}

\author{
Final Report
}

Work Performed Under Contract No.: DE-AC21-91MC27393

\author{
For \\ U.S. Department of Energy \\ Office of Fossil Energy \\ Morgantown Energy Technology Center \\ P.O. Box 880 \\ Morgantown, West Virginia 26507-0880 \\ By \\ International Fuel Cells Corporation \\ 195 Governors Highway \\ South Windsor, Connecticut 06074
}

August 1992 


\section{TABLE OF CONTENTS}

Section

Page

TABLE OF CONTENTS

iii

LIST OF TABLES

iv

LIST OF FIGURES

vii

INTRODUCTION

TASK 1 - STACK DESIGN

Subtask 1.1 Stack Design Requirements

Subtask 1.2 Stack Design Preparation

TASK 2 - REPEAT PART MANUFACTURING DEVELOPMENT AND FABRICATION

Subtask $2.1 \quad$ Porous Parts

Subtask 2.1.1 Electrode Casting

2.1-1

2.1-1

Subtask 2.1.2 Electrode Heat Treatment

2.1-6

Subtask 2.2 Repeat Part Quality Assurance and Testing

2.2-1

Subtask 2.2.1 Quality Assurance

TASK 3 - NON-REPEAT PARTS DEVELOPMENT FOR STACK

Subtask 3.1 Manifold Seal

Subtask 3.2 Manifold Development

TASK 4 - TEST STAND PREPARATION

TASK 5 - REPEAT PART TECFNOLOGY DEVELOPMENT

Subtask 5.1

Cathode Life

Subtask 5.3 Cathode Compatibility Tests 


\section{LIST OF TABLES}

\section{Table}

Page

1.1-1 Process Configuration Revisions

1.1-2 Scope of ISU Test Vehicle

1.1-3 General Requirements for Design and Operation of the $100 \mathrm{~kW}$ ISU

$1.1-4100 \mathrm{~kW}$ ISU Operating Modes

1.1-5 $100 \mathrm{~kW}$ ISU Preliminary Packaging Requirements

1.1-6 $100 \mathrm{~kW}$ ISU Preliminary Test Stand Requirements

1.1-7 Recycle Blowers Functional Design Requirements

1.1-8 Cell Stack Assembly Functional Design Requirements (Preliminary)

1.1-9 Sensible Heat Reformer Functional Design Requirements (Preliminary)

1.1-10 Catalytic Bumer Functional Design Requirements (Preliminary)

1.2-1 Estimated Pressure Vessel and Cell Stack Weights

1.2-2 Summary of Vessel Design

1.2-3 Comparison of 8- $\mathrm{Ft}^{2}$ Stack Data with Model

1.2-4 Summary of Thermal Analysis of 8- $\mathrm{Ft}^{2}$ Stack

1.2-5 Summary of Thermal Analysis

1.2-6 144 Cell Stack Instrumentation Requirements

1.2-7 Thermocouple Location

2.2-1 Drawing and Specification Documents - Sheet Metal Components

2.2-2 Drawing and Specification Documents - Matrix

2.2-3 Drawing and Specification Documents - Electrodes (Anode)

2.2-4 Drawing and Specification Documents - Electrodes (Cathode)

3.2-1 Manifold Baffle Test Flow Conditions

3.2-2 Flow Distribution Test Results w/Bafle

3.2-3 Pressure Drop Caused by Baffle

3.2-4 Flow Distribution Test Results Without Baffle

4-1 Comparison of Requirements With Existing Test Stand Capabilities

4-2 Modification Requiremients for Supply Systems: Fuel, Oxidant, Vessel Gas

4-3 Modification Requirements for Other Systems

5.1-1 Test History and Performance Summary of Cells Analyzed for Post-Test Nickel 


\section{LIST OF TABLES (Cont'd)}

\section{Table}

5.1-2 Metallographic Examination of Cell 729

5.1-5

5.1-3 Microprobe Characterization of Cell 729

5.1-4 Chemical Analysis of Cell 729

5.1-5 Microprobe Characterization of Cell 730 Matrix

5.1-6 Chemical Analysis of Cell 730 Matrix

5.1-7 Comparison of Calculated and Measured Nickel Loadinge in $\mathrm{LiAlO}_{2}$ Wafers

5.2-1 Test Plan for Cell 738

5.2-2 Fuel Compositions

5.2-3 Oxidant Compositions 


\section{LIST OF FIGURES}

Figure

Page

1.1-1 Product Vision

1.1-2 Baseline System Schematic

1.1-3 Effect of System Pressure on System Efficiency

1.1-4 100-kW ISU Test Article Interface

1.2-1 Separate Loop Configuration

1.2-2 Connected Loop Configuration

1.2-3 Integrated Stack Unit Pressure Vessel

1.2-4 Cathode Recycle Catalytic Burner Packaging

1.2-5 Attachment of Stack Compression Bellows to Vessel.

1.2-6 Performance Data from Cell No. 724

1.2-7 Cell Polarization vs. Temperature and Current Density

1.2-8 8- $\mathrm{Ft}^{2}$ Center Cell Performance Comparison

1.2-9 Manifold Attachment (Cross Section of Cell Stack)

1.2-10 Manifold for 100-kW Stack

1.2-11 Single-Piece Rails

1.2-12 Manifold Alignment Guides

1.2-13 Molten Carbonate $100 \mathrm{~kW}$ Cell Stack Top Box End Plate Loads at $1300^{\circ} \mathrm{F}$

1.2-14 Molten Carbonate $100 \mathrm{~kW}$ Cell Stack Top Box End Plate Stresses and Deflections for Loads at $1300^{\circ} \mathrm{F}$.

1.2-15 Cell Temperature Instrumentation Locations

2.1-1 Comparison of Viscosity of Binder in Stoddard Solvent and Isopar E

2.1-2 Drying Rate Comparison of Slurries Made With Stoddard Solvent and isopar E

2.1-3 Tape Basis Weight from First Anode Trial

2.1-4 Basis Weights of Trial Cathode Tapes

2.1-5 Effect of Temperature and Inert Gas Concentration on the Flammability Limits of Combustible Gases

2.1-6 Oven Used for Continuous Debinding of Electrode Tapes 2.1-8

2.1-7 Full-Scale Debinding Oven Conceptual Sketch 2.1-9

2.1-8 Continuous Debinding Oven (Inlet End) with Incinerator Mounted in Place 


\section{LIST OF FIGURES (Cont'd)}

\section{Figure}

Page

2.1-9 Atmosphere Control Muffle Being Installed in Continuous Debinding Oven (Exit End)

2.1-10 Cracks in Anode Tape after Debinding Process Trial

2.1-11 Anode Porosity Distribution

2.1-12 Anode Thickness Distribution

2.1-13 Cathode Porosity Distribution

2.1-14 Cathode Thickness Distribution

2.1-15 Anode and Cathode for 8- $\mathrm{Ft}^{2}$ Stack

2.2-1 Document Configuration Management - Initial Document Preparation

2.2-2 Document Configuration Management - Document Change Procedure

3.1-1 Shunt Current Test Rig

3.1-2 Cell Cross-Section for Shunt Current Test

3.1-3 Cumulative Leakage Current for Cell 10 Plus Reservoir in SHUNT20

3.1-4 Leakage Current Distribution in SHUNT20

3.1-5 Leakage Current "WAVE" in SHUNT20

3.1-6 Measured Values for Leakage Current in SHUNT21 as a Function of Position

3.1-7 Schematic of Stack Electrical Wiring in SHUNT21

3.1-8 Pre-and Post-Test Electrolyte Profiles for SHUNT21 .

3.1-9 Electrolyte Profiles After Adjustments for SHUNT21

3.1-10 Leakage Current as a Function of Time for Cells 1 and 2 in SHUNT21

3.1-11 Leakage Current Profile for SHUNT22 at 113.5 Hours of Operation

3.1-12 Leakage Current Profile for SHUNT22 at 209.5 Hours of Operation

3.1-13 Leakage Current Profile for SHUNT22 at 305.5 Hours of Operation

3.1-14 Leakage Current Profile for SHUNT22 at 712.5 Hours of Operation

3.1-15 Leakage Current Profile for SHUNT22 at 1001.5 Hours of Operation

3.1-16 Leakage Current for Cell 9 and for the Combination of Cell 10 Plus the Reservoir in SHUNT22 as a Function of Time

3.1-17 Pre-Test and Post-Test Electrolyte Profiles for SHUNT22

3.1-18 Pre-Test and Adjusted Post-Test Electrolyte Profiles for SHUNT22 


\section{LIST OF FIGURES (Cont'd)}

Figure

Page

3.1-20 Manifold Side Seal Deflection Versus Seal Load

3.1-21 Stack Side Seal Compression Versus Seal Load

3.1-22 Seal Leakage of Stack-Side Seal During First $1200^{\circ} \mathrm{F}$ Hold

3.1-23 Seal Leakage of Stack-Side Seal During Second $1200^{\circ} \mathrm{F}$ Hold

3.1-24 Seal Leakage of Stack-Side Seal During Third $1200^{\circ} \mathrm{F}$ Hold

3.1-25 Seal Leakage of Manifold-Side Seal During First $1200^{\circ} \mathrm{F}$ Hold

3.1-26 Seal Leakage of Manifold-Side Seal During Second $1200^{\circ} \mathrm{F}$ Hold

3.1-27 Seal Leakage of Manifold-Side Seal During Third $1200^{\circ} \mathrm{F}$ Hold

3.1-28 Sketch of SEALRIG2

3.1-29 Seal Deflection as a Function of Seal Load

- 3.1-30 Seal Leakage Data for SEALRIG2 at Room Temperature

3.1-31 Seal Leakage Data for SEALRIG2 at $383^{\circ} \mathrm{F}$

3.1-23

3.1-32 Seal Pressure as a Function of Cold Air Flow at $1200^{\circ} \mathrm{F}$ Prior to any Seal Travel

3.1-33 Seal Pressure at a Fixed Leakage Rate as a Function of Seal Plate Travel

3.1-34 Post-Test View of SEALRIG2 Showing Conduction of Seal

3.1-35 Top and Side Views of SEALRIG3

3.1-36 SEALRIG3 Gaskets as Viewed During Post-Test Analysis

3.2-1 Stack Manifold Sizing

3.2-2 Reactant Manifold Flow Distribution Test Rig 3.2-4

3.2-3 Exit Manifold 3.2-4

3.2-4 Reactant Manifold Flow Distribution Test Rig 3.2-5

3.2-5 Reactant Manifold Flow Test Apparatus 3.2-5

3.2-6 Definition of Exit Manifold Flow Distribution Results 3.2-7

3.2-7 30-kW Fuel Flow Distribution $\quad 3.2-9$

3.2-8 30-kW Oxidant Flow Distribution $\quad 3.2-10$

3.2-9 100-kW Oxidant Flow Distribution $\quad 3.2-11$

4-1 X-804 Test Facility Systems $\quad$ 4.1-4

4-2 Design Schedule and Subtask Definition 4.1-8

5.1-1 Experimental Values of Nickel Content in Post-Test Matrices at $1200^{\circ} \mathrm{F} \quad 5.1-3$ 


\section{LIST OF FIGURES (Cont'd)}

Figure

Page

5.1-2 Comparison of Post-Test Matrix Nickel Content With Predicted Content From Simpler Shorting Theory at $1200^{\circ} \mathrm{F}$

5.1-3 Nickel Deposited in Tile or Matrix

5.1-4 Cell 729, Specimen No. 6551 - Fuel Out-Air Out

5.1-5 Cell 729, Specimen No. 6552 - Fuel In - Air In

5.1-6 Cell 726, Cumulative Nickel Profiles for Multiple Passes

5.1-7 Microprobe Analysis of Cell 730 Matrix

5.1-8 Elemental Traces from Cell 730 Matrix

5.2-1 Effect of Reactant Composition on Initial Performance of Cell 738

5.2-2 Effect of Cathode Diluent Type on Initial Performance of Cell 738

5.2-3 Effect of Reactant Composition on Initial Performance of Cell 738

5.2-4 Effect of Oxidant Composition on Initial Polarization of Cell 738

5.2-5 Effect of Reactant Composition on Performance of Cell 738

5.2-6 Open Circuit History of Cell 738 on Accelerated Oxidant

5.2-7 Effect of Oxidant Composition on Cell Performance

5.2.8 Effect of Shorting Test on Performance of Cell 738

5.2-9 Effect of Oxidant Composition on Performance of Cell 738 


\section{INTRODUCTION}

This final report summarizes the technical work performed under Department of Energy Contract DE-AC21-91MC27393, "Simulated Coal-Gas-Fueled Molten Carbonate Fuel Cell Development Program." This work consists of five major tasks and their respective subtasks as listed below. A brief description of each task is also provided.

\section{TASK 1 - STACK DESIGN}

\section{Subtask 1.1 Stack Design Requirements}

The Stack Design Requirements task focused on requirements and specifications for designing, constructing, and testing a nominal 100-kilowatt integrated stack and on requirements for the balance-ofplant equipment to support a 100-kilowatt integrated stack demonstrator.

\section{Subtask 1.2 Stack Design Preparation}

The Stack Design Preparation task focused on the mechanical design of a 100-kilowatt stack comprised of $8-\mathrm{ft}^{2}$ cells incorporating the new cell configuration and component technology improvements developed in the previous DOE MCFC contract.

\section{TASK 2 - REPEAT PART MANUFACTURING DEVELOPMENT AND FABRICATION}

\section{Subtask 2.1 Porous Parts}

\section{Subtask 2.1.1 Electrode Casting}

Electrode Casting focused on developing a faster drying solvent for use in the electrode tape casting process.

\section{Subtask 2.1.2 Electrode Heat Treatment}

Electrode Heat Treatment was directed at scaling up the laboratory continuous debinding process to a new full-size IFC debinding oven coupled to a continuous belt furnace that will both debind and sinter the electrodes in one continuous process train.

\section{Subtask 2.2 Repeat Part Quality Assurance and Testing}

Repeat Part Quality Assurance and Testing provided the appropriate effort to ensure consistent, highquality, reproducible and comparable repeat parts.

\section{TASK 3 - NON-REPEAT PARTS DEVELOPMENT FOR STACK}

\section{Subtask 3.1 Manifold Seal}

The Manifold Seal task focused on completing development of manifold seal concepts identified in the previous program to provide an external manifold seal meeting the mechanical, electrical, and sealing requirements.

\section{Subtask 3.2 Manifold Development}

Manifold Development focused on verifying that the fuel and oxidant manifold designs provide uniform distribution of reactants to the cells in the 100-kilowatt stack. 


\section{TASK 4 - TEST STAND PREPARATION}

This task was directed at preparing a test facility capable of tall-stack testing at power levels up to 120 kilowatts.

\section{TASK 5 - REPEAT PART TECHNOLOGY IMPROVEMENT PLAN}

\section{Subtask 5.1 Cathode Life}

This task was directed at extending the life of molten carbonate fuel cells as affected by cathode dissolution. Electrolyte composition, cathode material, and matrix configurations are varied to obtain the maximum increase in endurance without adversely affecting performance or cost.

\section{Subtask 5.2 Single Cell Testing}

Single Cell Testing was directed at evaluating the repeat part technology improvements being developed under Task 5 in subscale single cells.

\section{Subtask 5.3 Cathode Compatibility Tests}

This task evaluated the compatibility of alternative cathode materials with matrix material in the presence of electrolyte. 


\section{TASK 1 - STACK DESIGN}

\section{Subtask 1.1 Stack Design Requirements}

Objective - The objective of Task 1.1 was to define the re quirements and specifications for designing, constructing, and testing a nominal $100-\mathrm{kW}$ integrated cell stack, and to define the design requirements for the balance-of-plant equipment to support a field test of the $100-\mathrm{kW}$ integrated cell stack.

\section{Summary}

The Integrated Stack Unit (ISU) conceptual design and MCFC power plant characteristics were reviewed for purposes of establishing the design process conditions for the cell stack. A preliminary set of design requirements was established. The ISU steady-state process flow conditions were derived as a basis for establishing ISU component design requirements, and design requirements for the long lead-time recycle blowers were defined. Design requirements were also derived for the cell stack, the sensible heat reformer, and the catalytic burner.

Some of the work reported here was performed on other programs but is included because of its relevance, perspective, and for completeness.

\section{Report of Work}

The starting point was the baseline Integrated Stack Unit product vision derived under the previous IFC contract with DOE, number DE-AC21-87MC23270. The approach is shown in Figure 1.1-1. The process schematic derived in the DOE program is shown in Figure 1.1-2. Based on those earlier studies, the ISU was designed to operate at 60 psia.

Studies in the current program investigated several process modifications, resulting in the following revisions:

- Pressure - Design pressure was reduced from 60 to $50 \mathrm{psia}$. This reduction permits use of a single-stage turbocompressor and simplifies the balance-of-plant equipment. This change is expected to impact system efficiency (due to increased recycle blower power requirements) by less than one percentage point, as shown in Figure 1.1-3.

- Process configuration - Changes to the baseline process flow configuration were made to facilitate packaging the ISU components and/or to alleviate severe operating conditions for the components. The specific revisions are tabulated in Table 1.1-1.

Table 1.1-1. Process Configuration Revisions

1. Move cathode recycle blower downstream of air inlet mix point

2. Move catalytic burner downstream of cathode recycle blower and air inlet mix point

3. Move anode recycle blower upstream of sensible heat reformer 


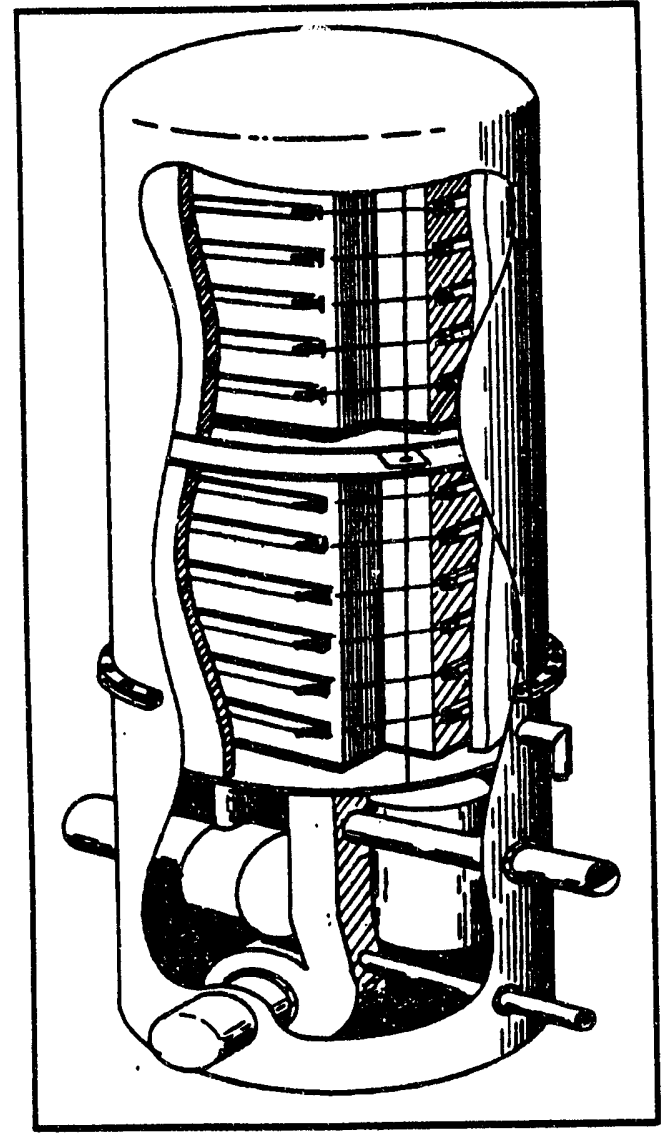

1-2 MW Integrated Stack Unit (ISU)
- ISU contalns all MCFC equipment

- Pressurized air/gas in $\rightarrow$ dc out

- Multt-fuel capablitity

- All coal gases and natural gas

- Environmentally clean

- No water consumption

- Equipment cost minimized

- Pressurized

- High power denstiy

- Large area cells

- Reasonable stack bullding block (100 kW)

- Installation and field costs minimized

- Factory assembly, check-out

- Rall transportable

- Engineer/constructor Integrates into plant

- Clean interfaces

- High avallablilty with low maintenance costs

- Simple system

- Accessible components

Fost20s o mersact

Figure 1.1-1. Product Vision 


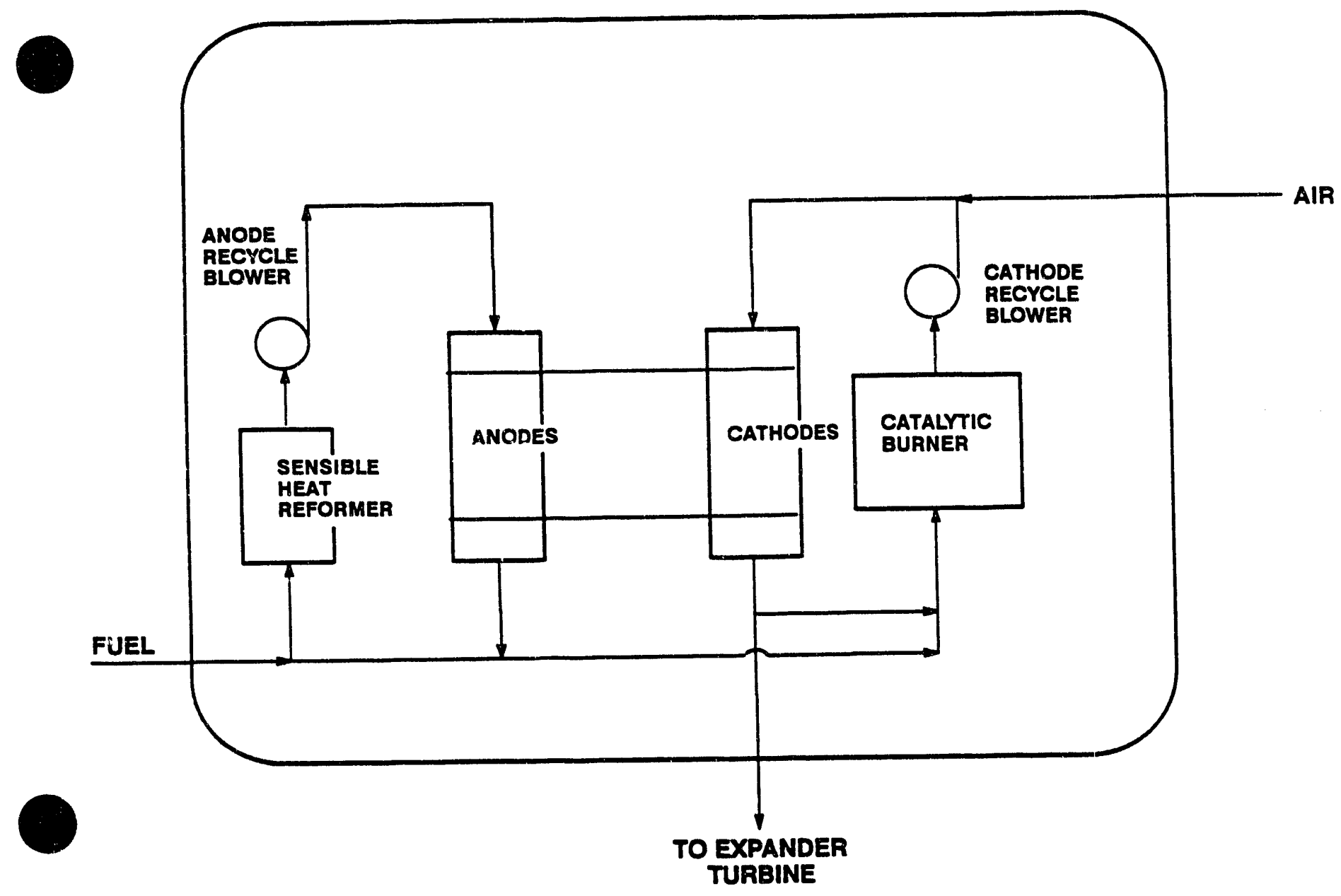

Figure 1.1-2. Baseline System Schematic 

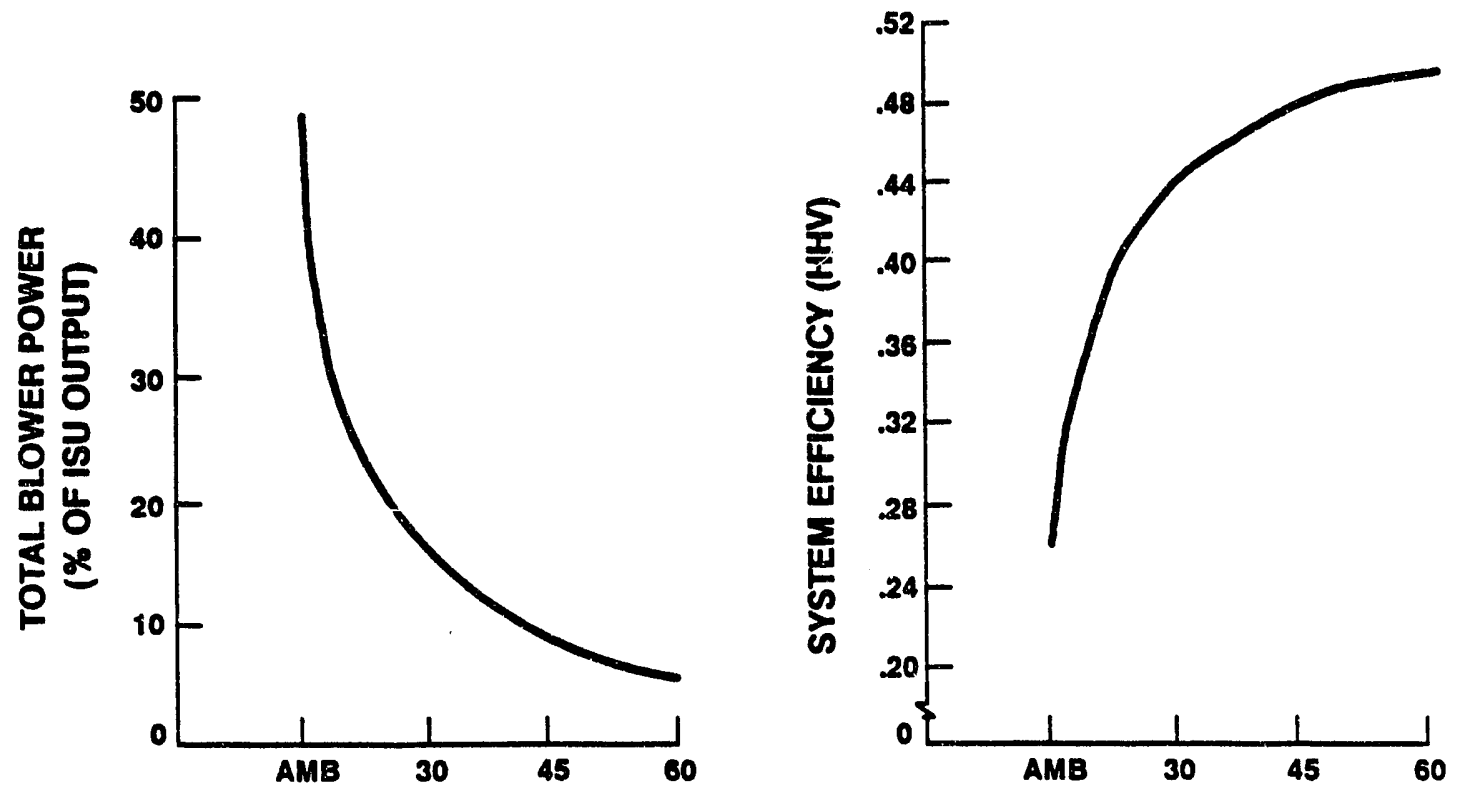

OPERATING PRESSURE (PSIA)

Figure 1.1-3. Effect of System Pressure on System Efficiency

A preliminary set of general design requirements was established. These included:

- Definition of the scope of the packaged 100-kW ISU, as defined in Table 1.1-2.

- General requirements for design and operation of the $100-\mathrm{kW}$ ISU, as indicated in Table 1.1-3.

- Definition of the functional inte faces between the stack and the test stand, as indicated in Figure 1.1-4.

- Definition of the operating modes of the 100-kW ISU, as listed in Table 1.1-4.

- Definition of ISU packaging requirements, as listed in Table 1.1-5.

- Definition of test stand requirements, as listed in Table 1.1-6.

The 100-kW ISU was operated over several test modes. Based on preliminary screening studies of several test modes, operation in a connected recycle loop configuration on methane fuel at $120 \mathrm{~kW}$ overload was selected to be the reference configuration mode and design point for establishing component design requirements. The steady-state process flows derived for this mode reflect the following:

- Fuel gas is desulfurized methane.

- Updated component pressure drop estimates adjusted for variations in gas properties (flow, density, temperature, pressure, etc.).

- Updated heat loss estimates.

- Updated cell temperature profiles and slightly reduced cell performance level, corresponding to output from the IFC updated 144-node performance and thermal profile computer model.

- Updated performance of the catalytic burner based on vendor input. 
Analysis of the process flow thermodynamics involved iteration with the analysis of the thermal distribution in the cell stack package and the relative waste heat picked up by the anode and cathode process cooling gases (See Subtask 1.2).

\begin{tabular}{|l|}
\hline Table 1.1-2. Scope of ISU Test Vehicle \\
\hline The 100-kW ISU is a packaged assembly which includes: \\
Cell Stack Assembly \\
Sensible Heat Reformer \\
Catalytic Burner \\
Anode Recycle Blower \\
Cathode Recycle Blower \\
Piping Thermal Insulation \\
Electrical Power Bus Bars \& Cabling \\
Instrumentation for Temperature, Pressure, Flow, Cell Voltage, \\
and Cas Composition \\
Containment Pressure Vessel \\
Relief Provisions \\
Electrical Penetrators \\
Instrument Penetrators \\
Fluid Penetrators
\end{tabular}

Table 1.1-3. General Requirements for Design and Operation of the $100-k W$ ISU

1. The stack shall be supported by the existing X-804 stack test stand, modified as required.

2. Design and operation of the stack and X-804 stand shall ensure personnel safety and equipment protection.

3. The stack configuration shall permit use in later field demonstration units by ease of assembly/ disassembly.

4. The cell stack shall be a truck-transportable configuration designed for shipment in a vertical orientation.

5. The stack system configuration and process conditions shall be consistent with the system and process conditions established for MCFC commercial product.

6. The stack design shall be to material gauge standards used at the origin of supply.

7: Dimensions on drawings shall be in English units of inches with metric dimensions shown in parentheses (millimeters). 


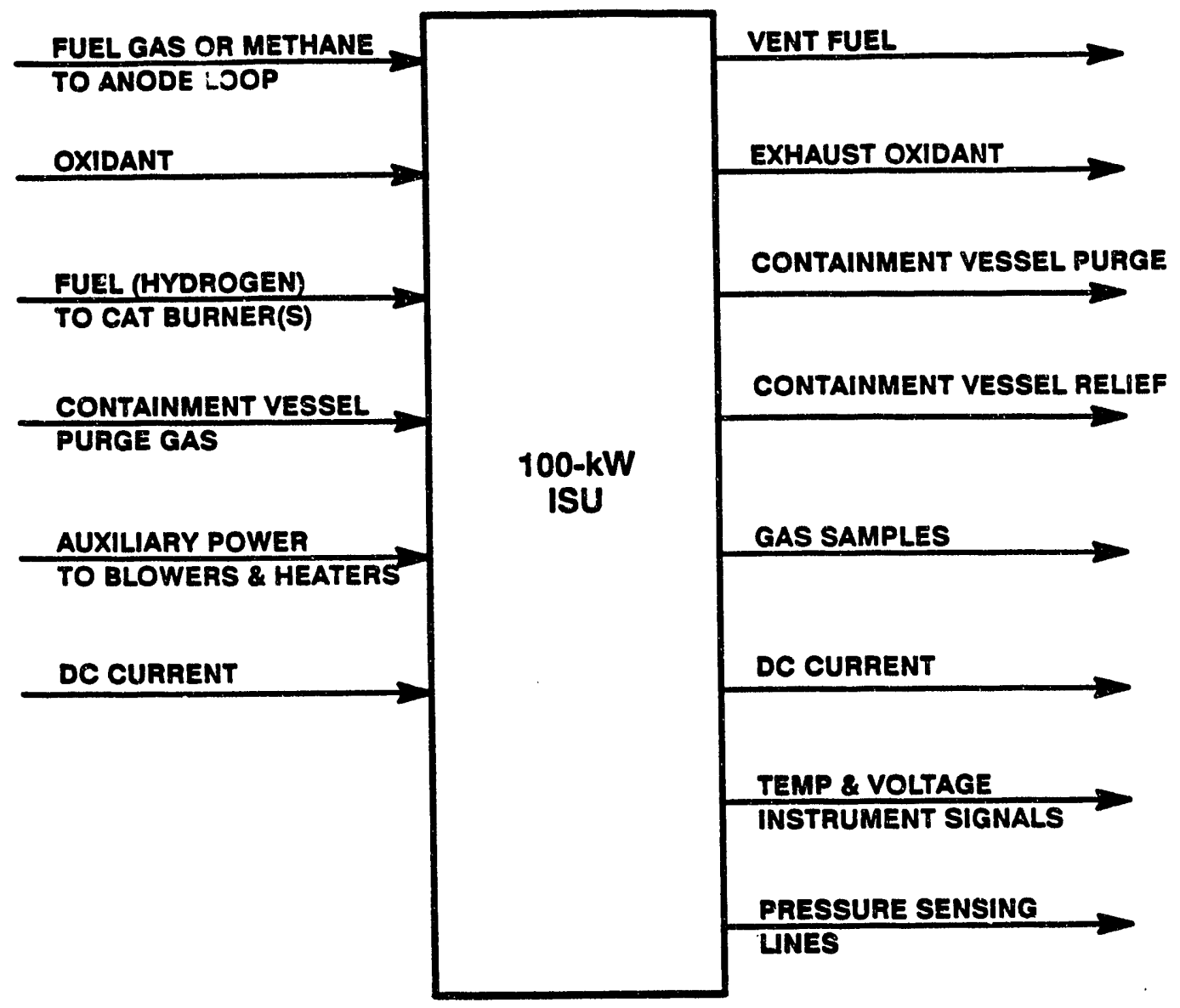

Figure 1.1-4. 100-kW ISU Test Article Interface

Table 1.1-4. 100-kW ISU Operating Modes

1. Initial start-up

2. Hot Stand-by

3. Load

4. Shutdown

5. Restart 
Table 1.1-5. 100-kW ISU Preliminary Packaging Requirements

1. The stack packaging configuration shall be consistent with demonstrating essential system characteristics of thermal management and pressure drop without the addition of supplementary test equipment.

2. The stack packaging configuration shall not preclude use of the stack in a field demonstration.

3. The stack packaging configuration shall be consistent with the approach for the eventual product and shall not be compromised by present X-804 test stand limitations. Modifications to the stand, alternatives for assembly location and location of the stack relative to the X-804 stand shall be considered.

4. The pressure vessel shall be designed in accordance with the ASME Code, ISPESL Code, and Jis Code.

5. The pressure vessel external touch temperature shall not exceed $140^{\circ} \mathrm{F}$ or shall use local guards.

6. Electrical design within the stack shall be in accordance with IEEE guidelines for dielectric isolation.

7. The stack shall be designed on the basis that units of similar configuration could be manufactured and acceptance tested at IFC and then transported by truck and shipped to remote sites in the U.S. or overseas for field demonstration.

On this basis the stack shall be designed in accordance with the IFC shipping and handling criteria.

8. Stack packaging shall permit access to system components for maintenance.
a) Removal of recycle blowers without stack cooldown or vessel head removal.
b) Replacement of SHR catalyst without affecting the stack.
c) Replacement of catalytic burner catalyst without affecting the stack.

Table 1.1-6. 100-kW ISU Preliminary Test Stand Requirements

1. The existing X-804 test stand shall be upgraded to support operation of the cell stack up to $120 \mathrm{~kW}$.

2. Supply of fuel and oxidant to the stack shall be based on the use of recycle blowers. No special provision for stack operation shall be made for loops without recycle blowers.

3. X-804 stand shall be capable of supporting the stack operation up to 100 psia for diagnostics.

4. The test stand shall be capable of providing several types of fuel gas as follows:
a) $\mathrm{CH}_{4}$
b) Simulated reformed methane
c) Simulated coal gasification fuel gas

5. The test stand shall include provision for initial stack start-up. 
Additionally, operation in a connected mode on methane fuel at off-design open circuit conditions was evaluated. This represented a case of particular interest in the derivation of recycle blower design requirements due to the large variation in anode gas composition, relative to the 20-percent-overload case (gas density is factor of 2.4 lower).

The process flows were generated based on the following methodology:

- Fuel is humidified methane.

- Recycle blower fixed design (flow, adiabatic head) based on $20 \%$ overload case.

- Blower characteristic obtained from vendor input.

- Loop pressure drops adjusted for variations in gas properties.

- Assume stack acts as a cross-flow heat exchanger with "both fluids mixed." This defines relationship between effectiveness and NTU (no. of heat exchanger transfer units). Design analysis estimates indicate the stack NTU is 27 (See Task 1.2).

Based on the selected test mode configuration and operating point, the following component design requirements were established:

Recycle Blowers - Table 1.1-7 lists the preliminary functional requirements for the anode and cathode recycle blowers.

Cell Stack Assembly - Table 1.1-8 lists the preliminary functional requirements for the cell stack assembly. Performance is based on the goal level for this stack.

Sensible Heat Reformer - Table 1.1-9 lists the preliminary functional requirements for the sensible heat reformer. Pressure drop requirement is 4-6 iwc, based on an assumed pelletized bed of large cross-sectional frontal area. Conversion assumes equilibrium at the exit of the bed.

Catalytic Burner - Table 1.1-10 lists the preliminary functional requirements for the catalytic burner. Pressure drop requirement is based on use of a catalyst bed from available commercial designs. Requirements are for 100 percent conversion of the $\mathrm{H}_{2}$ and $\mathrm{CO}$. Unit heat loss can be determined from further analyses. 
Table 1.1-7 Recycle Blowers Functional Design Requirements

Component

Fluid - type

- Volume flow rate $\sim$ ACFM

_ Properties: Density $\sim \mathrm{lbs} / \mathrm{ft}^{3}$

Mol. weight $\sim \mathrm{lbs} / \mathrm{mol}$

Viscosity $\sim$ lbs $/ \mathrm{ft} \cdot \mathrm{hr}$

Operating conditions

Temperature

Pressure

$\sim \circ \mathbf{F}$

$\sim$ psia

Pressure rise $\sim$ iwc

Adiabatic head $(\Delta P / P) \sim F t$

Operating limits

Min/max temp. $\sim \circ \mathbf{F}$

Min/max flow

Min. pressure

rise

$\sim$ iwe

\begin{tabular}{c}
$\begin{array}{c}\text { Anode Recycle } \\
\text { Blower }\end{array}$ \\
\hline Anode recycle - \\
reducing gases \\
\hline
\end{tabular}

907

.0903

32.98

.0933

1241

50

23.2*

1061

$70 / 1300$

—_ Regulated by blower speed

19
Cathode Recycle Blower.

Cathode recycle oxidizing gases

1037

.0906

28.66

.0877

1013

50

21.1*

973

$70 / 1300$

*With $20 \%$ design margin

\begin{tabular}{|l|l|}
\hline \multicolumn{2}{|c|}{ Table 1.1-8. Cell Stack Assembly Functional Design } \\
Requirements (Preliminary)
\end{tabular}




\begin{tabular}{|l|l|l|}
\hline \multicolumn{3}{|c|}{ Table 1.1-9. } \\
\multicolumn{3}{|c|}{$\begin{array}{c}\text { Sensible Heat Reformer Functional Design } \\
\text { Requirements (Preliminary) }\end{array}$} \\
\hline \multicolumn{1}{|c|}{ Item } & \multicolumn{1}{|c|}{ Inlet } & \multicolumn{1}{c|}{ Exit } \\
\hline Flow & $\begin{array}{l}149 \mathrm{moles} / \mathrm{hr} \\
4925 \mathrm{lbs} / \mathrm{hr}\end{array}$ & $\begin{array}{l}154 \mathrm{moles} / \mathrm{hr} \\
4925 \mathrm{lbs} / \mathrm{hr}\end{array}$ \\
\hline Compositions - Per steady state process flow. \\
\hline Temperature & $1249^{\circ} \mathrm{F}$ & $1112^{\circ} \mathrm{F}$ \\
\hline Pressure & $\begin{array}{l}50.3 \mathrm{psia} \text { normal } \\
100 \text { psia during diagnostics }\end{array}$ \\
\hline Pressure drop & $4-6$ iwc & \\
\hline Conversion & Equilibrium at exit of bed & \\
\hline Heat loss & 2700 Btu per hour & \\
\hline Life & 10.000 hour goal & \\
\hline
\end{tabular}

\begin{tabular}{|l|l|l|}
\hline \multicolumn{3}{|c|}{$\begin{array}{c}\text { Table 1.1-10. Catalytic Burner Functional Design } \\
\text { Requirements (Preliminary) }\end{array}$} \\
\hline \multicolumn{1}{|c|}{ Item } & \multicolumn{1}{|c|}{ Inlet } & \multicolumn{1}{c|}{ Exit } \\
\hline Flow & $\begin{array}{l}205 \mathrm{moles} / \mathrm{hr} \\
6091 \mathrm{lbs} / \mathrm{hr}\end{array}$ & $\begin{array}{l}204.7 \mathrm{moles} / \mathrm{hr} \\
6091 \mathrm{lbs} / \mathrm{hr}\end{array}$ \\
\hline Compositions - Per steady state process flow. \\
\hline Temperature & $1023^{\circ} \mathrm{F}$ & $1112^{\circ} \mathrm{F}$ \\
\hline Pressure & $\begin{array}{l}50.4 \mathrm{psia} \text { normal } \\
100 \mathrm{psia} \text { during diagnostics }\end{array}$ \\
\hline Pressure drop & $\leq 3 \mathrm{iwc}$ & \\
\hline Conversion & $100 \%\left(\mathrm{H}_{2}+\mathrm{CO}\right)$ & \\
\hline Heat loss & TBD & \\
\hline Life & Goal $=10,000$ hours & \\
\hline
\end{tabular}




\section{Subtask 1.2 Stack Design Preparation}

Objective -The objectiv, of this subtask was to prepare a design of a 100-kW stack comprised of nominal 8-ft ${ }^{2}$ cells incorporating the cell configuration and component technology improvements developed in DOE Contract No. DE AC21-87MC23270. The construction drawings for the repeat parts of the stack and the non-repeat hardware for the stack were to be completed. Construction drawings were also to be prepared for the vessel, reactant piping and accessory items required for the test of the stack. Thermal, flow, structural, mechanical, and electrical design analysis were to be performed so that components met the design requirements established in Task 1.1.

\section{Summary}

Arrangement of the $100-\mathrm{kW}$ stack, ancillary components, structure, and piping inside the ISU pressure vessel was defined conceptually. The pressure vessel, including the extension needed to accommodate the $100-\mathrm{kW}$ stack, was designed.

A 144-node mathematical model of a large-area molten carbonate cell in a stack was updated and found to be in good agreement with data generated on the 20 -cell stack of $8-\mathrm{ft}^{2}$ cells tested in 1990 . This model was used to calculate the thermal performance of the $100-\mathrm{kW}$ stack in order to set the functional requirements in Task 1.1.

The thermal and flow analysis of the stark at 100-percent and 120-percent power conditions was completed to identify the operating performance conditions, to estimate pressure drops, and to estimate temperatures in the cell package.

A flow analysis was performed to size the reactant manifolds and locate the inlet diffuser baffles. A manifold retention scheme involving Belleville washers and tie rods was selected. A dielectric rail design was established for the manifold seal. A design approach for the alignment guides at the top and bottom of the manifolds was selected. Detail drawings were prepared for the manifold hardware.

The cell stack instrumentation requirements were defined. The instrumentation for measuring cell temperature, voltage, reactant gas temperature, pressure, and gas composition was identified. Reactant manifold instrumentation penetrations were designed.

The cell stack end plates were designed. Changes reiative to the previous design included use of 310 SS versus INCO Alloy 825.

\section{Report of Work}

Preliminary Arrangement of Integrated Stack Unit (ISU) - The preliminary conceptual design of the Integrated Stack Unit (ISU) for testing a 100-kW cell stack was completed. Previous ISU arrangement studies, performed under another contract, served as the starting point for the ISU design in this contract, along with system cell stack and component requirements from Subtask 1.1.

The ISU consists of a 100-kW cell stack, anode and cathode recycle blowers, $\dot{a}$ catalytic burner in the cathode recycle loop, a sensible heat reformer in the anode recycle loop, recycle loop flow instrumentation venturis, the related interconnecting piping, instrumentation and electrical power connections to the cell stack, and components contained within the pressure vessel.

The ISU is designed to allow for testing the cell stack with simulated coal gas, simulated natural gas, and methane fuels. Additionally, the ISU is configured to allow the anode and cathode gas systems to be run as separate flow loops, as shown in Figure 1.2-1 and as connected loops where most of the fuel exhaust vents directly to the cathode gas system providing the necessary $\mathrm{CO}_{2}$ after combustion in the catalytic burner as shown in Figure 1.2-2. 


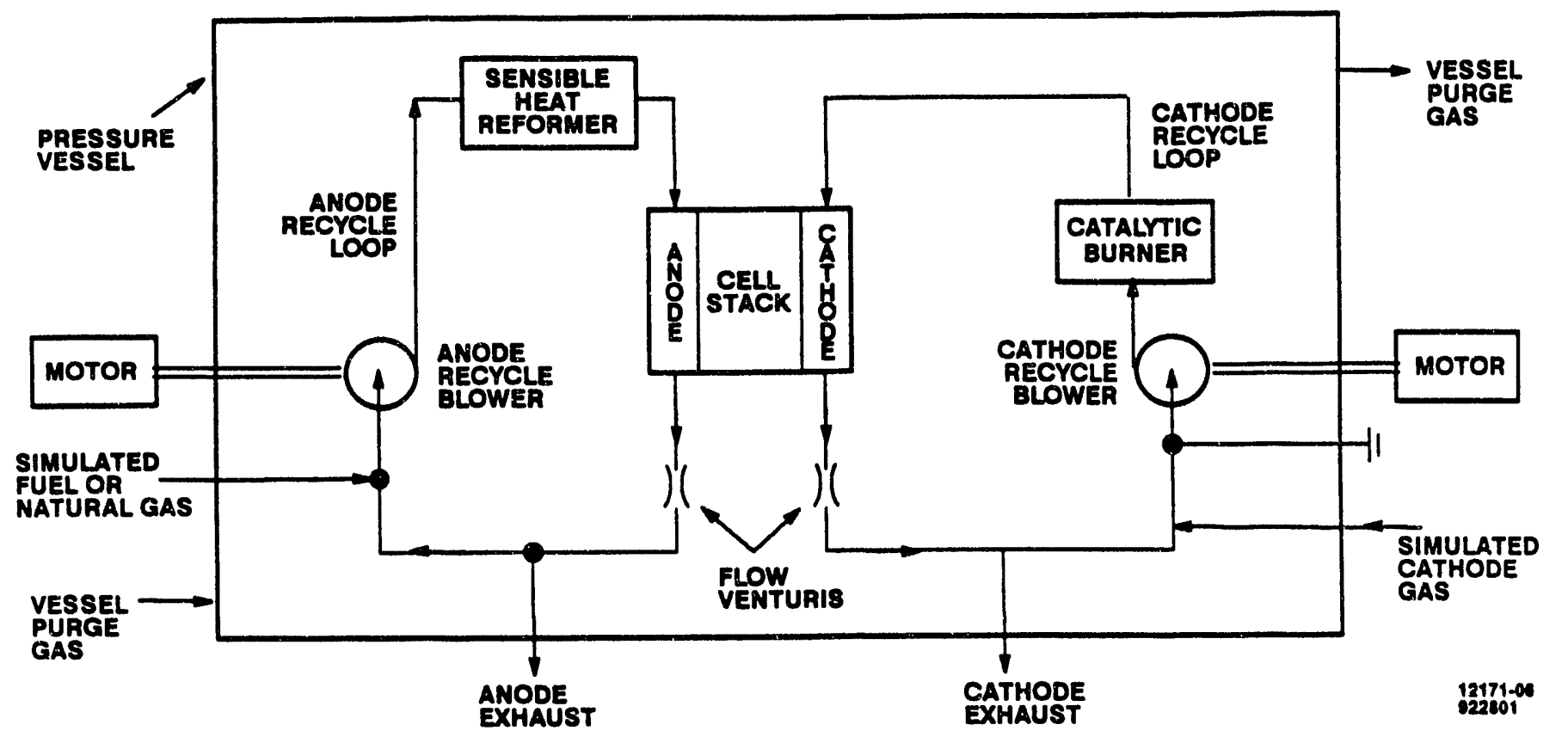

Figure 1.2-1. Separate Loop Configuration

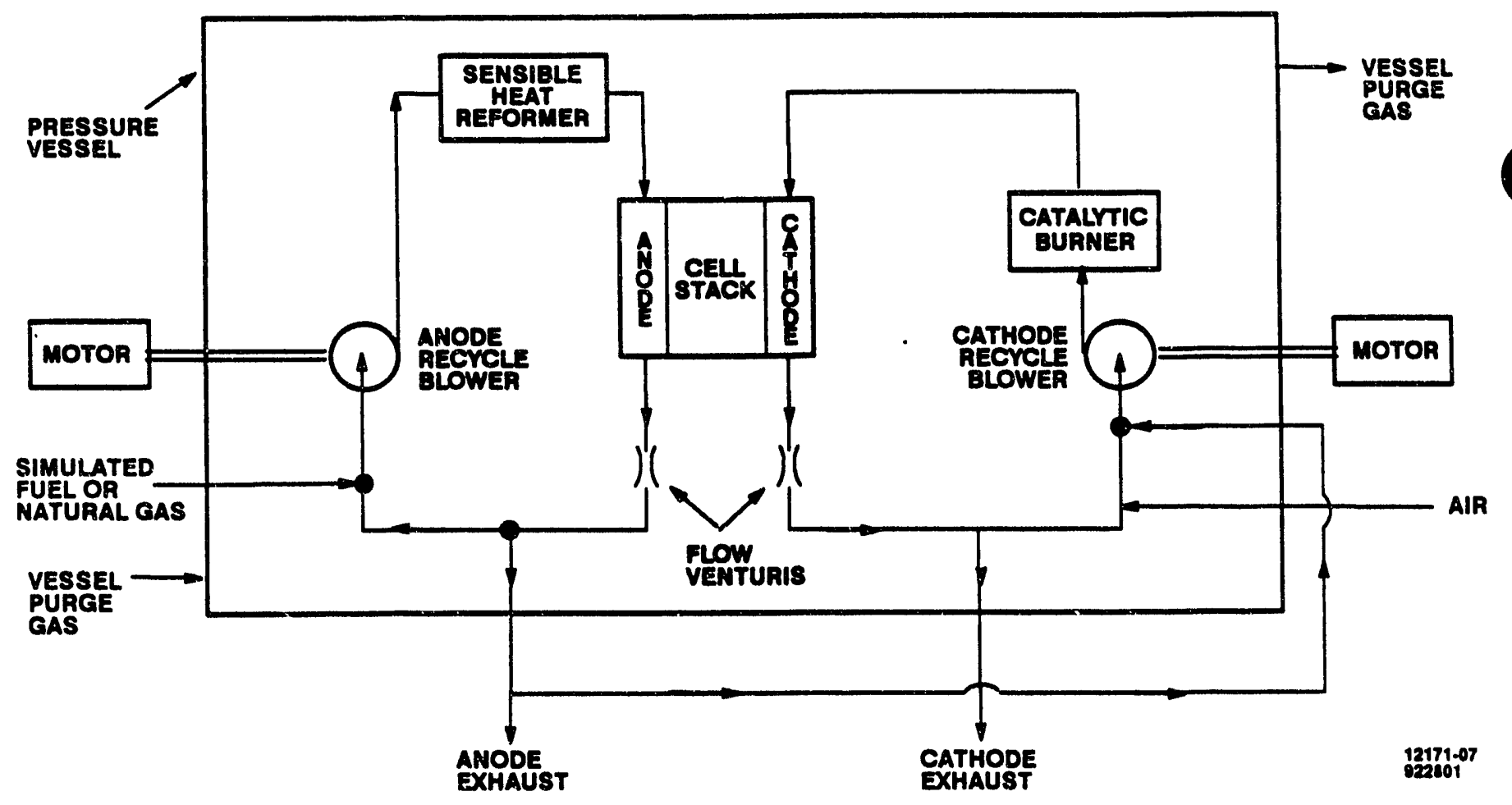

Figure 1.2-2. Connected Loop Configuration 
Packaging of the ISU was designed for assembly of the pressure vessel, components and cell stack at the existing IFC test stand location. The pressure vessel was designed with a flat head bottom and two sets of circumferential flanges. Reactant piping, recycle blowers, and electrical and instrumentation penetrations in the pressure vessel are located in the bottom section of the vessel as shown in Figure 1.2-3 to minimize disconnection and reconnection during stack mounting and maintenance.

Pressure vessel and cell stack weights were estimated to determine lifting gantry requirements for assembling the $100-\mathrm{kW}$ stack and pressure vessel at the test stand facility. The weights are presented in Table 1.2-1.

\begin{tabular}{|c|c|}
\hline \multicolumn{2}{|c|}{ Table 1.2-1. Estimated Pressure Vessel and Cell Stack Weights } \\
\hline Component & Maximum Estimated Weight (lbs) \\
\hline Pressure Vessel Top & 5,000 \\
\hline Pressure Vessel Center Section & 7,000 \\
\hline Pressure Vessel Bottom Section & 15,000 \\
\hline Cell Stack & 12,000 \\
\hline
\end{tabular}

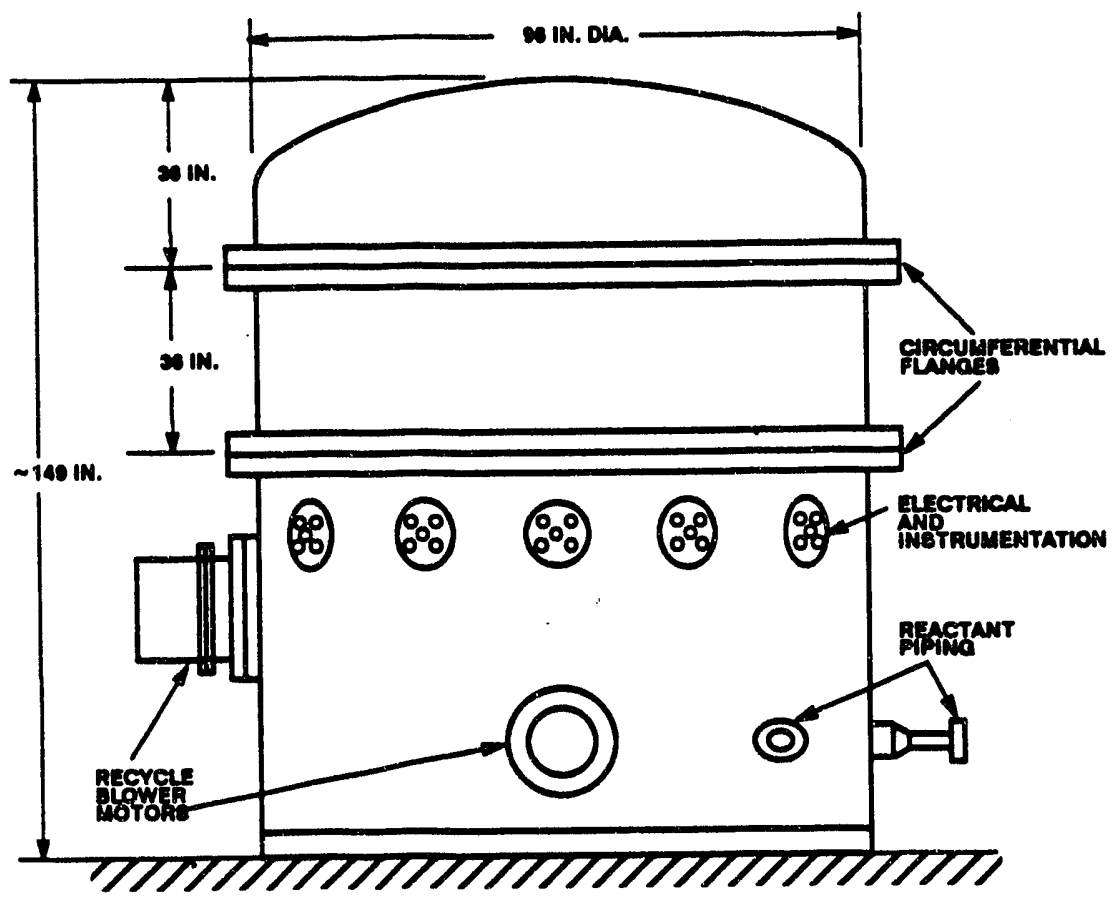

Figure 1.2-3. Integrated Stack Unit Pressure Vessel 
The cathode recycle catalytic burner preliminary size estimate v''as increased from 8 to 12 inches in diameter based on vendor input. The catalytic burner was previously packaged in the 8-inch diameter piping of the cathode recycle loop between the recycle blower and the cell stack inlet manifold. The catalytic burner was modified at the same location with the addition of an inlet diffuser and exit reducer such as pictured in Figure 1.2-4. This design causes the pressure drop increase to be only 0.25 inches of water, which was judged acceptable.

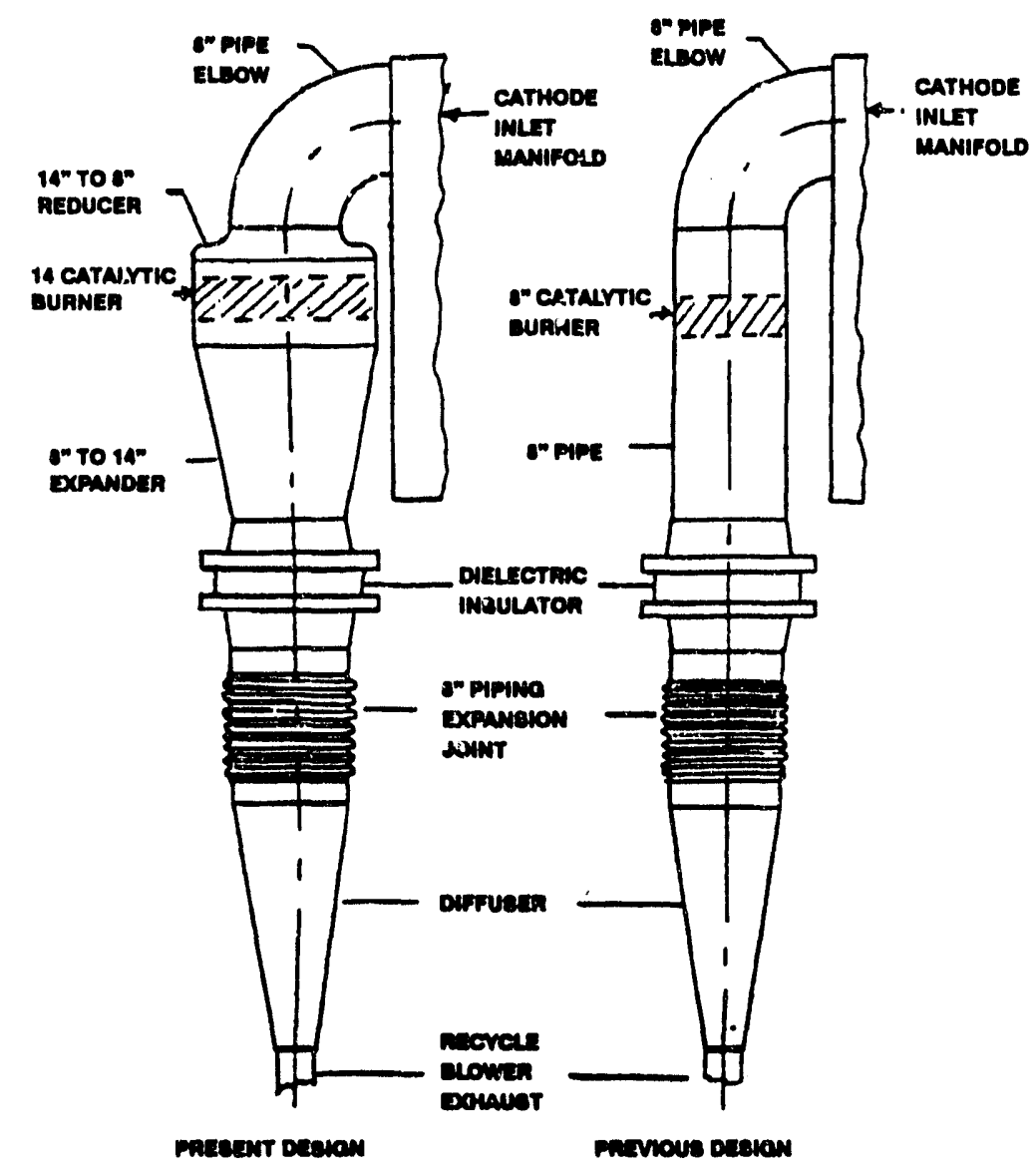

$12171-0$

Figure 1.2-4. Cathode Recycle Catalytic Burner Packaging

A 36-inch diameter bellows was selected to provide the compressive load on the cell stack. The selected bellows will provide the required axial motion to accommodate both the necessary creep and assembly tolerances.

Packaging studies of the cell stack compressive load bellows established mounting interface requirements to the pressure vessel and ISU packaging heights. The selected 36 -inch diameter bellows has a high lateral spring rate. The location of the top of the cell stack in relation to the flange on the vessel could vary by $\pm 3 / 8$ inch with typical manufacturing tolerances. A misalignment of this magnitude is within acceptable limits for the bellows, but would result in an excessive lateral load to align the pressure vessel flanges. The attachment of the bellows to the top dome has therefore been made adjustable to compensate for misalignment. The bellows is installed and compressed to allow utilization of its full travel capability. In addition, the packaging includes a machined spacer to compensate for initial stack height variations. The bellows travel is primarily set by stack compaction and thermal growth. 
To minimize packaging height, pressure vessel height is established by the maximum anticipated stack height, and the spacer is used to compensate if the stack is shorter.

The approach developed to attach the stack compression bellows is shown in Figure 1.2-5. The pressure vessel head thickness was increased from $7 / 16$ to $9 / 16$ inch to provide for the higher pressure inside the bellows. The top of the bellows is welded to a ring inside the head and the bottom of the bellows is sealed with a flat plate. A guide pin is attached to the bottom of the bellows to prevent the bellows from shifting. Initial stack height variations are compensated with a machined stack height spacer. The radial misalignment between the top head and the cell stack top is compensated for with a bored bushing.

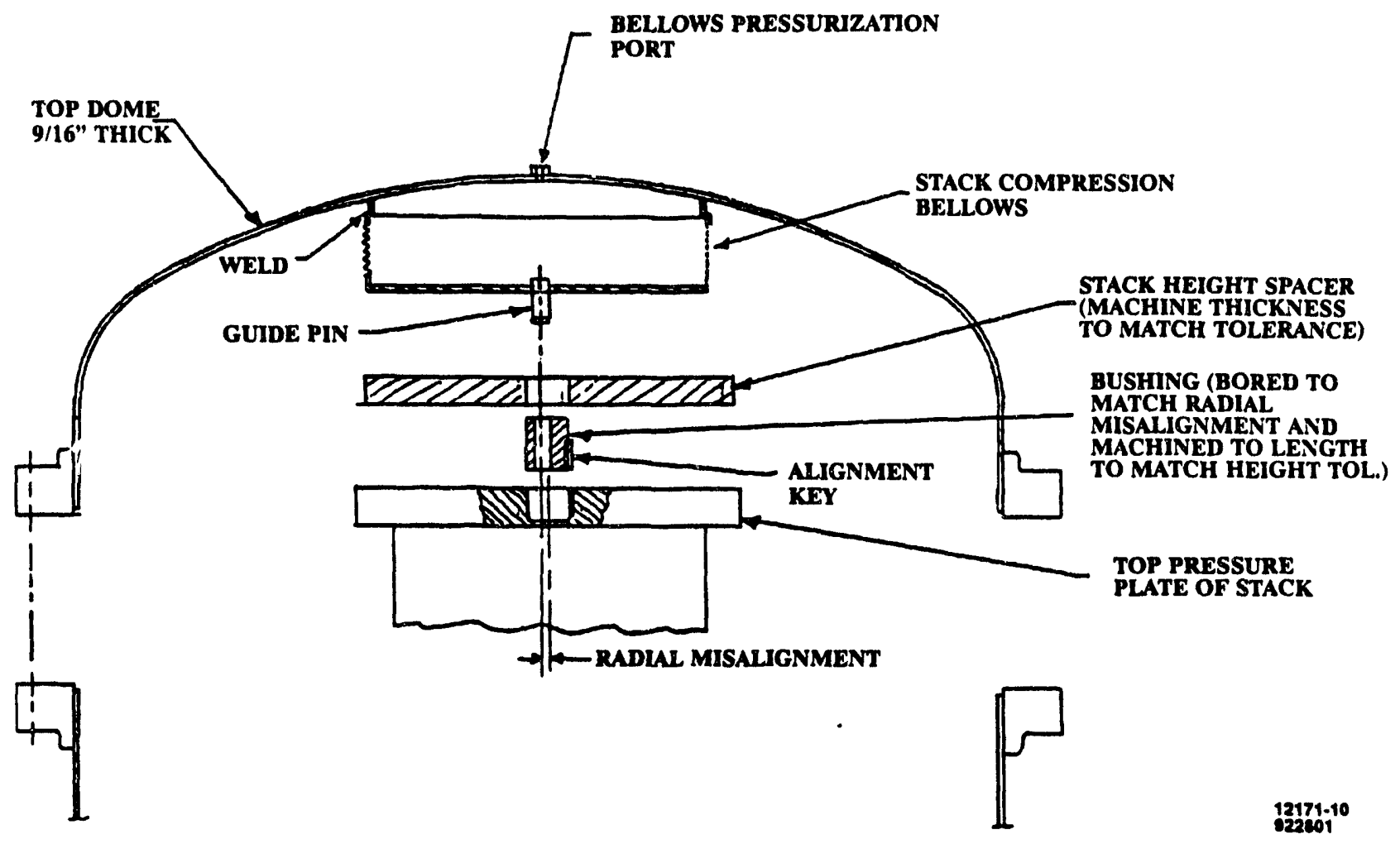

Figure 1.2-5. Attachment of Stack Compression Bellows to Vessel 
The vessel design (Figure 1.2-3) is summarized in Table 1.2-2.

\begin{tabular}{|l|l|}
\hline \multicolumn{2}{|c|}{ Table 1.2-2. Summary of Vessel Design } \\
\hline Design Criteria: & ASME Section VIII, Div. 1 \\
\hline Design Pressure: & 110 psig \\
\hline Design Temperature: & $650^{\circ} \mathrm{F}$ \\
\hline Material: & Carbon Steel (SA516-70) \\
\hline Size: & $96^{\prime \prime}$ OD, 149" Overall Height \\
\hline Upper Head: & $\mathrm{t}=0.5625^{\prime \prime}$ thick \\
\hline Cylinder: & $\mathrm{t}=0.4375^{\prime \prime}$ thick \\
\hline Bottom Head - Flat: & $\mathrm{t}=4.5^{\prime \prime}$ thick \\
\hline Flanges: & $175^{\prime \prime}$ Class Slip On \\
\hline
\end{tabular}

An extension spool-piece was designed to adapt the existing 20-cell stack containment vessel to accommodate the $100-\mathrm{kW}$ stack for initial startup and part power testing. The pressure vessel code data sheets were revised from the National Board of Boiler and Pressure Vessel Inspectors. Inc. The $100-\mathrm{kW}$ stack requires several additional instrumentation bosses.

Thermal and Electrochemical Performance Analysis - The 144-node mathematical model of an 8- $\mathrm{ft}^{2}$ cell was updated to enable prediction of stack thermal parameters which influence the functional requirements which were being establirhed in Subtask 1.1. The performance data from 4-inch by 4-inch single cell No. 724 (Figure 1.2-6) were used to describe the electrochemical performance as a function of current density over the temperature range of $1050^{\circ} \mathrm{F}$ to $1350^{\circ} \mathrm{F}$. The results are shown in Figure 1.2-7. The model was then tested by comparing performance measurements from the 20-cell stack of 8- $\mathrm{ft}^{2}$ cells tested in 1990 with predicted performance from the mathematical model.

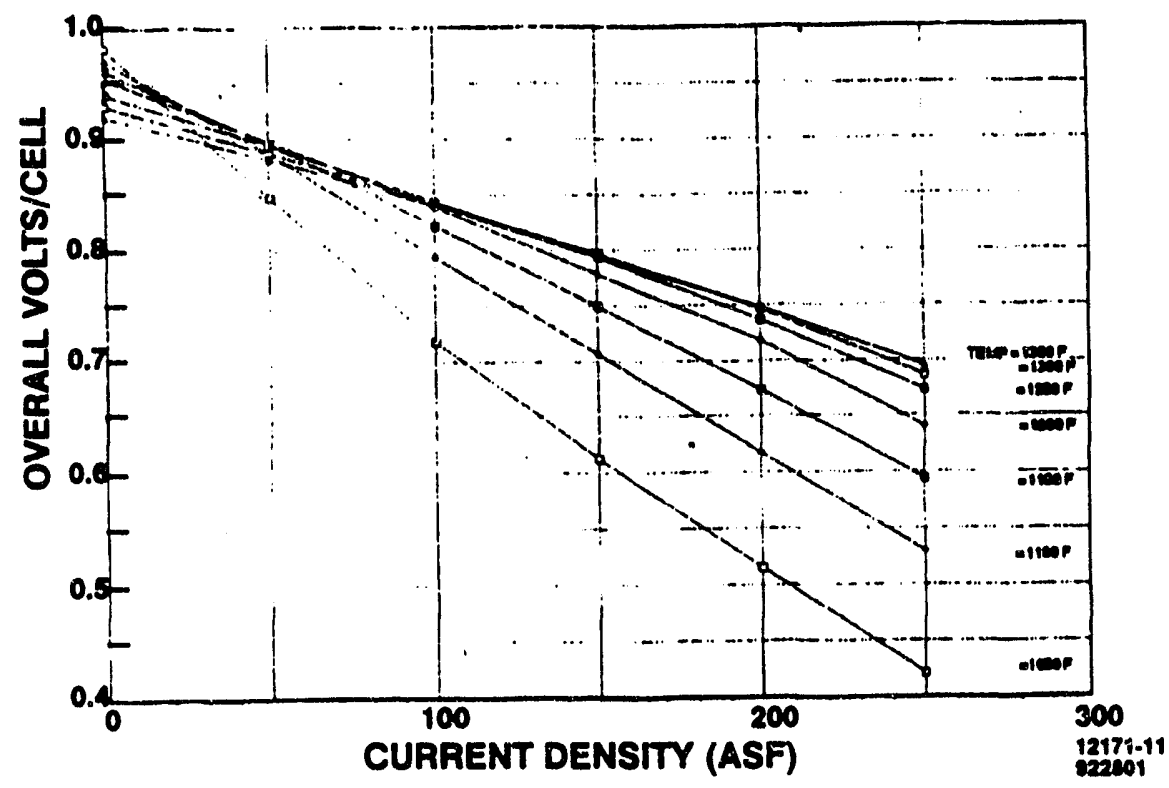

Figure 1.2-6. Performance Data from Cell No. 724 


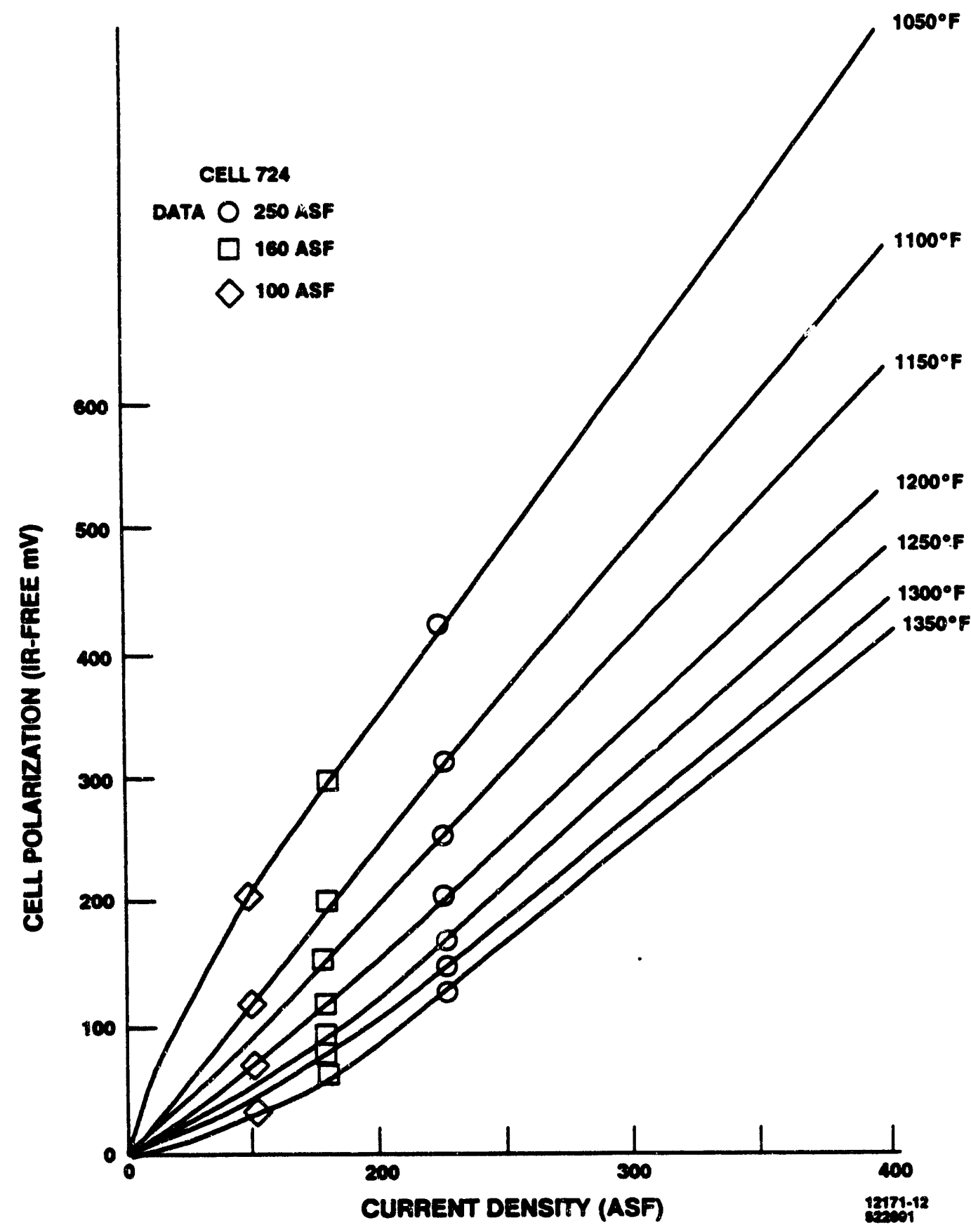

Figure 1.2-7. Cell Polarization vs. Temperature and Current Density 
The results of this comparison are shown in Table 1.2-3 and Figure 1.2-8 for three operating current densities of 156, 209, and 250 ASF. Good agreement was achieved between projected and measured voltage of the center cells.

\begin{tabular}{|c|c|c|c|c|}
\hline & & \multicolumn{3}{|c|}{ Volts vs, Current Density } \\
\hline & & $156.2 \mathrm{ASF}$ & 209 ASF & 250 ASF \\
\hline Measured & $\begin{array}{l}\text { - Avg. of Center Cells No. } 4 \\
\text { to No. } 16 \\
\text { Hot Load Time } \\
2060 \text { hours }\end{array}$ & 0.722 & 0.669 & 0.628 \\
\hline Calculated & $\begin{array}{l}\text { - 144-Node Model } \\
\text { Using data from 4" x 4" } \\
\text { Cell No. } 724 \\
\text { Hot Time - } 864 \text { hours }\end{array}$ & 0.723 & 0.657 & 0.612 \\
\hline \multicolumn{2}{|c|}{$\Delta$ Measured - Calculated } & -0.001 & +0.012 & +0.016 \\
\hline \multicolumn{2}{|c|}{ Oxidant Inlet Temperature } & $1125^{\circ} \mathrm{F}$ & $1128^{\circ} \mathrm{F}$ & $1131^{\circ} \mathrm{F}$ \\
\hline \multicolumn{2}{|c|}{ Fuel Inlet Temperature } & $1042^{\circ} \mathrm{F}$ & $1058^{\circ} \mathrm{F}$ & $1065^{\circ} \mathrm{F}$ \\
\hline \multicolumn{2}{|c|}{ Oxidant Utilization } & 36.5 & 36.7 & 34.6 \\
\hline \multicolumn{2}{|c|}{ Fuel Utilization } & 55.4 & 56.1 & 53.6 \\
\hline
\end{tabular}

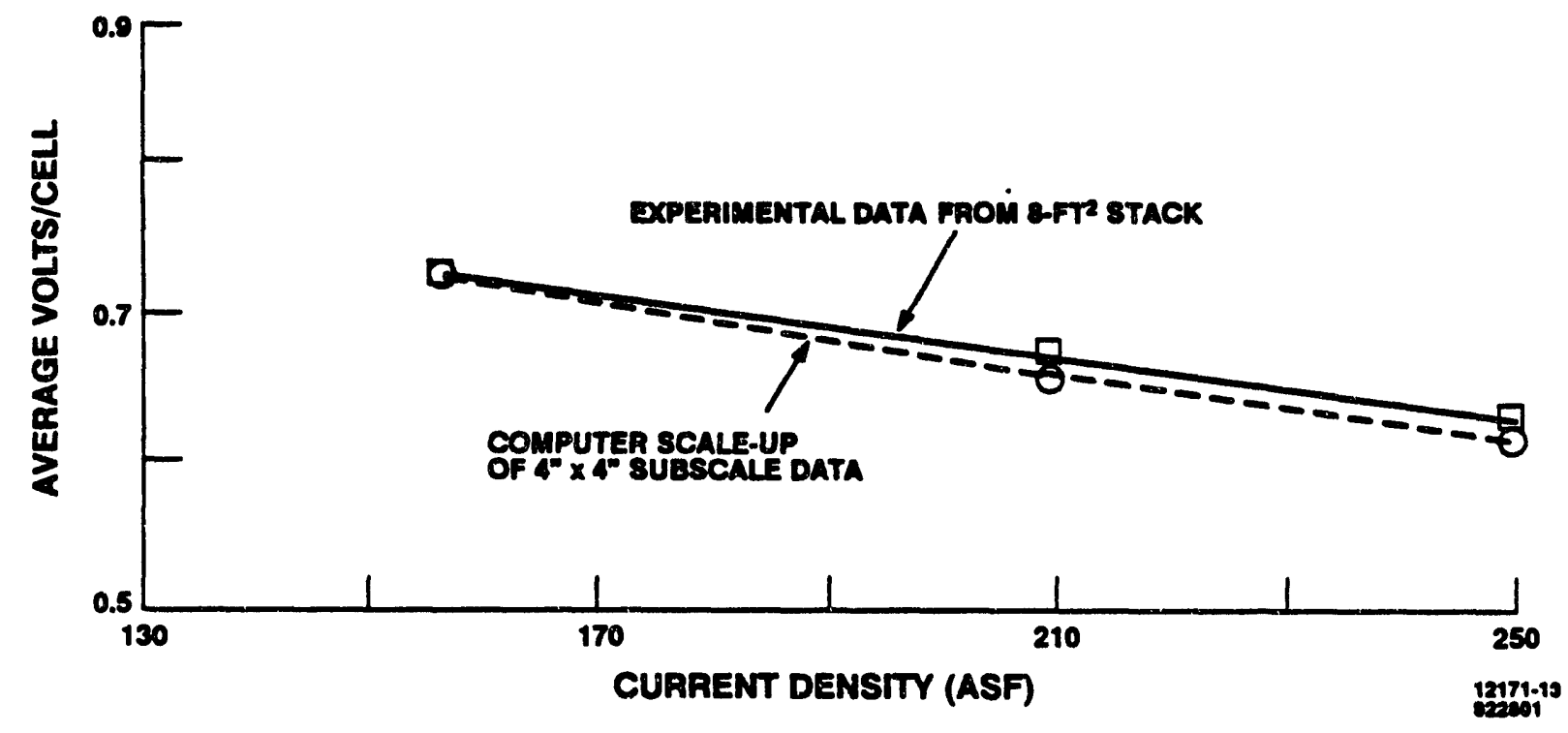

Figure 1.2-8. 8-Ft Center Cell Performance Comparison 
The results of the thermal analysis are presented in Table 1.2-4. This table shows that the calculated oxidant outlet temperature was lower than the measured oxidant outlet temperature. A comparison of the thermocouple measurements with the predicted values of the hottest spot in the cell package showed reasonable agreement.

\begin{tabular}{|l|c|c|c|}
\hline \multicolumn{4}{|c|}{ Table 1.2-4. Summary of Thermal Analysis of 8-Ft ${ }^{2}$ Stack } \\
\hline & \multicolumn{3}{|c|}{ Current Density } \\
\hline & $156 \mathrm{ASF}$ & $209 \mathrm{ASF}$ & $250 \mathrm{ASF}$ \\
\hline Measured Oxidant Outlet Temperature & $1284^{\circ} \mathrm{F}$ & $1305^{\circ} \mathrm{F}$ & $1287^{\circ} \mathrm{F}$ \\
\hline Calculated Oxidant Outlet Temperature & $1251^{\circ} \mathrm{F}$ & $1266^{\circ} \mathrm{F}$ & $1278^{\circ} \mathrm{F}$ \\
\hline$\Delta$ Measured-Calculated & $33^{\circ} \mathrm{F}$ & $39^{\circ} \mathrm{F}$ & $9^{\circ} \mathrm{F}$ \\
\hline Measured Hot Spot Temperature & $1293^{\circ} \mathrm{F}$ & $1313^{\circ} \mathrm{F}$ & $1289^{\circ} \mathrm{F}$ \\
\hline Calculated Hot Spot Temperature & $1286^{\circ} \mathrm{F}$ & $1305^{\circ} \mathrm{F}$ & $1312^{\circ} \mathrm{F}$ \\
\hline
\end{tabular}

As a result of the agreement of the 144-node mathematical model with test results, it was concluded that this model could be used as a design tool for setting the functional design requirements for the $100-\mathrm{kW}$ ISU. Calculations were performed for rated power and 20 percent power overload to calculate the reactant gas exit temperatures and the hot-spot temperature. These data were then iterated with the rest of the system to define the operating points.

Table 1.2-5 summarizes the results at 100 percent power (rated) and 120 percent power (overload). The maximum cell ("hot spot") temperatures were calculated to be $1290^{\circ} \mathrm{F}$ and $1354^{\circ} \mathrm{F}$ at 100 percent and 120 percent power, respectively, assuming the recycle blowers are not adjusted. The maximum temperature at rated power is judged to be acceptable. At 120 percent power the maximum temperature is marginally acceptable for extended operation.

The thermal performance of the cell at open circuit conditions was calculated to be equivalent to a cross-flow heat exchanger with no internal heat generation. Both fluids are considered to be mixed in plane. The NTU (number of thermal units) was calculated to be equal to 27 , which is a relatively high value. An equation was generated to be used for approximating the cell stack thermal performance in Subtask 1.1. 


\begin{tabular}{|c|c|c|}
\hline \% Power & $120 \%$ & $100 \%$ \\
\hline Power Level & $120 \mathrm{~kW}$ & $100 \mathrm{~kW}$ \\
\hline Current Density & $201 \mathrm{ASF}$ & $160 \mathrm{ASF}$ \\
\hline Voltage & 0.612 Volts & 0.650 Volts \\
\hline Temp. Fuel In & $1112^{\circ} \mathrm{F}$ & $1112^{\circ} \mathrm{F}$ \\
\hline Temp. Fuel Out & $1274^{\circ} \mathrm{F}$ & $1231^{\circ} \mathrm{F}$ \\
\hline Temp. Oxidant In & $1112^{\circ} \mathrm{F}$ & $1112^{\circ} \mathrm{F}$ \\
\hline Temp. Oxidant Out & $1243^{\circ} \mathrm{F}$ & $1208^{\circ} \mathrm{F}$ \\
\hline Avg. Cell Temp. & $1206^{\circ} \mathrm{F}$ & $1183^{\circ} \mathrm{F}$ \\
\hline Center Cell Temp. & $1231^{\circ} \mathrm{F}$ & $1201^{\circ} \mathrm{F}$ \\
\hline Maximum Cell Temp. & $1354^{\circ} \mathrm{F}$ & $1290^{\circ} \mathrm{F}$ \\
\hline Minimum Cell Temp. & $1119^{\circ} \mathrm{F}$ & $1117^{\circ} \mathrm{F}$ \\
\hline \% Heat Pickup - Oxidant & $38.9 \%$ & $38.8 \%$ \\
\hline \% Heat Pickup - Fuel Gas & $61.1 \%$ & $61.2 \%$ \\
\hline Max. Current Density & $228 \mathrm{ASF}$ & 176 ASF \\
\hline Min. Current Density & $160 \mathrm{ASF}$ & 132 ASF \\
\hline Fuel Utilization $\left(\mathrm{H}_{2} \& \mathrm{CO}\right)$ & $39.3 \%$ & $33.1 \%$ \\
\hline Oxidant Utilization $\left(\mathrm{CO}_{2}\right)$ & $57.5 \%$ & $51.8 \%$ \\
\hline \multicolumn{3}{|c|}{ Fuel Gas Composition, \% by vol. } \\
\hline Hydrogen & 7.66 & 7.10 \\
\hline Carbon Dioxide & 56.34 & 57.12 \\
\hline Water & 30.10 & 30.34 \\
\hline Carbon Monoxide & 5.61 & 5.23 \\
\hline Methane & 0.29 & 0.21 \\
\hline \multicolumn{3}{|c|}{ Oxidant Gas Composition, $\%$ by vol. } \\
\hline Oxygen & 13.10 & 12.85 \\
\hline Carbon Dioxide & 7.12 & 6.35 \\
\hline Water & 8.23 & 9.34 \\
\hline Nitrogen & 70.53 & 71.45 \\
\hline
\end{tabular}


Design of Cell Stack Non-Repeat Parts - Designs were prepared for many of the cell stack non-repeat parts. Emphasis was on manifolds, instrumentation, and end plates.

a) Manifolds - The detail drawings of the manifolds and manifold attachment hardware were completed and approved. The fuel and cathode inlet manifolds have the flow-baffle configuration defined in Subtask 3.2. The manifold attachment configuration is shown in Figure 1.2-9. Inconel X-750 Belleville washers provide load follow-up for thermal expansion and seal compaction. The high-temperature fuel exhaust/cathode exhaust corner has thermal insulation bushings to allow the Belleville washers to operate at a lower temperature to provide adequate creep life.

Analysis resulted in a manifold size with good flow distribution of reactant gases. The inlet manifold inside depth is 6 inches with the inlet diffuser flow baffles spaced approximately 2 inches from the back wall, leaving 4 inches of effective manifold depth for even flow distribution. The exit manifolds have the same 6-inch depth to provide symmetry for the manifold attachment. The design for the inlet baffles was tested in a full scale rig under Subtask 3.2 to verify the analysis.

The manifold material is AISI Type 321 stainless steel which is stabilized to prevent carburization during welding, heat treatment, and while being used in the susceptible temperature region of 850 to $1250^{\circ} \mathrm{F}$. The manifold walls are constructed from $1 / 8$-inch sheet stock. The back wall is reinforced with formed channels 3 inches deep by 4 inches wide of $3 / 16$-inch sheet stack. A flange 1 inch wide by approximately $1 / 2$ inch thick has a recessed groove to position the dielectric insulator rail between the flange and the cell stack. A sketch of the manifold is provided in Figure 1.2-10. 


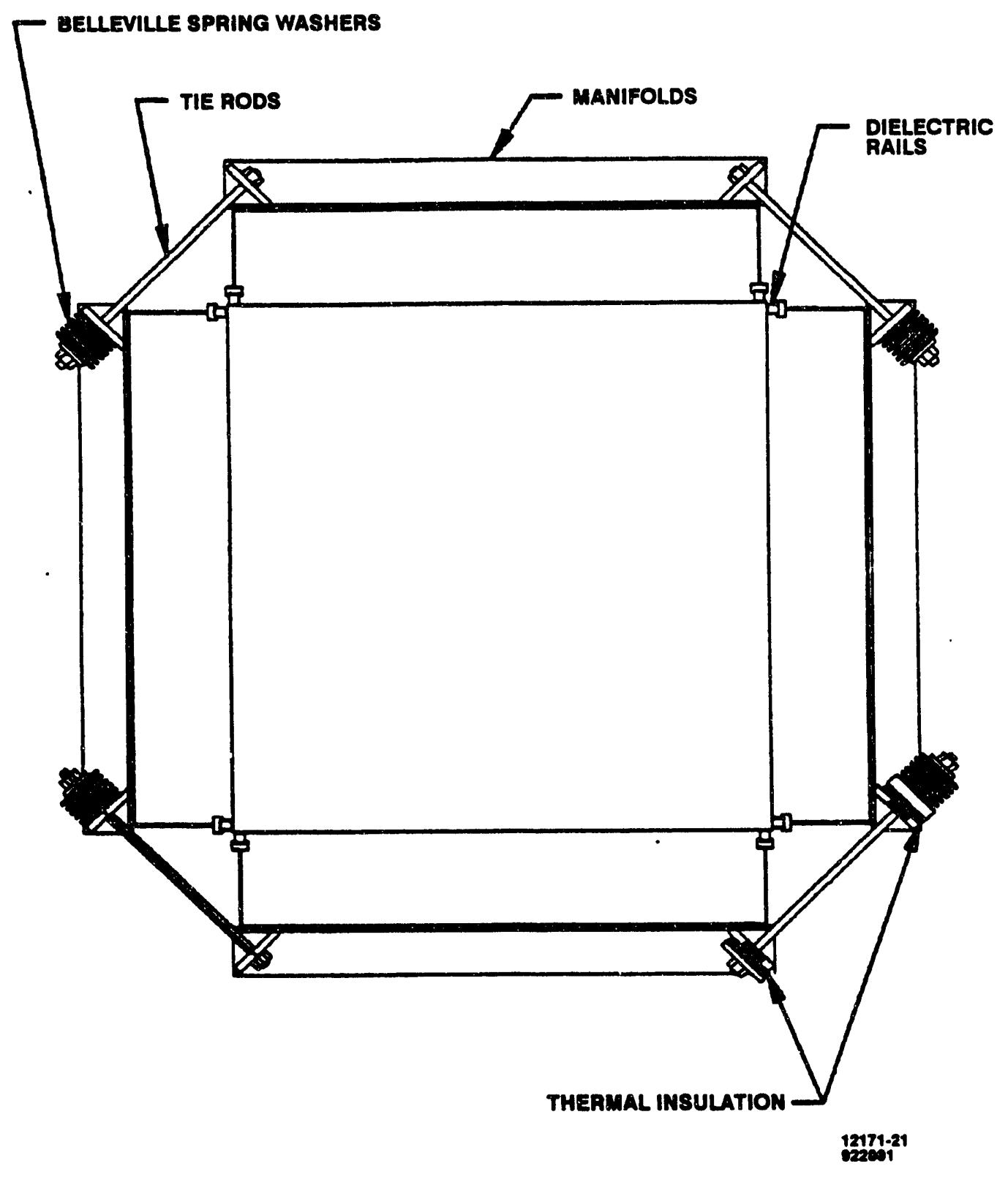

Figure 1.2-9. Manifold Attachment (Cross Section of Cell Stack) 

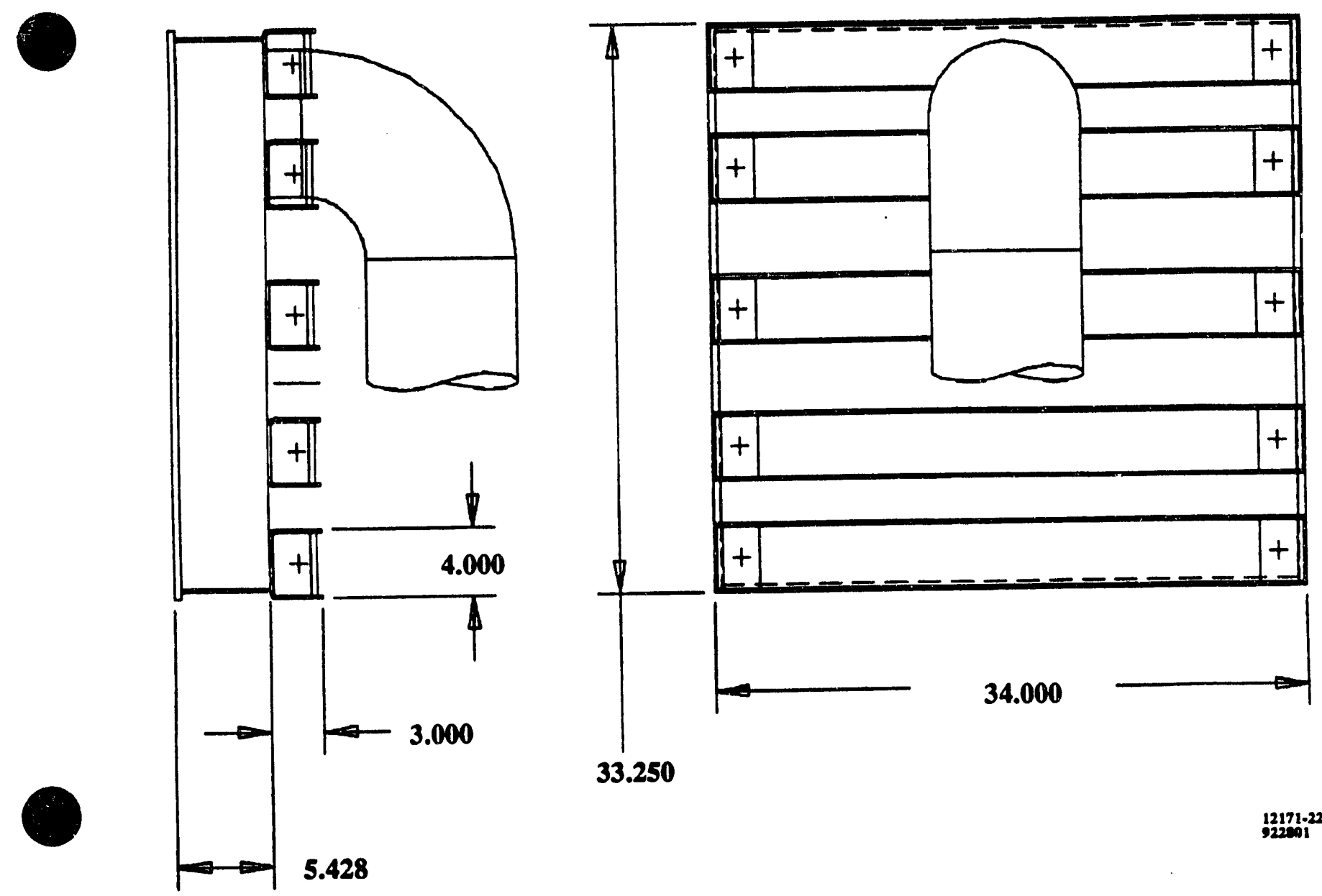

33.250

$12171-22$

Figure 1.2-10. Manifold for 100-kW Stack

Two potential configurations for the dielectric insulator rails were identified. The first configuration is a picture frame consisting of four single-piece side rails of approximately 33 inches in length. The shape is 5/8-inch square in cross section with a locating tab approximately 0.8 inches wide at one end. This tab fits into a recess in the manifold flange which keeps the end of the rail in close contact with the side of the adjacent rail to minimize gas leakage at the joints, see Figure 1.2-11. 


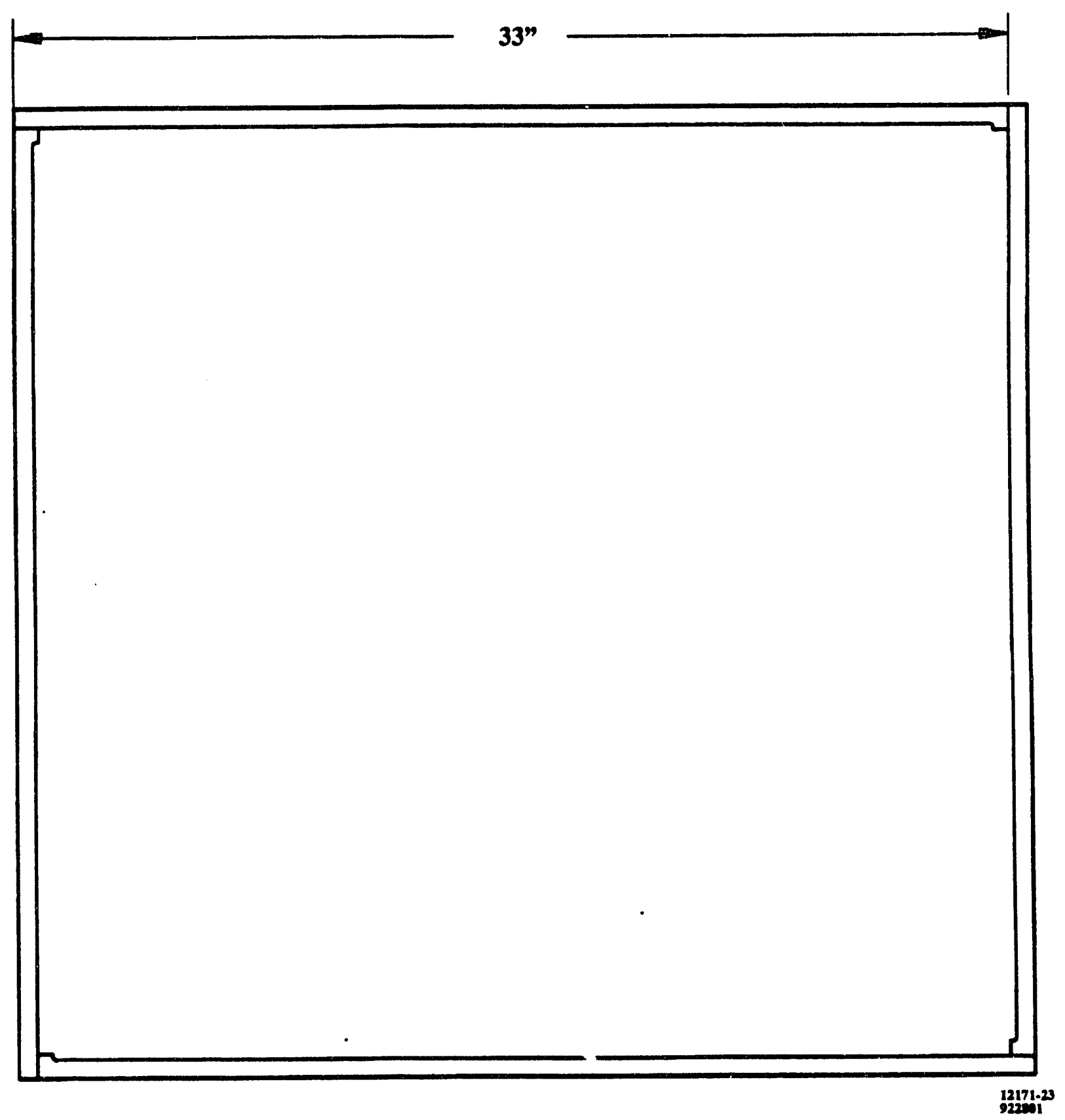

Figure 1.2-11. Single-Piece Rails

The second concept is similar in function to the first but uses two pieces per side, each approximately 17 inches long (eight pieces per manifold). The shorter lengths used in the second configuration can be produced by many vendors. The rail material in both concepts is aluminum oxide ceramic.

The dielectric rail drawings were transmitted to vendors for technical assessment and cost estimates. Leakage estimates were done for the four-piece rail design. The estimated leakage is between two and $85 \mathrm{pph}$ of $50 \% \mathrm{~N}_{2} / 50 \% \mathrm{CO}_{2}$, which is well within the 300-pph purge allocation for the test stand. The leakage was also analyzed for a projected large stack of 500 cells with a six-piece rail design and an air purge. Depending on dimensional tolerances of the rails, system efficiency loss due to the rail joint 
leakage was estimated to be between 0.025 percent and 1 percent in relation to an allocation of 0.5 percent for rails and seals.

Estimates were received for the cost of fabricating the single-piece-per-side and the two-piece-per-side dielectric rail designs. The three potential vendors contacted responded they could make either design. The single-piece-per-side design was less expensive. The single-piece-per-side design was selected. This configuration minimizes gas leakage because of the fewer number of joints.

The manifolds are clamped to the stack with Belleville spring washers and tie rods between adj, rent manifold corners as shown in Figure 1.2-9. This retention system is similar in appearance to tha. used on IFC acid stacks, but higher temperature alloys are required. The Belleville washers are Inconel $X-750$, the tie-rods are Inconel 625 or stainless steel, and the retention brackets are 316 stainless steel. An initial seal load of $\mathbf{4 0}$ to 50 pounds per linear inch is sufficient to guarantee at least 5 psi seal load with the worst combination of internal manifold pressure and seal compaction (or creep).

The retention spacing for the reactant manifold was also defined. The maximum reinforcement spacing is 10 inches in the center of the manifolds. The calculated maximum stress in the back of the manifold is $7.6 \mathrm{ksi}$ for the 2.5-psi maximum differential pressure. This gives a safety factor of 2.1 for the 16.1 $\mathrm{ksi}$ yield strength of 316 stainless steel at $1300^{\circ} \mathrm{F}$. The calculated maximum continuous bending stress in the manifold from seal loading is $4.6 \mathrm{ksi}$ at $1300^{\circ} \mathrm{F}$. This compares reasonably well to a very conservative allowable of $4.1 \mathrm{ksi}$ from the A.S.M.E. Boiler and Pressure Vessel Code.

A design approach was selected for alignment guides at the top and bottom of the manifold. Vertical bars are welded to the top and bottom ends of the manifold. These bars extend through brackets attached to the top and bottom end plates. Dielectric insulation is provided with ceramic rods located in semi-circular slots in the brackets, see Figure 1.2-12. The guides allow for relative movement between the manifolds and the end plates caused by differences in thermal growth, cell compaction, and compaction of manifold seals.

A rig was also designed to test the ability of the manifold seal to accommodate relative movement between the cell stack and the reactant manifold. The rig allows a maximum of two inches movement between the simulated manifold and cell stack surfaces. This represents the initial compaction and creep of the cell stack and differential thermal growth between the stack and manifold. The rig is designed to allow the movement while in an oven at $1300^{\circ} \mathrm{F}$. Seal rig testing is reported in Subtask 3.1.

The diffuser baffle design for the manifold was selected and verified in a full scale flow rig by measuring the flow distribution. This work is described in Subtask 3.2, Manifold Development.

Requirements for the instrumentation provisions in the manifolds were established. All manifolds will have pressure taps, gas analysis taps, and six thermocouples. Additionally, the fuel exit manifold will have four bosses for substack voltage leads that extend through the manifold and into the anode current collector flow fields. Individual cell voltages will be located in the corners of the separators and will extend between the edges of the manifolds to the vessel. Ninety-six (96) cell temperature thermocouples will be routed through 24 bosses in the oxidant exit manifolds. A more detailed description of the instrumentation is presented in the section that follows. 


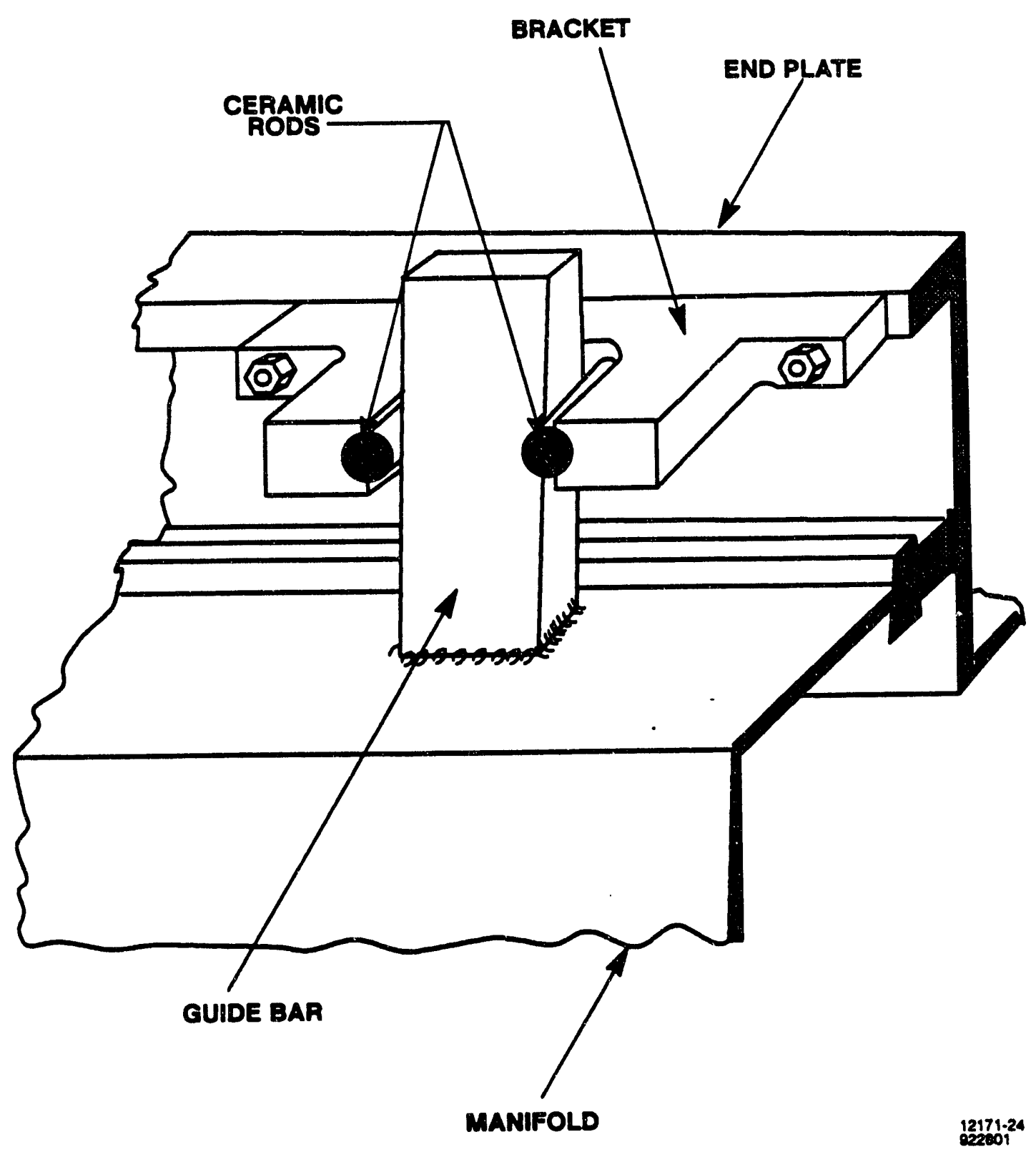

Figure 1.2-12. Manifold Alignment Guides 
b) End Plates - The top and bottom box end plates for the $100 \mathrm{~kW}$ stack were designed. The major design changes relative to the previous design of these parts for the 8- $\mathrm{ft}^{2}$ short stack included: (1) changing the material from INCO ALLOY 825 to Type 310 Stainless Steel, (2) increasing the sidewall height of the top box end plate, and (3) changing the weld fabrication procedure.

The top box end plate experiences more severe stresses than the bottom box end plate because of the larger sidewall height. The structural analysis of the top box end plate is reported since it represents the most severe case.

The top box end plate for the $100 \mathrm{~kW}$ stack was analyzed for mechanical loads, using the finite element model shown in Figure 1.2-13. The loads considered were manifold seal, busbar, and cell axial loads at the $1300^{\circ} \mathrm{F}$ maximum operating temperature. The stresses and deflections in the top box end plate for $1300^{\circ} \mathrm{F}$ mechanical loads using the finite element model are shown in Figure 1.2-14. The maximum calculated stress is $2.2 \mathrm{ksi}$. This stress is located in the flange at one of the bus bar locations. This may result in some long term distortion but dimensional stability is not as crucial in the flange as in the sidewalls. The Boiler Code allowable for the material is $2.9 \mathrm{ksi}$, therefore the stress is acceptable. The calculated deflection between cross braces is 0.0018 inches and is acceptable. The maximum sidewall stress due to manifold seal loads is $1.3 \mathrm{ksi}$ and the deflection is 0.0027 inches at the bus bar locations. These values should be acceptable for the manifold seal which has 0.0100 inches compression.

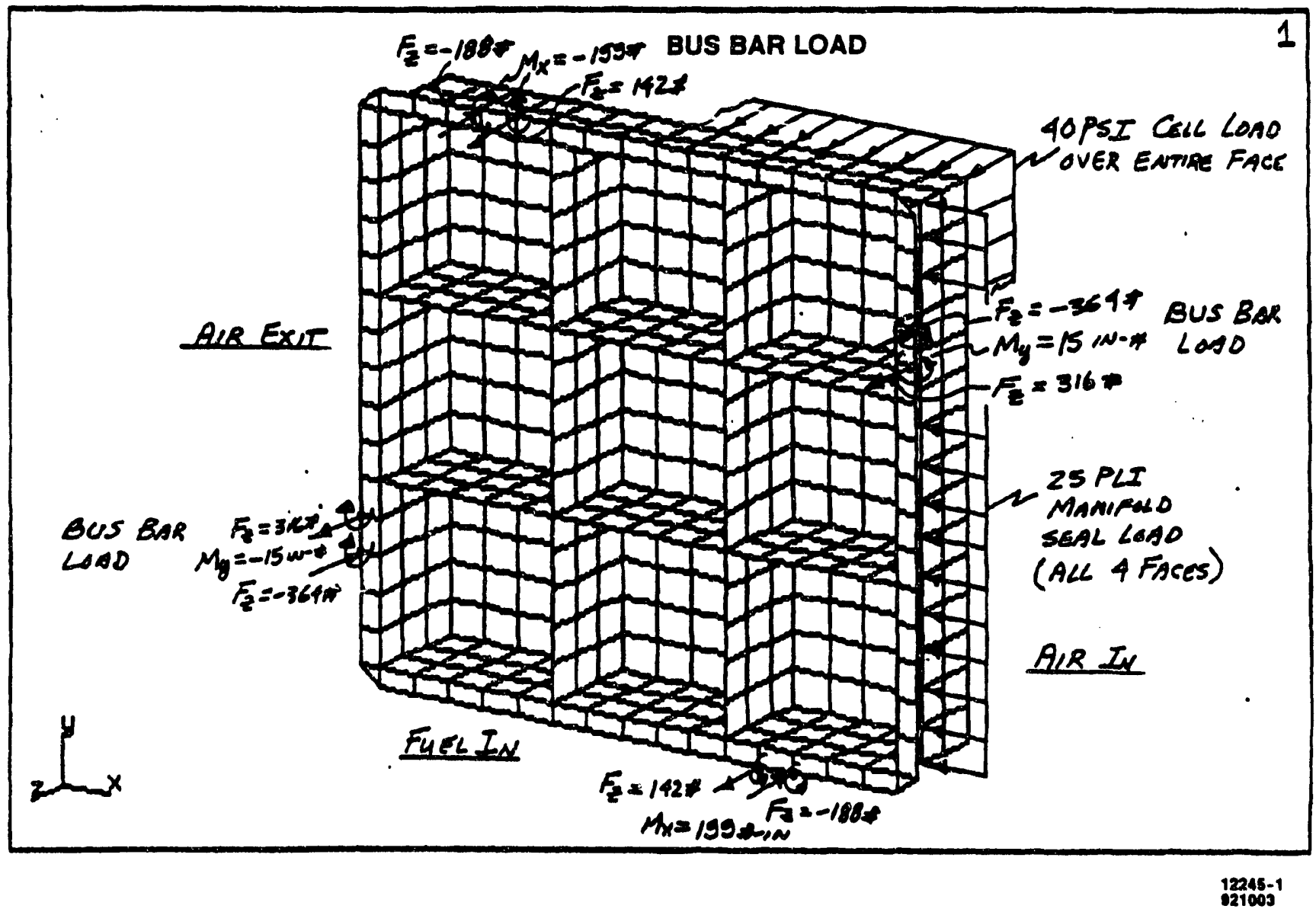

Figure 1.2-13. Molten Carbonate $100 \mathrm{~kW}$ Cell Stack Top Box End Plate Loads at $1300^{\circ} \mathrm{F}$ 


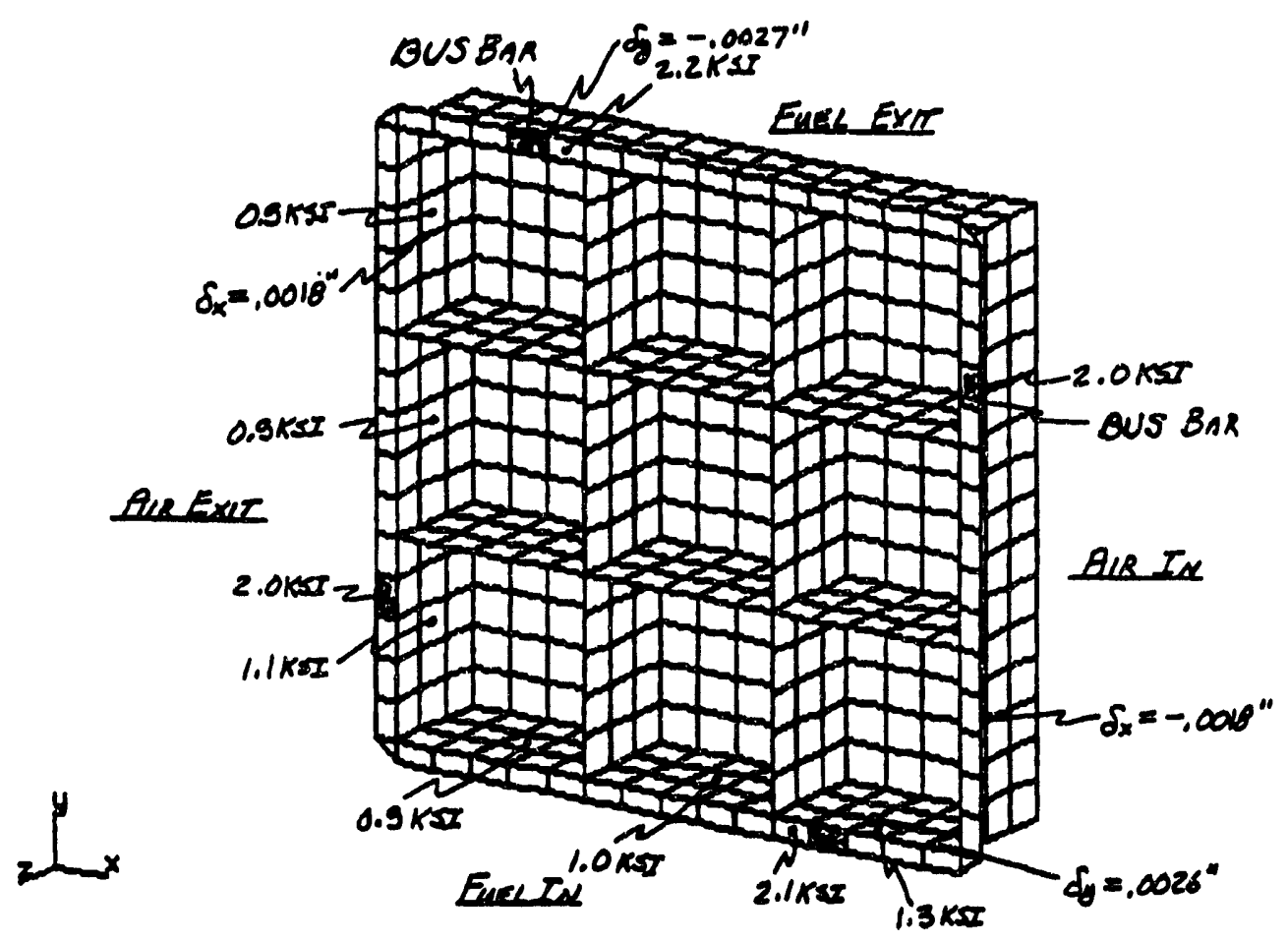

Figure 1.2-14. Molten Carbonate $100 \mathrm{~kW}$ Cell Stack Top Box End Plate Stresses and Deflections for Loads at $1300^{\circ} \mathrm{F}$

Welding fabrication of the box end plates was reviewed with Pratt and Whitney Weld Technology engineers. The following observations and recommendations were made:

- The flanged side wall should be weld fabricated vs. machining from 1.5 inches of thick material for lower cost in making prototypes. Suggested investigating cost of extrusions for production quantities.

- Automated machine or robot gas metal arc welding (MIG) was recommended to control distortion.

- Welding sequence, fixturing and use of chill bars at some locations is very important.

- Use of automated welding and finish machining would be cost effective compared to electron beam or laser welding.

- Minimizing weld penetrations at the side wall corner and flange joints would be beneficial in limiting distortion.

- The amount of finish machining could be reduced significantly with experience.

- A convex fillet joint between the 0.125 inch cover sheet and 0.25 inch side wall was recommended to be suitable and cost effective compared to the electron beam weld used previously.

- Welding equipment supplier contacts were suggested to aid in locating vendors with automated welding equipment.

The welding fabrication recommendations were incorporated into the box end plate drawings. The drawings have been completed and approved. 
Instrumentation Requirements for 144-Cell Stack - The instrumentation requirements for testing the $100-\mathrm{kW}, 144-\mathrm{cell}$ stack are presented in Table 1.2-6. Each individual cell voltage is to be monitored, requiring 145 voltage leads. The large number of leads required for a 144-cell test make it impractical to route the leads through the fuel exit manifold as in previous test articles. The individual voltage measurements are to be taken from the cell corners. In addition, four "quarter stack" voltage measurements are to be taken in the traditional manner, requiring five voltage leads in the anode exhaust. Ninety-six individual cell temperature locations were selected to be representative of the temperature distribution within a cell and of the temperature variation from cell to cell. The five positions for measuring each reactant gas temperature in and out of the stack are to be between the stack and any flow distribution device (baffle) which may be contained in the manifold. The reactant gas analysis taps are located in the inlet and exit piping with the exception of the anode inlet. The anode inlet tap is located between the exit of the sensible heat reformer and the inlets to the anode flow fields.

\begin{tabular}{|c|}
\hline $\begin{array}{l}\text { Cell Voltages } \\
145 \text { corner voltage leads } \\
5 \text { internal voltage leads (fuel exit manifold) } \\
\text { (located at cells } 1,36,72,108 \text {, and 144) }\end{array}$ \\
\hline $\begin{array}{l}\text { Cell Temperatures } \\
\qquad 96 \text { thermocouples (See Figure } 1.2-20 \text { and Table } 1.2-10 \text { ) }\end{array}$ \\
\hline $\begin{array}{l}\text { Manifold Temperature } \\
\qquad 5 \text { gas thermocouples per manifold (top, } 25 \% \text {, mid } 75 \% \text {, bottom) }\end{array}$ \\
\hline $\begin{array}{l}\text { Manifold Pressure Taps } \\
11 \text { per manifold }\end{array}$ \\
\hline $\begin{array}{l}\text { Manifold Gas Analysis Taps } \\
1 \text { per Manifold (required for ISU manifolds only) }\end{array}$ \\
\hline
\end{tabular}

Thermocouple leads are to be taken out of the stack assembly through the cathode exhaust manifold utilizing an insulating penetrator which holds four leads. Each penetrator holds thermocouples from only a single cell. This minimizes the possibility of leads of different potential from coming in contact with one another. There are 15 elevation levels on each side of the cathode exhaust manifold where the penetrators can be conveniently located, for a total of 30 penetrators. Figure 1.2-15 is a schematic representation of a single cell showing the relative position of 11 selected thermocouple locations within any given cell. The locations were selected to monitor temperatures for:

\author{
Initial conditioning $(1,2,3,5,7,8,10,11)$ \\ Reactant crossover (1 and 11) \\ Average cell temperature (5) \\ Maximum cell temperature ( 2 and 3 ) \\ Edge leaks and diagnostic temperatures $(4,6,8,9,10)$
}


Thermocouples at locations $1,4,5,8$, and 9 are routed through the penetrators on the fuel inlet side of the cathode exhaust manifold to minimize the lead length in the hot environment. Similarly, thermocouples at locations $3,6,7,10$, and 11 are routed through penetrators on the fuel exhaust side of the manifold. At location 2, thermocouples can be routed to either side.
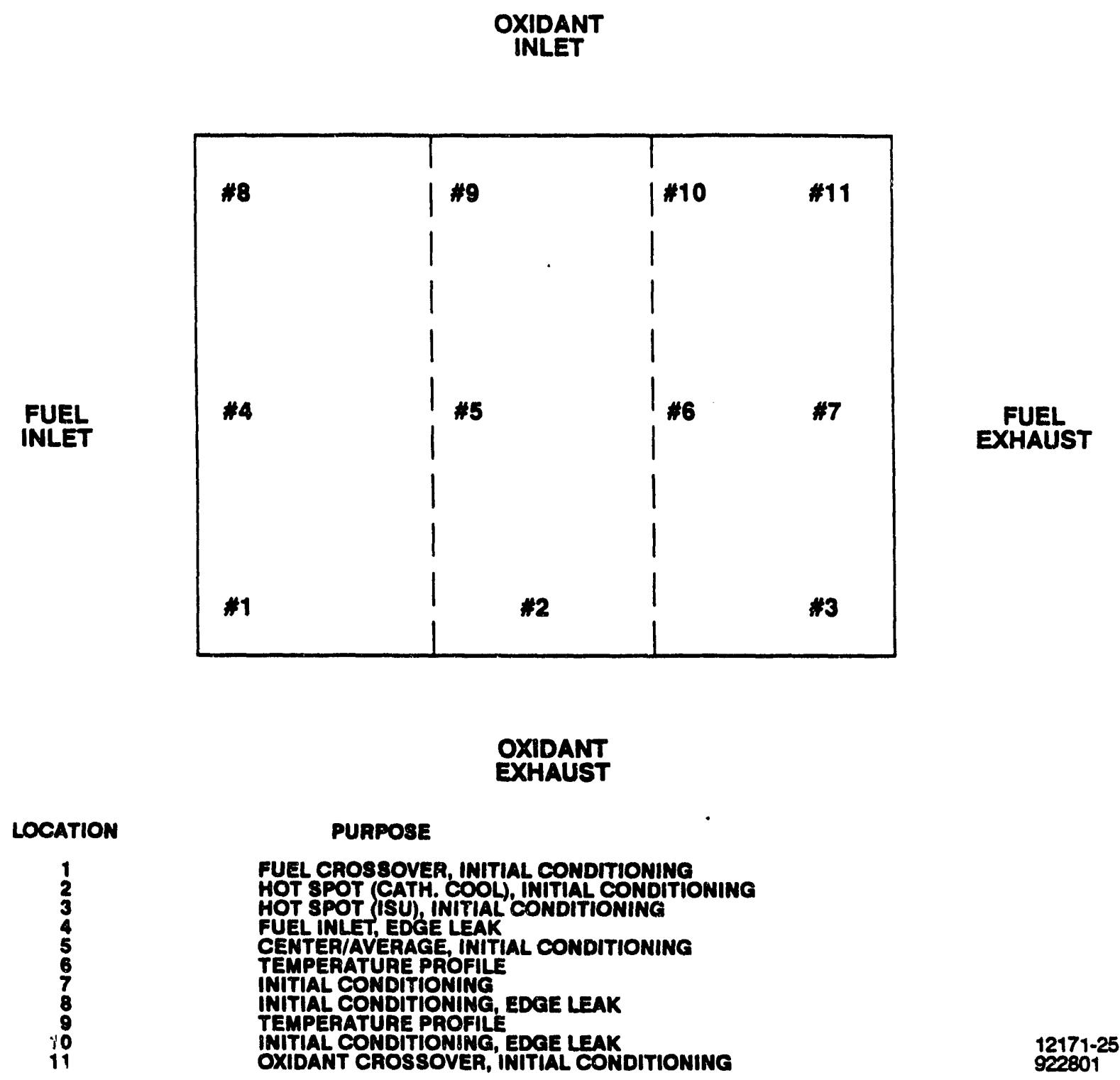

Figure 1.2-15. Cell Temperature Instrumentation Locations

Twenty-four of the available 30 locations for penetrators were utilized for a total of $\$ S$ thermocouples. Five cells at the top, bottom quarter, half, and three-quarter points in the stack contain the maximum number of thermocouples for a single cell (8). These provide $\mathbf{4 0}$ thermocouples for monitoring initial conditioning (burnout), crossover, average cell temperature, and maximum cell temperature. The remaining 56 thermocouples are located four per cell on 14 additional cells distributed uniformly throughout the stack. Table 1.2-7 is a matrix defining the cell and location for each thermocouple. The table uses the notation I to indicate the lead is routed to a penetrator on the fuel inlet side of the manifold and an $\mathrm{X}$ for routing to the fuel exit side of the manifold. 
Table 1.2-7. Thermocouple Location

I- T/C IS TAREN OFF ON FUEL INLET MANIFOLD SIDE OF OXIDANT EXIT MANIFOLD

$X-T / C$ IS TAKE OFF ON FUEI EXIT MANIFOLD SIDE OF OXIDANT EXIT MANIFOLD

\begin{tabular}{|c|c|c|c|c|c|c|c|c|c|c|c|c|c|}
\hline & & & & & & & IOC & TION & & & & & \\
\hline CELL NOMBER & $x / C$ & PENYY - & 1 & 2 & 3 & 4 & 5 & 6 & 7 & 8 & 9 & 10 & 11 \\
\hline 1 & 8 & 2 & $I$ & $I$ & $x$ & - & $I$ & - & $x$ & $I$ & - & $x$ & $x$ \\
\hline 3 & 4 & 1 & - & $x$ & $x$ & - & - & $x$ & - & - & - & - & $x$ \\
\hline 5 & 4 & 1 & $I$ & - & - & $I$ & $I$ & - & - & - & $I$ & - & - \\
\hline 15 & 4 & 1 & - & - & $x$ & - & - & $x$ & $x$ & - & - & - & $x$ \\
\hline 25 & 4 & 1 & $I$ & $I$ & - & - & $I$ & - & - & - & $I$ & - & - \\
\hline 35 & 8 & 2 & $I$ & $I$ & $x$ & - & $I$ & - & $x$ & $I$ & - & $x$ & $x$ \\
\hline 45 & 4 & 1 & - & $x$ & $x$ & - & - & $x$ & - & - & - & - & $x$ \\
\hline 55 & 4 & 2 & $I$ & - & - & $I$ & $I$ & - & - & - & $I$ & - & - \\
\hline 65 & 4 & 2 & - & - & $x$ & - & - & $x$ & $x$ & - & - & - & $x$ \\
\hline 72 & 8 & 2 & $I$ & $I$ & $x$ & - & $I$ & - & $x$ & $I$ & - & $x$ & $x$ \\
\hline 80 & 4 & 2 & $I$ & $I$ & - & - & $I$ & - & - & - & $I$ & - & - \\
\hline 90 & 4 & 1 & - & $x$ & $x$ & - & - & $x$ & - & - & - & - & $x$ \\
\hline 100 & 4 & 2 & $I$ & - & - & $I$ & $I$ & - & - & - & $I$ & - & - \\
\hline 110 & 8 & 2 & $I$ & $I$ & $x$ & - & $I$ & - & $x$ & $I$ & - & $x$ & $x$ \\
\hline 120 & 4 & 1 & - & - & $x$ & - & - & $x$ & $x$ & - & - & - & $x$ \\
\hline 130 & 4 & 2 & $I$ & $I$ & - & - & $I$ & - & - & - & $I$ & - & - \\
\hline 140 & 4 & 1 & - & $x$ & $x$ & - & - & $x$ & - & - & - & - & $x$ \\
\hline 142 & 4 & 1 & $I$ & - & - & $I$ & $I$ & - & $=$ & - & $I$ & - & - \\
\hline 144 & 8 & 2 & $I$ & $I$ & $x$ & - & $I$ & - & $x$ & $I$ & - & $x$ & $x$ \\
\hline Torats & 96 & 24 & 12 & 12 & 12 & 4 & 12 & 7 & 8 & 5 & 7 & 5 & 12 \\
\hline
\end{tabular}

- MUMBER OF PENETRATORS 


\section{TASK 2 - REPEAT PART MANUFACTURING DEVELOPMENT AND FABRICATION}

\section{Subtask 2.1 Porous Parts}

\section{Subtask 2.1 .1 Flectrode Casting}

Objective - The objective of this subtask was to develop a faster drying solvent for an organic-based slurry and to fabricate electrode tapes using an improved tape casting process.

\section{Summary}

Work was initiated to develop a faster drying solvent system to replace Stoddard solvent in the electrode tape casting process. Screening tests were developed using Stoddard solvent as a baseline for comparison with the candidate solvents.

Samples of several potential solvent substitutes were received. The solvents all had faster evaporation rates than Stoddard solvent. Electrode slurries were made from the binder solutions, and the drying rates of tapes cast from some of the slurries were measured. A tape made using Isopar E solvent was dried in approximately 60 percent of the time required for Stoddard solvent slurries.

Laboratory-scale casting trials were then conducted to reduce the drying rate of tapes made with Isopar E solvent. Full-scale continuous casting trials were conducted using two slurry formulations. Both trials were successful; the tapes were sufficiently dried at the end of the machine and contained no visual defects.

A large batch of slurry was then prepared using binder and Isopar E solvent. Using this slurry, a full-scale tape casting trial produced 259 feet of anode tape. The basis weight of the tape was within the desired range and the tape was prepared for debinding process trials.

Two production anode tape casting runs produced 1000 and 1100 feet of tape respectively. One production cathode tape casting run produced 525 feet of tape. The production anode and cathode tapes were prepared for heat treating in Subtask 2.1.2.

\section{Background}

An alternative binder/solvent system was developed previously to avoid the instability problems encountered with the butyl latex system used to fabricate electrode tapes for the $19908-\mathrm{ft}^{2} 20$-cell stack test. The new system, binder in Stoddard solvent, demonstrated excellent stability and produced tapes with no visual defects in laboratory casting trials. However, the relatively slow evaporation rate of Stoddard solvent prevented the continuous casting of electrode tape on the tape casting machine at the tape casting vendor. Therefore, it was proposed to substitute a solvent with a higher evaporation rate.

\section{Report of Work}

Solvent Selection Criteria - A primary consideration in selecting a solvent is evaporation rate. The solvent also must have sufficient solvency to dissolve the concentration of binder required to obtain the desired viscosity and green strength. Flash point and Inhalation Threshoid Limit Value (ACGIH limit to which workers may be exposed without adverse affect) are relevant to safe transport, storage, and use. These properties affect the engineering controls required to properly handle the solvent.

Solvent Screening Tests - The first step of the screening process was to determine the relationship between viscosity and binder concentration in each of the solvents. These data were necessary to determine the binder concentration required to achieve the desired solution viscosity prior to addition of the nickel powder. 
Two solvents were obtained for evaluation: Isopar $\mathrm{E}$ and Isopar $\mathrm{G}$. They are cuts from the isoparaffin series, predominantly paraffinic hydrocarbons with minor amounts of cycloparaffins. Although their evaporation rates are greater than Stoddard solvent, their solvency is lower.

The rapid evaporation rate of Isopar E relative to Stoddard solvent suggested that a slurry made with it might have the faster drying characteristics required for continuous tape casting. Its lower solvency raised the concern that the solubility of binder in Isopar $\mathrm{E}$ may be lower than required to obtain the desired slurry viscosity and rheology.

Several concentrations of binder were dissolved in Isopar $E$ to address the solubility concern and determine the viscosity-concentration relationship. Solutions with 5,10 , and $15 \% / 0$ binder were made, demonstrating that the binder had reasonable solubility in Isopar $\mathrm{E}$. The viscosity of these solutions is compared to that of the binder in Stoddard solvent in Figure 2.1-1. The data show that higher concentrations of Isopar $E$ were required to maintain the viscosity equivalent to that obtained with Stoddard solvent. This result was expected since the viscosity of Isopar E is lower than Stoddard solvent.

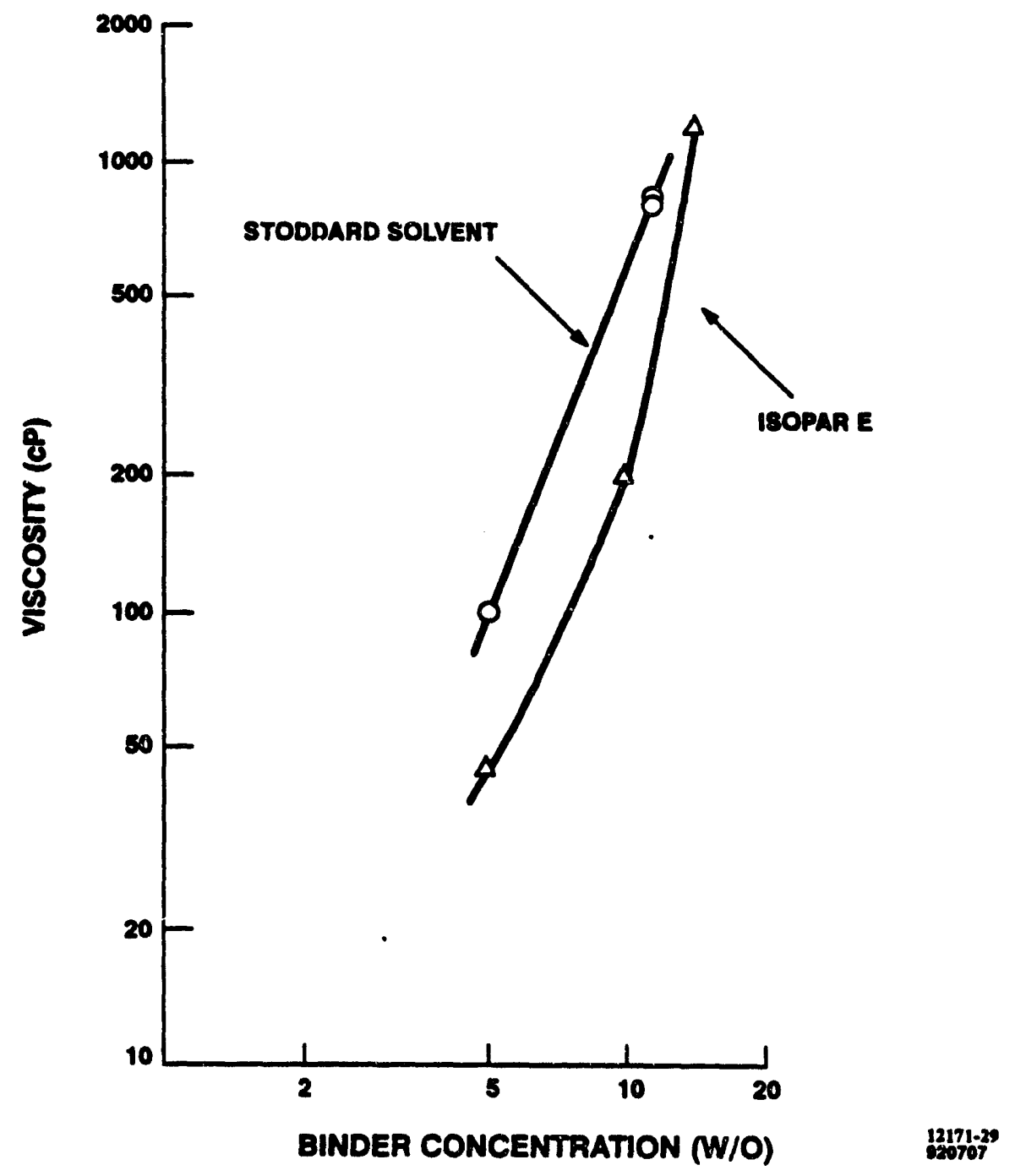

Figure 2.1-1. Comparison of Viscosity of Binder in Stoddard Solvent and Isopar E 
Slurry Formulation Studies - Nickel powder was added to each of the above binder solutions to make a slurry with 50 percent solids (weight ratio of powder plus binder to total solution). The same trends observed in the binder solutions were evident in the nickel slurries.

Laboratory-scale tapes were cast from several of the slurries described above and dried on the heated platen which monitored solvent loss as a function of time. This apparatus provided data on tape drying rates at various drying temperature profiles. The drying rate of an Isopar E slurry is compared to that of a Stoddard solvent slurry in Figure 2.1-2. The figure shows that at a lower temperature drying condition, the Isopar E slurry dried in approximately 60 percent of the time required for Stoddard solvent slurries. This result was on the order of the estimated reduction in drying rate required for compatibility with continuous tape casting.

Tapes cast from the two lower binder concentrations of each type of slurry could not be stripped from the carrier film in one piece. This fact appeared to be the result of insufficient binder for adequate tape integrity and suggested that a practical minimum binder content existed for each binder.

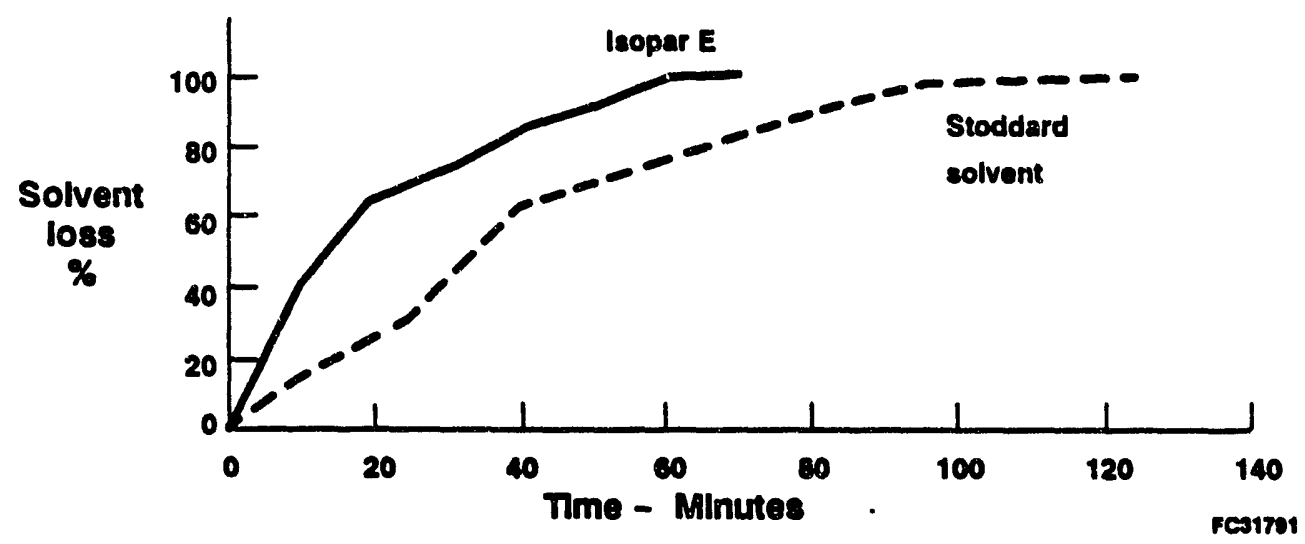

Figure 2.1-2. Drying Rate Comparison of Slurries Made With Stoddard Solvent and Isopar E

Trials were then conducted to reduce drying time further by optimizing the drying temperature profile. The approach used was to increase the temperature of the heated platen underneath the tape. A high temperature, particularly during the initial drying stage, can cause the tape to blister or crack. Several trials were conducted with slurry made using the binder and Isopar E solvent. Solvent evaporation was measured gravimetrically as the platen temperature was increased. The data show that more than 90 percent of the solvent was lost in $\mathbf{4 0}$ minutes, and evaporation was practically completed in approximately 50 minutes. These results indicated that continuous tape casting would likely be successful given that the tape casting vendor machine allows 60-75 minutes for drying.

Two Isopar E slurry formulations were prepared in 1.5-gallon batches and shipped to the tape casting vendor for continuous cathode tape-casting trials. All of the tape cast in the continuous trials was adequately dried at the end of the machine (first pass) and contained no defects. The tape thickness ranged from 10 to 24 mils. However, it was evident from samples of the 24-mil-thick tape taken near the end of the machine that the tape was not completely dried; a slight residue remained on the carrier film. The remaining solvent was removed in the second pass, after the tape made the turn at the end of 
film. The remaining solvent was removed in the second pass, after the tape made the turn at the end of the machine and returned upside-down in a heated chamber to the casting end of the machine, where it was wound on to a spool. This observation indicated that little, if any, margin existed for drying slurries made with less volatile solvents, such as Isopar $G$. Based upon this result and the success obtained with Isopar E slurries, further development of Isopar G slurries was discontinued.

Large Scale Tape Casting Trials - Based on the results of the trials above, two large scale slurries were prepared for casting. The first was a 20 gallon anode type slurry with eight-percent binder concentration. It was prepared and shipped to the tape casting vendor for casting. Approximately 250 feet of anode tape were successfully cast from the slurry.

After approximately 20 feet were trimmed off both ends of the tape, the remainder was cut into strips 42 inches long. Seventy-four (74) strips were cut from 259 feet of tape. Each of the strips was weighed and a basis weight (weight per unit area) calculated. Figure 2.1-3 shows the variation in basis weight of the tape from the anode casting trial. Almost 90 percent of the parts fell within a narrow range of +2 percent to +4 percent. While these parts exceeded the target value slightly, all of the parts trimmed were within the allowable tolerance range, as shown in the figure. The results indicated that once the tape casting process parameters are established to produce the target basis weight, a narrow range well within allowable limits can be expected for the majority of the tape. The greatest variations in basis weight are associated with unsteady conditions at the beginning and end of the casting trial.

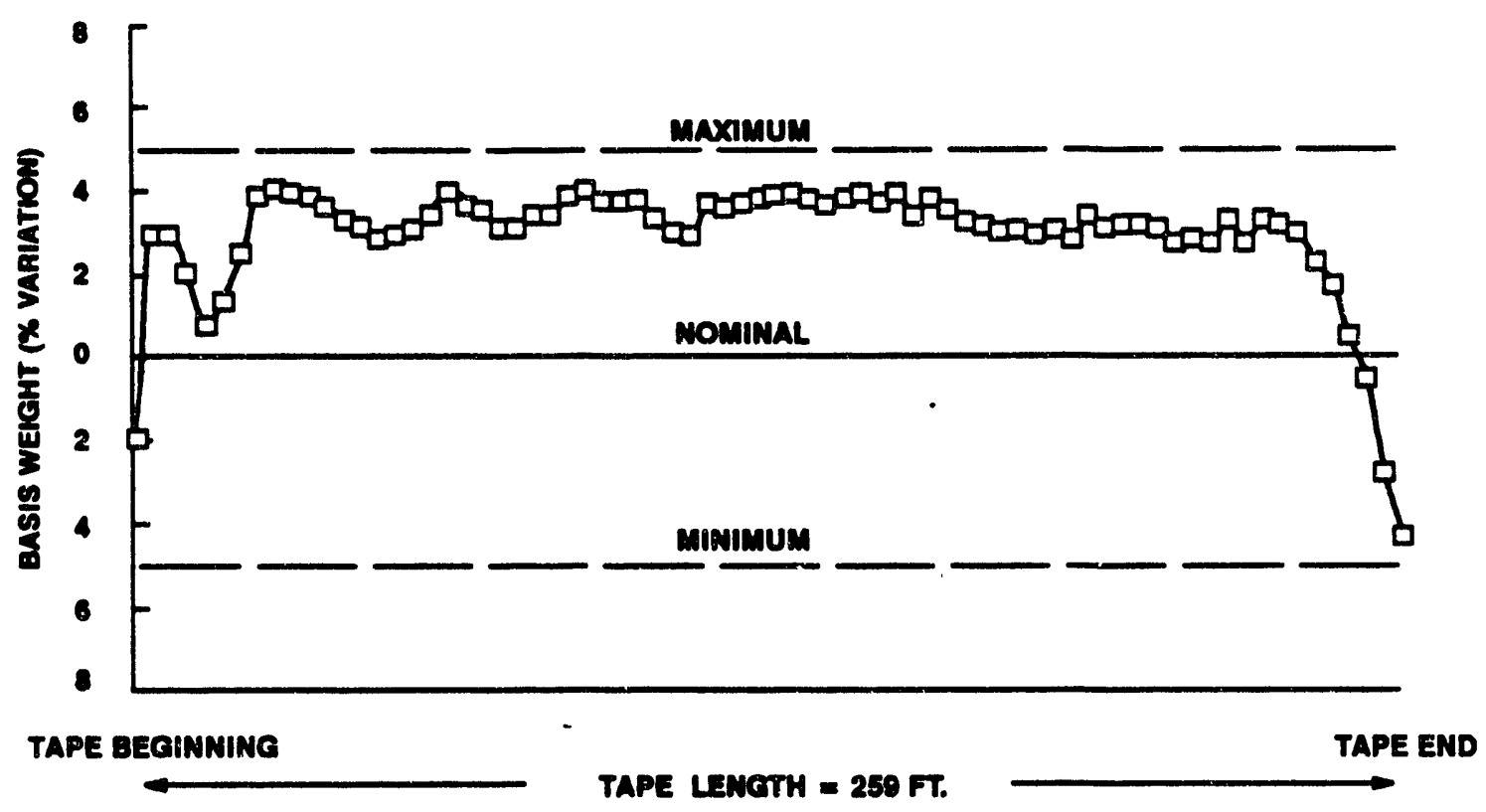

Figure 2.1-3. Tape Basis Weight from First Anode Trial

The second large scale slurry was a 25 gallon cathode tape slurry with 13.4 percent binder concentration. It was prepared and shipped to the tape casting vendor for casting. A total of approximately 430 feet of tape was cast in two thicknesses.

The tape was cut into 42-inch long strips and weighed. The basis weight (weight per unit area) of the individual tape strips is shown in Figure 2.1-4. Two thicknesses, and consequently two nominal basis 
weights of tape, were cast. The thicker tape represented the basis weight required of a cathode tape to meet porosity and thickness specifications. The thinner tape that was cast corresponded to approximately half the basis weight requirement. The half-thickness tapes can be laminated prior to debinding and would be an option in the event that more margin was required in the drying process. Thus, this trial provided process data on both approaches. Figure 2.1-4 shows that the single-ply tapes were within the desired basis weight range. However, the half-thickness plies were cast slightly thinner than desired. The single-ply cathode tapes were readily stripped from the carrier film and prepared for heat treating process trials in Subtask 2.1.2.

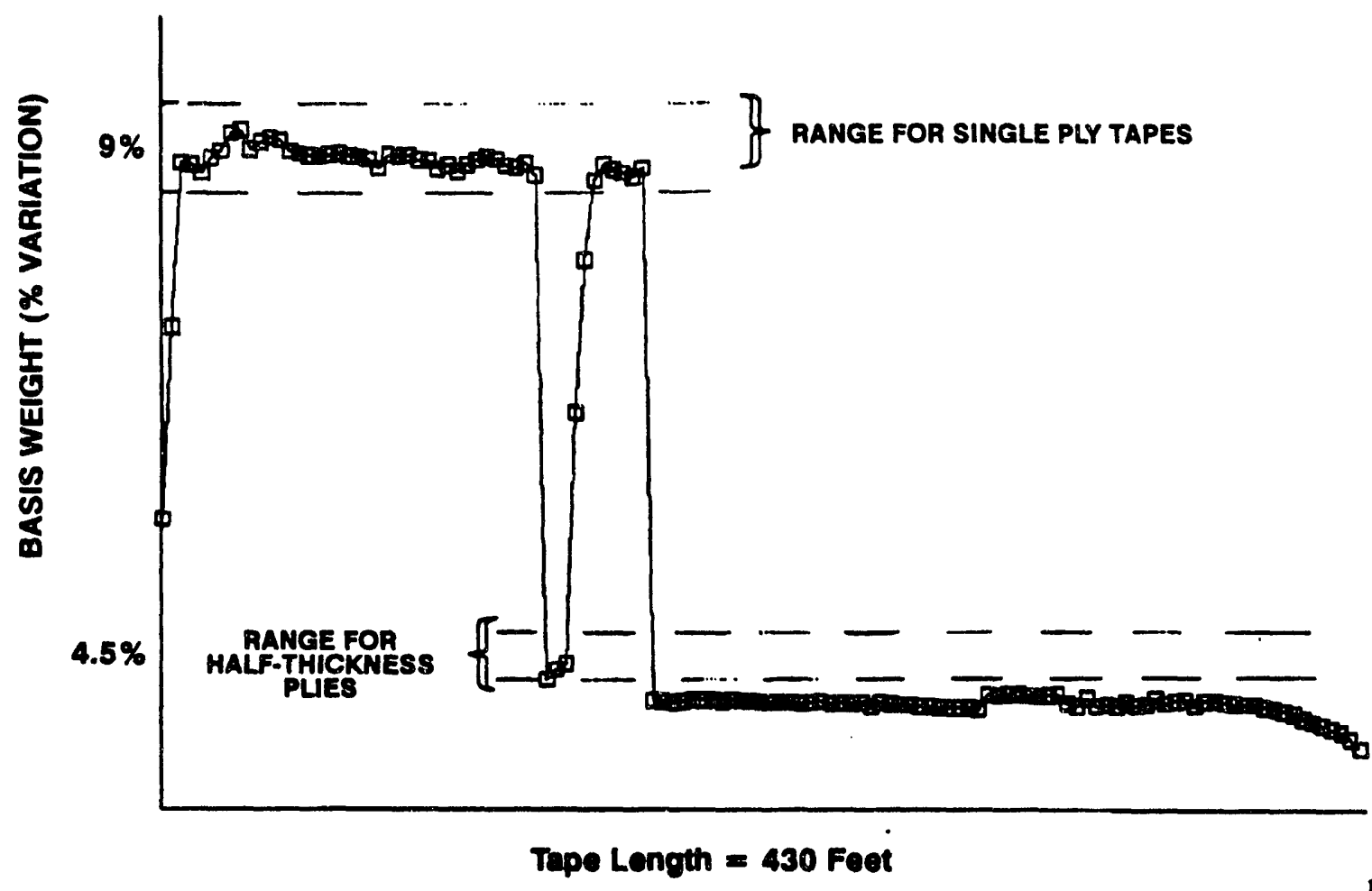

Figure 2.1-4. Basis Weights of Trial Cathode Tapes

The half-thickness tape, which would be laid up in two plies could not be readily stripped from the carrier film. The tape stretched excessively as it was stripped, and tears frequently resulted. It was apparent that a simple manual operation would not be suitable for stripping half-thickness cathode tapes.

Second Anode Tape Casting Trial - Another 25-gallon batch of slurry was completed for a second anode casting trial. The slurry composition was nearly identical to that used for the cathode casting trial. Approximately 250 feet of anode tape were cast and the visual quality of the tape was excellent.

Production Tape Casting - A large batch of anode slurry was prepared for the first tape casting production run. The slurry composition was identical to that used in the second anode casting trial. This batch represented an intermediate stage in the scale-up process toward the procedure that will be used to fabricate parts for the 100 -cell stack test. The binder solution for this and previous batches was mixed in a ball mill in approximately 20 gallon batches. In the future, this step will be performed in 55 gallon drums. The binder solution was transferred to 55 gallon drums, and the nickel powder was then 
added to the solution. The slurry was rolled in the drums to disperse the nickel. Two drums containing a total of approximately $\mathbf{8 0}$ gallons of anode slurry were prepared in this manner. The drums were shipped to the tape casting vendor and approximately 1000 feet of anode tape were cast. This run demonstrated that the slurry can be mixed and shipped successfully in 55 gallon drums. This size was convenient for two reasons: (1) equipment for routine handling was available; and (2) approximately 500 feet of tape can be cast from $\mathbf{4 0}$ gallons of slurry in one two-shift day of casting.

A second anode tape casting production run was conducted. The tape was cast from slurry that was mixed in two 55 gallon drums. Approximately 1100 feet of tape were cast from 83 gallons of slurry. Two hundred and nine (209) parts were prepared for heat treating.

A cathode tape casting production run was conducted. The slurry composition was identical to that used in the cathode casting trial. Approximately 525 feet of tape were cast from 42 gallons of slurry. A total of 110 cathodes were cut and stripped from the batch of cathode tape. These parts were prepared for heat treating.

\section{Subtask 2.1.2 Electrode Heat Treatment}

Objective - The objective of this subtask was to scale up the continuous debinding process using a new full-size IFC debinding oven located near a continuous belt furnace. This arrangement provides debinding and sintering capability in one continuous process train. Once operational, it would be capable of producing the necessary quantities of each electrode for the 100-kilowatt stack.

\section{Summary}

The process requirements for a full-scale continuous debinding oven were defined. An existing IFC oven used in PAFC programs was found capable of meeting the requirements with the addition of a muffle, an incinerator, and appropriate controls. The muffle was designed, fabricated, and installed. Specifications were prepared for the incinerator; an incinerator was purchased and installed. Controls were purchased and installed.

Subscale tests determined the flammability limits of the debinding gases. The debinding times required at various oxygen concentrations below the flammability limit were determined. A concentration of seven percent was selected as the operating condition. Proper temperature and atmosphere control were demonstrated in a pre-trial check-out.

The results of electrode tape debinding process trials indicated that the binder was successfully removed and that the electrodes could be subsequently sintered. Modifications of the muffle exit were required to accommodate thermal distortion of the baffles. Modifications were made to the baffles, and parts were processed through the muffle. The parts did, however, develop cracks during the debinding process. Several tests were conducted to determine the cause, and an approach to reduce the incidence of cracking was identified. The results of process trials indicated that a primary cause of cracking during debinding was related to the stripping operation. The incidence of cracking was significantly reduced on tapes that were stripped using new tooling. Additional modifications to the debinding muffle eliminated the problem. Continuous debinding process trials using cathode tapes were successful. An 82-percent yield of crack-free parts was observed for one run.

The production anode and cathode tapes that were produced under Subtask 2.1.1 were processed through debinding, sintering, rolling, and trim operations. A total of 55 anodes and 67 cathodes meeting specifications were produced. 


\section{Background}

Significant difficulties were encountered with the batch debinding process used to fabricate electrodes for the 20-cell, 8- $\mathrm{ft}^{2}$ stack tested in 1990. A continuous debinding process was developed using a laboratory apparatus. The effort resulted in a preliminary component specification for a full-size oven which could be coupled to a belt furnace to continuously debind/sinter electrodes. The specification was sent to 13 equipment vendors for review and quotation.

\section{Report of Work}

Trials were conducted in the subscale debinding oven apparatus used to demonstrate the feasibility of the continuous debinding process. In the first series of trials, air was directed countercurrent to the direction of electrode tape through the debinding oven. In a continuous operating mode, a part entering the oven is exposed initially to the depleted air and binder decomposition products of the upstream parts. As the part proceeds through the oven, the oxygen content of the gas it is exposed to increases. At the exit, parts are exposed to essentially pure air. The results of these trials indicated that the product gases were flammable when debinding was performed in an air atmosphere.

Combustible gas-air mixtures are flammable within a certain range of compositions. The range of compositions expands with increasing temperature and is decreased by the addition of an inert gas. Flammable mixtures can be avoided by keeping the combustible gas concentration either above the upper limit, or below the lower limit of flammability. Flammable mixtures can also be avoided by adding sufficient inert gas, such as nitrogen. These generalized effects are shown in Figure 2.1-5.

Processing trials were conducted in a laboratory furnace with a sealed retort which provided a controlled atmosphere. These trials determined that the debinding was successfully completed in dilute air atmosphere. Further tests determined the minimum oxygen concentration required to support combustion of the debinding product gases. The rate of debinding was then determined as a function of oxygen concentration below the flammability limit. These data were used to establish the debinding process conditions for the full-scale debinding oven.

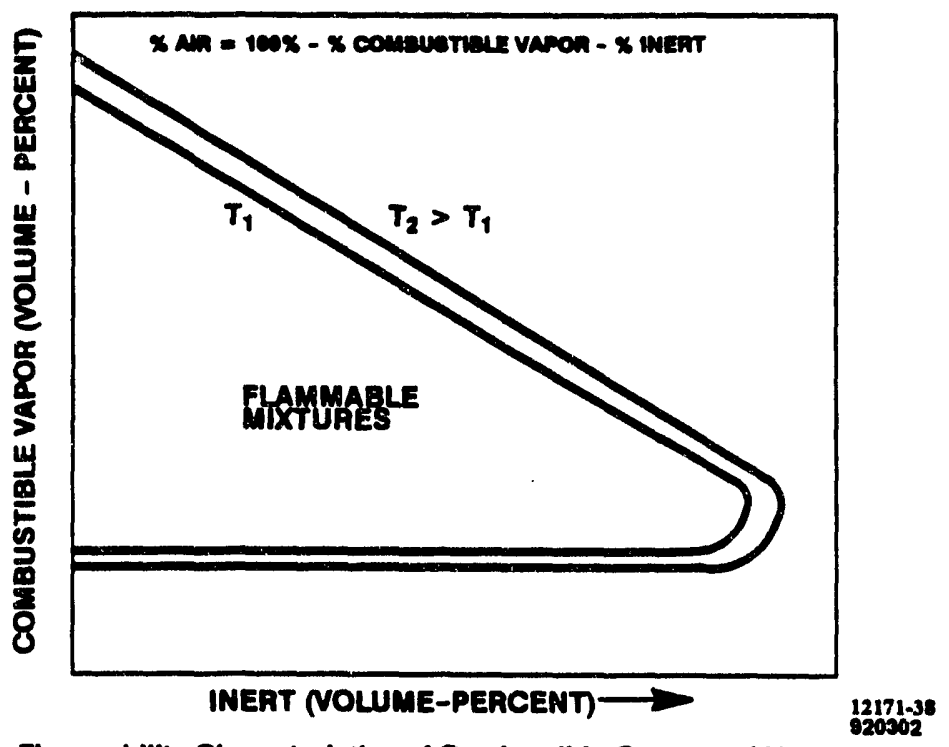

REF. Zabotakis, M.G., Elammablliv Characterietles of Combusttble Gases and Vapors. Bureau of Mines Bulletin 627. 1965.

Figure 2.1-5. Effect of Temperature and Inert Gas Concentration on the Flammability Limits of Combustible Gases 
Full Scale Continuous Debinding Equipment - An existing oven, used to process PAFC components for other programs, was adapted for the full-scale debinding process. The 30 -foot-long oven, shown in Figure 2.1-6, could operate up to approximately $700^{\circ} \mathrm{F}$. It had one temperature control zone, maintaining the temperature within a narrow range except near the inlet and exit. The oven was located adjacent to the IFC sintering belt furnace, which was used to presinter and sinter electrodes after debinding.

To adapt the existing oven to the debinding process, a continuous muffle was inserted into the oven with openings on either end. The controlled atmosphere was maintained by gas curtains at both openings. The muffle contained the off-gases generated during debinding, and channeled them to the incinerator. A belt moved parts through the muffle. A conceptual sketch of the process is shown in Figure 2.1-7. In order to maintain flexibility for processing both MCFC and PAFC components, the muffle was designed for easy installation and removal.

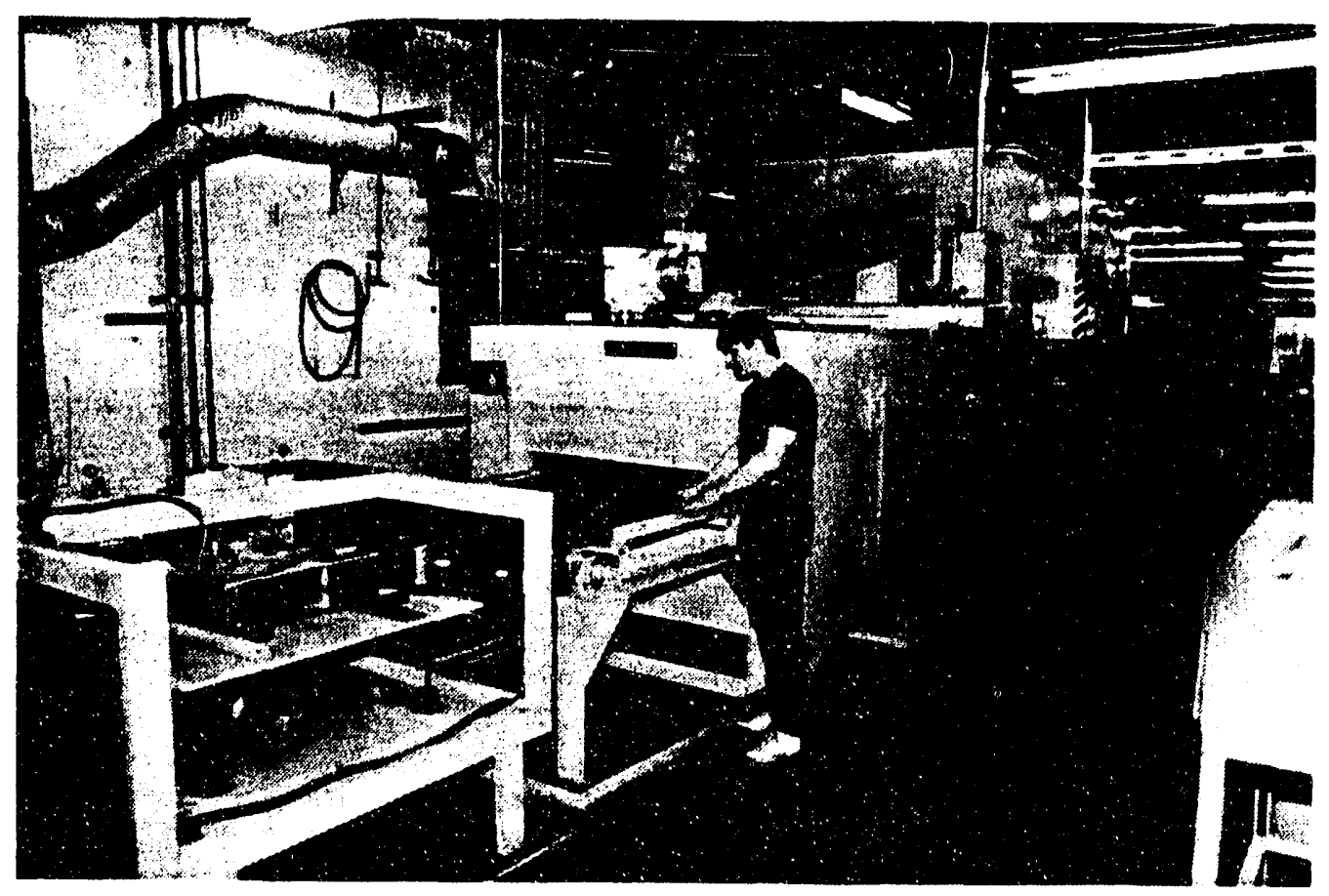

punsers

Figure 2.1-6. Oven Used for Continuous Debinding of Electrode Tapes 


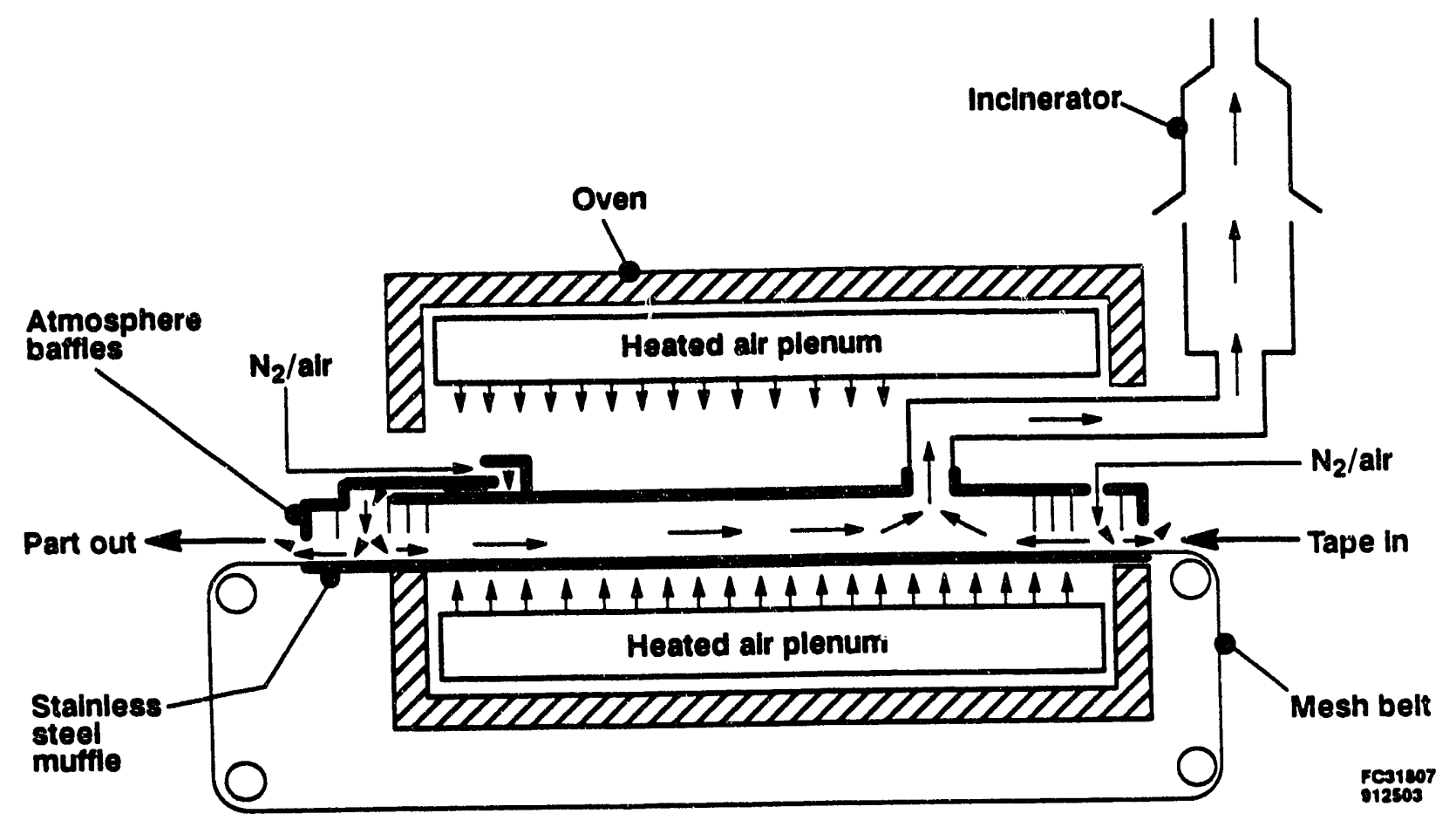

Figure 2.1-7. Full-Scale Debinding Oven Conceptual Sketch

The process requirements for the muffle design were defined. These included the gas flow rates and pressures relative to ambient pressure at either end of the muffle and at the inlet to the incinerator. In addition, the number of gas baffles and the openings beneath them were determined so that the required flows and pressures could be maintained.

The debinding process control system has sensors to monitor the oxygen concentration of the gases near both the inlet and the exit of the muffle to ensure that the desired atmosphere is maintained. If the oxygen concentration rises to the trigger level at either sensing location, due to air leakage in, for example, the annunciator sends a signal which shuts off the air in the gas mixture to the muffle. If the oxygen level continues to rise to 2 percent above the trigger level, another signal is sent which results in a large nitrogen flow into the muffle. The trigger levels were chosen to maintain a safe margin from the oxygen flammability limit.

Specifications were prepared for the off-gas incinerator. These were discussed with potential vendors. A supplier was selected, and a purchase order was placed. The incinerator was delivered and mounted in place. Gas and electrical hook-ups were made. Figure 2.1-8 shows the incinerator mounted in place. 


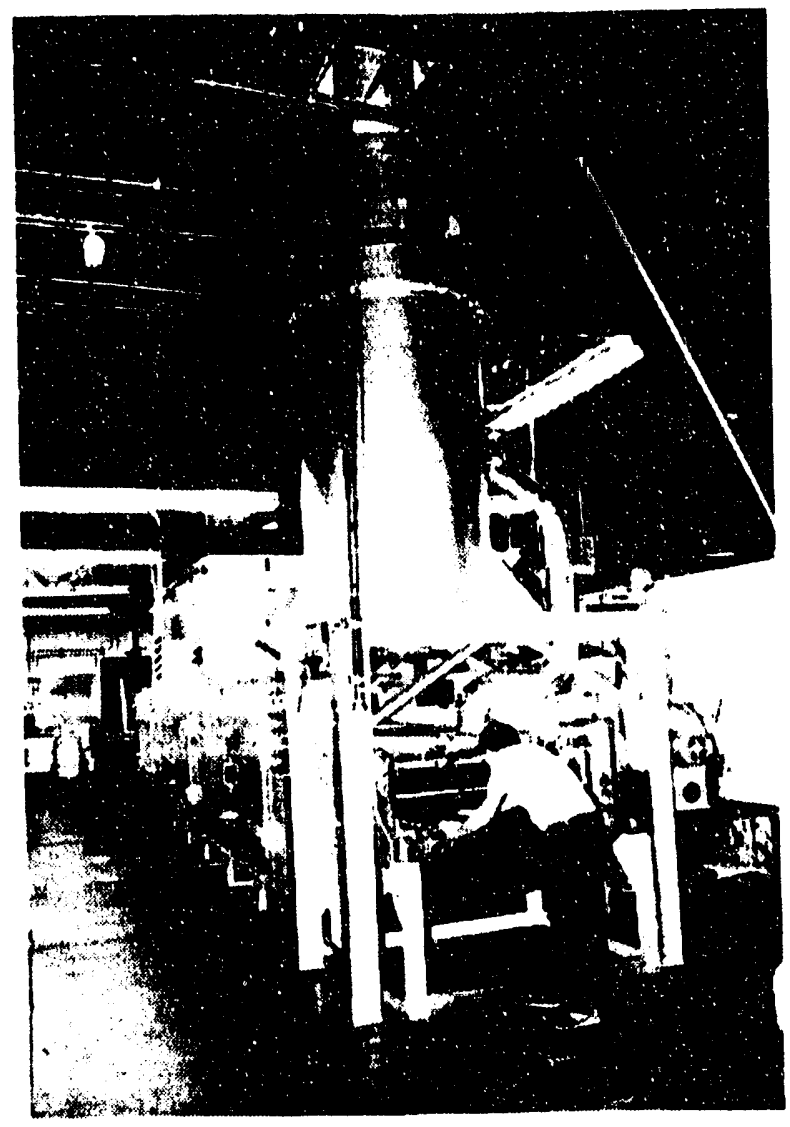

Punsas72

Figure 2.1-8. Continuous Debinding Oven (Inlet End) with Incinerator Mounted in Place

Fabrication of the debinding process muffle was completed, and the muffle was installed in the oven. Figure 2.1-9 shows the muffle being installed. A check-out and conditioning test of the incinerator was completed. A temperature profile obtained at operating conditions verified that the requirements were met. 


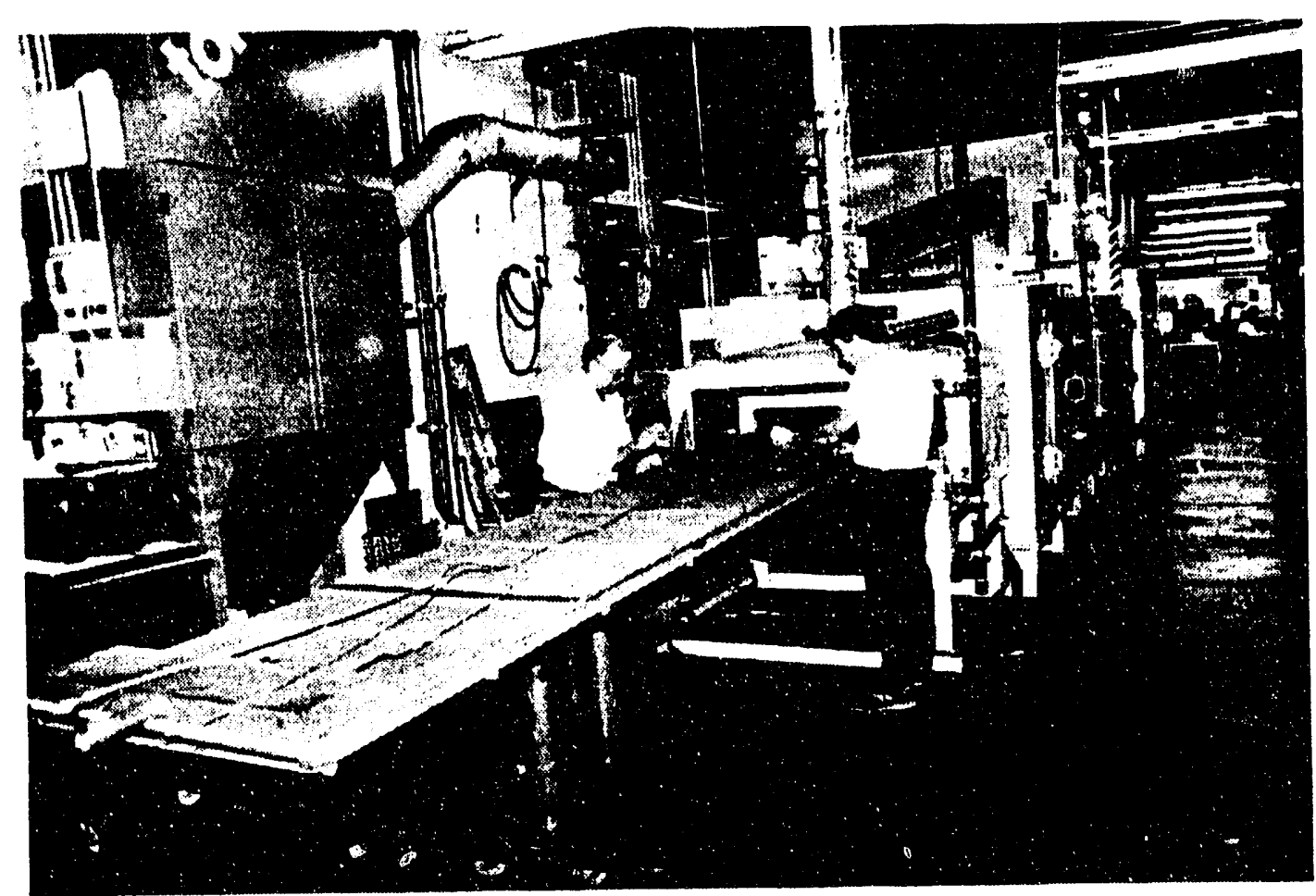

pussess?

Figure 2.1-9. Atmosphere Control Muffle Being Installed in Continuous Debinding Oven (Exit End)

Heat Treating Trials - Initial trials revealed a problem with the muffle exit baffles. Parts run through the oven at process condition caught on these baffles. The muffle was removed and modified. Subsequent trials demonstrated that the modification was successful, however, another problem became evident. One or two cracks developed in the parts across their width, perpendicular to the direction of travel through the oven. Figure 2.1-10 shows cracks in a typical anode tape after debinding. Several runs were made at a variety of processing conditions, including runs in which the oven was cooled down full of parts to determine the point at which cracking occurred. It was clear from these trials that the cracking occurred during the heat-up portion of the cycle. A procedural change was made to the process for insertion of the parts into the muffle. Seventeen trial parts were used to evaluate this change resulting in an 82 percent yield. Prior to presintering the crack-free parts, several samples were cut from one of the cathodes after it was processed through the debinding oven. The samples were sintered in the laboratory furnace to verify that the binder removal was complete and that the parts met the cathode porosity specification. After sintering, the porosity of the samples were within 1 percent of the target specification. This result confirmed that the debinding process was capable of producing parts which met the design specifications. 


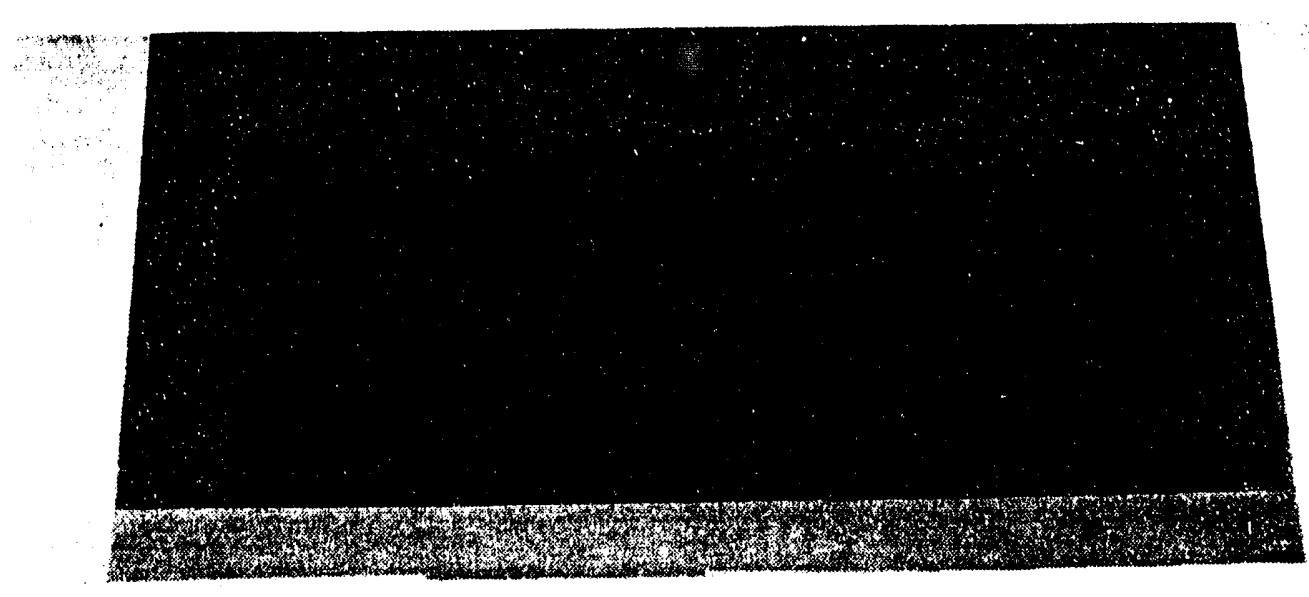

PUBS 8754

Figure 2.1-10. Cracks in Anode Tape after Debinding Process Trial

Another debinding process trial was conducted on a batch of parts after modifications were made to the stripping tool to eliminate the stripping discontinuity. Small edge cracks developed on only one of six parts stripped with the improved tool. Although the sample size was small, the results were believed to be significant. It was concluded that an improper stripping technique could significantly increase the incidence of cracking during the debinding operation. The stripping technique probably was also responsible for most of the variable yields of crack-free parts that were observed after making the procedural change.

Production Heat Treating - The production anode and cathode tape that was cast under Subtask 2.1.1 was processed through heat treating, rolling, and trim operations to produce electrodes for $8-\mathrm{ft}^{2}$ cells.

(a) Anodes - Tapes cut from the first production tape casting run were processed through the debinding and presintering steps. The yield of crack-free parts was 88 percent.

After presintering at $1600^{\circ} \mathrm{F}$, the parts were shipped to the sintering vendor. These anodes were sintered at $1950^{\circ} \mathrm{F}$ and rolled to final thickness.

Tapes from the second anode production tape casting run were processed through the debinding and presintering process steps. Several parts were damaged during debinding by defects in the graphite carrier sheets which the parts were placed on. After this problem was corrected, the yield through the debinding line was excellent; practically all parts processed on good carrier sheets were acceptable, and processed through the presintering furnace. 
A total of 55 acceptable anodes were obtained from the two prociuction runs. The 55 acceptable parts plus five parts with slight deviations in the thickness or porosity were processed through the dispersion strengthening heat treatment operation. Twelve (12) of these anodes were processed through the electrolyte addition heat treat cycle to verify this process. No problems were experienced in either heat treating operation. Porosity and thickness distrubutions are shown in Figure 2.1-11 and 2.1-12.

(b) Cathodes - The cathode tapes from the production casting run were processed through debinding and $1600^{\circ} \mathrm{F}$ sintering. Ninety five (95) good quality cathodes were obtained which was an 86 percent yield. After completing the roll and trim operations, 67 parts met all requirements. Most of the reject parts were due to minor edge cracks or a high density band that was probably in the green tape. Porosity and thickness distributions are shown in Figures 2.1-13 and 2.1-14. Pictures of the finished electrodes are shown in Figure 2.1-15.

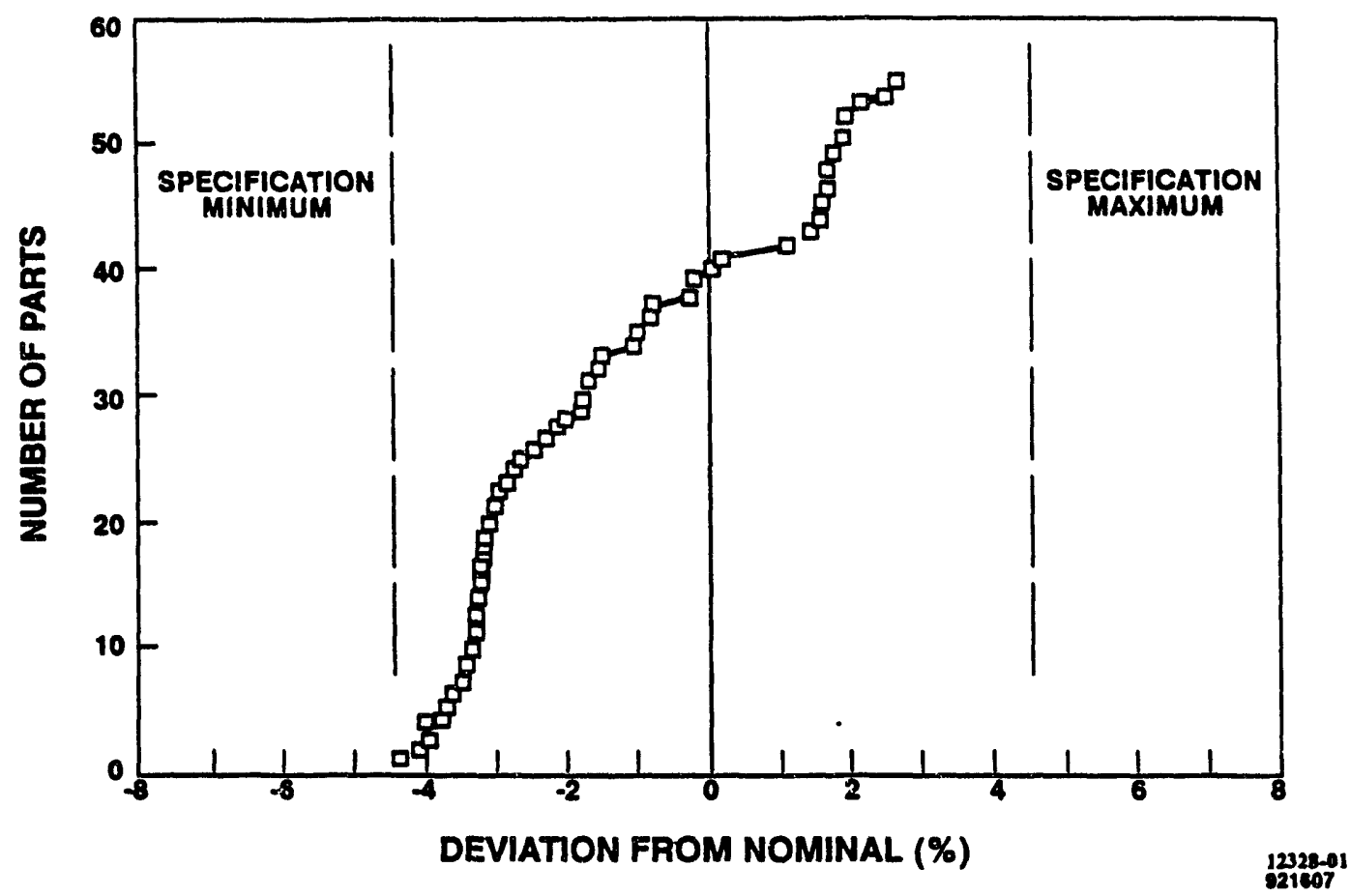

Figure 2.1-11. Anode Porosity Distribution 


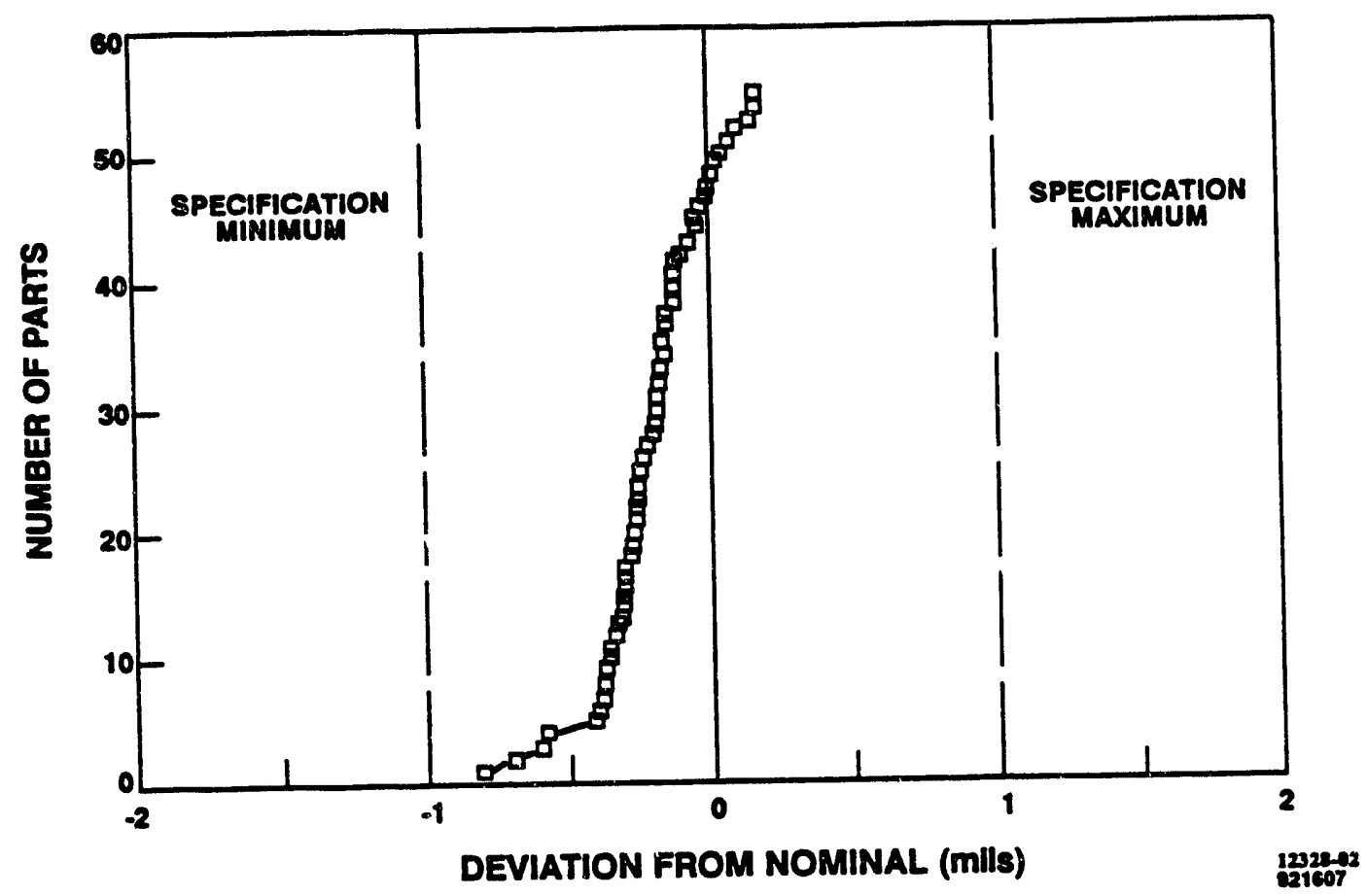

Figure 2.1-12. Anode Thickness Distribution

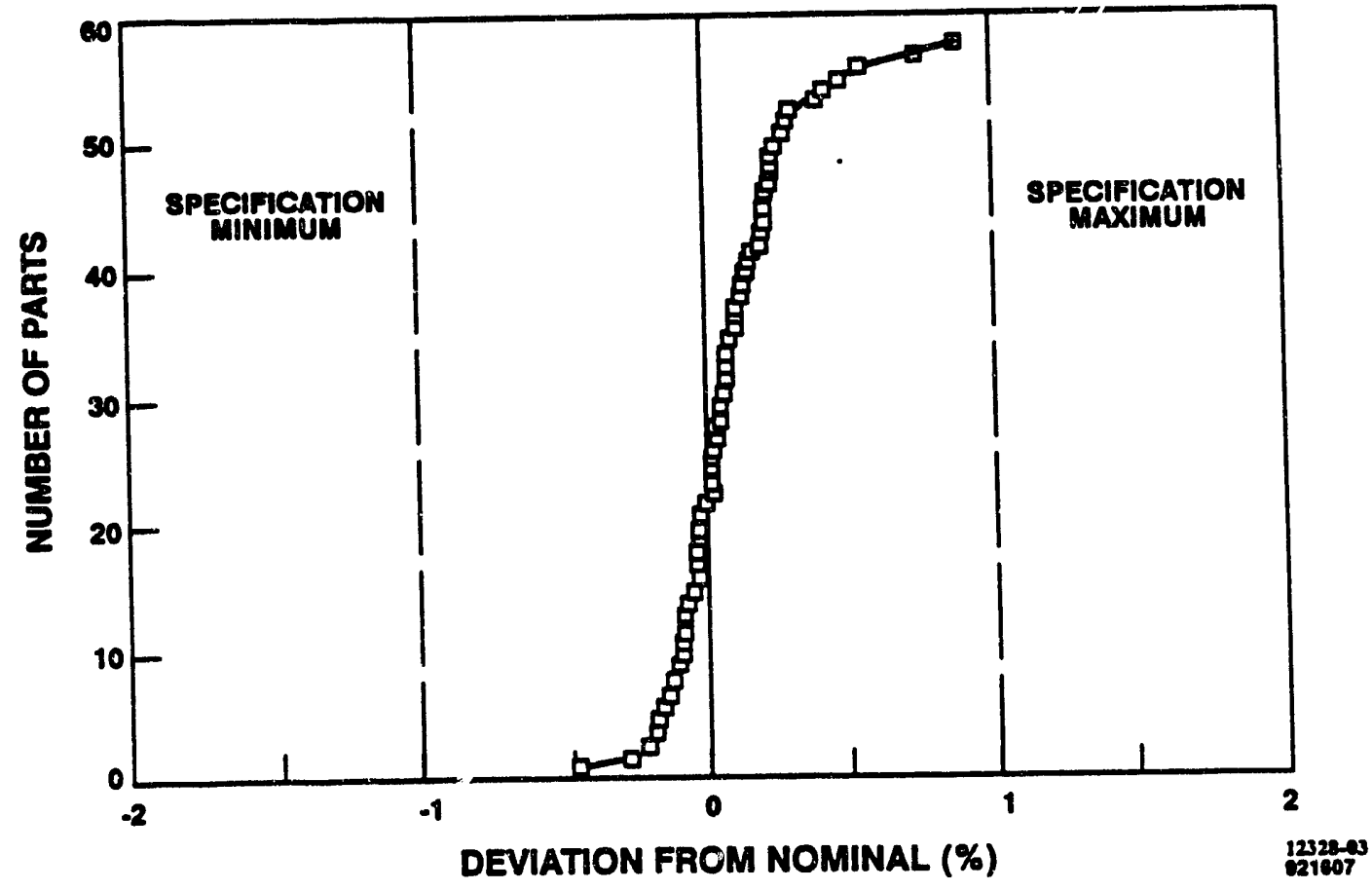

Figure 21-13. Cathode Porosity Distribution 


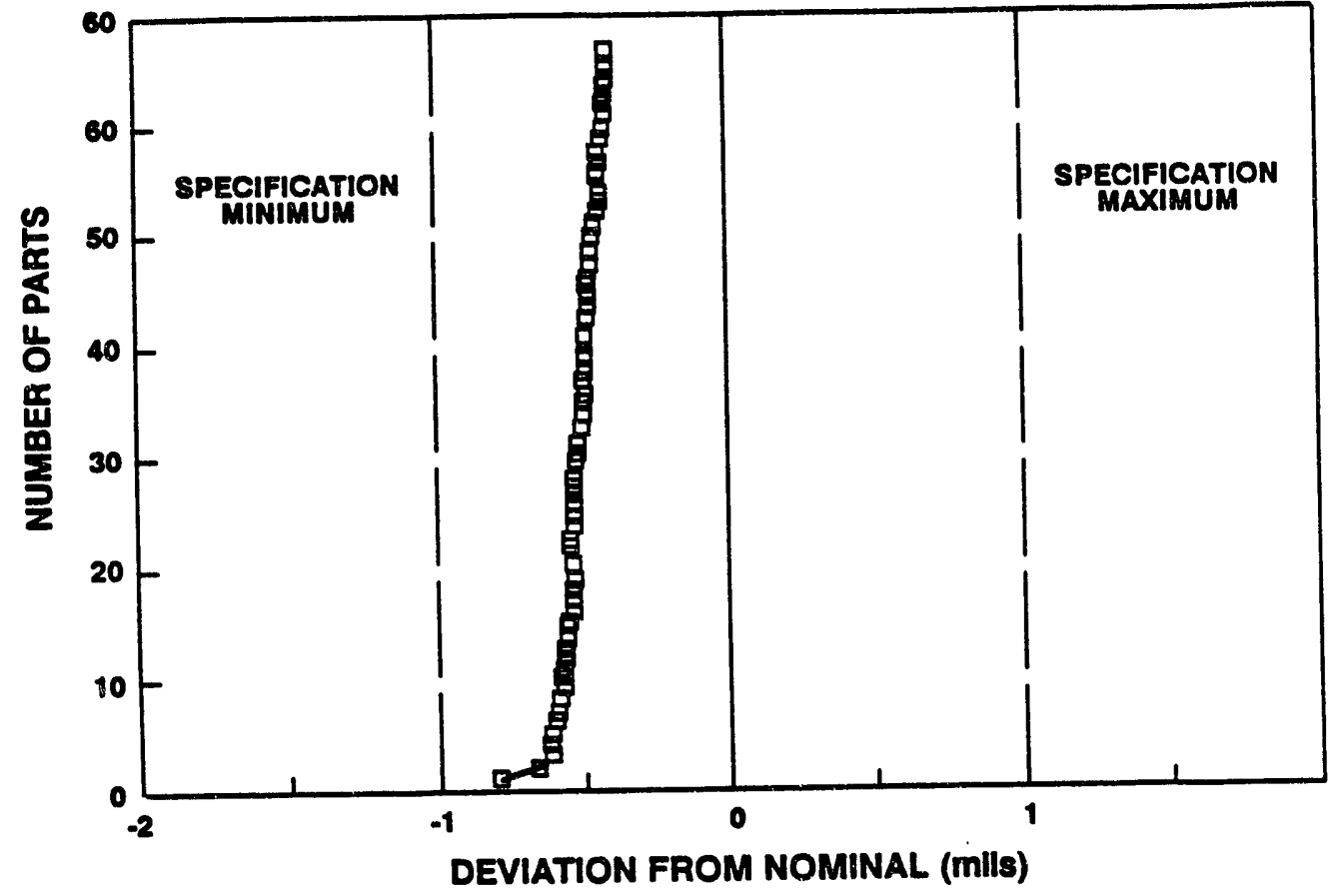

12326004

Figure 2.1-14. Cathode Thickness Distribution 


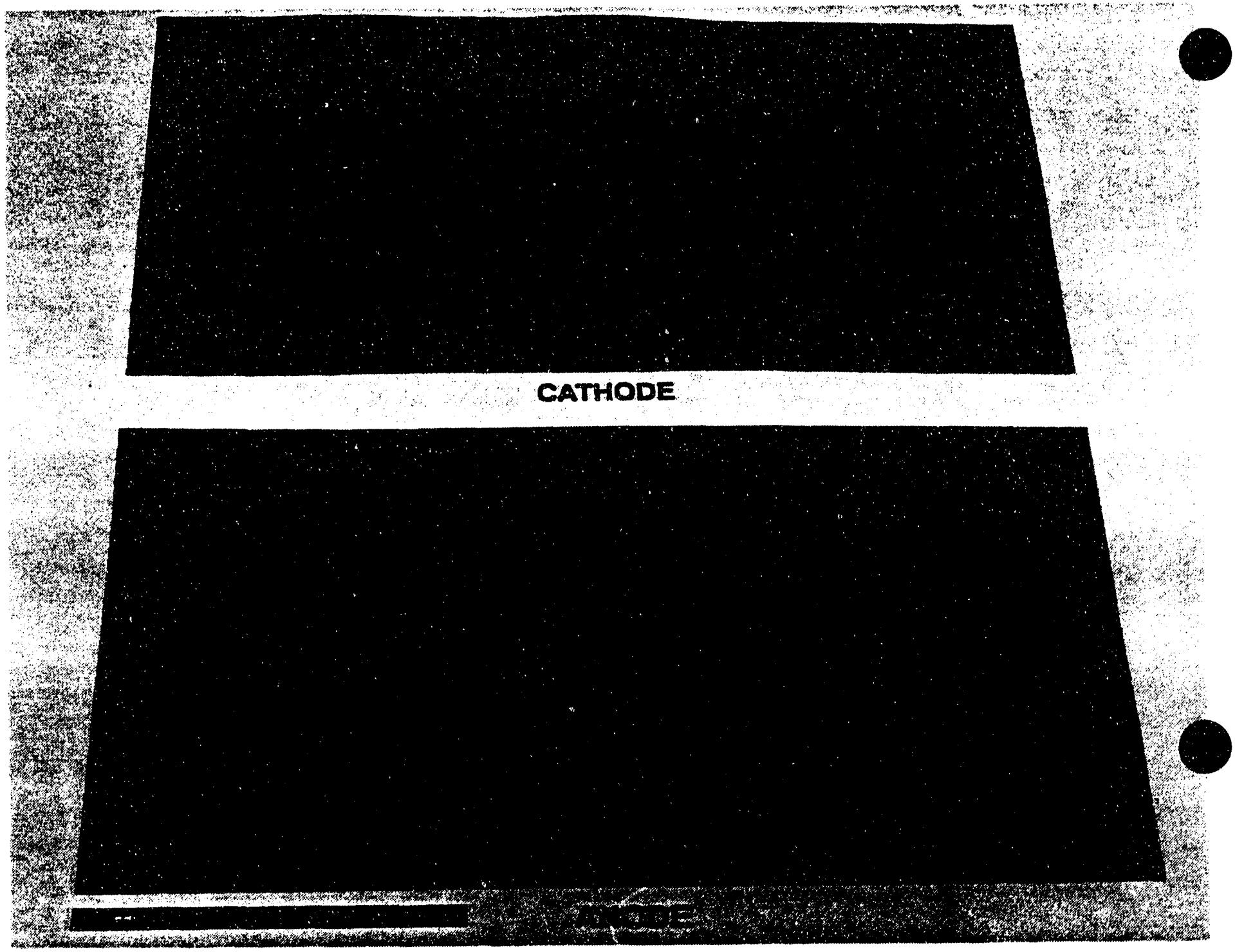

WCN14:01

Figure 2.1-15. Anode and Cathode for 8-Ft' Stack 


\section{Subtask 2.2. Repeat Part Quality Assurance and Testing}

Objective - The objective of this task was to provide appropriate quality assurance to ensure that consistent, high quality, reproducible and comparable repeat parts are produced for stack use.

\section{Subtask 2.2.1 Quality Assurance}

\section{Summary}

The Quality Assurance Plan for repeat parts was prepared based on documents generated in the previous DOE program, Contract No. DE-AC21-87MC23270. The plan was updated to include the material, process, and configuration changes proposed for the $100-\mathrm{kW}$ stack.

The elements of the Quality Assurance Plan for the repeat parts included a Document Configuration Management Plan, Product Definition Documents, Process and Quality Assurance Flow Diagrams, and Quality Control Monitoring Plans.

The Document Configuration Management Plan established document initiation and change control for joint activity with the Share Partner. The Production Definition Documents included drawings, specifications, and inspection standards. Process and Quality Assurance Flow Diagrams defined operation sequence and associated quality control checks. Quality Control Monitoring Plans provided detailed instructions for quality control checks.

\section{Report of Work}

Quality Assurance Plan - The elements of the Quality Assurance Plan for the repeat parts for the 100-kW stack included:

- Document Configuration Management Plan for joint activity between IFC and the Share Partner.

- Product Definition

- Process and Quality Assurance Flow Diagrams

- Quality Control Monitoring Plan

(a) Configuration Management Plan - The Document Configuration Management Plan for the joint activity established the controls for initiating new documents and change control on existing documents. This plan utilized existing procedures within IFC and the Share Partner. The Configuration Management Plan is shown in Figures 2.2-1 and 2.2-2. 
IFC

Joint Activity

Share Partner

- Create Design Documents (1)

- Obtain IFC approvals :

- Send coples to Share Partner

- Create Manufacturing Documents (2)

- Obtain approvals

- Roviow by IFC

Send coples to IFC

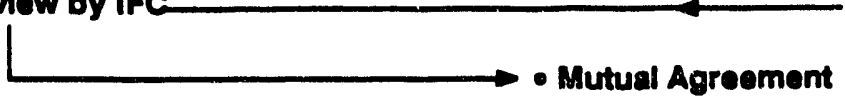

- Written confirmation

- Prepare final drawings

- Send coples to IFC

(1) Design Documents Trawings - Process Specifications

- Material Specifications

- Material Test Methods
(2) Manufacturing Documents

Trawngs

- Process inatruetions

- Quality standarde

- Inspection Procedures

Figure 2.2-1. Document Configuration Management - Initial Document Preparation

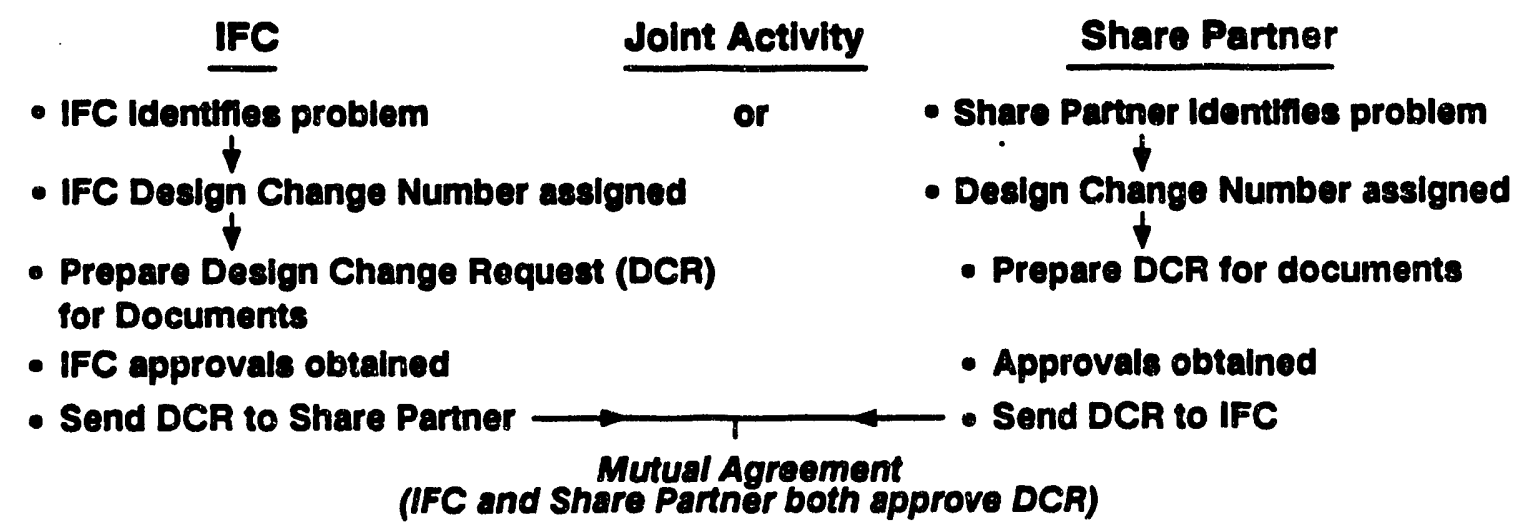
- IFC changes Design Documents
- Share Partner Changes Manufacturing Document
- Send revised coples to Share Partner $\rightarrow+\infty$
DCR Item Closed
(with record of Document Rovisions)

Fcsoss9:

Figure 2.2-2. Document Configuration Management-Document Change Procedure 
(b) Product Definition - The repeat part product definition consisted of drawings, material specifications, process specifications, and inspection standards. Preliminary drawings and specifications were prepared in the previous DOE program, Contract No. DE-AC21-87MC23270. These drawings and specifications are being finalized during the present program.

A listing of the drawing and specification documents for each of the repeat parts is shown in Tables 2.2-1, 2.2-2, 2.2-3, and 2.2-4.

Design Change Requests were prepared as required for revising and updating the drawings and specifications. Comments from the Share Partner on the documents were evaluated and incorporated according to the guidelines of the Configuration Management Plan.

\begin{tabular}{|c|c|c|}
\hline \multicolumn{3}{|c|}{$\begin{array}{c}\text { Table 2.2-1 Drawing and Specification Documents } \\
\text { Sheet Metal Components }\end{array}$} \\
\hline $\begin{array}{c}\text { Component } \\
\text { drawings }\end{array}$ & Specification title & $\begin{array}{c}\text { Specification } \\
\text { type }\end{array}$ \\
\hline Separator plate & $\begin{array}{l}\text { - IVD aluminum coating } \\
\text { - Aluminization heat treatment } \\
\text { - Diffusion aluminide coating } \\
\text { - Specimen preparation test method }\end{array}$ & $\begin{array}{l}\text { Process } \\
\text { Process } \\
\text { Material } \\
\text { Material test } \\
\text { method }\end{array}$ \\
\hline $\begin{array}{l}\text { Current collectors } \\
\text { - Anode side } \\
\text { - Cathode side }\end{array}$ & - Visual and dimensional acceptance & Inspection \\
\hline Spring assemblies & - Sheet Metal Material & Material \\
\hline Separator plate assembly & $\begin{array}{l}\text { - Caulk } \\
\text { - Bonding procedure } \\
\text { - Visual acceptance }\end{array}$ & $\begin{array}{l}\text { Material } \\
\text { Process } \\
\text { Inspection }\end{array}$ \\
\hline
\end{tabular}




\begin{tabular}{|c|c|}
\hline \multicolumn{2}{|c|}{ Table 2.2-2. Drawing and Specification Documents } \\
Matrix
\end{tabular}

Table 2.2-3. Drawing and Specification Documents

\section{Electrodes}

\section{Component} drawings

Anode
Specification title

- Nickel Powder

- Chrome Powder

- Binder

- Solvent

- Anode Tape

- Debinding

- Sintering

- Preoxidation

- Anode

- Electrolyte Fill

- Visual Acceptance

\section{Specification} type

Material

Material

Material

Material

Material

Process

Process

Process

Material

Process

Inspection 
Table 2.2-4. Drawing and Specification Documents Electrodes

\section{Component drawings}

Cathode

\author{
Specification title \\ - Nickel Powder \\ - Binder \\ - Solvent \\ - Cathode Tape \\ - Debinding \\ - Sintering \\ - Cathode \\ - Visual Acceptance
}

\begin{tabular}{|c|}
\hline $\begin{array}{c}\text { Specification } \\
\text { type }\end{array}$ \\
\hline $\begin{array}{l}\text { Material } \\
\text { Material } \\
\text { Material }\end{array}$ \\
\hline Material \\
\hline Process \\
\hline Process \\
\hline $\begin{array}{l}\text { Material } \\
\text { Inspection }\end{array}$ \\
\hline
\end{tabular}

(c) Flow Diagrams - The Process and Quality Assurance Flow Diagrams define the sequence of operations and the quality control tests or measurements for each process step. Preliminary flow diagrams were prepared in the previous DOE program for all of the repeat parts. The material and process changes defined in the current program were incorporated into the flow diagrams.

(d) Monitoring Plans - The Quality Control Monitoring Plans provide the detailed instructions for in-process and finished part quality control checks. Monitoring plans were prepared for all repeat part processing and finished parts.

The Quality Control Monitoring Plans consist of three basic parts:

Part 1) This is the basic controlling document and is set up in a flow chart format covering all operations. This document specifies the measurements or tests to be conducted at each operation. It references the data recording forms, what to do in case of a deviation, and requires operator sign off.

Part 2) This is the data recording form and includes instructions on the measurement or test being conducted.

Part 3) This form is for joint activity only and provides means for the Share Partner to report deviations to IFC.

Separator Plate Aluminization - A series of trials was conducted to verify the aluminization process for the Alloy-A separator plates. These trials resulted in defining a simple surface preparation method, an acceptable band of aluminum thickness, and a lower heat treatment temperature. A pre-production run of 15 full-scale separator plates was conducted by using these parameters. The morphology of the coated zones was acceptable and plate distortion was minor. Based on these results, aluminization of separator plates for the $100-\mathrm{kW}$ stack was approved.

Current Collectors - Extensive field-height measurements will be taken on the initial production current collectors. These measurements will be used not only to qualify the dimensional accuracy of the 
parts, but to determine if a skew might develop in the assembly of the parts in the stack. Skew can occur if parts are consistently fabricated with a dimensional bias, even though dimensional variation is within drawing tolerances. This is particularly true for fabrication techniques such as those used in forming the current collector, where repetitive operations may produce a series of parts with a consistent bias within the acceptable tolerance band. The field-height dimensions from the initial batch of production parts will be statistically analyzed to determine if any dimensional bias exists, and the effect on the skew of the assembled stack. If an unacceptable amount of skew is projected, changes will be made to reduce the dimensional bias in the current collectors. 


\section{TASK 3. NON-REPEAT PARTS DEVELOPMENT FOR STACK}

\section{Subtask 3.1 Manifold Seal}

Objective - The objective of this subtask was to complete the development of the manifold seal concepts identified in the previous program in order to obtain a manifold seal meeting the mechanical, electrical, and sealing design requirements. This manifold seal configuration employs electrolyte barriers in the plane of the matrix to retard electrolyte transfer from individual cells to the manifold seal. A caulk/zirconia cloth composite manifold seal provides enhanced mechanical stability with minimal contribution to electrolyte transfer.

\section{Summary}

The seal between an external manifold and an MCFC stack must meet a number of requirements. The most important from the standpoint of this development subtask are:

1) It must prevent gas leakage between the manifold and the rough surface of the cell stack.

2) It must be flexible enough to maintain a good seal despite relative motion between manifold and stack due to differential thermal expansion.

3) It must not act as a conduit for electrolyte transfer from the more positive cells to the more negative ones.

The first two requirements are apparently in conflict with the third, because the qualities of a resilient conforming seal tend to allow electrolyte wicking.

Through an evolutionary process, IFC developed a configuration that apparently resolves these conflicts. The key is an electrolyte-blocking component between the seal material and the electrolyte-filled cell components. This electrolyte barrier is effective enough that little electrolyte is lost from the cells to the seal. Therefore, the seal is not required to act as the only barrier to electrolyte transport, and the characteristics of a good gas seal need not be comprised.

The development effort in this subtask was concentrated in two areas:

1) Evaluation of twelve combinations of electrolyte barrier configurations and materials in a shunt current rig.

2) Evaluation of gas leakage in two seal rig tests.

\section{Report of Work}

\section{1) Shunt Current Rig Evaluation of Electrolyte Barriers}

Thirteen simulated mini-stacks have been tested in this period (SHUNT9-SHUNT12 and SHUNT14-SHUNT22). The narrative which follows describes these tests.

\section{Test Rig Definition}

The shunt current rig was designed and testing was initiated under the previous program, Contract No. DE-AC21-87MC23270. Considerable effort was made to develop a conceptual design of test rigs which would reliably assess the important characteristics of a manifold seal in non-stack component tests. The important characteristics were deemed to be:

- Cell-to-cell and top-to-bottom shunt currents

- Seal leakage rates at normal pressure differentials (less then 10 inches of water)

- Stability of the seal to erosion at normal leakage rates

- Blow-out tolerance (resistance to transient pressure upsets). 
After careful consideration it was decided that the only single rig which would accomplish all of this is an operating stack. This was beyond the scope of the development program. A decision was made to use two test rigs instead, the shunt current rig and the seal rig, for development.

A conceptual sketch of the shunt current rig is shown in Figure 3.1-1. Ten simulated cells are stacked between alumina dielectric sheets. The alumina rail traps the seal between the simulated stack edge and the rail. The only electrical path between cells is through the electrolyte-wetted seal.

Figure 3.1-2 illustrates the repeating cell package elements. Electrolyte is supplied to the seal from reservoirs simulating the pore size distribution of an operating cell. The cell edges (separator flanges) can be positioned to simulate the real stack-face roughness set by in-plane tolerances of the 8- $\mathrm{ft}^{2}$ sheet metal hardware.

A string of zener diodes is used to set a voltage on each cell to simulate an operating cell stack. Current is measured at each cell and total for the stack.

In this rig, as in a stack, the electrolyte moves out of the + end of the stack into the - end. The maximum currents are seen in the end cells. The highest individual cell current seen in any test is taken as the shunt current for that seal test. It is this current which would establish the size of the end cell reservoirs required by a stack employing the manifold seal under test. A current of $1 \mathrm{~mA}$ corresponds to moving 0.1 grams of electrolyte per 100 hours.

At the conclusion of each test, the mini-stacks were cooled down, removed from the retort and disassembled for post-test analysis to determine the electrolyte content in the various components of the stack. The electrolyte content was determined by weighing the post-test parts before and after a glacial acetic acid wash. The electrolyte content in each electrode package (consisting of all parts between adjacent alumina plates) was obtained along with the amount of electrolyte on each alumina plate and in the seals. 


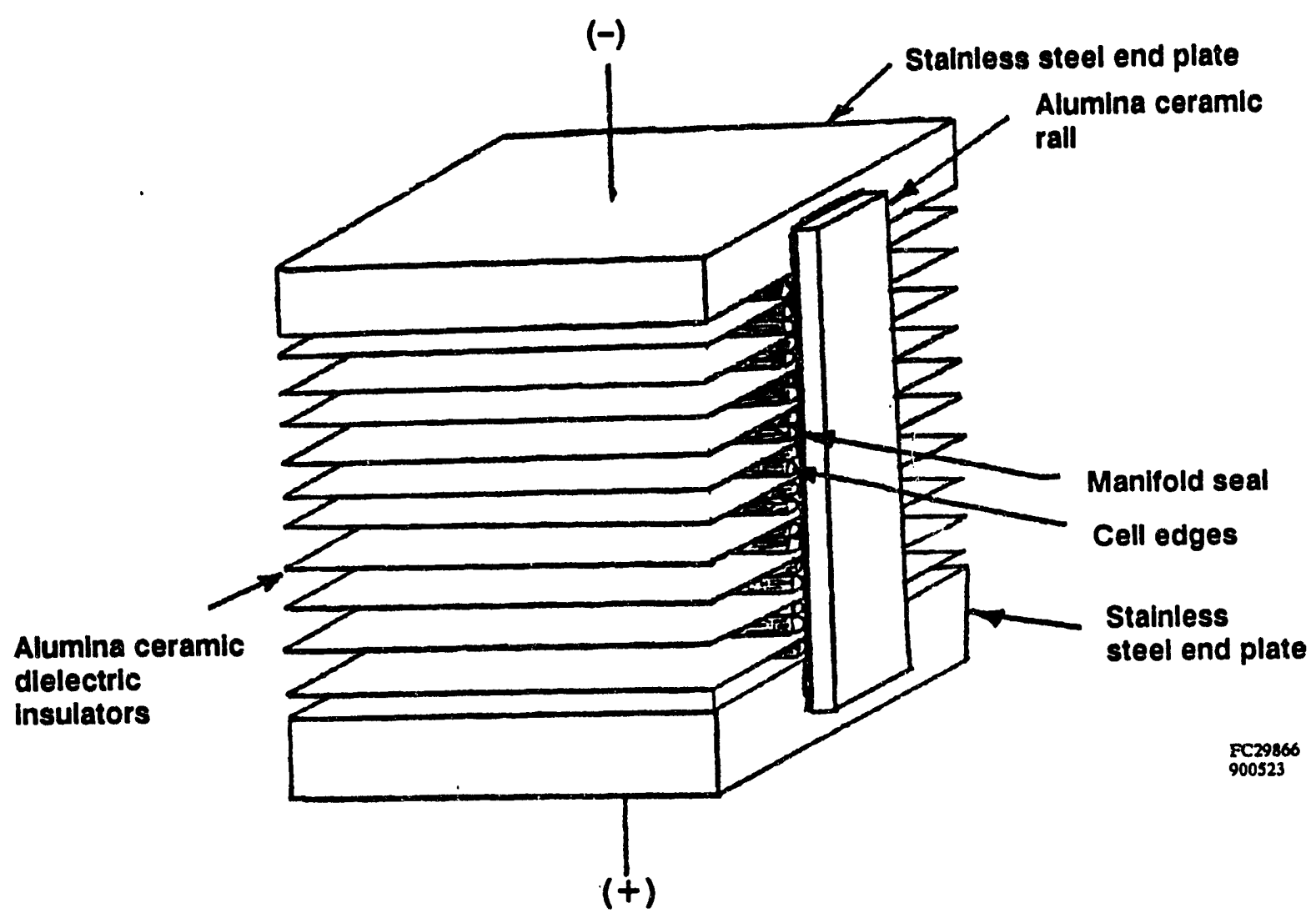

Figure 3.1-1. Shunt Current Test Rig

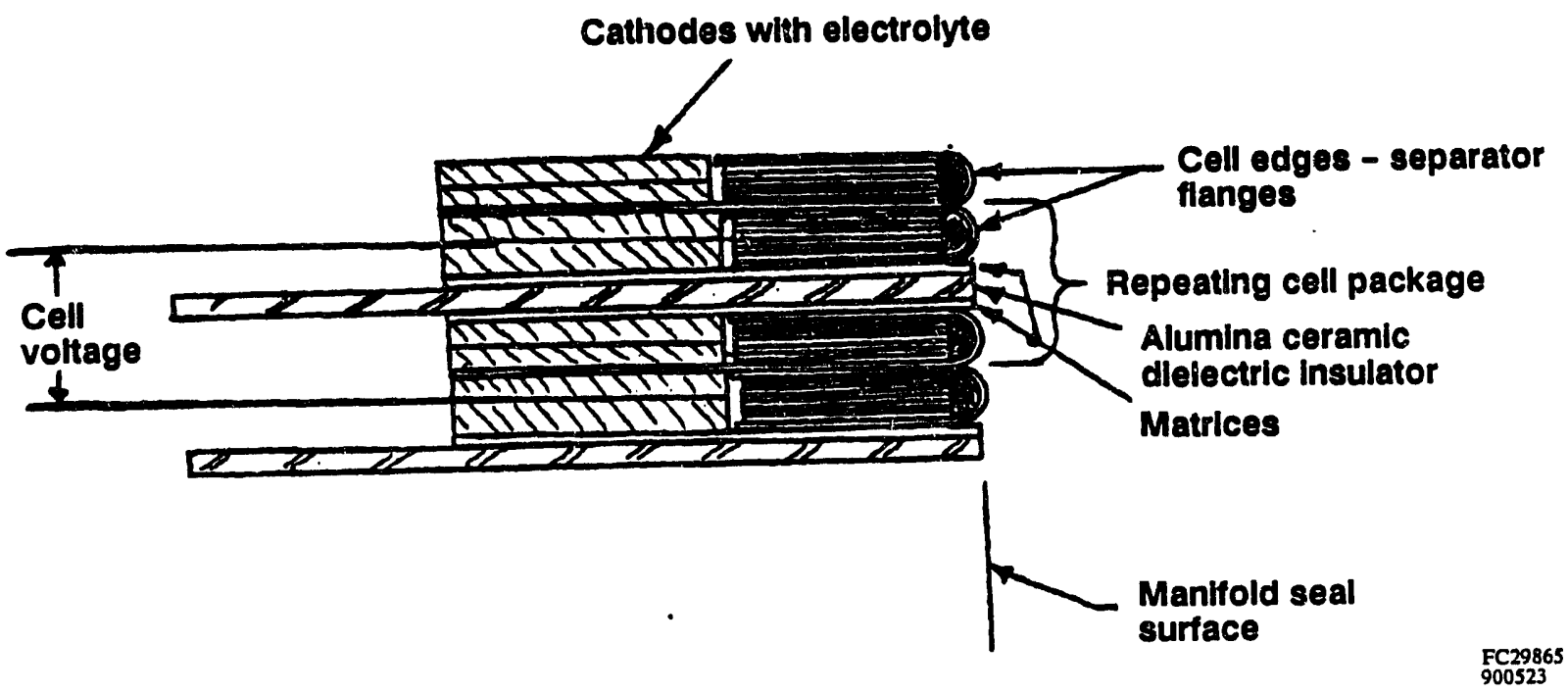

Figure 3.1-2. Cell Cross-Section For Shunt Current Test 


\section{Shunt Current Rig Testing}

The following summarizes the work on this task from the end of the previous program to the end of the present contract.

Twelve different configurations were tested in thirteen different tests. The final two test configurations were identical. The purpose in repeating the configuration was to confirm the results prior to committing the design for evaluation on an actual fuel cell stack test.

All configurations were directed toward preventing the electrolyte from migrating from the cell to the manifold seal. The selection of configurations for each test in this series was based on the results of the prior tests and the estimated cost for the configuration in a mature commercial seal application. The results consisted of the measured current across each cell as a function of time, confirmed by post test cell-by-cell electrolyte inventory analysis.

The final three tests in the series were similar in that cell three contained the design concept selected for further stack testing. These three tests were designated SHUNT20, SHUNT21 AND SHUNT 22. The only difference between SHUNT20 and SHUNT21 and 22 was in the estimated cost. SHUNT20 was judged to require significantly more assembly labor then the other two. The detailed results of these tests are described below.

\section{SHUNT20}

This stack was run for 400 hours at $1200^{\circ} \mathrm{F}$. Figure $3.1-3$ shows the cumulative leakage current for Cell 10 and the reservoir at the top of the stack just prior to shut-down. (This leakage current is also the sum of the leakage currents of the other 9 cells in the stack.) This leakage current is also the sum of the leakage currents of the other 9 cells in the stack. The data show that the total amount of electrolyte leaving the cells in the stack is quite small. Figure 3.1-4 shows the distribution of the leakage currents as a function of cell position. These data again indicate that the leakage currents are small. The largest currents in this stack were in the lower portion of the stack, and the currents for the first four cells each reached a maximum at a different time similar to a "wave" moving up the stack. Figure 3.1-5 illustrates this effect.

The average current per cell is so low that it corresponds to $1-2$ grams/40,000 hours/cell for a stack with the usual eight vertical manifold seals. A single reservoir is needed at the end of the stack to hold the 128 grams $/ 100$ cells $/ 40,000$ hr calculated from the SHUNT20 data. 


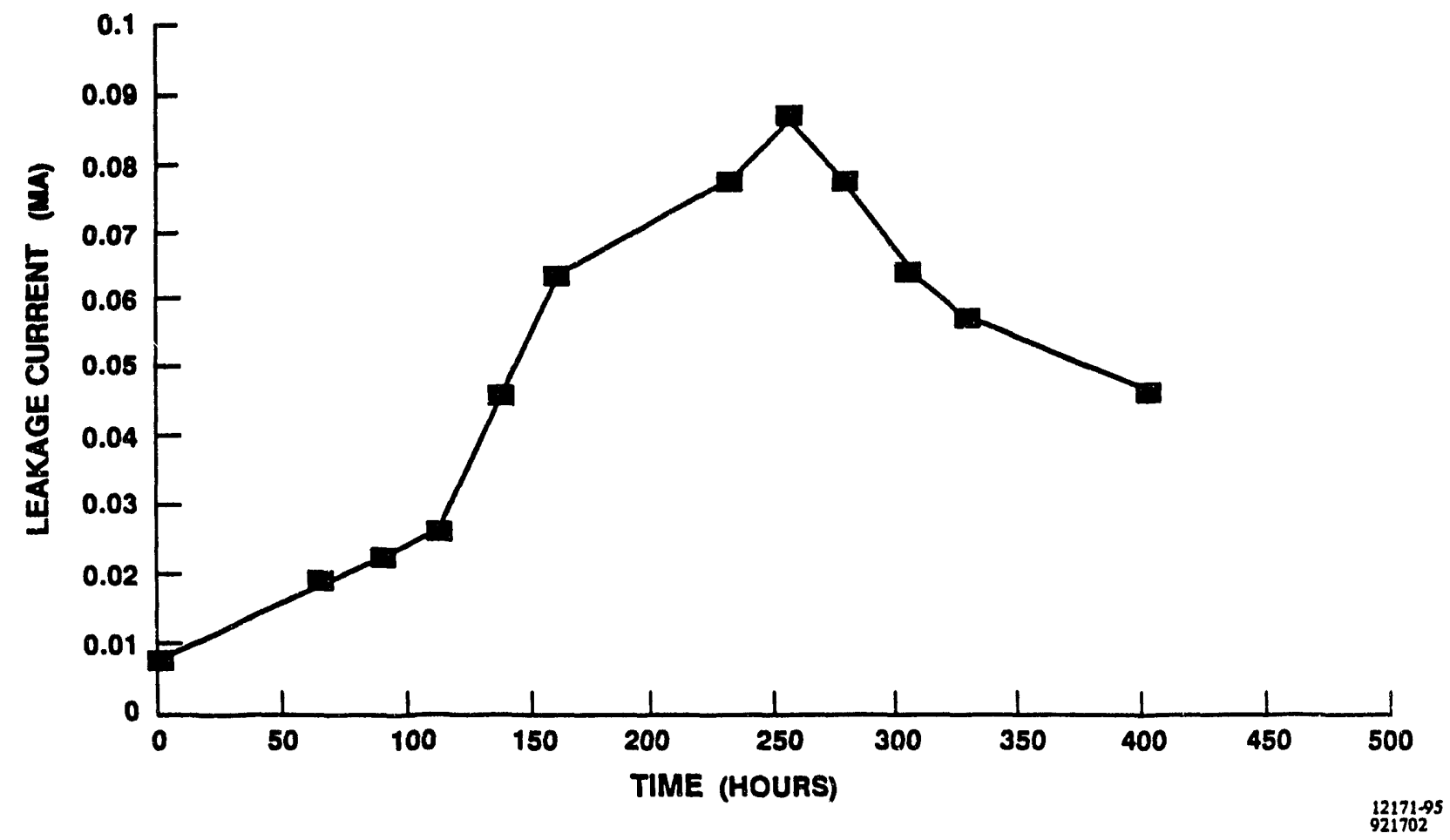

Figure 3.1-3. Cumulative Leakage Current for Cell 10 Plus Reservoir in SHUNT20

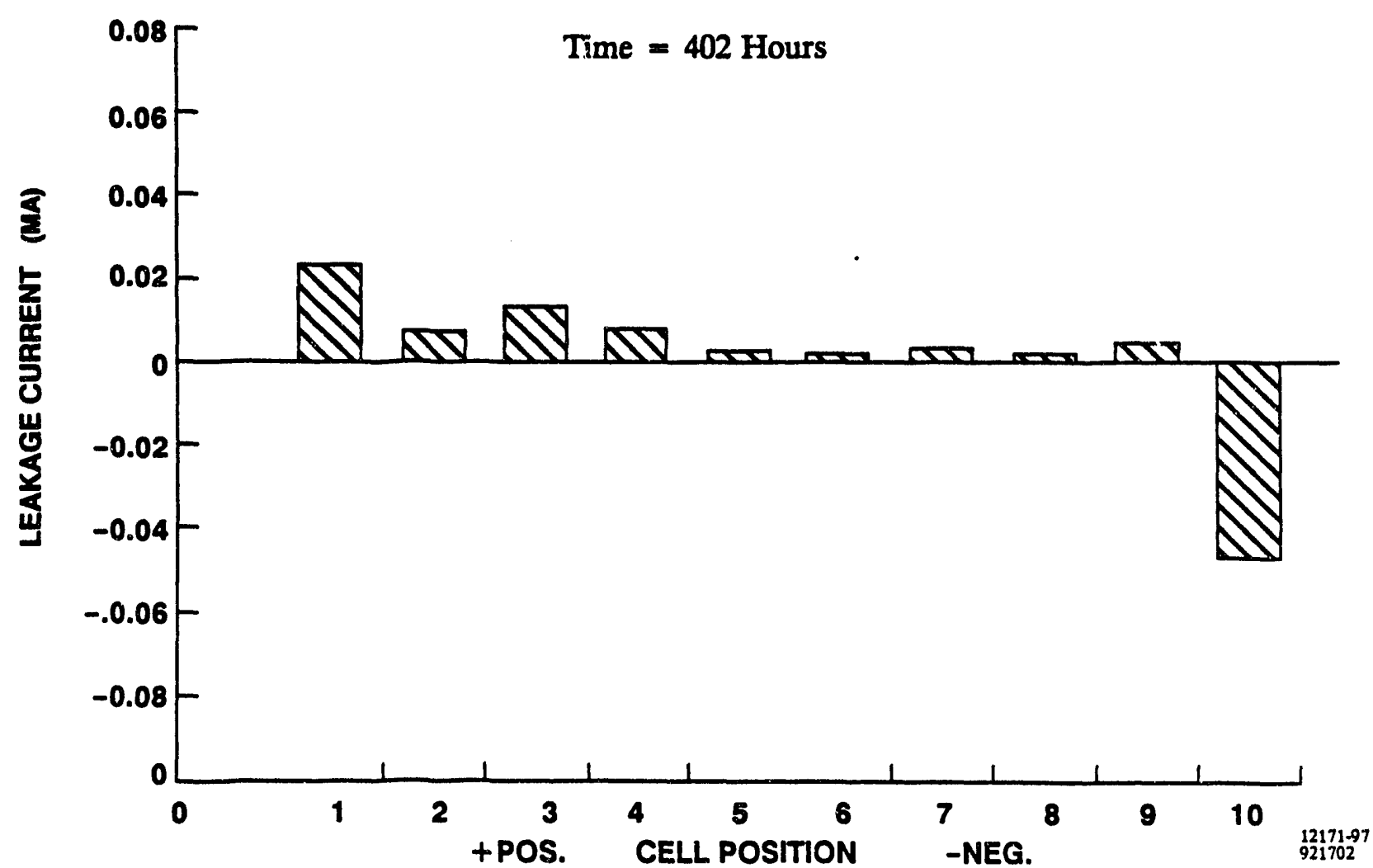

Figure 3.1-4. Leakage Current Distribution in SHUNT20 


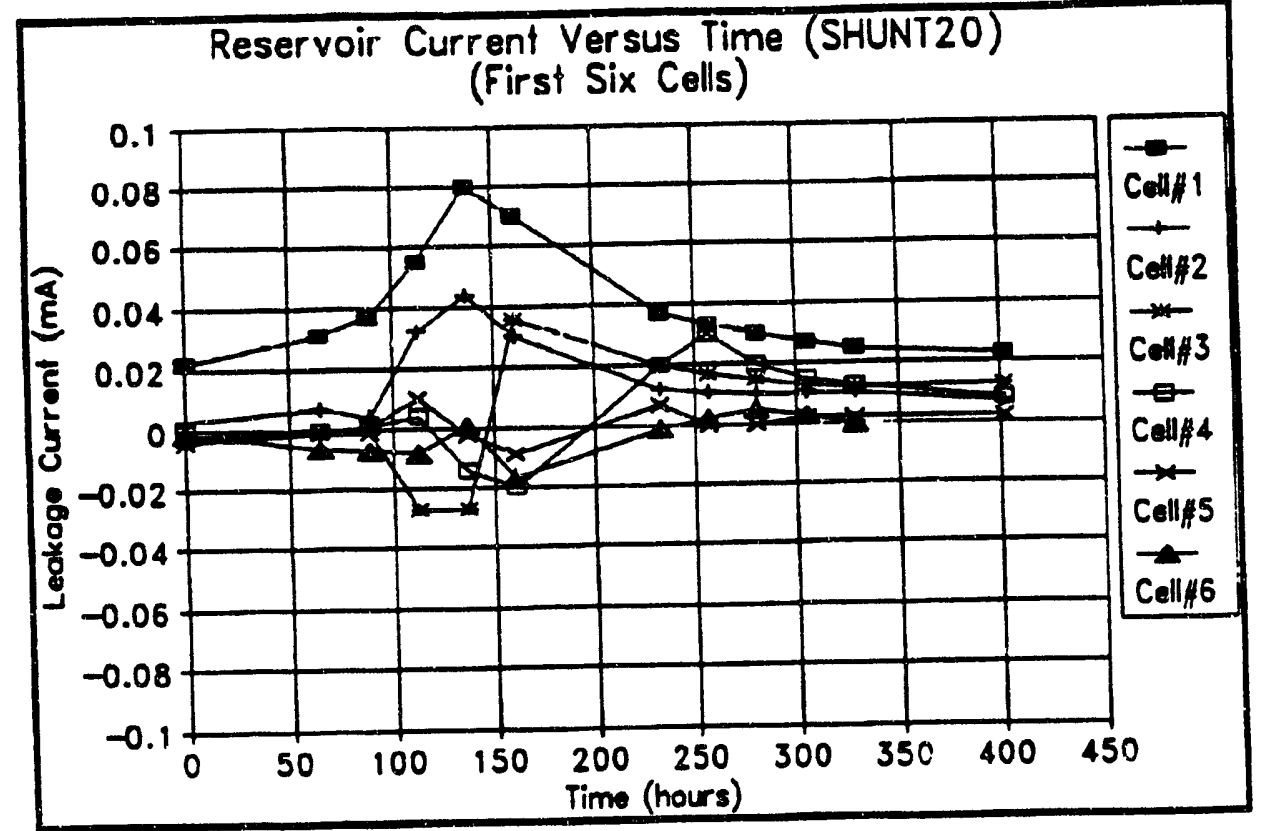

Figure 3.1-5. Leakage Current "Wave" in SHUNT20

\section{SHUNDT21}

Figure 3.1-6 shows the measured leakage currents just prior to shutting the stack down at 1103.5 hours of operation. The first six cells had leakage currents low enough to meet the required 40,000 -hour life goal for a stack with eight vertical manifold seals. However, the top four cells showed values too high to meet the goal, and they also showed a remarkable symmetry between Cell pair 7 and 9 and Cell pair 8 and 10. This symmetry between non-adjacent cells could not be explained during the operation of the stack.

Post-test observations of the stack showed that the electrical leads connected to cells 8 and 9 had been reversed at the point where they connect to the external electronics. A schematic of the electrical connections to SHUNT21 is shown in Figure 3.1-7 indicating the reversal. This reversal caused 1.6 volts to be impressed across the alumina separators between cells 9 and 10 and between cells 7 and 8 , which may have caused currents to flow between these cell pairs which did not represent actual electrolyte transfer between the cell pairs (e.g. gas evolution). The reversal in the wiring explains the large currents and symmetry observed between the non-adjacent cells described above and indicates the reason that these cells did not meet the 40,000 hour life goal. A post-test electrolyte analysis was performed on the stack to obtain more information about electrolyte transfer in the stack.

The analysis for SHUNT21 indicated that all the electrolyte initially placed in the stack can be accounted for within the accuracy of the analytical technique. Figure 3.1-8 shows the pre-and post-test quantities of electrolyte in the stack. The data indicated that the post-test values were too high by some slight amount. The analytical techniques used for the electrolyte analysis may have removed nickel oxide fines, which would make the measured post-test electrolyte contents too high. This was assumed to be the case, and an adjustment to the data was made by lowering all the post-test values in cells 3,4 , 5 , and 6 . These cells were chosen because they never showed any appreciable electrolyte transfer for the 1100 hours of operation and should have had the same electrolyte content at the end of the test as 
they had at the beginning. Figure 3.1-9 shows the adjusted post-test data compared to the pre-test values.

The data in Figure 3.1-9 indicate electrolyte transfer between Cell pairs 1 and 2,7 and 8, and 9 and 10 . These were the cells that showed the highest leakage currents during operation of the stack. The Cell pairs 7 and 8 , and 9 and 10 were the ones that had the high voltage (1.6 volts) imposed across the alumina separator plates between these cells. These cells would therefore be expected to have higher-thannormal leakage currents. However, the data for the Cell pair 1 and 2 should be valid. Figure 3.1-10 shows the time plot for Cells 1 and 2.

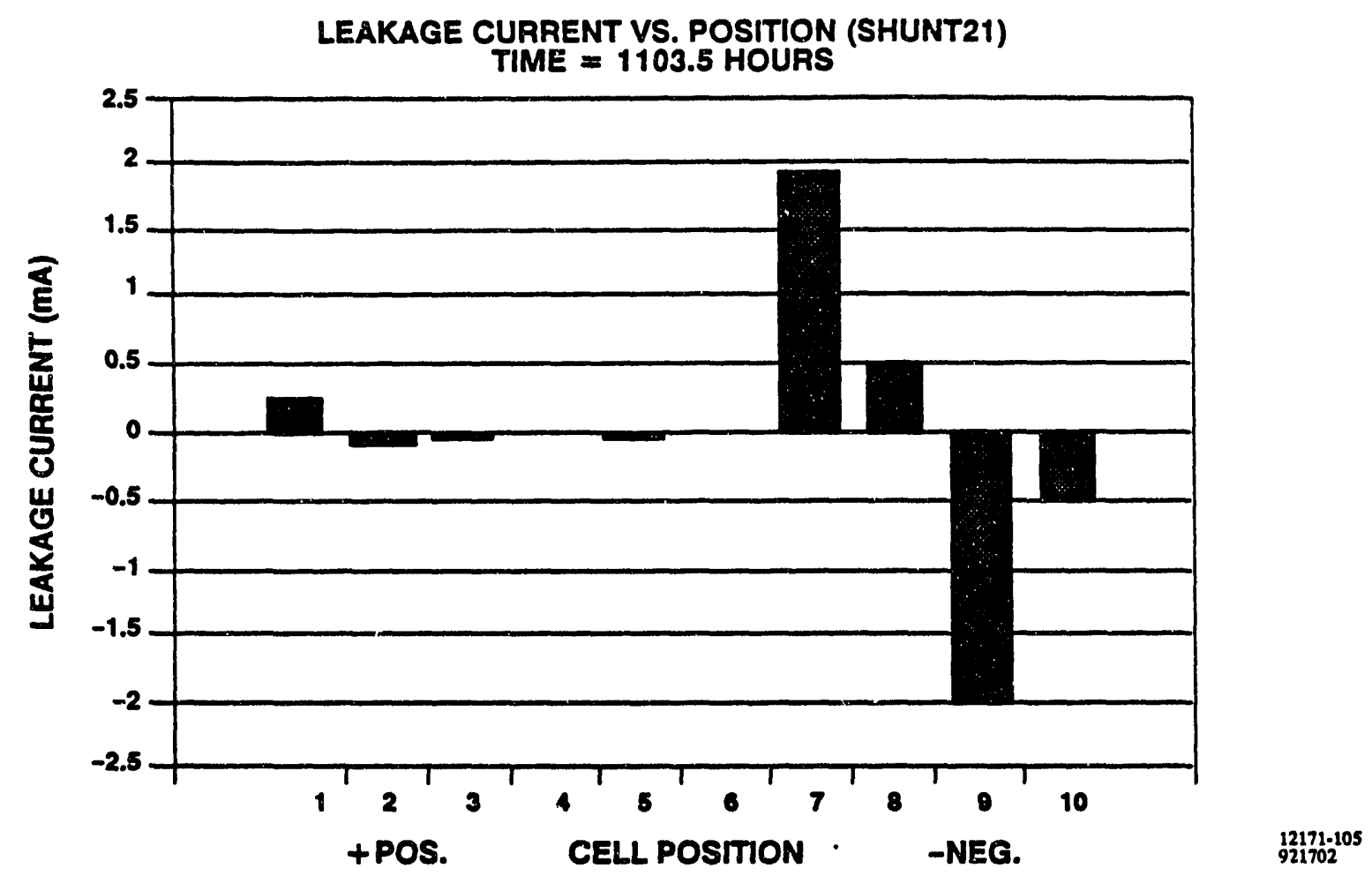

Figure 3.1-6. Measured Values for Leakage Current in SHUNT21 as a Function of Position 


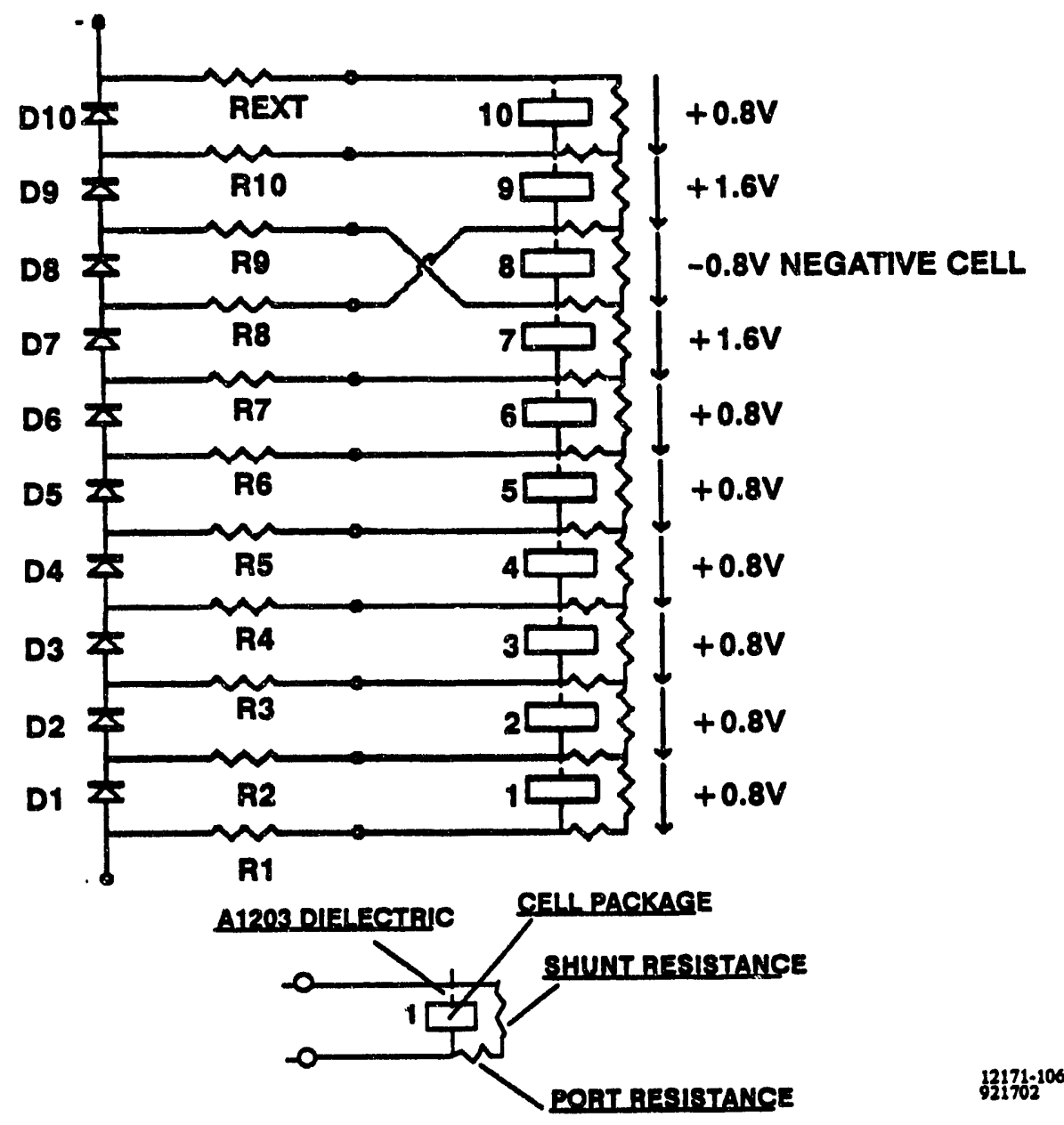

Figure 3.1-7. Schematic of Stack Electrical Wiring in SHUNT21

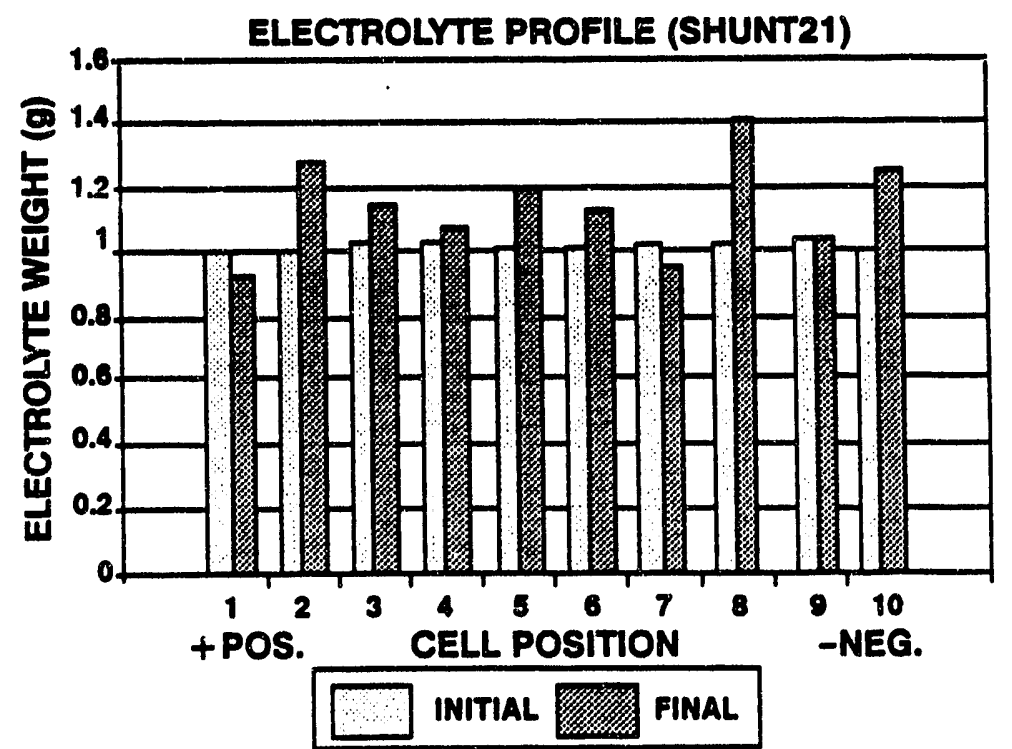

${ }_{921702}^{12171-107}$

Figure 3.1-8. Pre and Post-Test Electrolyte Profiles for SHUNT21 

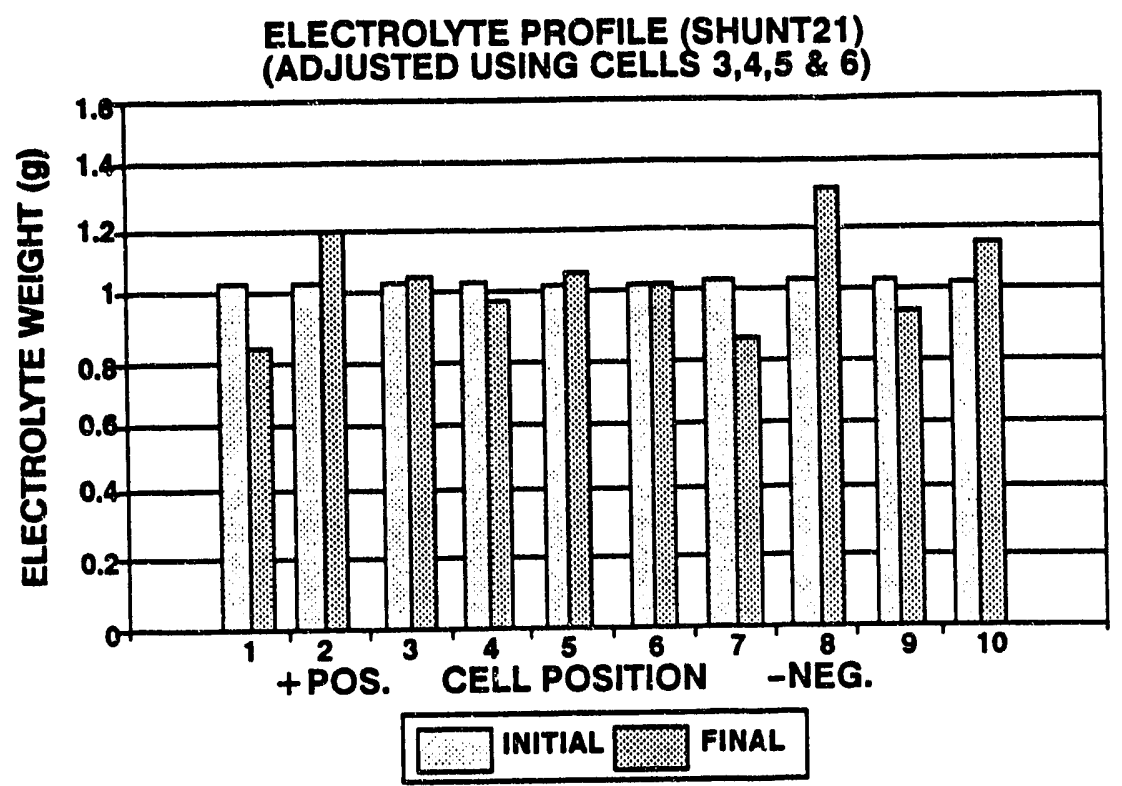

Figure 3.1-9. Electrolyte Profiles After Adjustments for SHUNT21

Using the data in Figure 3.1-10 and assuming that the transference number is 0.6 , the calculated value for electrolyte transfer between cells 1 and 2 is 0.14 grams. The measured difference from Figure 3.1-9 is about 0.17 grams. This is excellent agreement given the constraints of the data.

The amount of electrolyte transferred to the reservoir was found to be 0.33 gram. In 40,000 hours of operation at this rate, there would be approximately 96 grams of electrolyte transferred to the reservoir through the eight seals in a 10-cell stack, assuming that each seal has an equal electrolyte transfer rate. The amount of electrolyte transferred to the reservoir may have been affected by the lead reversal discussed above.

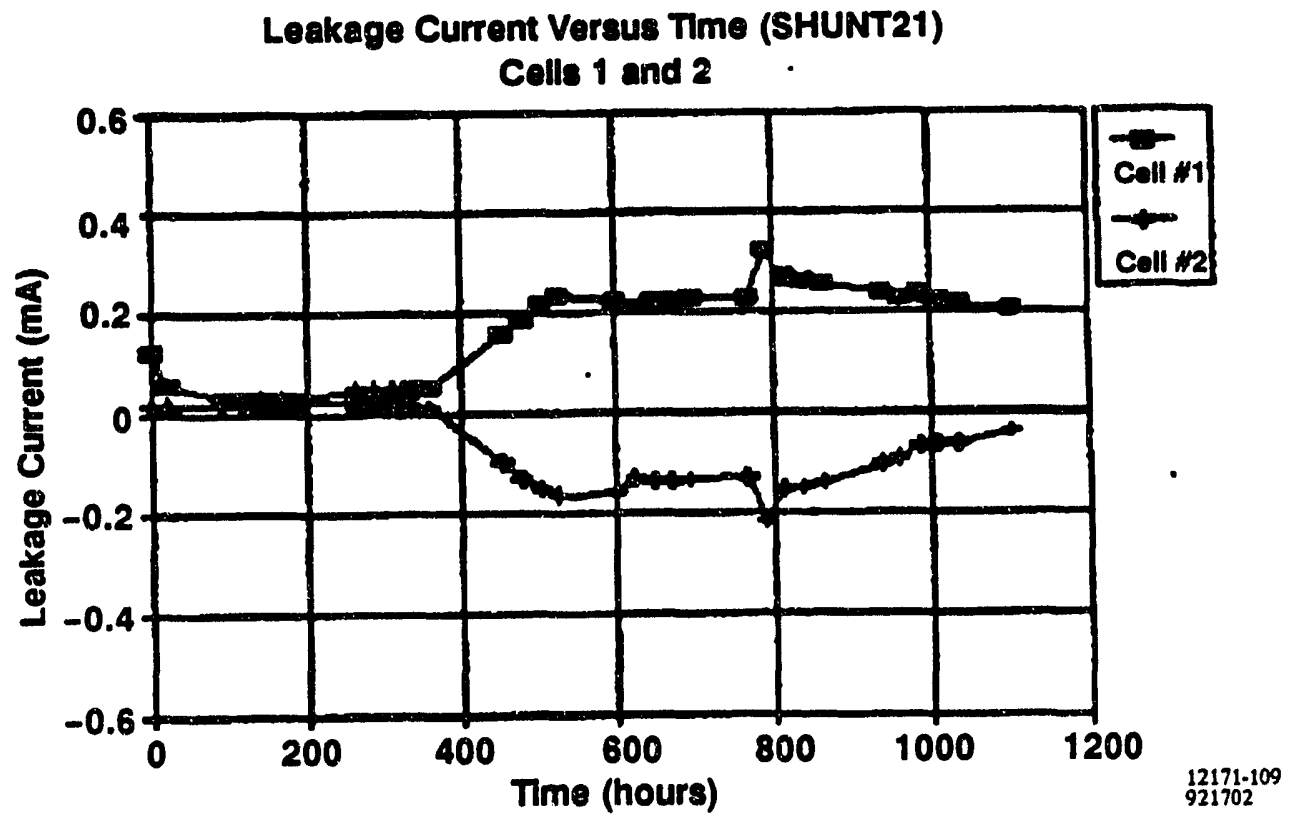

Figure 3.1-10. Leakage Current as a Function of Time for Cells 1 and 2 in SHUNT21 


\section{SHUNT22}

SHUNT22 was run to confirm the results obtained from SHUNT21. Figures 3.1-11 through 3.1-15 show leakage current profiles for the stack over the 1000-hour period of operation. Figure 3.1-16 shows the leakage currents for Cells 9 and 10 as a function of operating time. The value measured for Cell 10 is a combination of the leakage current in Cell 10 and the current into the reservoir since they are electrically connected.

The data in Figure 3.1-15 shows that the leakage currents for Cells 1 through 8 were well below the maximum allowable leakage current goal for 40,000 hours of operation. (The maximum allowable leakage current for 40,000 hours of operation in a stack with eight manifold rails is 0.25 to $0.35 \mathrm{~mA}$.) However, as shown in Figure 3.1-16, the leakage current in Cell 9 increased steadily with time and eventually passed the point where it could last for 40,000 hours.

The stack was shut down and disassembled after the 1000 hours of operation at $1200^{\circ} \mathrm{F}$. Observations made during disassembly indicated that there was a hard, black deposit on the seal edge of the alumina plate which separated Cells 9 and 10. The material had enough bulk to bridge the alumina plate and possibly cause an electrical short between Cells 9 and 10 . Measurements of the material using an ohmmeter indicated that it was slightly conductive at room temperature. A value of approximately 1200 ohms at $1200^{\circ} \mathrm{F}$ would be required to yield the observed current in Cell 9 . The deposit was found to be predominantly chrome by both KEVEX and microprobe analysis on this basis, it is assumed that the large leakage current noted in Cell 9 was not due to electrolyte transport but to an electronic short across the separator plate between Cells 9 and 10.

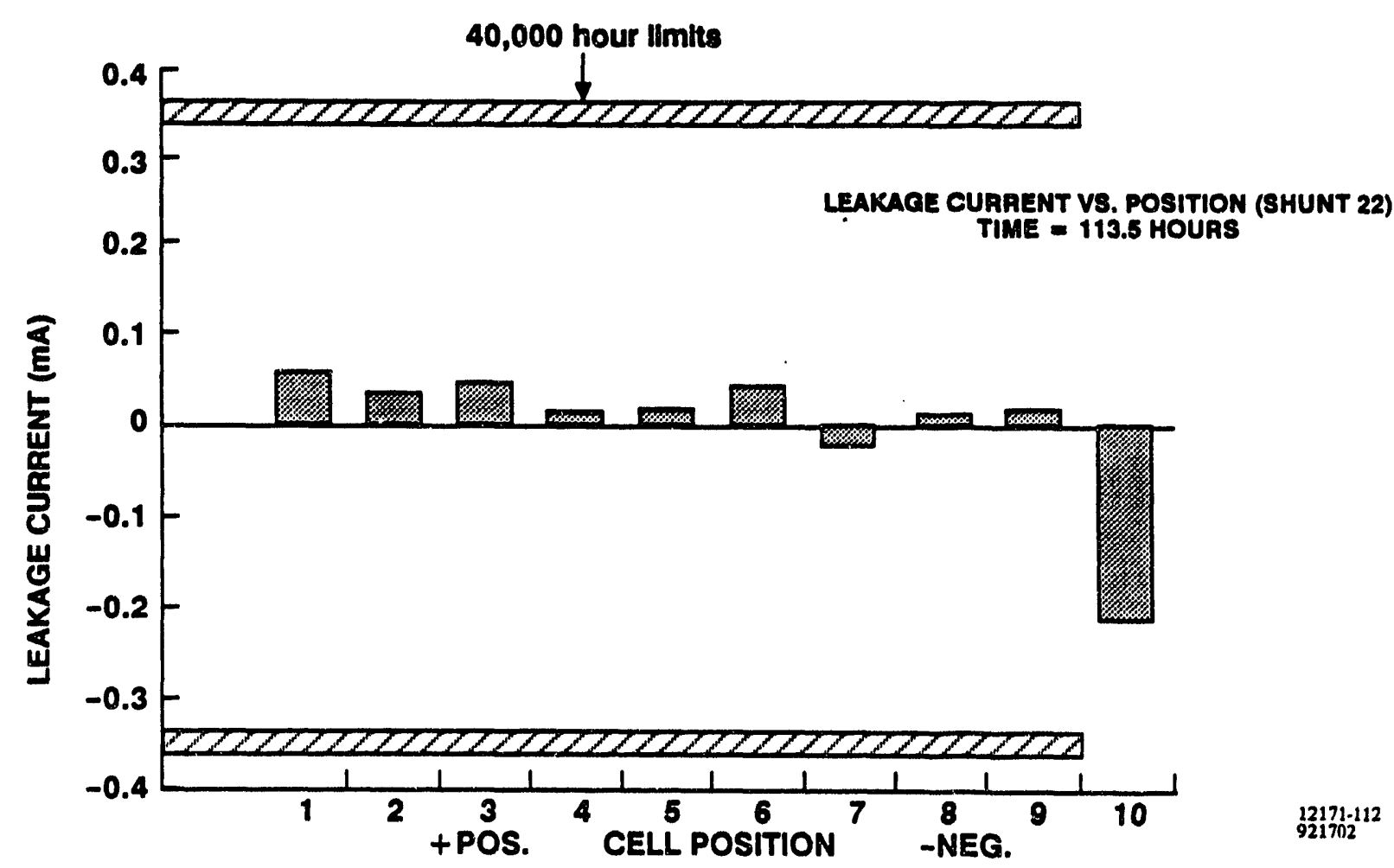

Figure 3.1-11. Leakage Current Profile for SHUNT22 at 113.5 Hours of Operation 


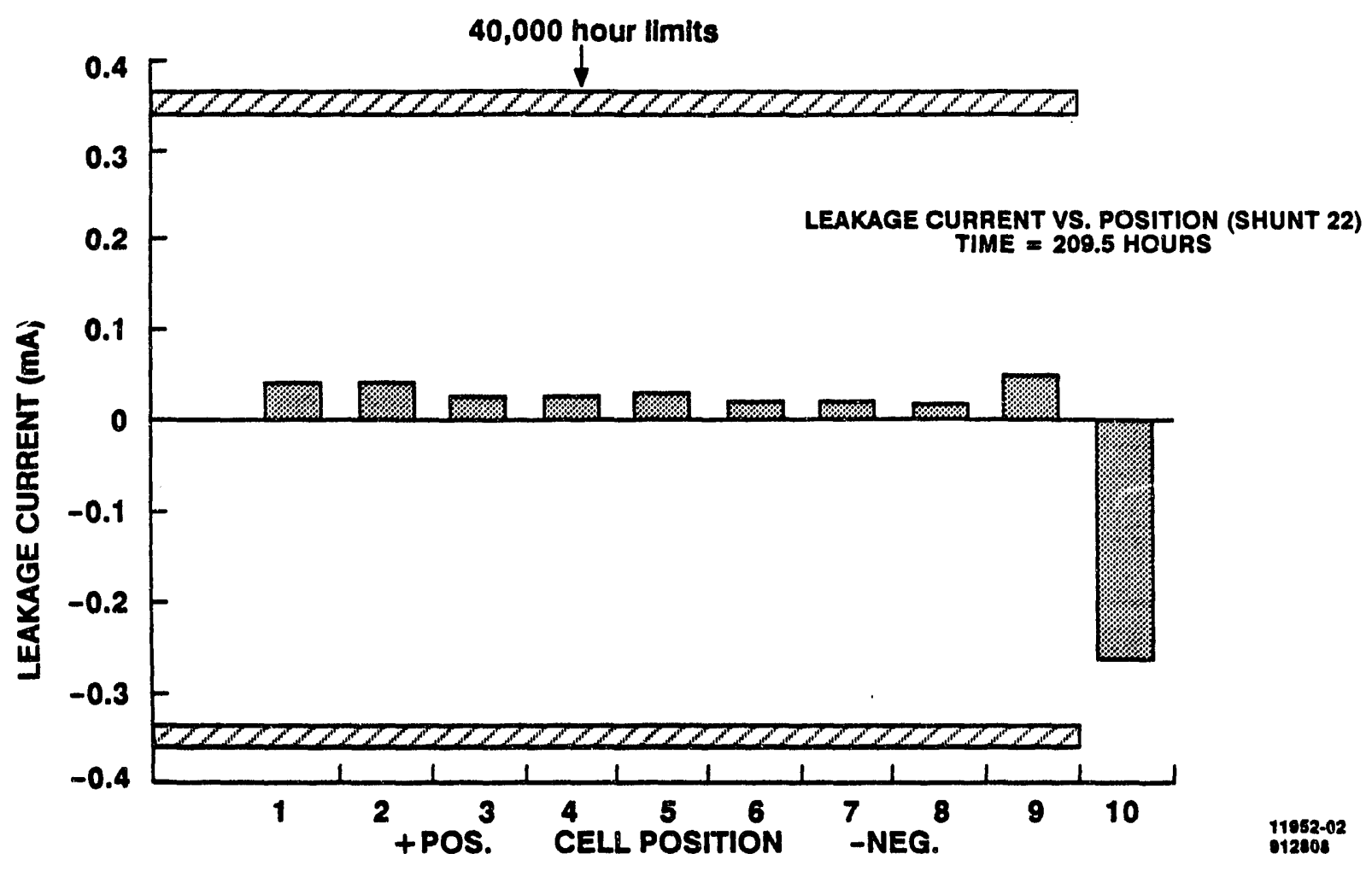

Figure 3.1-12. Leakage Current Profile for SHUNT22 at 209.5 Hours of Operation

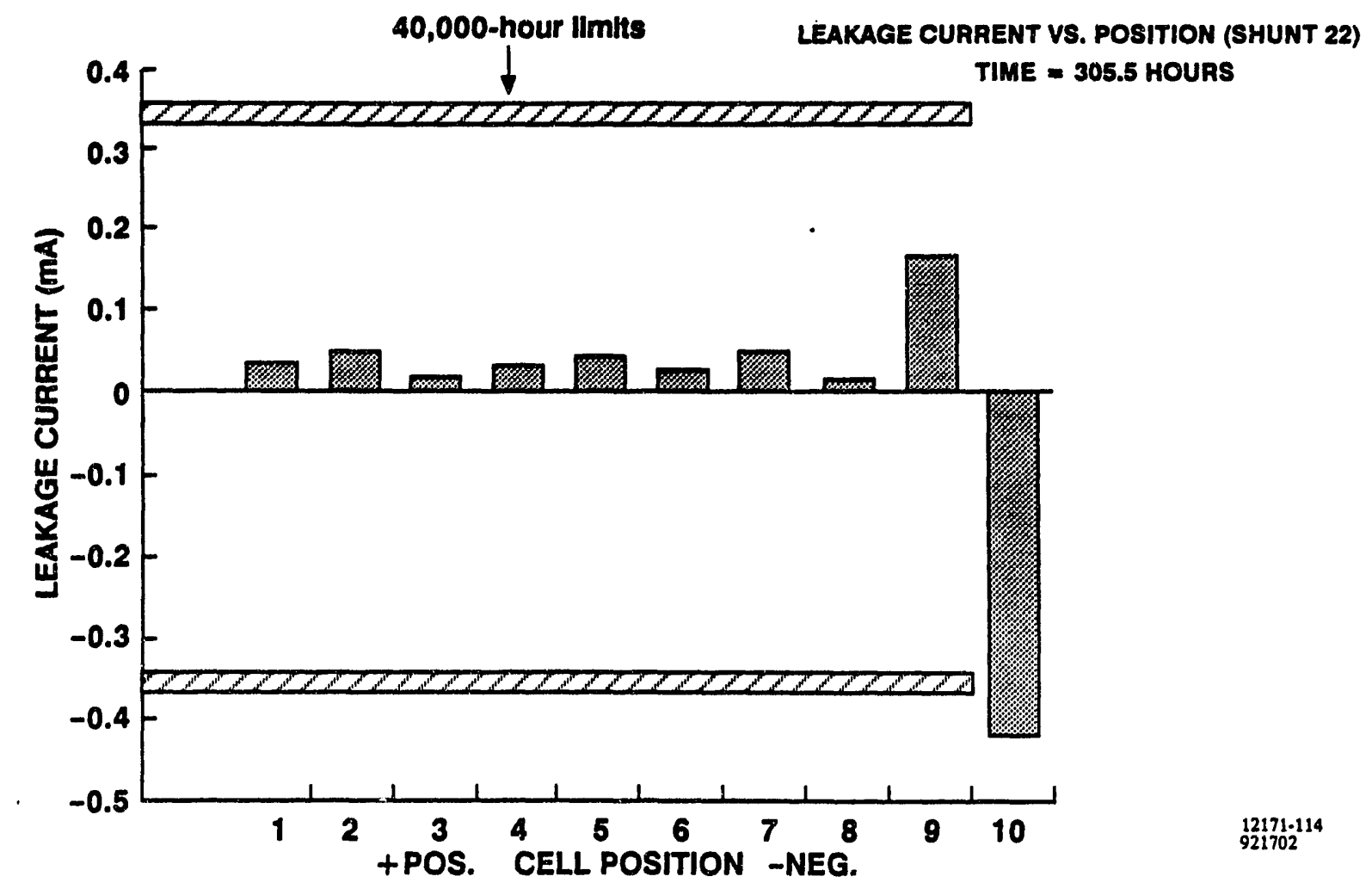

Figure 3.1-13. Leakage Current Profile for SHUNT22 at 305.5 Hours of Operation 


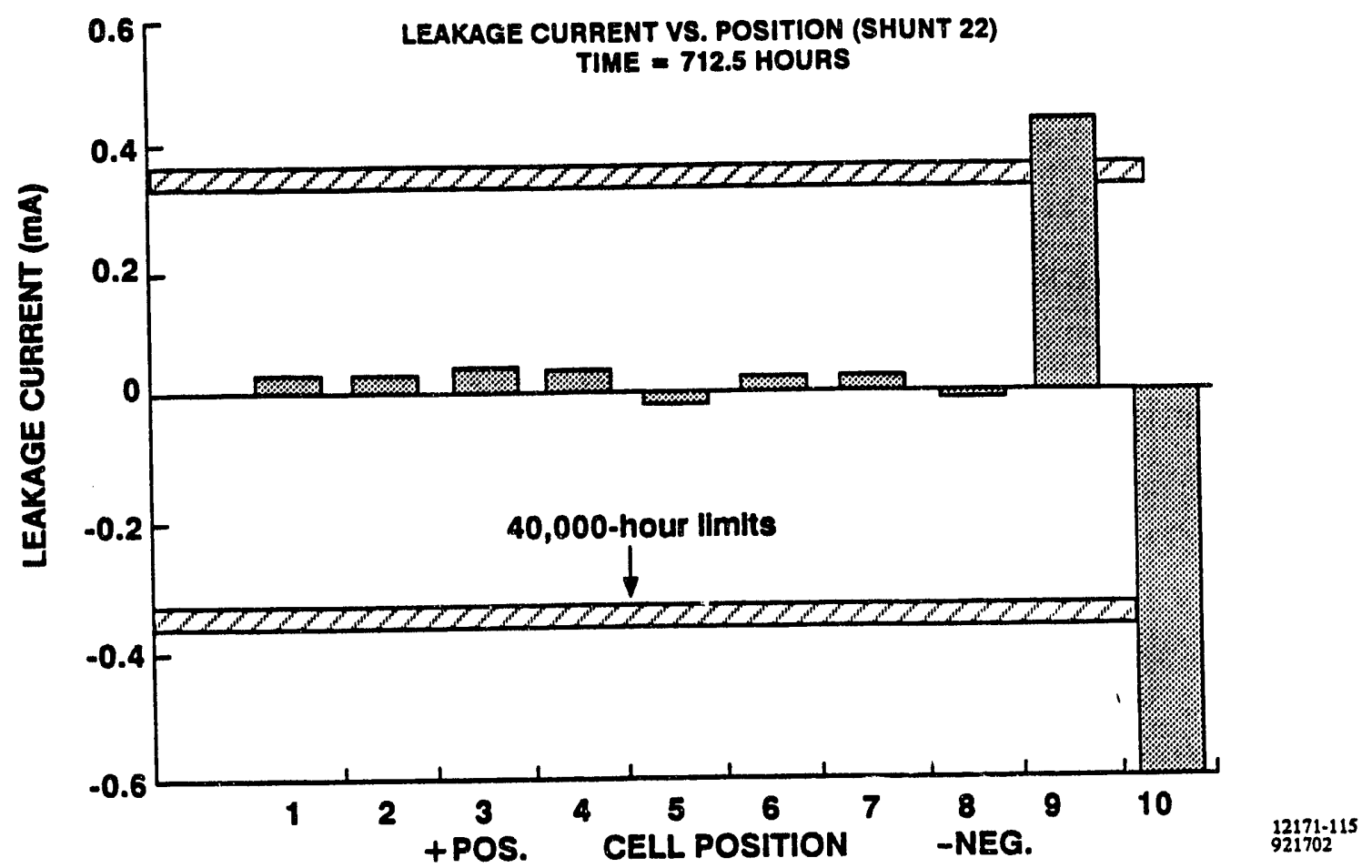

Figure 3.1-14. Leakage Current Profile for SHUNT22 at 712.5 Hours of Operation

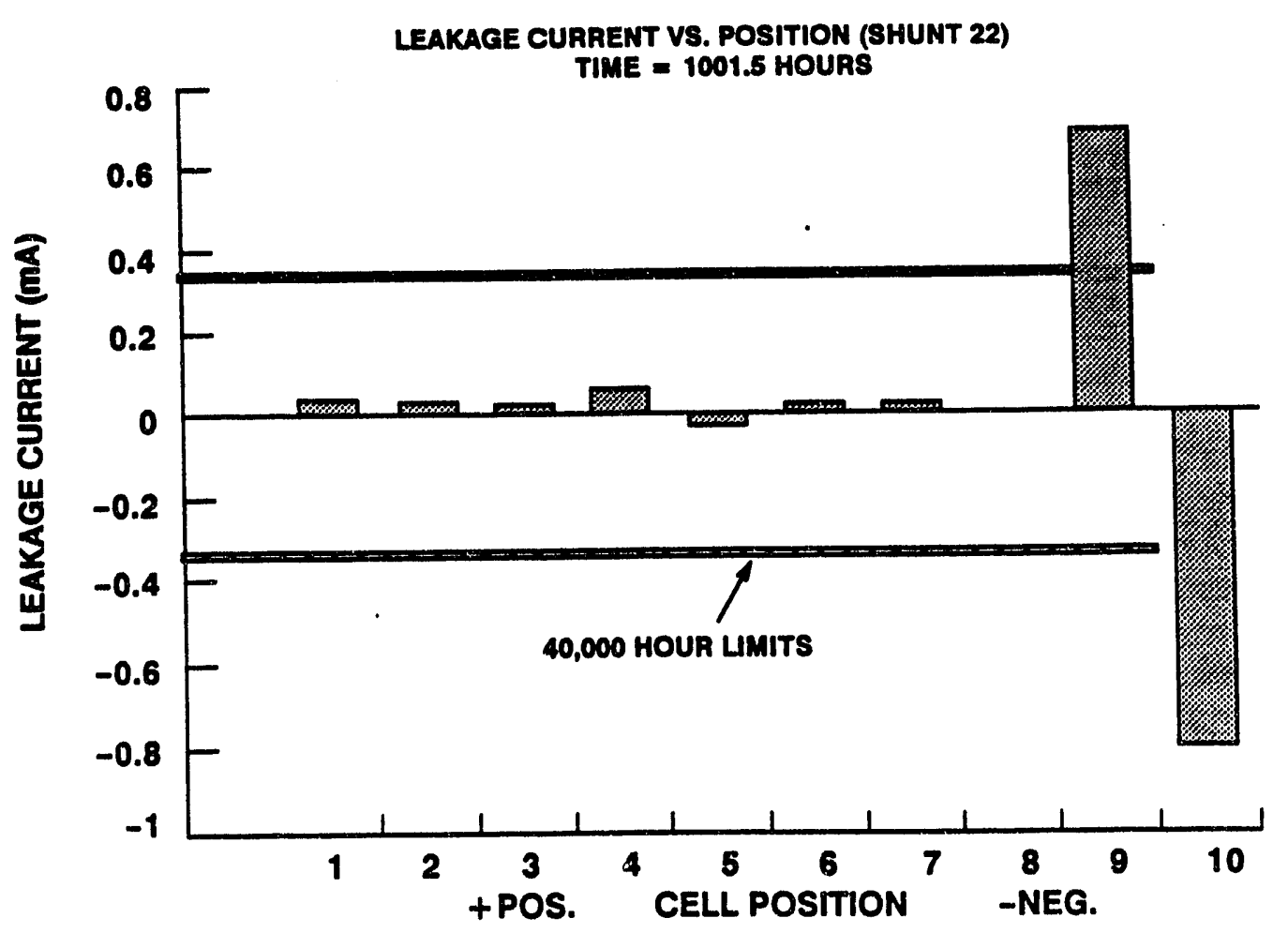

Figure 3.1-15. Leakage Current Profile for SHUNT22 at 1001.5 Hours of Operation 


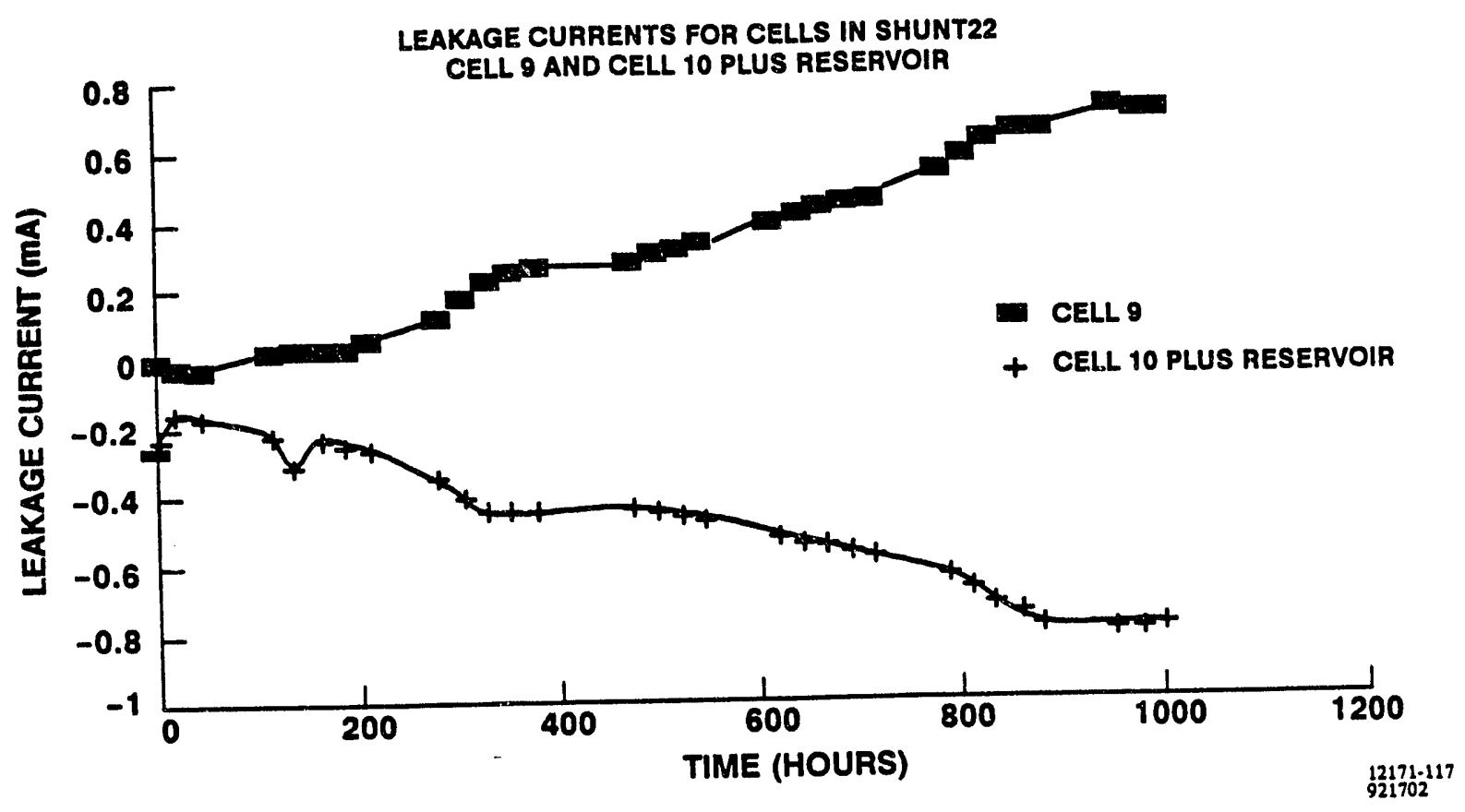

Figure 3.1-16. Leakage Current for Cell 9 and for the Combination of Cell 10 Plus the Reservoir in SHUNT22 as a Function of Time

A post-test electrolyte analysis was performed on the stack components from SHUNT22. Figure 3.1-17 shows the pre-test and post-test electrolyte values measured. Note that on the average there is more electrolyte in the post-test analysis then there was to start with. This occurs because the electrolyte analysis involves multiple washings in glacial acetic acid and in alcohol. Each washing increases the risk of dissolving some metal and of losing some fine particles while decanting the liquids.

ELECTROLYTE PROFILE (SHUNT 22)

TIME $=1001.5$ HOURS

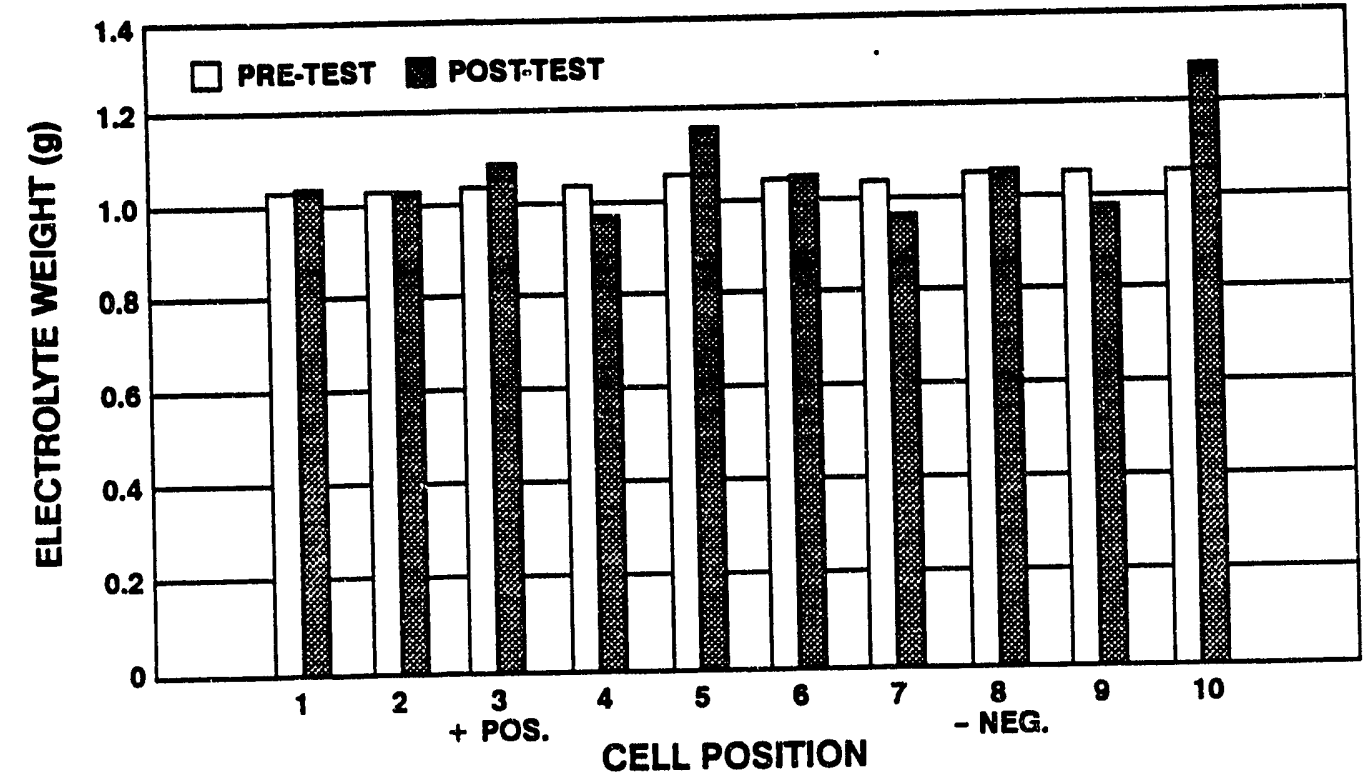

Figure 3.1-17. Pre-Test and Post-Test Electrolyte Profiles for SHUNT22 
Adjustments were made to the post-test electrolyte data in an attempt to account for these losses and for the amount of electrolyte found in the reservoir. Figure 3.1-18 shows the electrolyte profiles after adjustments were made to the raw data. With every adjustment some continuity of the data is lost, but the results in either case tell the same story: very little electrolyte was lost from the cell packages.

There was about 0.12 grams of electrolyte transferred out of Cell 9 . The average electrical current for Cell 9 was about $0.35 \mathrm{~mA}$ for 1000 hours implying that about 0.35 grams of electrolyte should have been transferred from Cell 9. These data show that the apparent current efficiency for transferring electrolyte out of Cell 9 was about 30 percent, indicating that the extra current was electronic and did not transfer electrolyte.

The amount of electrolyte increase in Cell 10 was about 0.171 grams, indicating that a small amount of electrolyte was transported from the lower cells into Cell 10 along with the electrolyte from Cell 9. The reservoir contained 0.32 grams of electrolyte which corresponds to about 0.032 grams of electrolyte from each cell if they gave up electrolyte uniformly. Using 1 gram of electrolyte per $m A$ per 1000 hours as a constant would imply that the leakage current from each cell should have been about $0.032 \mathrm{~mA}$ for the full 1000 hours. The measured leakage currents varied along the stack as a function of position and as a function of time, but they were in that ball park in magnitude.

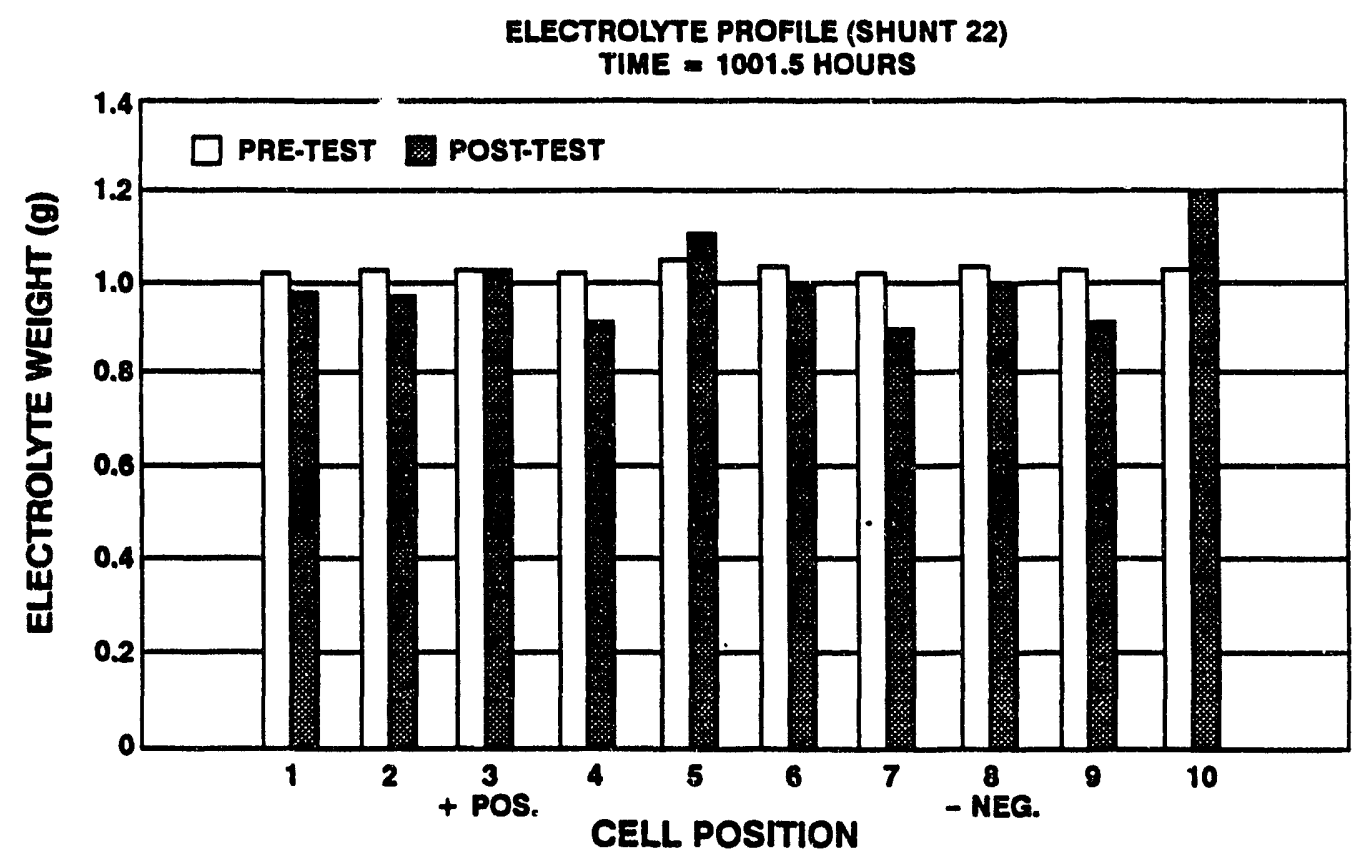

Figure 3.1-18. Pre-Test and Adjusted Post-Test Electrolyte Profiles for SHUNT22

\section{2) Seal Rig Tests}

A rig was constructed to test the gas leakage characteristics of the seal materials used for the manifoldto-rail seal and the stack-to-rail seal. A view of the rig is shown in Figure 3.1-58. The hardware consists of two stainless steel end plates with one of the plates containing a simulated stack face machined into the inside edge. The simulated edge consists of a repeating pattern of 40 height changes representing the variation in the face of a stack as a function of cell position up the stack. The other plate is flat and is a simulation of the smooth manifold. Both plates have gas inlet tubes and pressure taps which are used to flow gas into the seal rig and to measure the pressure drops developed across the seals. An 
alumina plate is used to simulate the alumina rail between the stack and the manifold. The plate is solid alumina and is also used as a gas barrier between the two sides of the rig.
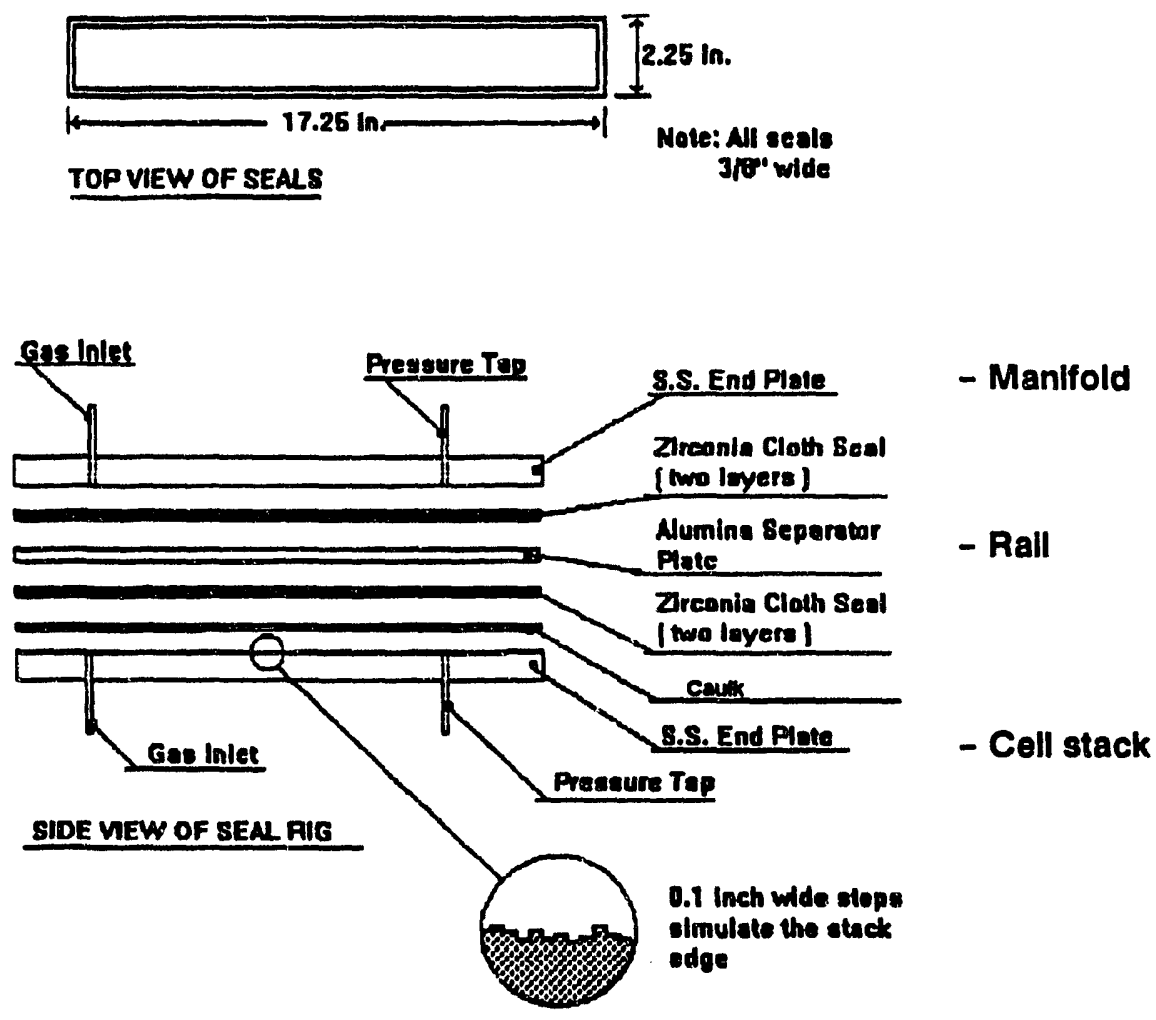

Figure 3.1-19. Manifold Seal Leak Test Rig

Three versions of this rig were tested. They are designated SEALRIG1, SEALRIG2, and SEALRIG3. SEALRIG1 was a static assembly. SEALRIG2 and SEALRIG3 had provisions for the simulated stack surface to be slid relative to the simulated manifold.

\section{SEALRIG1}

The manifold-to-rail seal was composed of two zirconia cloth layers. Each layer was cut into the shape of a "picture frame" which eliminates leaks at the corners of the seal. The stack-to-rail seal was composed of two similar layers of zirconia cloth against the alumina plate and a layer of particulate lithium aluminate/glass caulk spread into the roughness of the simulated stack face. A 60-mil layer of caulk tape was placed between the edge and the zirconia cloth. This was used as a conformable body to account for any variations in the stack face.

The rig was assembled and held together with a system of tie rods and Tinador leaf springs. A force of $100 \mathrm{psi}$ was applied to the seals by bending the leaf springs to a fixed deflection. Compression data was taken as a function of load for both the manifold-to-rail and stack-to-rail seals. These data are shown in Figure 3.1-20 and Figure 3.1-21.

The rig was mounted in an oven which allowed seal leakage data to be acquired as a function of temperature and time. 


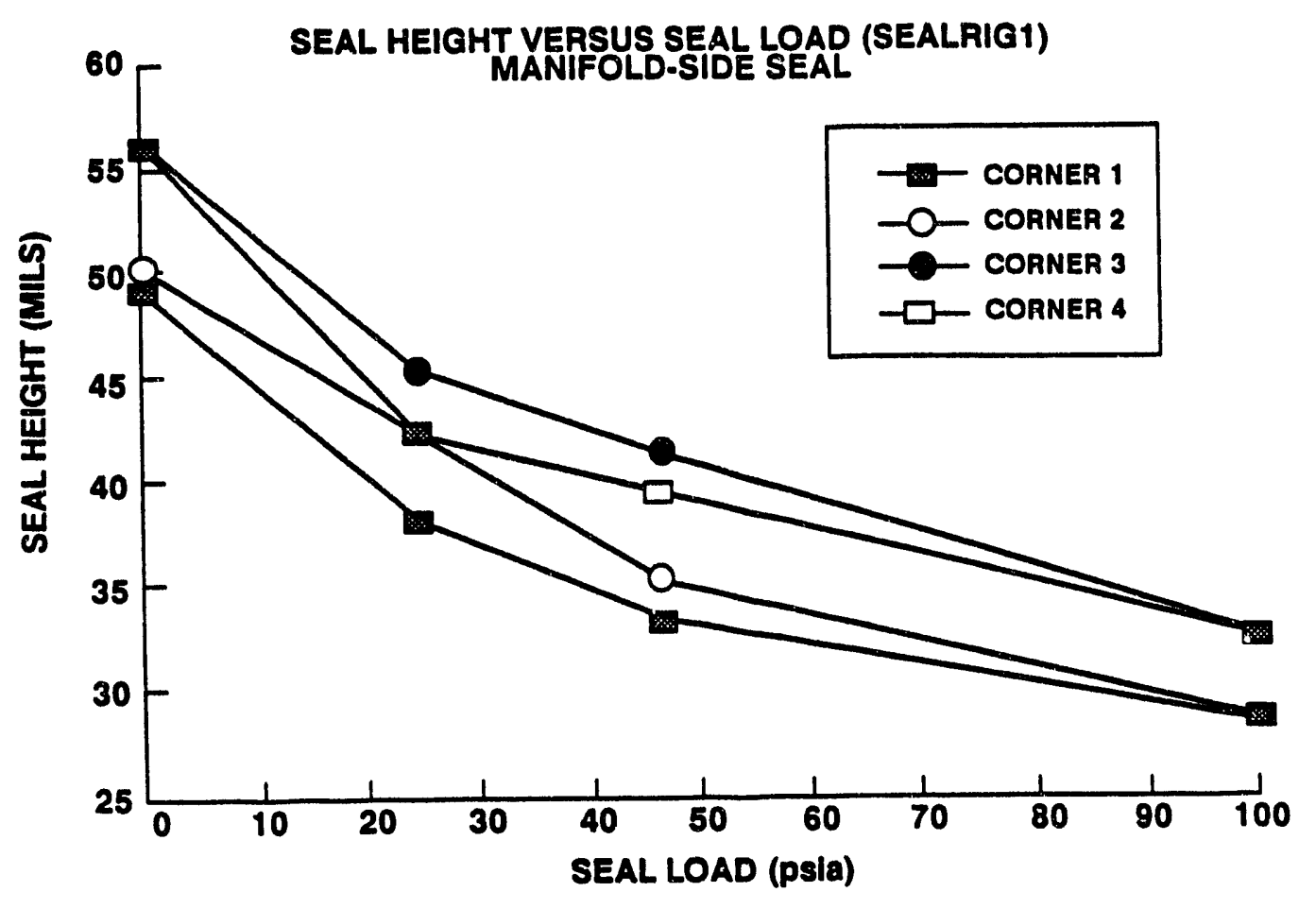

${ }_{921702}^{12171 \cdot 121}$

Figure 3.1-20. Manifold Side Seal Deflection Versus Seal Load

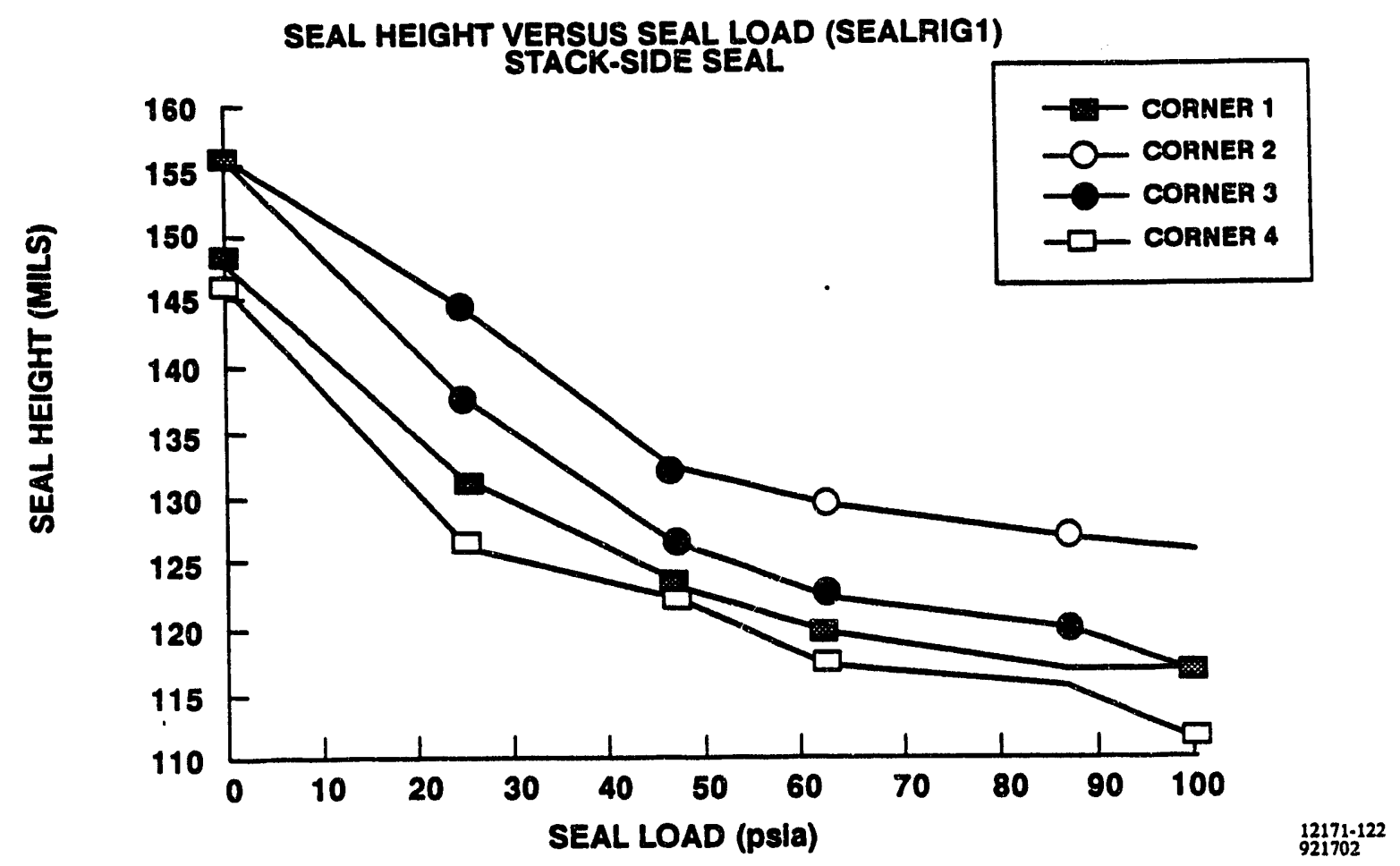

Figure 3.1-21. Stack Side Seal Compression Versus Seal Load 
The rig was then tested at $1200^{\circ} \mathrm{F}$ to determine the amount of gas leakage across the manifold-to-rail and stack-to-rail seals as a function of pressure developed across the seals. The rig was thermal cycled from room temperature to $1200^{\circ} \mathrm{F}$ three times at a controlled rate of approximately $70^{\circ}$ per hour. The first thermal cycle had the usual holds at $440^{\circ} \mathrm{F}$ and $800^{\circ} \mathrm{F}$ to simulate the burn-out cycle in a stack.

Figures 3.1-22 through 3.1-24 show the results for the three thermal cycles on the stack-side seal and Figures 3.1-25 through 3.1-27 show the data for the manifold-side seal. The flow-rate data in these figures are expressed in cc's per minute at room temperature. The data show that no significant changes occurred in the leakage rate of either the stack side or manifold side seals as a function of thermal cycling.

Measurements of the degree of bend in the Tinador leaf springs, which are used to apply pressure to the seals, indicated that the mechanical pressure on the seals dropped from 100 psi to about 50 psi during the three thermal cycles. These data indicate that the seals compressed and became more dense as a function of time and thermal cycling. Inspection of the seals in the rig after thermal cycling showed no visual degradation of the seals.

SEAL LEAKAGE VS. SEAL PRESSURE (SEALRIG1) STACK-SIDE SEAL - $1200^{\circ} \mathrm{F}$

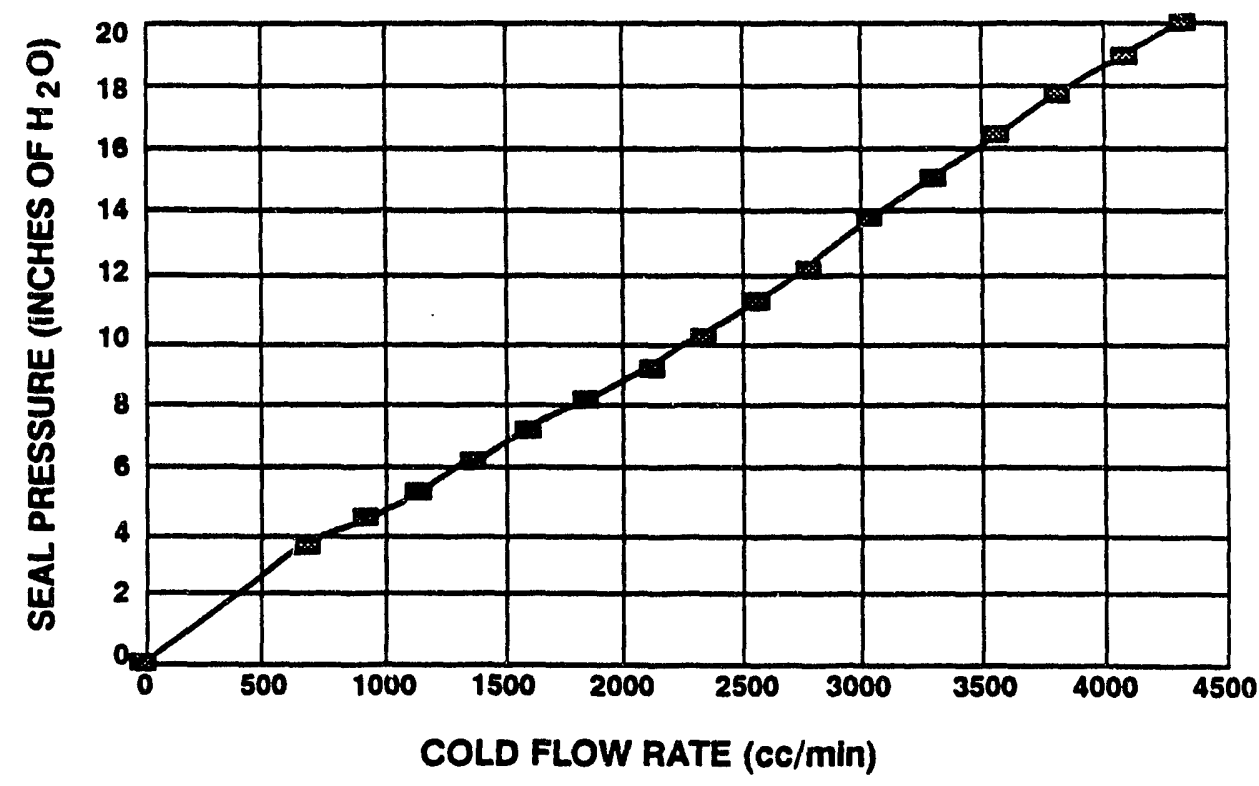

Figure 3.1-22. Seal Leakage of Stack-Side Seal During First $1200^{\circ} \mathrm{F}$ Hold 
SEAL LEAKAGE VS. SEAL PRESSURE (SEALRIG1) STACK-SIDE SEAL - $1200^{\circ} \mathrm{F}$

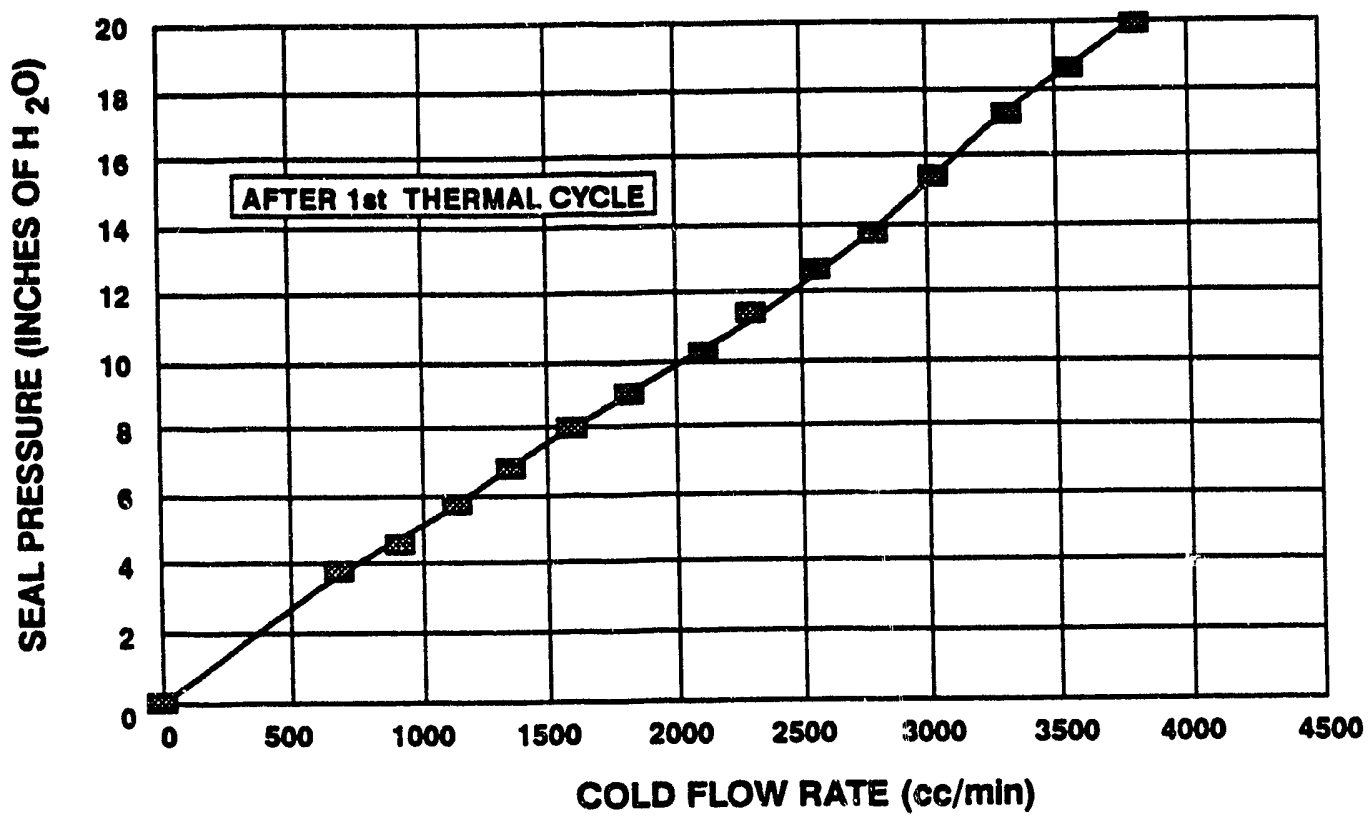

Figure 3.1-23. Seal Leakage of Stack Side Seal During Second $1200^{\circ}$ F Hold

SEAL LEAKAGE VS. SEAL PRESSURE (SEALRIG1) STACK-SIDE SEAL - $1200^{\circ}$

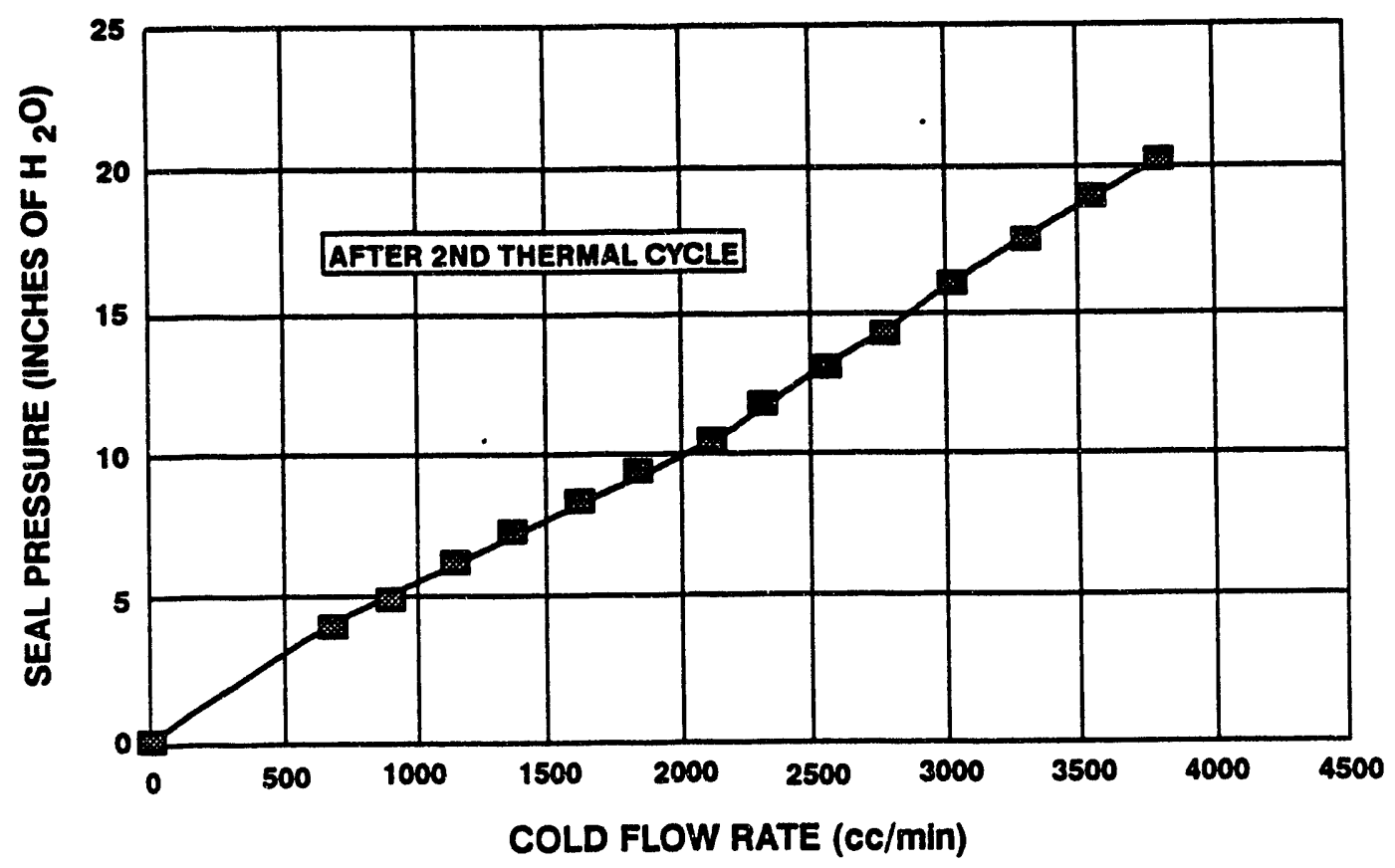

Figure 3.1-24. Seal Leakage of Stack Side Seal During Third $1200^{\circ}$ F Hold 
SEAL LEAKAGE VS. SEAL PRESSURE (SEALRIG1) MANIFOLD-SIDE SEAL (CLOTH - $1200^{\circ} \mathrm{F}$ )

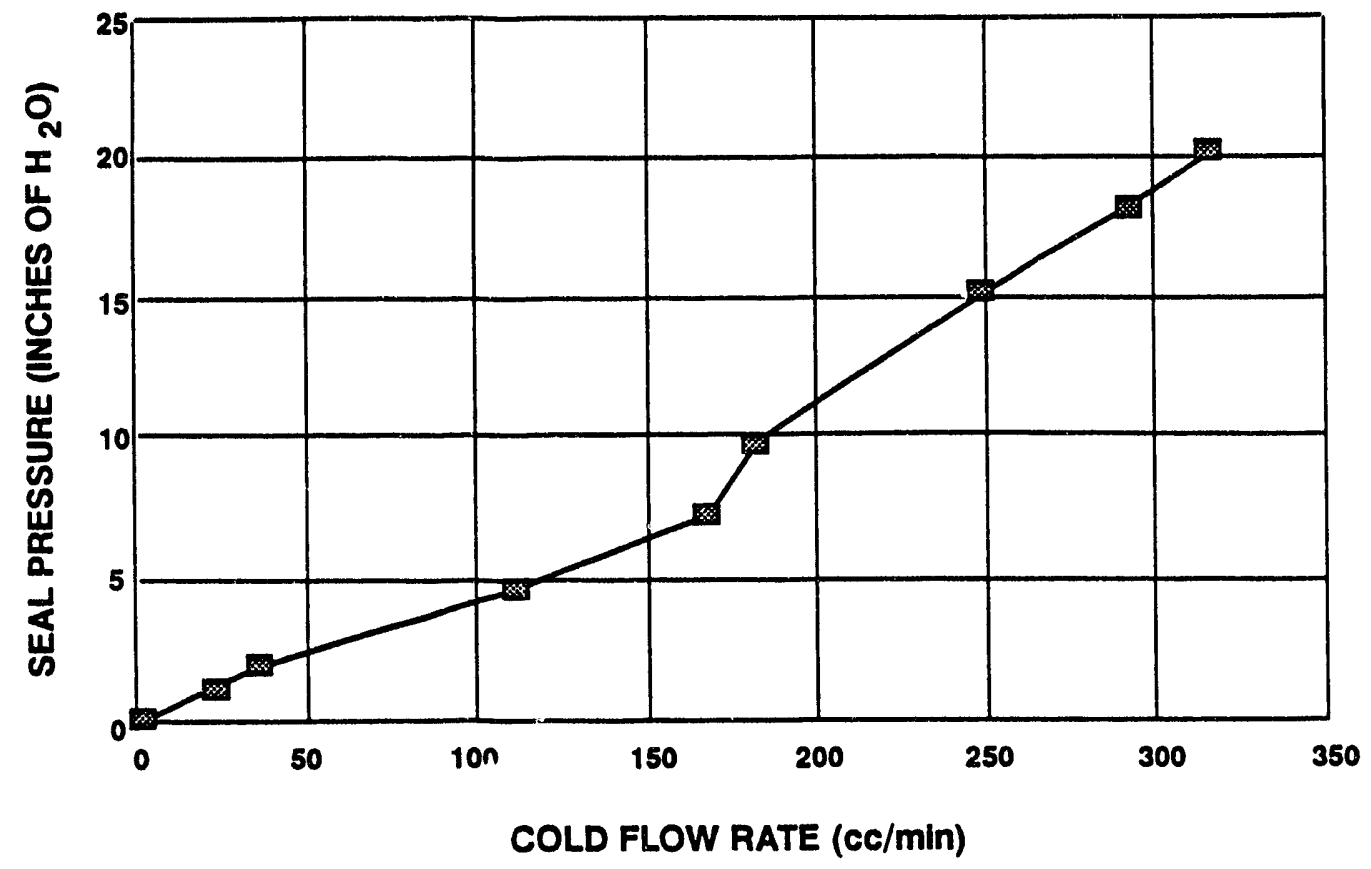

Figure 3.1-25. Seal Leakage of Manifold-Side Seal During First $1200^{\circ} \mathrm{F}$ Hold

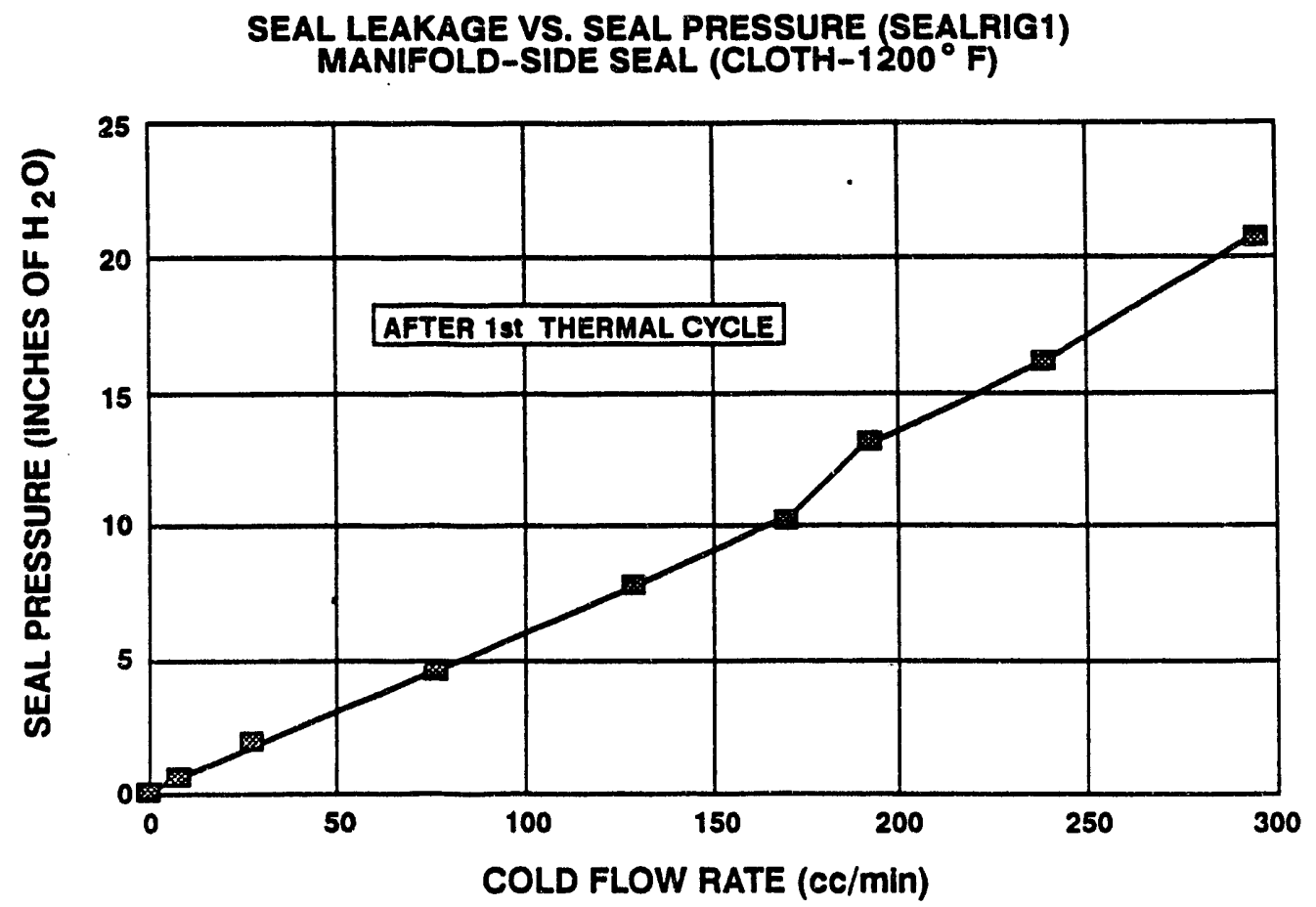

Figure 3.1-26. Seal Leakage of Manifold-Side Seal During Second $1200^{\circ} \mathrm{F}$ Hold 
SEAL LEAKAGE VS. SEAL PRESSURE (SEALRIG1) MANIFOLD-SIDE SEAL (CLOTH-1200' F)

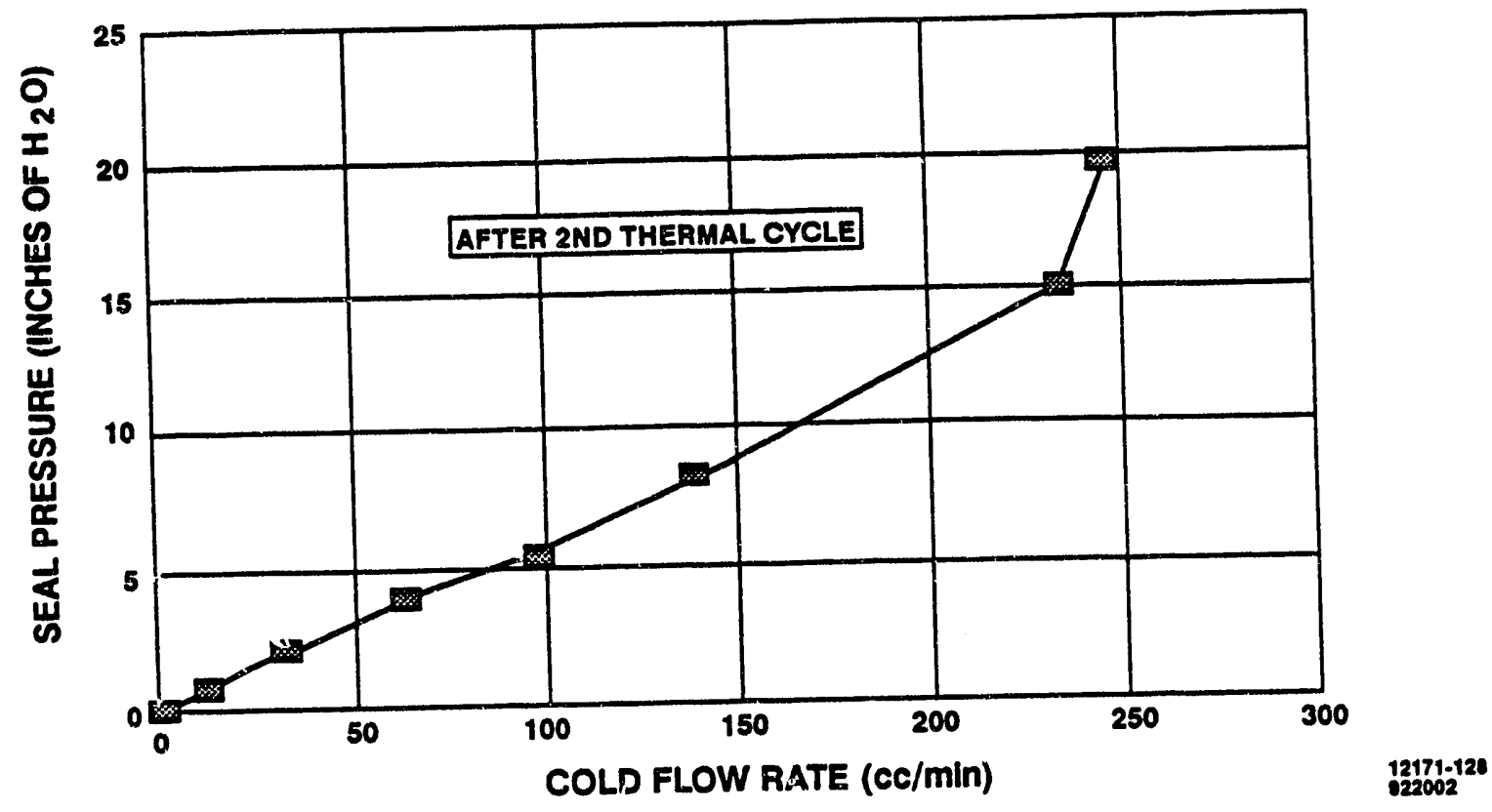

Figure 3.1-27. Seal Leakage of Manifold-Side Seal During Third $1200^{\circ}$ F Hold

The rig was disassembled and visual observations made to determine the mechanical quality of the seal. It was noted that the seal caulk that was spread over the simulated stack edge had penetrated all the small radius regions in the seal, producing an excellent-looking seal. The caulk had become strongly adhered to the simulated stack with no gaps noted anywhere along the seal.

In general, the seal materials looked good and there was no evident reason to change the materials in the seal region.

\section{SEALRIG2}

Th: seal rig was modified to allow relative motion between the simulated stack and the simulated manifold. Figure 3.1-28 shows a sketch of the rig. 


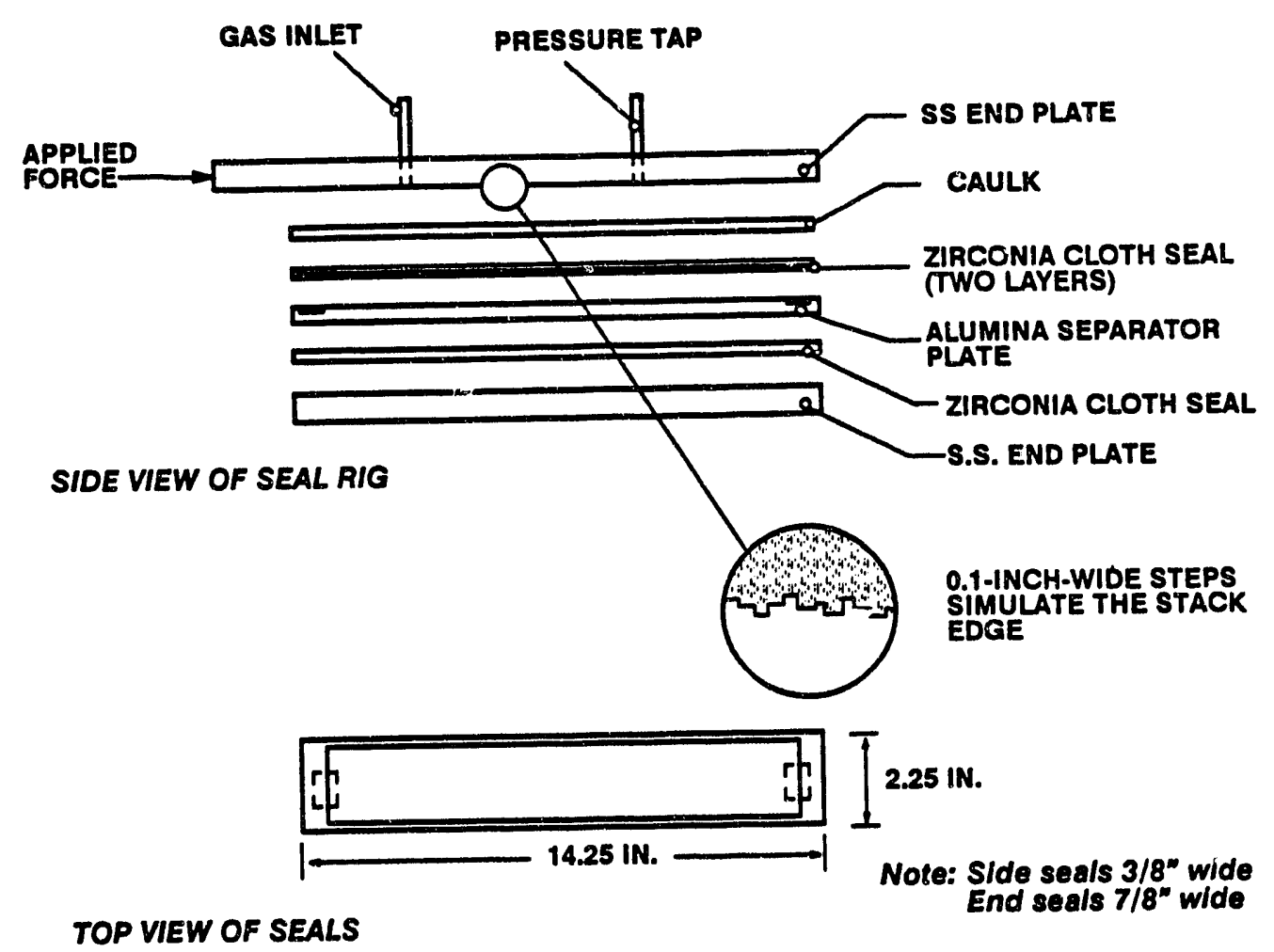

Figure 3.1-28. Sketch of SEALRIG2

The rig was assembled, and force was slowly applied to the load bars while making height change measurements at the corners of the seal. Figure 3.1-29 shows the corner measurements as a function of applied load. The 50-psi point for corner 3 is believed to be in error, and corner 3 really parallels the other corners. The amount of deflection noted is smaller than that recorded for SEALRIG1, implying that the seals in this rig are slightly more stiff than those in SEALRIG1.

The rig was mounted in the oven and seal leakage data was taken at room temperature. These data are shown in Figure 3.1-30. The quality of the seal looked good since the leakage rate at a given pressure was less than that found on SEALRIG1 even after adjusting the data for the different seal lengths in the two rigs. 

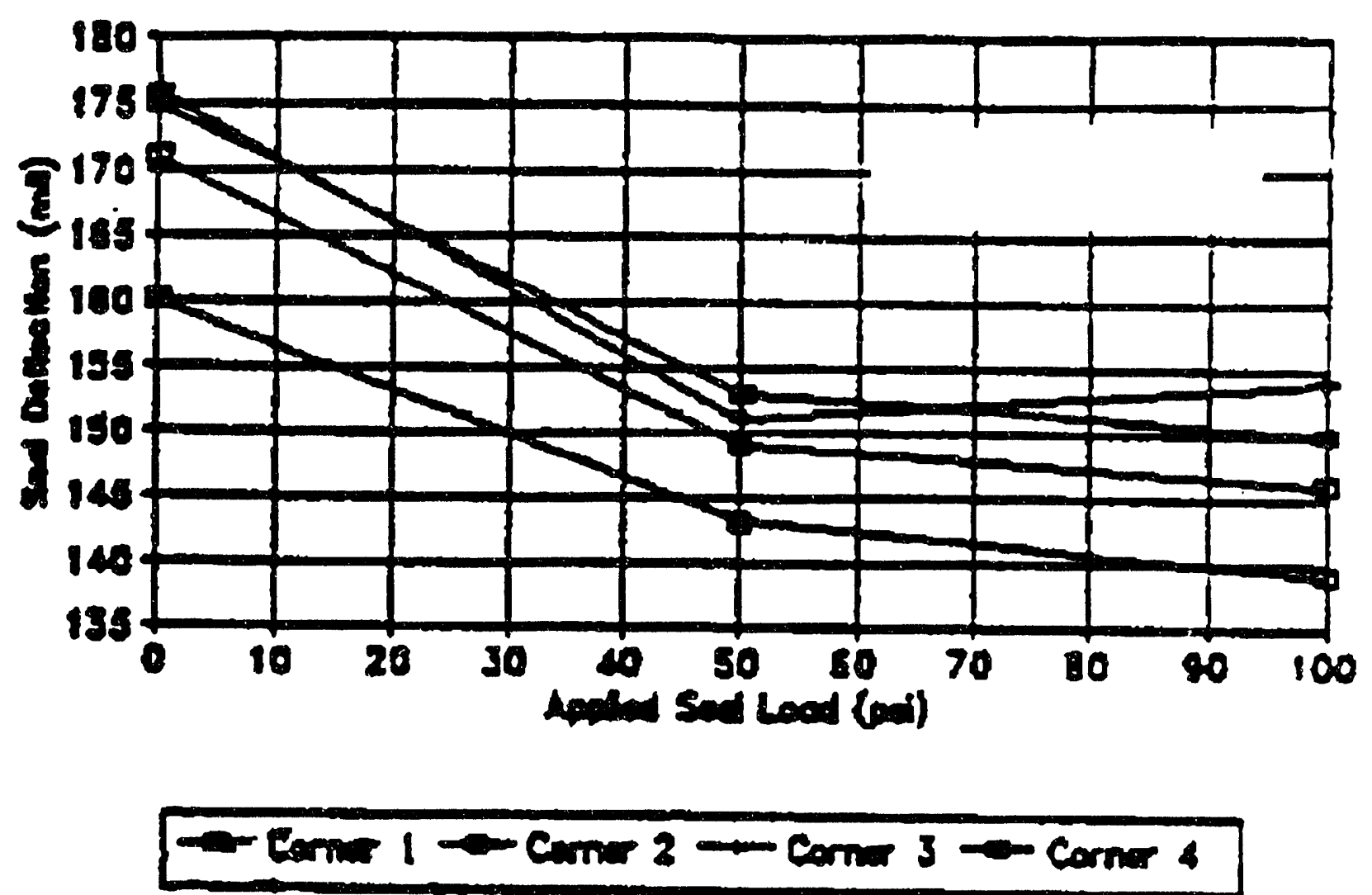

Figure 3.1-29. Seal Deflection as a Function of Seal Load

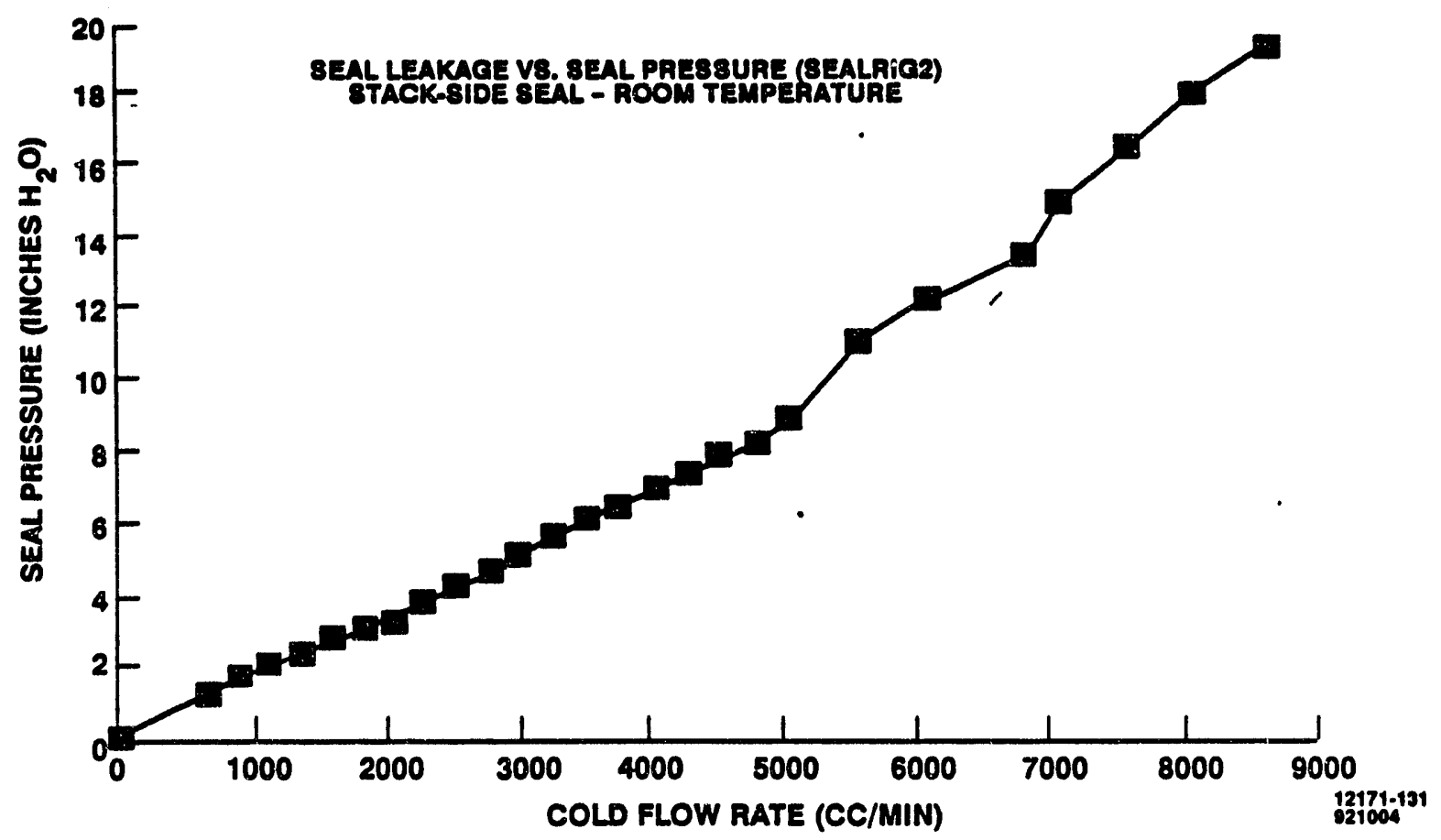

Figure 3.1-30. Seal Leakage Data for SEALRIG2 at Room Temperature 
The rig was then raised in temperature at $70^{\circ} \mathrm{F}$ per hour up to $383^{\circ} \mathrm{F}$. The temperature was held at this point and a second set of data acquired. Figure 3.1-31 shows these data.

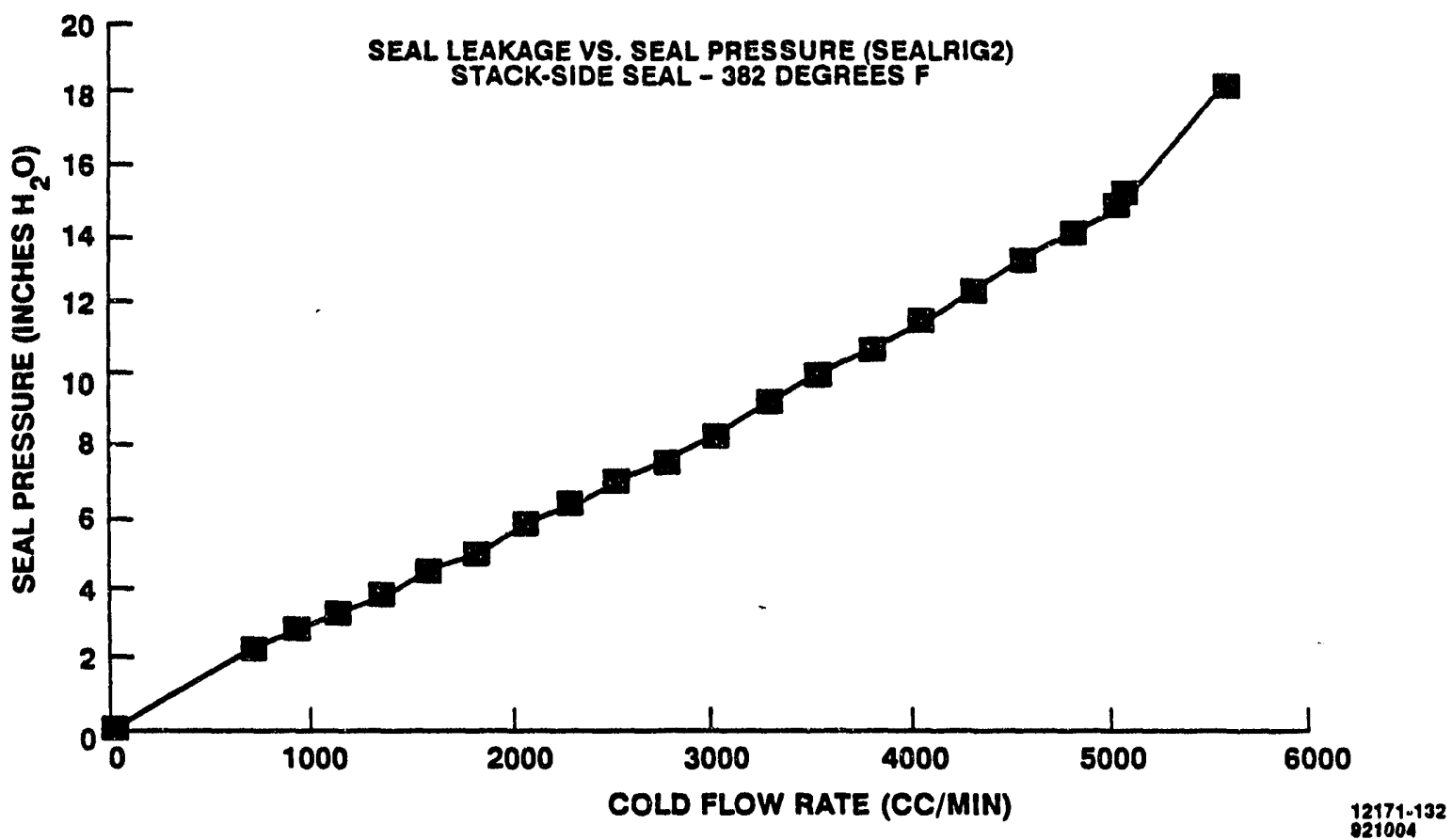

Figure 3.1-31. Seal Leakage Data for SEALRIG2 at $383^{\circ} \mathrm{F}$

The rig was brought to $1200^{\circ} \mathrm{F}$. Figure 3.1-32 shows the seal pressure as a function of cold air flow at $1200^{\circ} \mathrm{F}$ prior to any seal movement. The data shows that the leakage rate at any given pressure was better in this rig than it was in SEALRIG1 even after corrections were made for the differences in seal length between the two rigs. Then the sliding tests began. The sliding seal plate was moved about 0.1 " per hour. Seal pressure versus seal leakage curves were obtained for each increment of plate travel. A total plate travel of $0.9^{\prime \prime}$ was completed before the seal failed. Figure 3.1-33 shows the seal pressure at a fixed cold flow seal leakage rate of $3300 \mathrm{cc} / \mathrm{min}$ versus the total distance of seal plate travel. It is interesting to note that the seal pressure increased for the first 0.2 " of travel. 


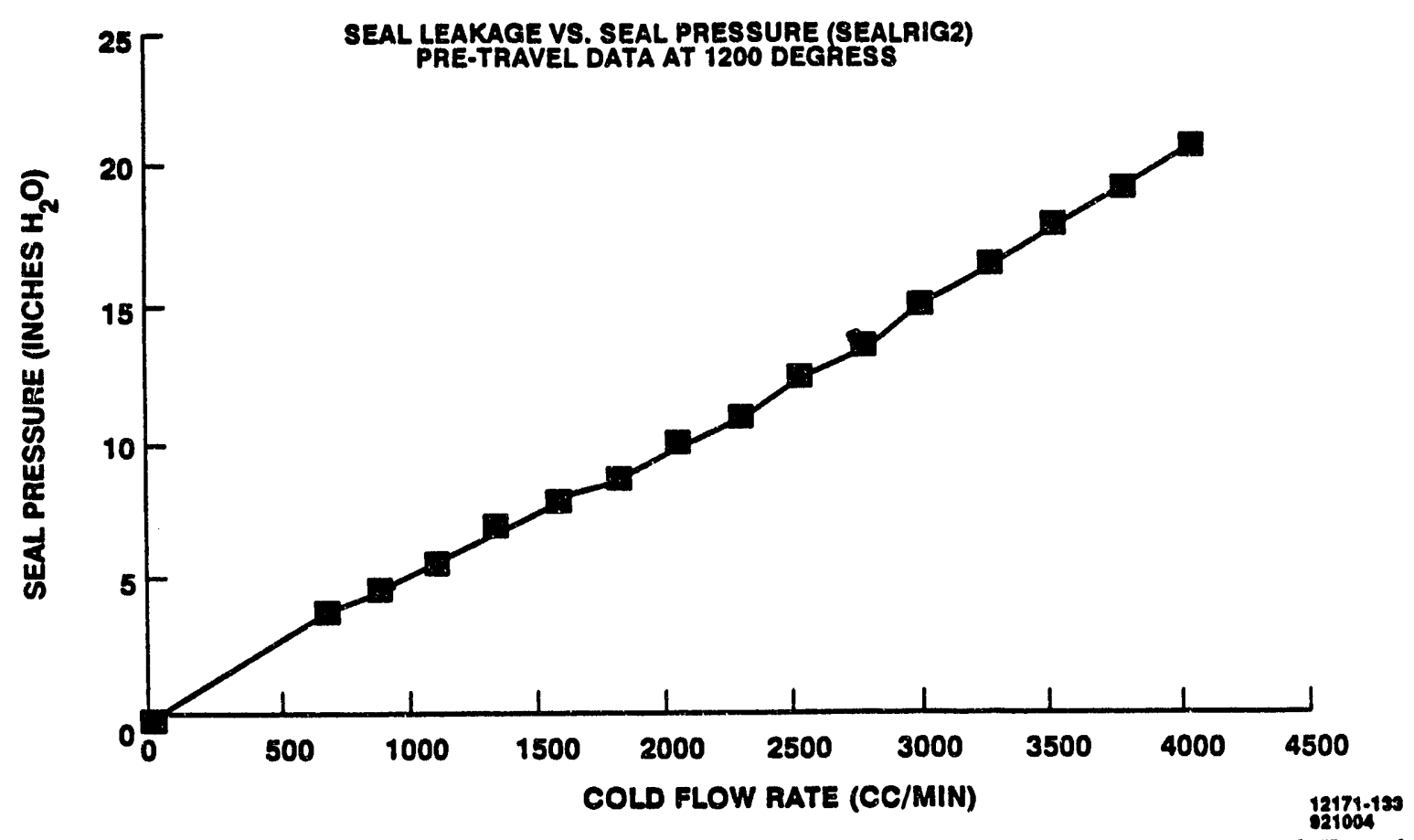

Figure 3.1-32. Seal Pressure as a Function of Cold Air Flow at $1200^{\circ} \mathrm{F}$ Prior to any Seal Travel

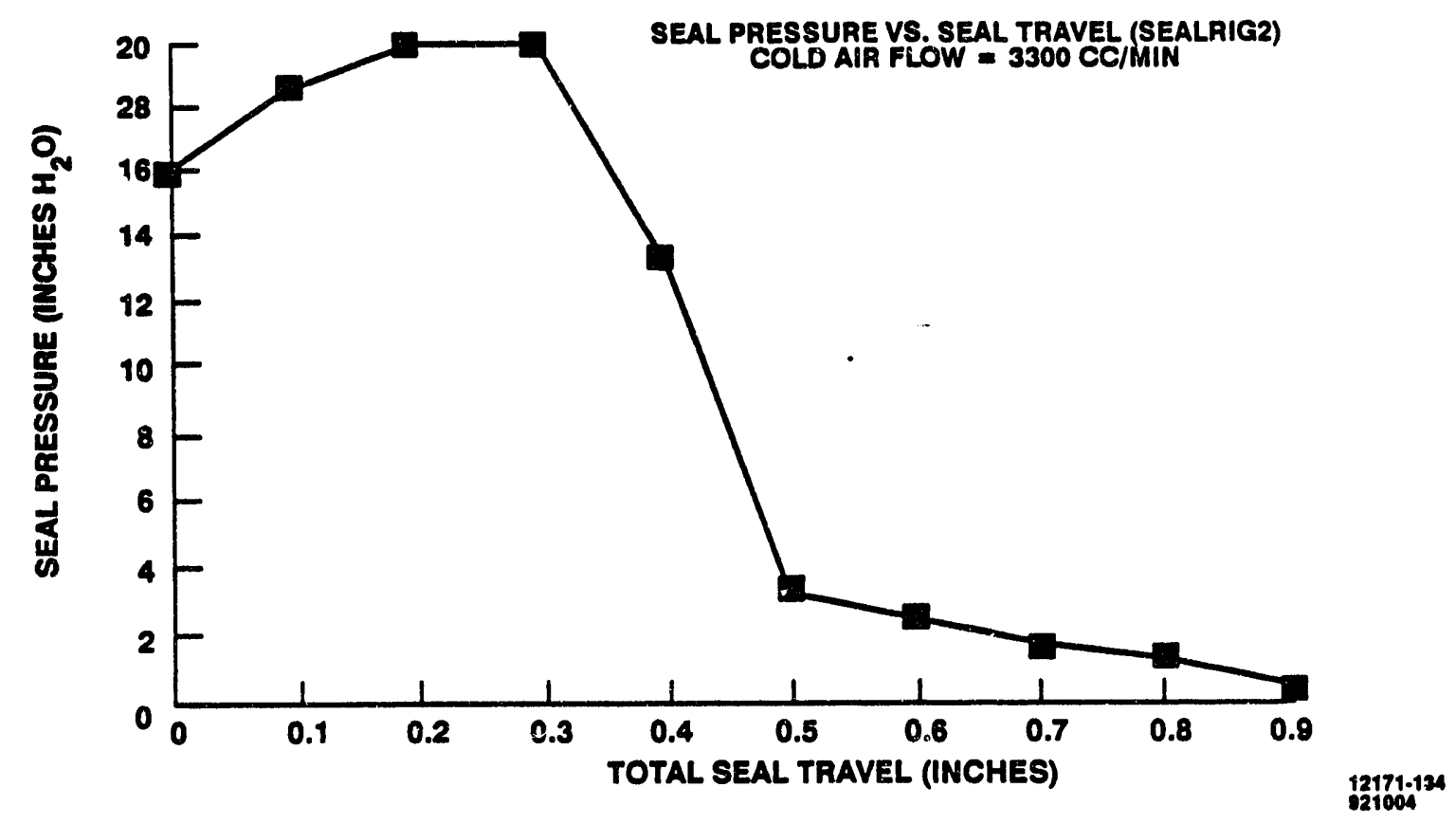

Figure 3.1-33. Seal Pressure at a Fixed Leakage Rate as a Function of Seal Plate Travel 
A post-test visual inspection of SEALRIG2 was performed. The following observations and conclusions were made:

- Before disassembly of the rig a visual observation was made of the seal. The two sides of the seal were in excellent shape and no crumbling of the caulk was observed. A gap in the caulk was observed about 1 inch in from the end closest to the drive screw. A similar gap was noticed on the opposite side of the rig in about the same location.

- The end of the seal on the opposite end from the drive screw had been pushed off the stationary alumina plate. This was an obvious location for a major seal leak since no seal remained at this end of the rig.

- Measurements were taken of the seal height at the four corners of the seal. The measurements indicated that the drive screw end of the seal had become thinner. The height at that end decreased from 145 mils to 97 mils. The end opposite the drive screw decreased from 150 mils to 125 mils.

- The deflection of the three load bars was also measured pre and post-test. The load at the drive screw end of the seal had fallen from 100 psi to near zero. The load at the other end had fallen from 100 psi to about 35 psi.

- The top movable plate which contained the simulated stack edge was removed and allowed a view looking down on the seal which was resting on the stationary alumina plate. Figure 3.1-73 shows the seal resting on the alumina plate after the top movable plate was removed. The edges of the cracks in the seal at the drive screw end of the rig were noted in the side view of the seal prior to disassembly. However, a continuous seal was maintained all around the rig except at the end where it was pushed off the alumina.

- The zirconia cloth on the drive screw end of the rig had turned into loose powder, but everywhere else it appeared to have good integrity. There were a few tears along the long edges of the seal but there were no notable separations at these points.

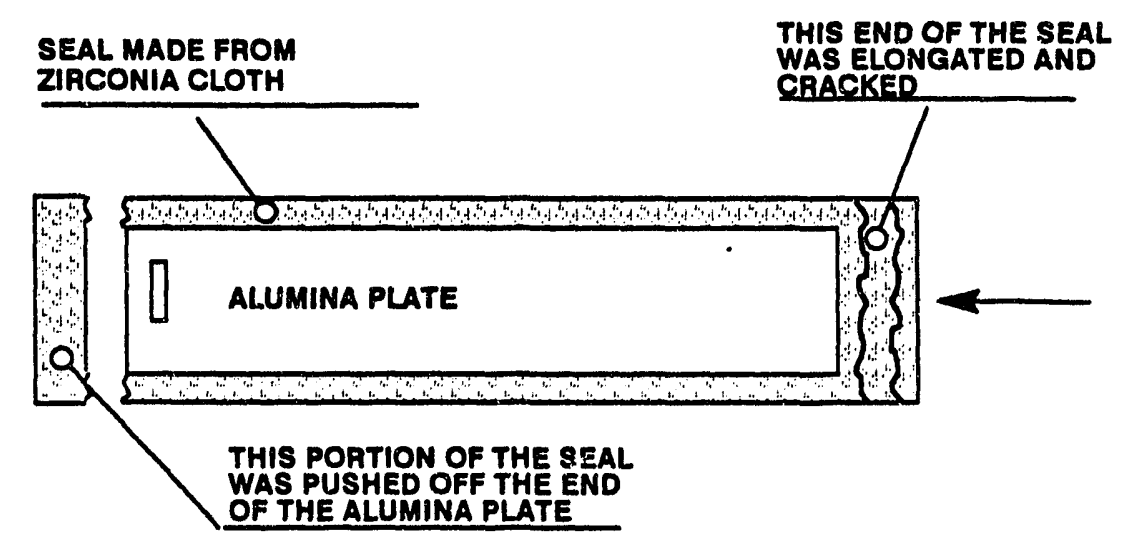

VIEW LOOKING DOWN ON SEAL AND ALUMINA PLATE

Figure 3.1-34. Post-Test View of SEALRIG2 Showing Conduction of Seal 
The conclusions from the post-test observation of the rig were as follows:

- The caulk material was grabbed by the rough edges of the moving simulated stack edge and forced to follow the moving body.

- The major slide took place between the zirconia cloth and the smoother alumina piece.

- The grooves in the alumina piece grabbed the seal at the drive screw end of the rig and caused the seal to be torn apart at that point. However, this did not cause the seal to fail since there was still a continuous seal at this end of the rig.

- The groove at the end opposite the drive screw failed to grab the seal and the seal slid off the end of the alumina plate at this end causing the seal to fail.

\section{SEALRIG3}

An approach was devised for building SEALRIG3 that would allow a longer seal travel without pushing the seal off the end of the alumina plate as occurred in SEALRIG2. The approach also more closely simulated the materials that would be found at the top and bottom of a typical MCFC stack. Figure 3.1-74 is a sketch of SEALRIG3 showing the top and side views of the seal approach.

The seal caulk was made just prior to construction to ensure that the caulk was fresh. A 20-mil layer of caulk was applied to the simulated stack edge. The cloth layers at the ends and the cloth picture frames were then added.

The rig was placed in its housing and the load bars added. The load for each load point was calculated to be 325 pounds which corresponds to 100 psi on the seal.

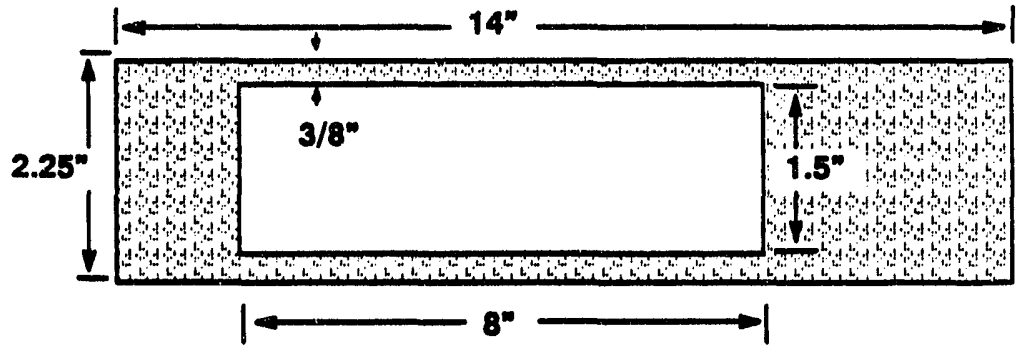

TOP VEW OF GASKETS

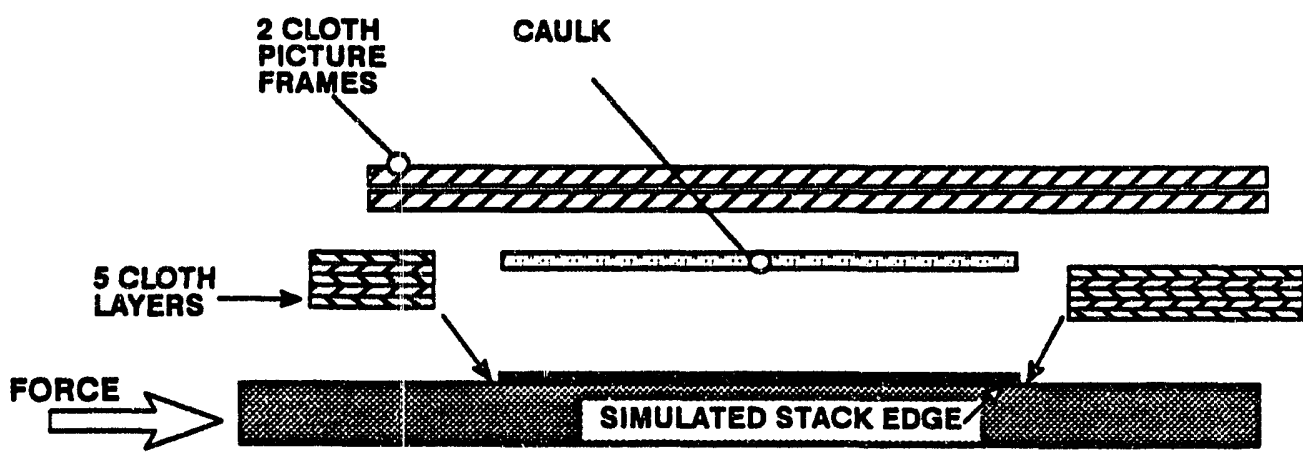

SIDE VIEW OF SEALRIG3

Figure 3.1-35. Top and Side Views of SEALRIG3

SEALRIG3 was heated to $1200^{\circ} \mathrm{F}$ for testing. The sliding portion of the seal rig was moved in $0.1^{\prime \prime}$ increments for 5 increments. The movement of the sliding portion of the rig was different for this rig than it was for SEALRIG2. In SEALRIG2, when the 0.1" increments were made, the sliding portion of 
the rig remained stationary. In SEALRIG3 the sliding portion of the rig moved backward by some amount as the drive screw was removed after the 0.1 " of travel. At about 0.3 " of drive-screw travel the seal failed and a high gas flow occurred.

Post-test analysis showed that the seal had failed where the caulk portion of the seal joined the cloth portion of the seal. Figure 3.1-36 shows a sketch of what the seal looked like when the rig was opened during the post-test analysis. The gap between the caulk and the cloth portion was almost $1 / 4$ " wide and had no cloth remaining in the gap. The results showed that the cloth portion of the seal representing the cloth at the top of the stack was pinned in place while the caulk portion of the seal traveled along with the moving plate. A method for handling this junction is required in the design of the seal for a real stack.

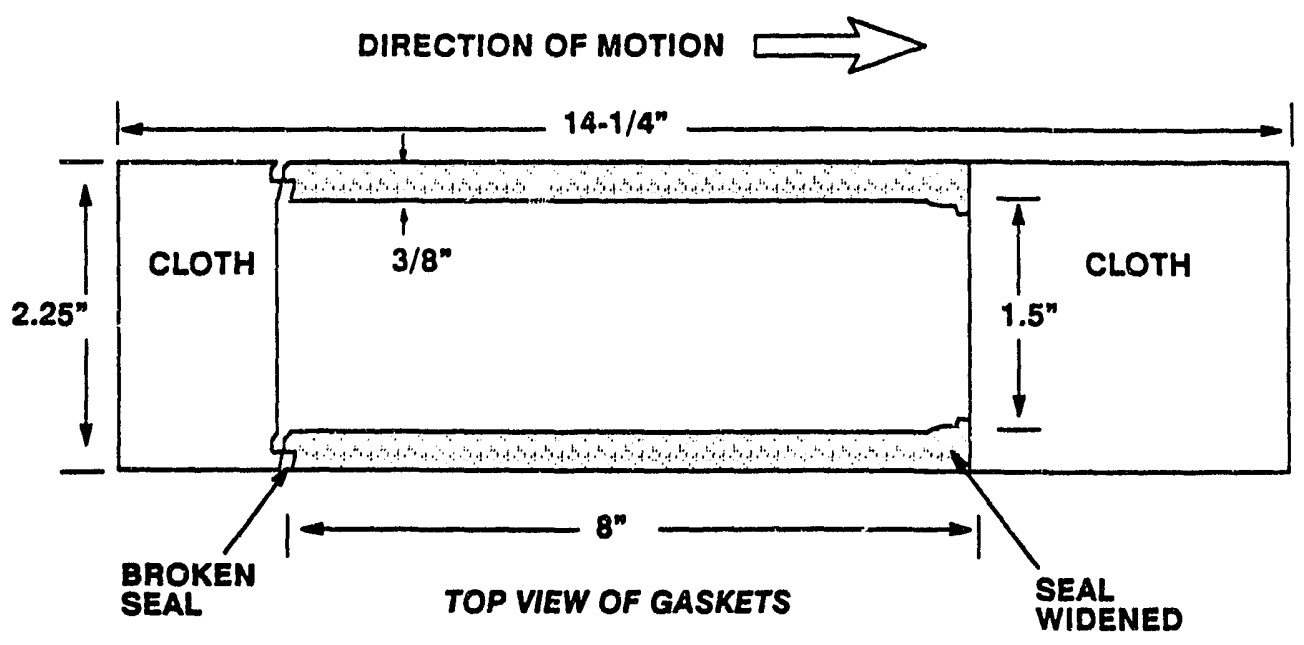

Figure 3.1-36. SEALRIG3 Gaskets as Viewed During Post-Test Analysis

The caulk portion of the seal appeared to be in excellent shape with no crumbling or spalling at the edges. The far end of the caulk seal was wider than at the start of the test. It is assumed that some of the seal material being pushed by the moving plate was deposited here, making the seal wider. The joint between the cloth and the caulk at this end of the rig was tight. 


\section{Subtask 3.2 Manifold Development}

Objective - The objective of this subtask was to verify that the fuel and oxidant manifold designs for the 144-cell stack provide uniform distribution of reactants to the cells at the anticipated stack operating conditions.

\section{Summary}

Fuel and oxidant manifolds were designed for the 144 cell molten carbonate stack to distribute the flow of reactants uniformly. Maldistribution of the reactant flow exists due to manufacturing tolerance within the cell stack. A baffle has been included in the manifold to minimize this maldistribution. A full scale test rig was constructed to verify the effectiveness of the manifold baffle design. The rig duplicates the actual dimensions of the $100-\mathrm{kW}$ stack manifolds and inlet piping. Flow distribution was determined at $30-\mathrm{kW}$ fuel, $30-\mathrm{kW}$ oxidant, and $100-\mathrm{kW}$ oxidant flows. The fuel manifold to be used for operation at $100-\mathrm{kW}$ will include a sensible heat reformer and was not evaluated in this test. Good flow distribution was achieved with the selected baffle configuration at all conditions tested. Testing was also done with the baffle removed from the manifold. Flow distribution was slightly better with the baffle at the higher oxidant flows. At the low fuel flow, distribution was similar with or without the baffle. However, inclusion of the baffle may reduce maldistribution due to natural convection at the high stack operating temperatures.

The following results show that the selected baffle configuration provides uniform distribution of reactants. In all cases, the distribution of flow is sufficient for proper reactant utilization.

\begin{tabular}{|l|c|c|c|c|}
\hline & & \multicolumn{3}{|c|}{ Flow Distribution } \\
\hline \multicolumn{1}{|c|}{ Simulated Flow Condition } & CFM & $\begin{array}{c}\text { Avg Across } \\
\text { Row }\end{array}$ & Local Max. & Local Min. \\
\hline 30-kW Fuel Side & 40 & $+/-1 \%$ & $+1 \%$ & $-2 \%$ \\
\hline $30-\mathrm{kW}$ Oxidant Side & 340 & $+3 \% /-5 \%$ & $+9 \%$ & $-10 \%$ \\
\hline $100-\mathrm{kW}$ Oxidant Side & 1180 & $+/-4 \%$ & $+9 \%$ & $-12 \%$ \\
\hline
\end{tabular}

\section{Report of Work}

\section{Manifold and Bame Design}

Manifolds were sized for the 144-cell molten carbonate fuel cell stack to provide uniform distribution of reactants to the cells. The required size for all four manifolds, air and fuel, both inlet and exit, is 6 inches deep, as shown in Figure 3.2-1. The manifolds were sized to minimize flow maldistribution due to manufacturing tolerances within the cell stack. Flow distribution was analyzed for both $30-\mathrm{kW}$ and $100-\mathrm{kW}$ flows.

The inlet pipe to each manifold was sized to prevent the flow from jetting into the manifold. By keeping a low velocity head in the incoming gas, flow distribution in the manifold is not affected. A 6-inch pipe is used for the fuel side, and an 8-inch pipe for the oxidant side, to keep the velocity head of the incoming gas below 10 percent of the stack pressure drop.

A diffuser baffle was included in each inlet manifold to spread out the flow uniformly in the manifold (except in the case of the fuel inlet manifold for operation at $100 \mathrm{~kW}$ as an ISU, which contains a sensible heat reformer). 
FUEL MANIFOLD
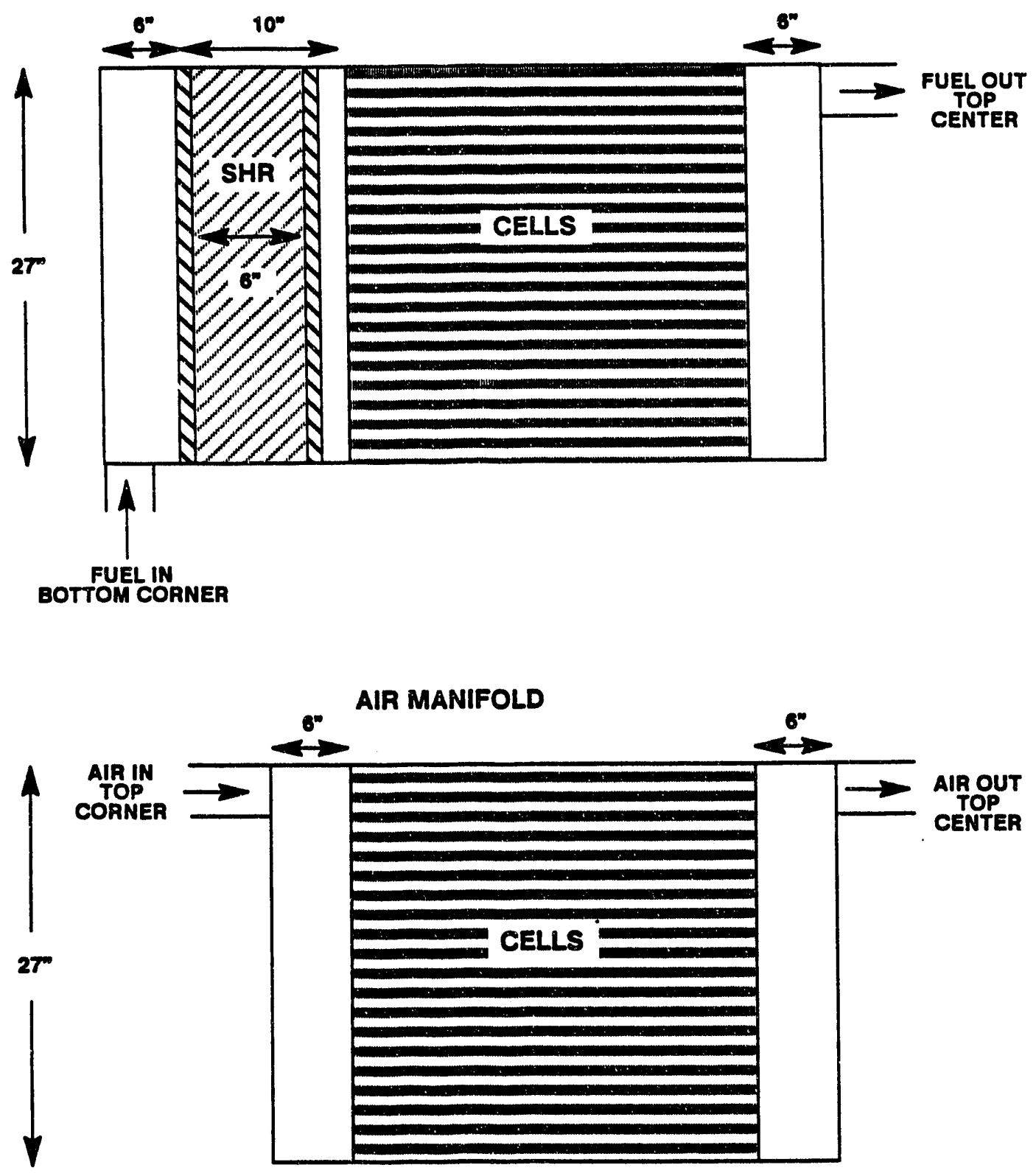

Figure 3.2-1. Stack Manifold Sizing 


\section{Design of Flow Test Rig}

A full-size rig was constructed to test the effectiveness of the manifold baffle in providing uniform flow to the stack. A schematic of the test rig is shown in Figure 3.2-2. The rig consists of three sections: the inlet manifold, the stack simulator, and the exit manifold. The inlet manifold was made of plexiglas to allow for observation of streamers to determine direction of flow. The stack simulator section was composed of sheets of filter paper, selected to match the pressure drop characteristics of the cell stack. The plywood exit manifold consisted of a gridwork of 36 equal-size chambers. The gas flowing through each chamber exits through a hole in which the flow is measured. The flow distribution was determined by comparing the flow measurements from the 36 chambers.

A schematic of the exit manifold is shown in Figure 3.2-3. The holes were sized for each flow condition to prevent the flow distribution from being influenced by the test apparatus. The holes were sized so that the velocity head of the exiting gas was less than 10 percent of the simulated stack pressure drop.

The filter paper was selected for each flow condition to provide the required stack pressure drop. Characteristics of the papers were determined by testing done previously in conjunction with acidstack manifolds.

The completed test rig is shown in Figure 3.2-4. The air flow was provided by an air blower. The flow was measured with a pitot tube inserted into the hole in each chamber of the exit manifold. The pitot tube was mounted in a sleeve to ensure the same placement for each measurement. The flow measurement apparatus is shown in Figure 3.2-5.

\section{Flow Testing and Results}

A summary of the flow conditions for testing of the manifold baffle design is given in Table 3.2-1. Testing was done using air at room temperature and pressure, at volumetric flow rates equal to $30-\mathrm{kW}$ and $100-\mathrm{kW}$ stack flow conditions.

\begin{tabular}{|l|c|c|c|}
\hline \multicolumn{3}{|c|}{ Table 3.2-1. Manifold Bame Test Flow Conditions } \\
\hline \multicolumn{1}{|c|}{ Flow Condition } & CFM & $\begin{array}{c}\text { Simulated Stack } \\
\text { Delta P }\end{array}$ & Inlet Pipe Dia. \\
\hline $30-\mathrm{kW}$ Fuel Side & 40 & $0.6 \mathrm{IWC}$ & 6 in. \\
\hline $30-\mathrm{kW}$ Oxidant Side & 340 & $2.4 \mathrm{IWC}$ & 8 in. \\
\hline $100-\mathrm{kW}$ Oxidant Side & 1180 & $7.6 \mathrm{IWC}$ & 8 in. \\
\hline
\end{tabular}




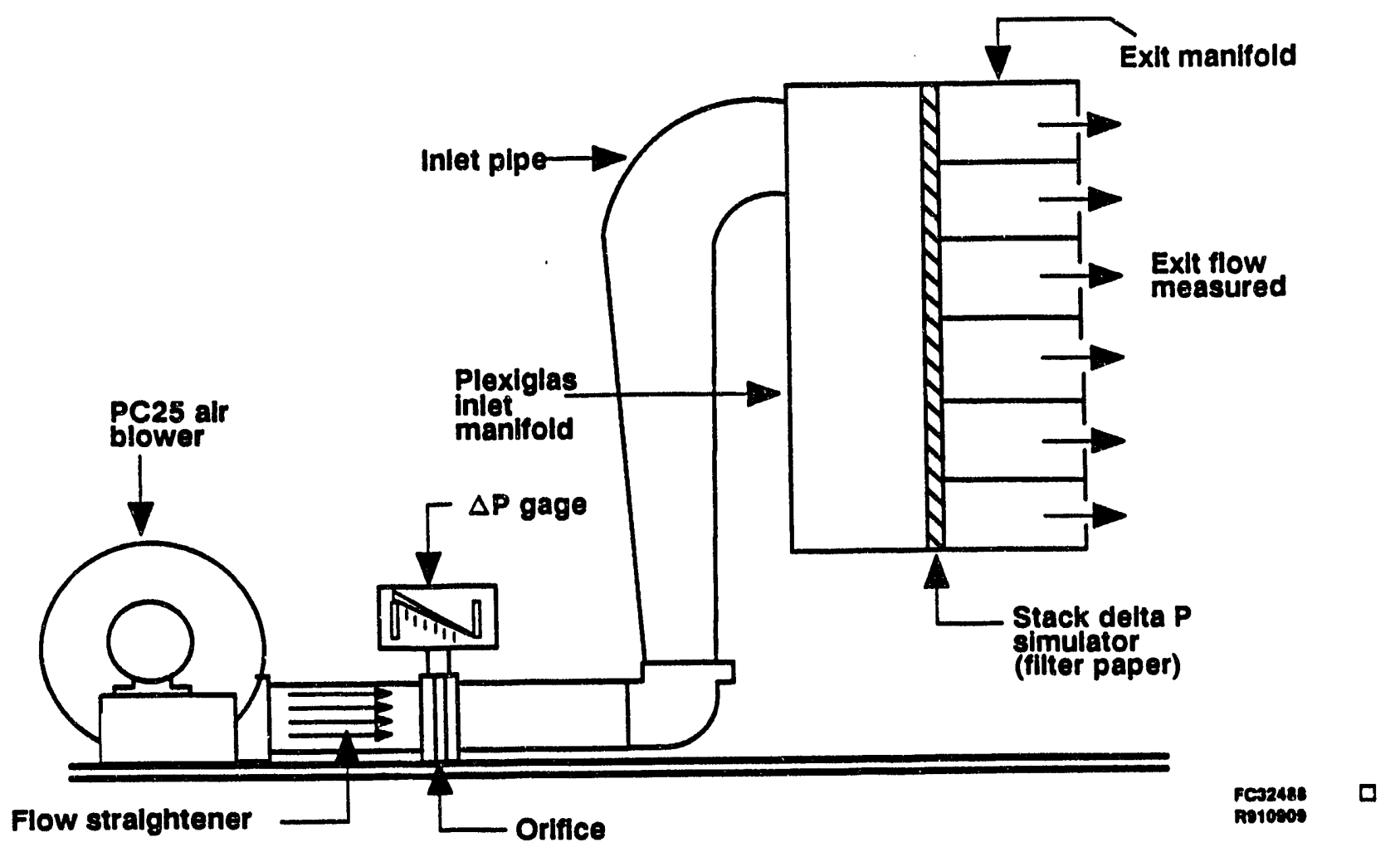

Figure 3.2-2. Reactant Manifold Flow Distribution Test Rig

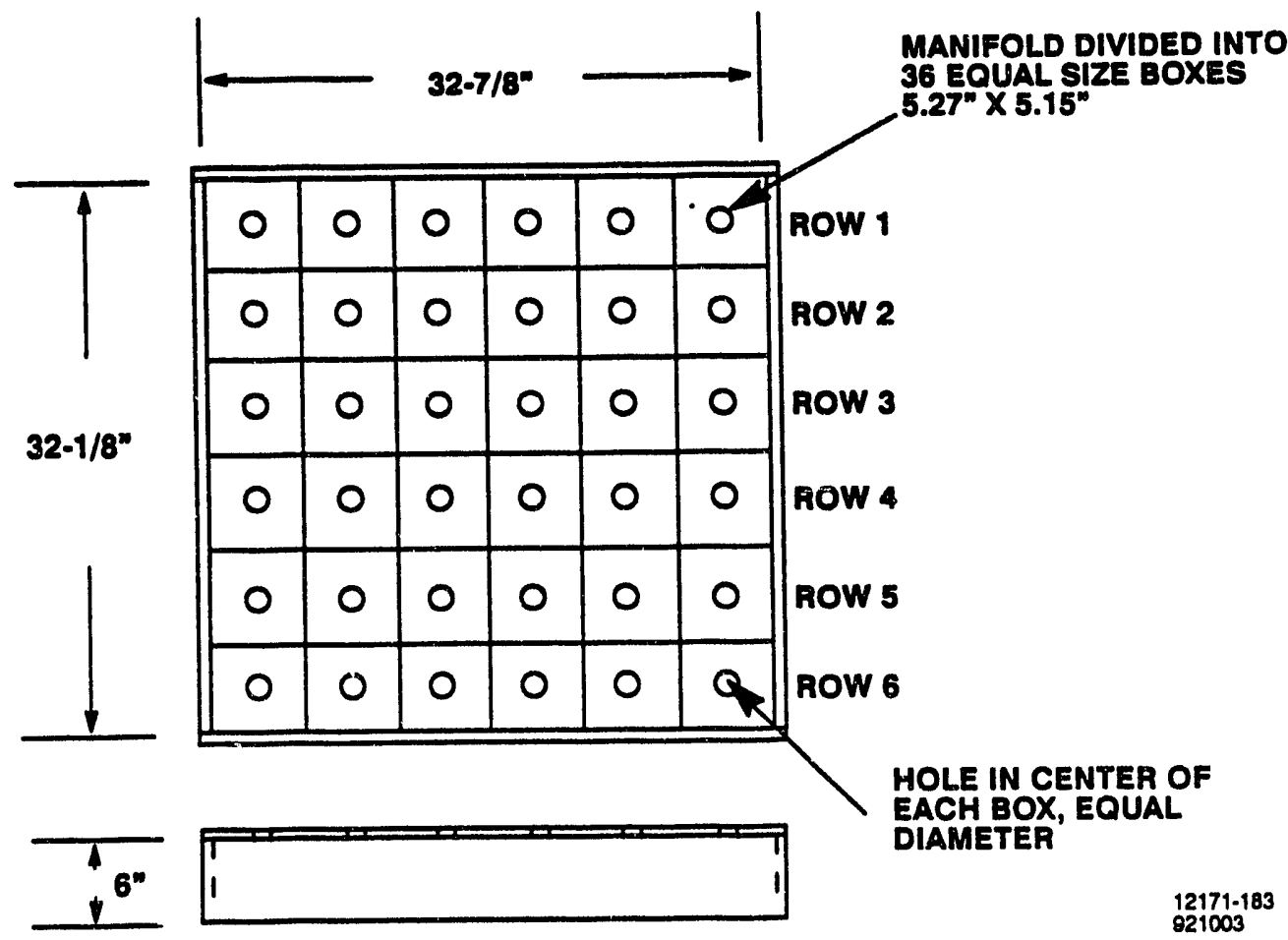

Figure 3.2-3. Exit Manifold 


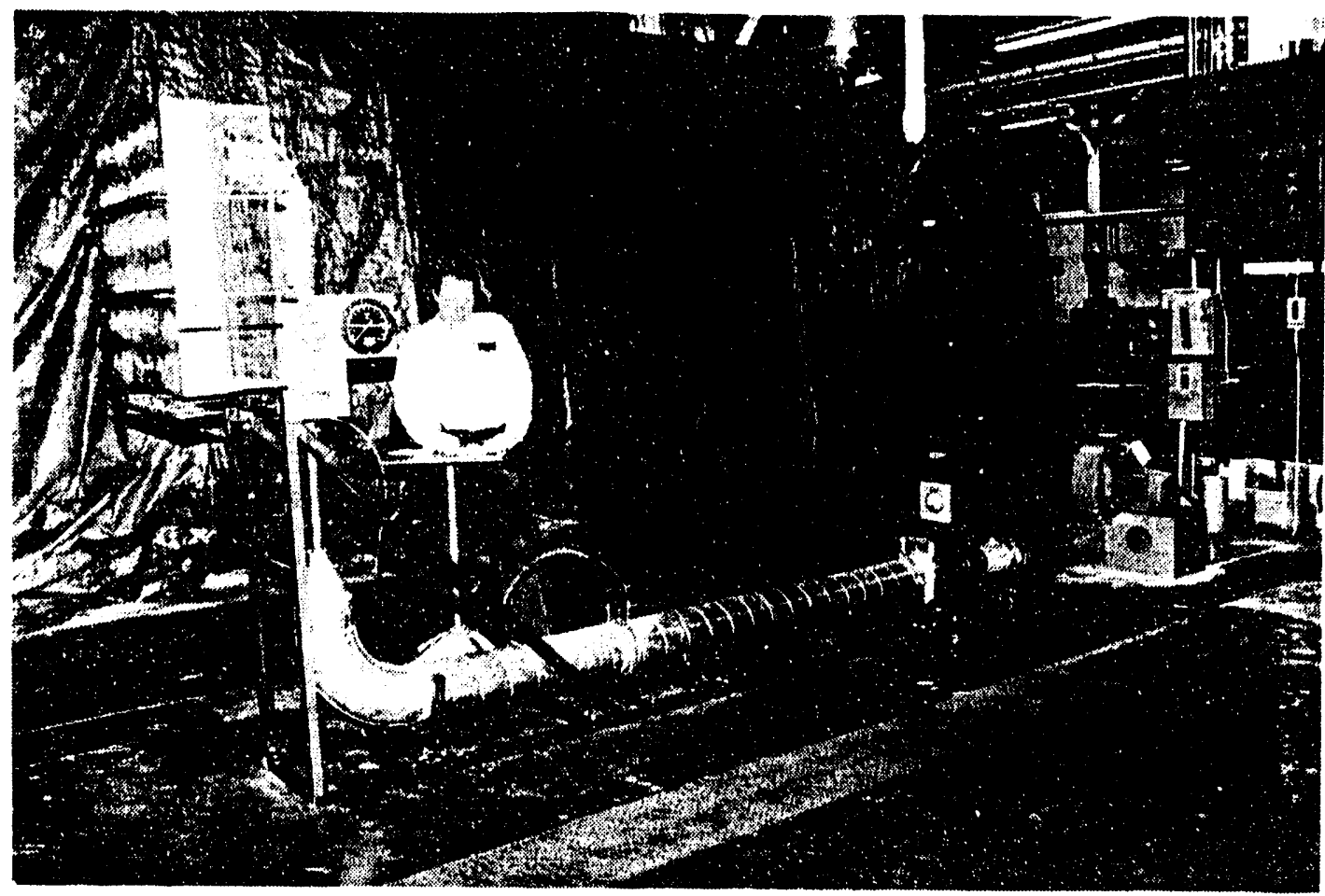

PUBS8905

Figure 3.2-4. Reactant Manifold Flow Distribution Test Rig

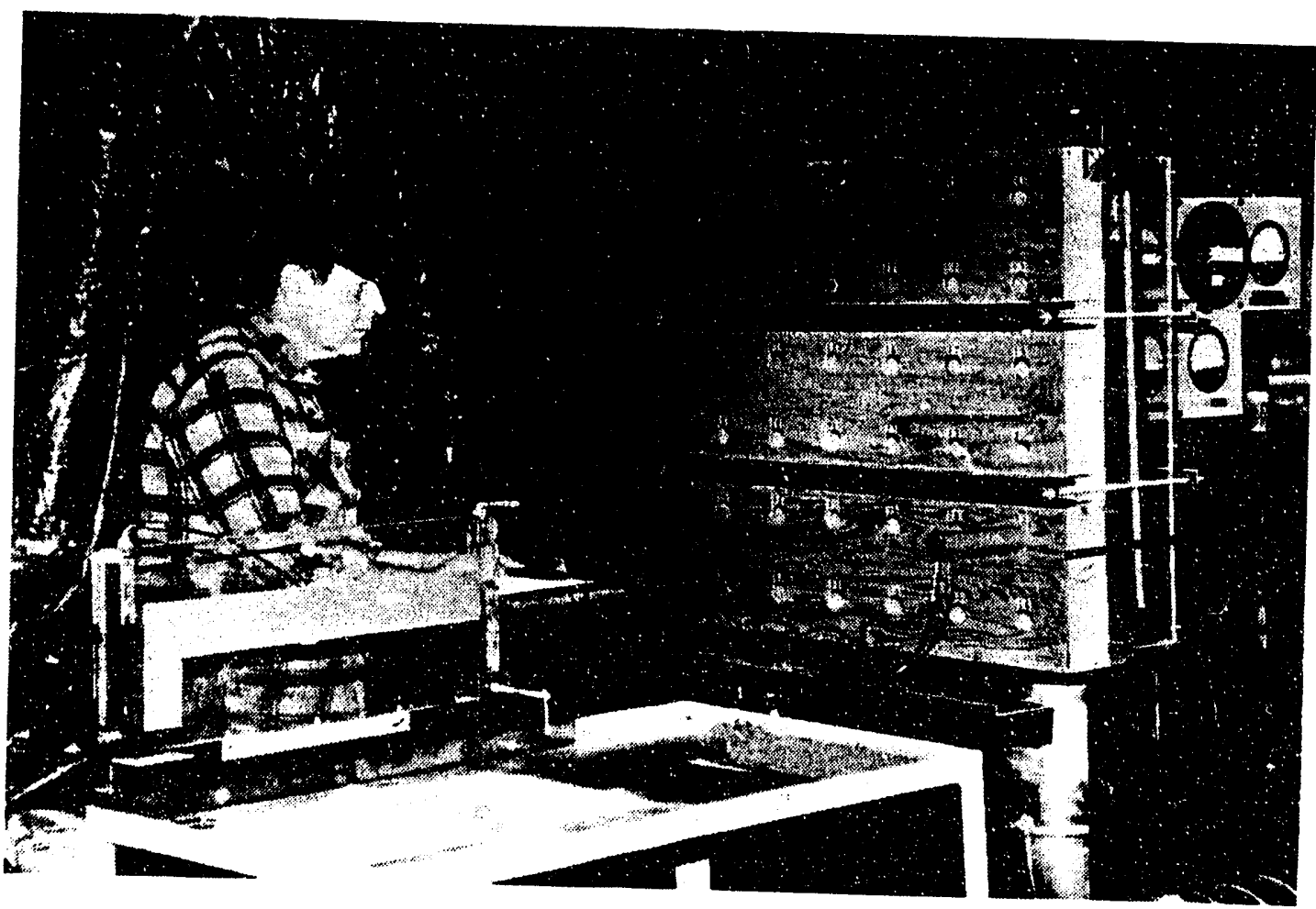

Figure 3.2-5. Reactant Manifold Flow Test Apparatus 
For each of the design conditions above, testing was done over a range of flows. For the 30-kW flows, testing was done at 50-160 percent of the design flow on the fuel side, and 50-150 percent on the oxidant side. For the $100-\mathrm{kW}$ condition, testing was done at 50 percent and 100 percent of the design flow. Flow distribution results for all these cases are given in Table 3.2-2. A definition of the flow distribution results presented in the tables and figures below is shown in Figure 3.2-6.

\begin{tabular}{|c|c|c|c|c|}
\hline \multirow[b]{2}{*}{ Flow Condition } & \multirow[b]{2}{*}{ CFM } & \multicolumn{3}{|c|}{ Flow Distribution } \\
\hline & & $\begin{array}{l}\text { Variation of } \\
\text { Row Averages }\end{array}$ & Local Max. & Local Min. \\
\hline \multicolumn{5}{|l|}{ 30-kW Fuel Flow } \\
\hline $50 \%$ & 20 & $+1-2 \%$ & $+4 \%$ & $-4 \%$ \\
\hline $100 \%$ & 40 & $+/-1 \%$ & $+1 \%$ & $-2 \%$ \\
\hline $110 \%$ & 44 & $+/-1 \%$ & $+3 \%$ & $-3 \%$ \\
\hline $160 \%$ & 64 & $+/-1 \%$ & $+3 \%$ & $-3 \%$ \\
\hline \multicolumn{5}{|l|}{ 30-kW Oxidant Flow } \\
\hline $50 \%$ & 170 & $+1-3 \%$ & $+7 \%$ & $-7 \%$ \\
\hline $100 \%$ & 340 & $+3 \% /-5 \%$ & $+9 \%$ & $-10 \%$ \\
\hline $108 \%$ & 367 & $+1-4 \%$ & $+10 \%$ & $-9 \%$ \\
\hline $150 \%$ & 510 & $+1-5 \%$ & $+9 \%$ & $-12 \%$ \\
\hline \multicolumn{5}{|l|}{ 100-kW Oxidant Flow } \\
\hline $50 \%$ & 590 & $+6 \% /-3 \%$ & $+11 \%$ & $-12 \%$ \\
\hline $100 \%$ & 1180 & $+1-4 \%$ & $+9 \%$ & $-12 \%$ \\
\hline
\end{tabular}




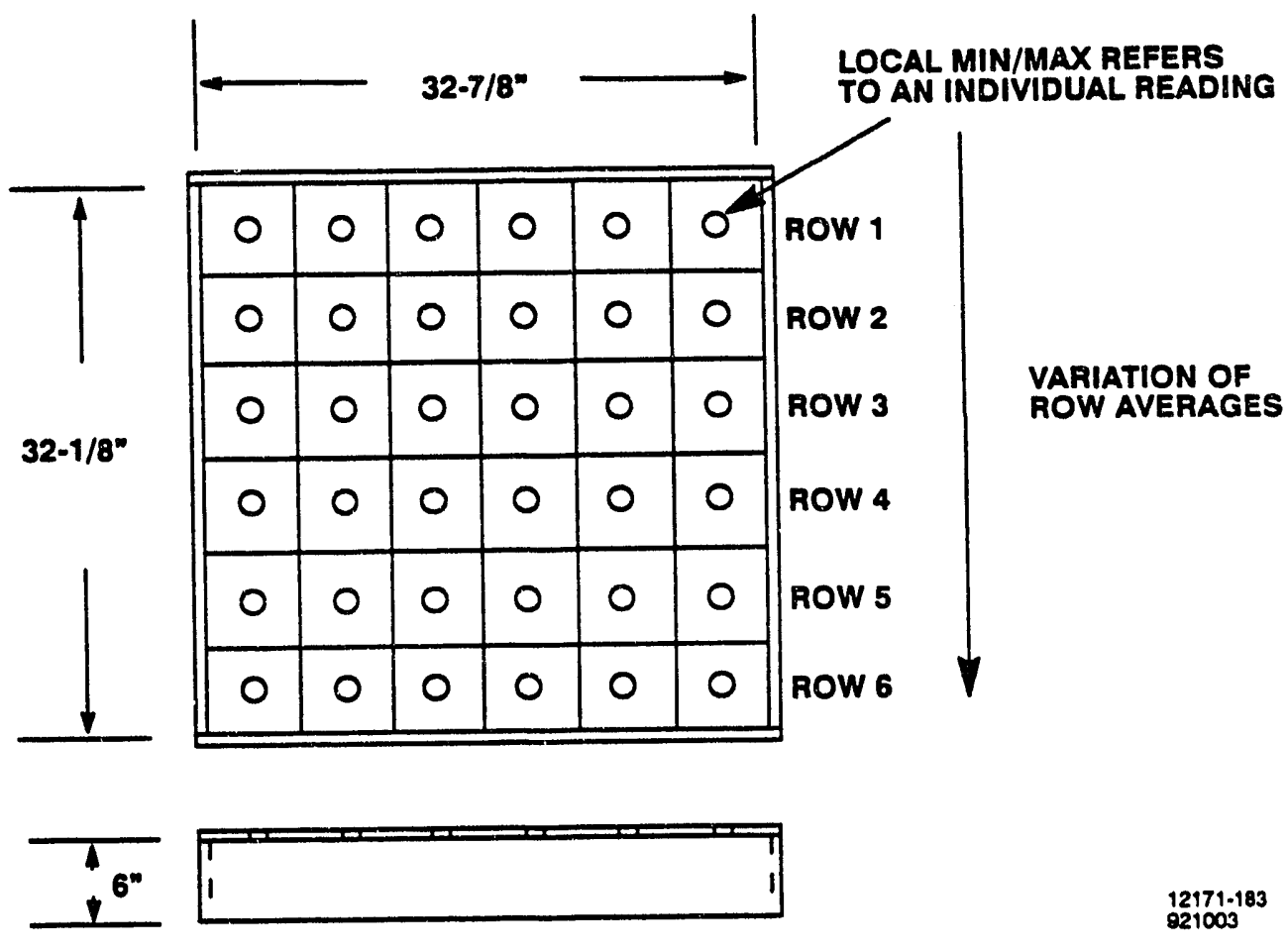

Figure 3.2-6. Definition of Exit Manifold Flow Distribution Results

Flow distribution test results for the 100 percent design flows are shown graphically in Figure 3.2-7 through 3.2-9. Good distribution was achieved with the selected baffle design in all cases. For 30-kW fuel flow, Figure 3.2-7A shows that the average flow distribution across each row, from top to bottom of the stack is \pm 1 percent. Figure 3.2-7B shows the distribution from top to bottom of the stack, as well as from left to right across the manifold. Maldistribution locally is within \pm 2 percent. Test results for the 30-kW oxidant flow are shown in Figure 3.2-8. The average distribution from top to bottom of the stack is +3 percent/ -5 percent. Local maldistribution is within \pm 10 percent. For $100-\mathrm{kW}$ oxidant flow, the results are shown in Figure 3.2-9. The average distribution from top to bottom is \pm 4 percent; local maldistribution is +9 percent $/-12$ percent.

For all the conditions tested, the flow distribution is sufficient for proper reactant utilization. In the cases of the $30-\mathrm{kW}$ and $100-\mathrm{kW}$ oxidant flows, a slightly higher cell hot-spot temperature may result due to the local maldistribution.

Inclusion of the baffle within the manifold results in additional pressure drop, which was measured in the test and is summarized below. This additional pressure drop, shown in Table 3.2-3, is negligible at the $30-\mathrm{kW}$ flows, but in the case of the $100-\mathrm{kW}$ oxidant, should be added to the stack delta $P$ estimate. 


\begin{tabular}{|l|c|c|c|}
\hline \multicolumn{4}{|c|}{ Table 3.2-3. Pressure Drop Caused by Bame } \\
\hline \multicolumn{1}{|c|}{ Flow Condition } & CFM & $\begin{array}{c}\text { Simulated Stack } \\
\text { Delta P }\end{array}$ & $\begin{array}{c}\text { Additional Delta P } \\
\text { Due to Bame }\end{array}$ \\
\hline 30-kW Fuel Side & 40 & 0.6 IWC & $<0.1$ IWC \\
\hline 30-kW Oxidant Side & 340 & 2.4 IWC & 0.2 IWC \\
\hline 100-kW Oxidant Side & 1180 & 7.6 IWC & 1.7 IWC \\
\hline
\end{tabular}

The flow distribution test rig was also run with the baffle removed, to determine if the baffle is really necessary. The results of these tests are summarized below in Table 3.2-4.

\begin{tabular}{|c|c|c|c|c|}
\hline \multicolumn{2}{|c|}{ Table 3.2-4. Flow Distribution Test Results Without Baffe } \\
\hline & & \multicolumn{3}{|c|}{ Flow Distribution } \\
\hline Flow Condition & CFM & $\begin{array}{c}\text { Variation of } \\
\text { Row Averages }\end{array}$ & Local Max. & Local Min. \\
\hline 30-kW Fuel Flow & & & & \\
\hline $100 \%$ & 20 & $+/-2 \%$ & $+8 \%$ & $-4 \%$ \\
\hline $110 \%$ & 40 & $+/-1 \%$ & $+1 \%$ & $-2 \%$ \\
\hline $160 \%$ & 44 & $+/-2 \%$ & $+2 \%$ & $-2 \%$ \\
\hline $210 \%$ & 64 & $+/-1 \%$ & $+2 \%$ & $-2 \%$ \\
\hline $500 \%$ & 84 & $+/-1 \%$ & $+2 \%$ & $-2 \%$ \\
\hline $100 \%$ & 200 & $+/-3 \%$ & $+4 \%$ & $-6 \%$ \\
\hline $30-k W$ Oxidant Flow & & & & \\
\hline $100-\mathrm{kW}$ Oxidant Flow & 340 & $+1-3 \%$ & $+11 \%$ & $-12 \%$ \\
\hline $100 \%$ & & & & \\
\hline
\end{tabular}

At both $30-\mathrm{kW}$ and $100-\mathrm{kW}$ oxidant flows, maldistribution without the baffle is slightly higher than with the baffle. At the low $30-\mathrm{kW}$ fuel flows, distribution is similar with or without the baffle. However, inclusion of the baffle in the manifold may reduce maldistribution due to natural convection at the high stack operating temperatures. Therefore, the baffle will be included in both the fuel and oxidant manifolds. 

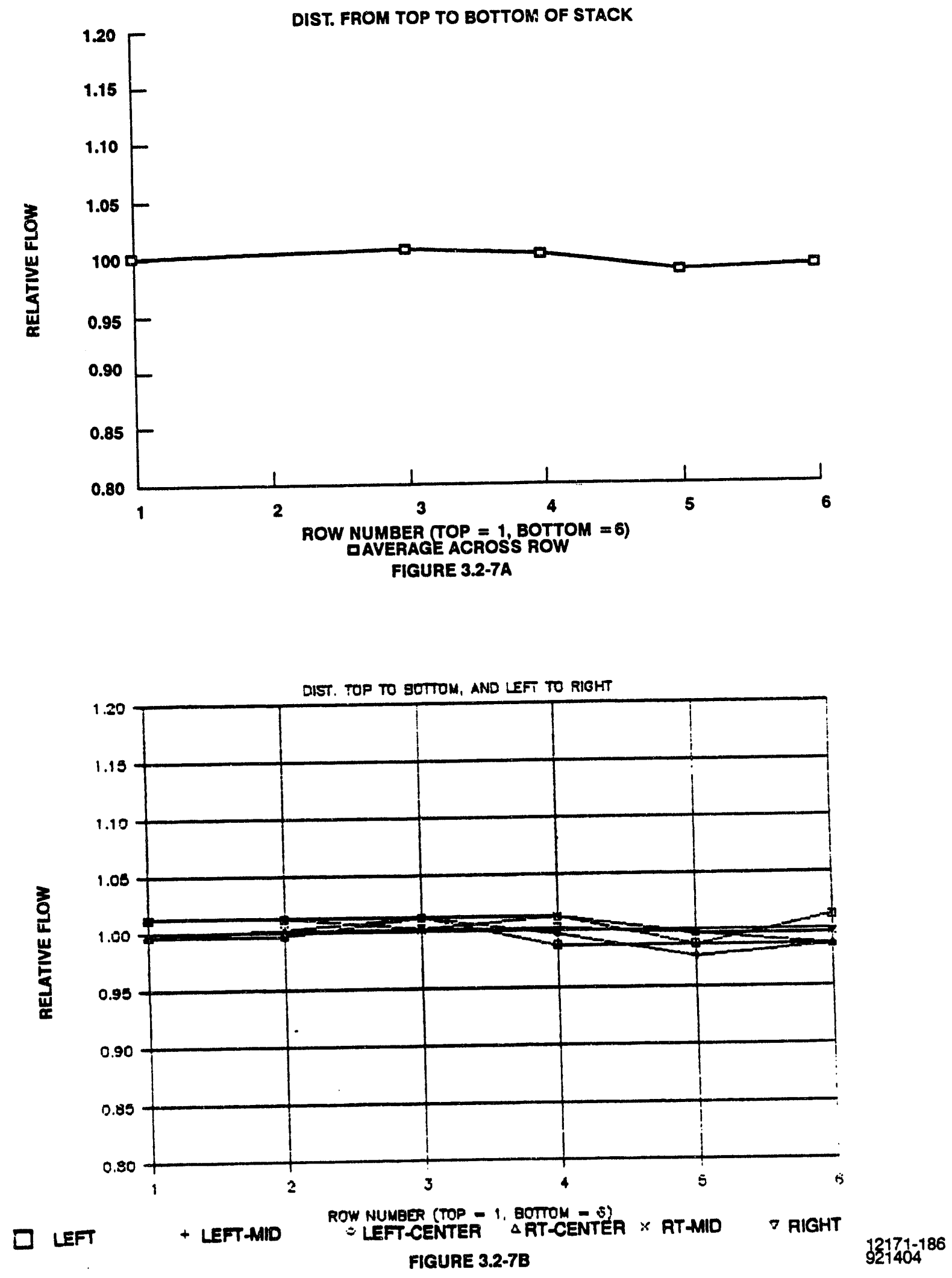

Figure 3.2-7. 30-kW Fuel Flow Distribution 


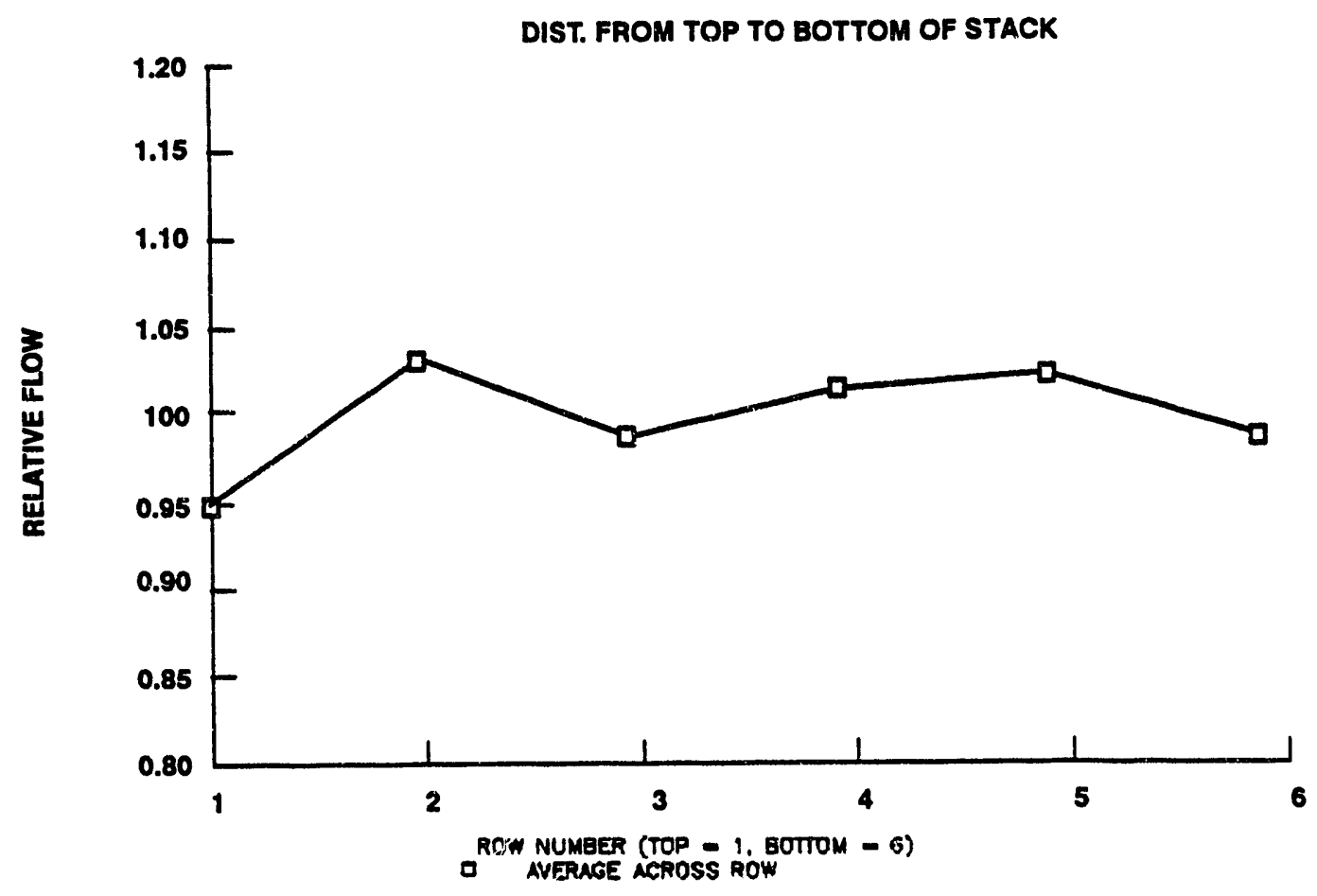

FIGURE 3.2-8A

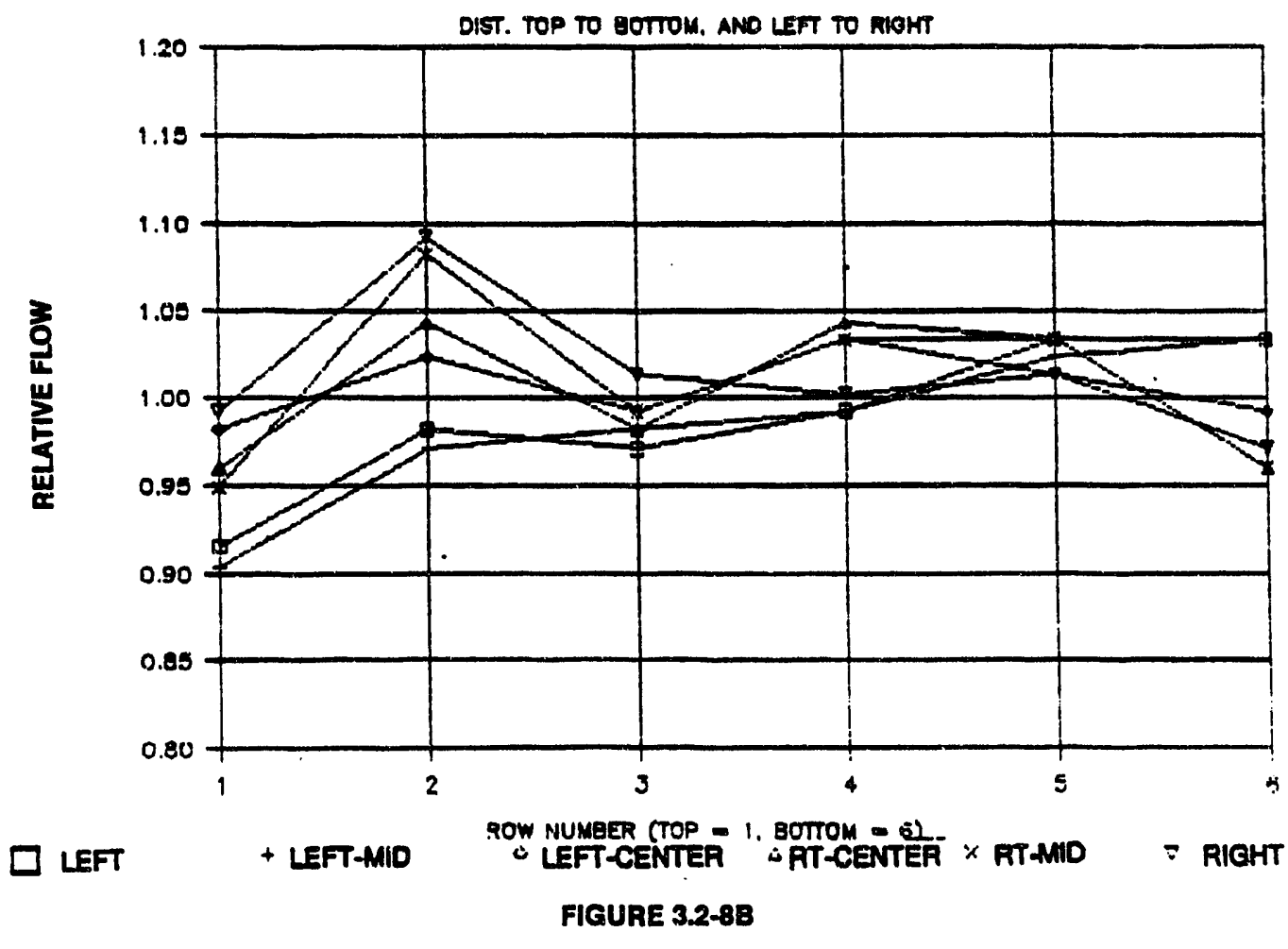

Figure 3.2-8. 30-kW Oxidant Flow Distribution 

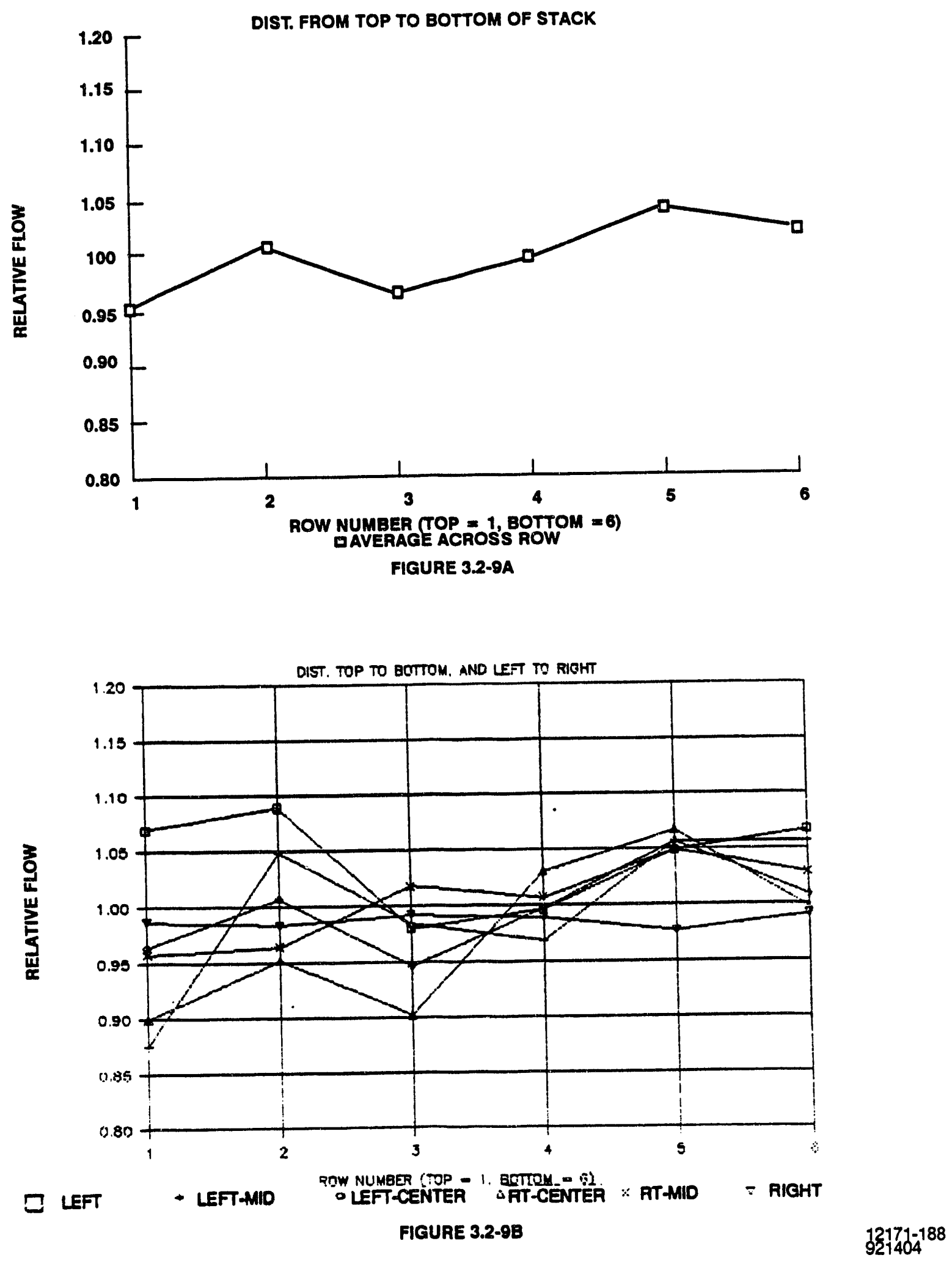

Figure 3.2-9. 100-kW Oxidant Flow Distribution 


\section{TASK 4 - TEST STAND PREPARATION}

Objective - The objective of this subtask was to prepare a test facility capable of stack testing at power levels up to 120 kilowatts.

\section{Summary}

Test stand requirements were derived for initial conditioning and startup of the cell stack, and for operation of the cell stack as a "stand-alone" unit and as an ISU. Modifications to the existing test stand to support the requirements were identified. A two-step modification approach initially allows for conditioning and testing a stand-alone stack, followed by additional modifications that permit operation of the ISU up to $120 \mathrm{~kW}$.

The requirements and modification approach for controlling the emissions of the stack during initial startup and conditioning were defined.

The design effort for modification of the test stand was initiated, with definition of a design schedule and design task elements.

\section{Report of Work}

The test facility to be used for the test of the 144-cell stack is the existing X-804 test stand. This stand has been used for testing the last two 20-cell, 8- $\mathrm{ft}^{2}, 25-\mathrm{kW}$ stacks at IFC. However, as presently configured, the test stand is not capable of supporting an $8-\mathrm{ft}^{2}$ tall stack test. The first step in determining the modifications to be done was to identify the stack and ISU requirements that the test stand must provide. This involves consideration of the following test modes:

- Initial stack conditioning and startup. In this mode, the test stand must supply prescribed fuel and oxidant flows to provide for gradual heatup of the cell stack, complete vaporization, oxidation, and exhaust of the matrix tape binder materials, electrolyte melt, and oxidation of the lithiated nickel cathode.

- Operation of the "stand-alone" stack on a "once-through" reactant-flow configuration, similar to the way all previous stacks have been operated. This mode provides stack functional verification at the earliest possible schedule and least program risk. In this mode, the test stand must supply fuel and oxidant at flows consistent with once-through utilizations and at cell temperature.

- Operation of the stack in an ISU configuration. In this mode, dual recycle loops on the anode and cathode are utilized, and the test stand is required only to provide makeup fuel and oxidant to the recycle loops at temperatures less than cell temperature.

For each mode, the fuel and oxidant compositions, flow rates (pounds per hour), and temperatures were derived as a function of startup sequence rates, or current densities and utilizations. These requirements were compared with the current test stand capabilities to determine those areas that needed to be modified. The results of this activity are shown in Table 4-1. These results indicate:

- Existing test stand fuel flow capacity can support initial startup and low-power stand-alone operation, but modifications are required for both ISU operation and higher power standalone operation.

- Existing test stand oxidant flow capacity cannot support initial startup, based on identical sequencing (compositions, flows/unit cell area, rates) to previous 20-cell, 8- $\mathrm{ft}^{2}$ stacks. Alternative startup procedures may be possible.

- Existing oxidant flow capacity needs modification to support either ISU operation or highpower stand-alone operation. 
- Existing fuel and oxidant heaters have adequate design capacities for all but high-power stand-alone operation, but actual heater outputs from previous use do not approach design outputs.

- Purge gas capabilities need to be increased for all modes of operation.

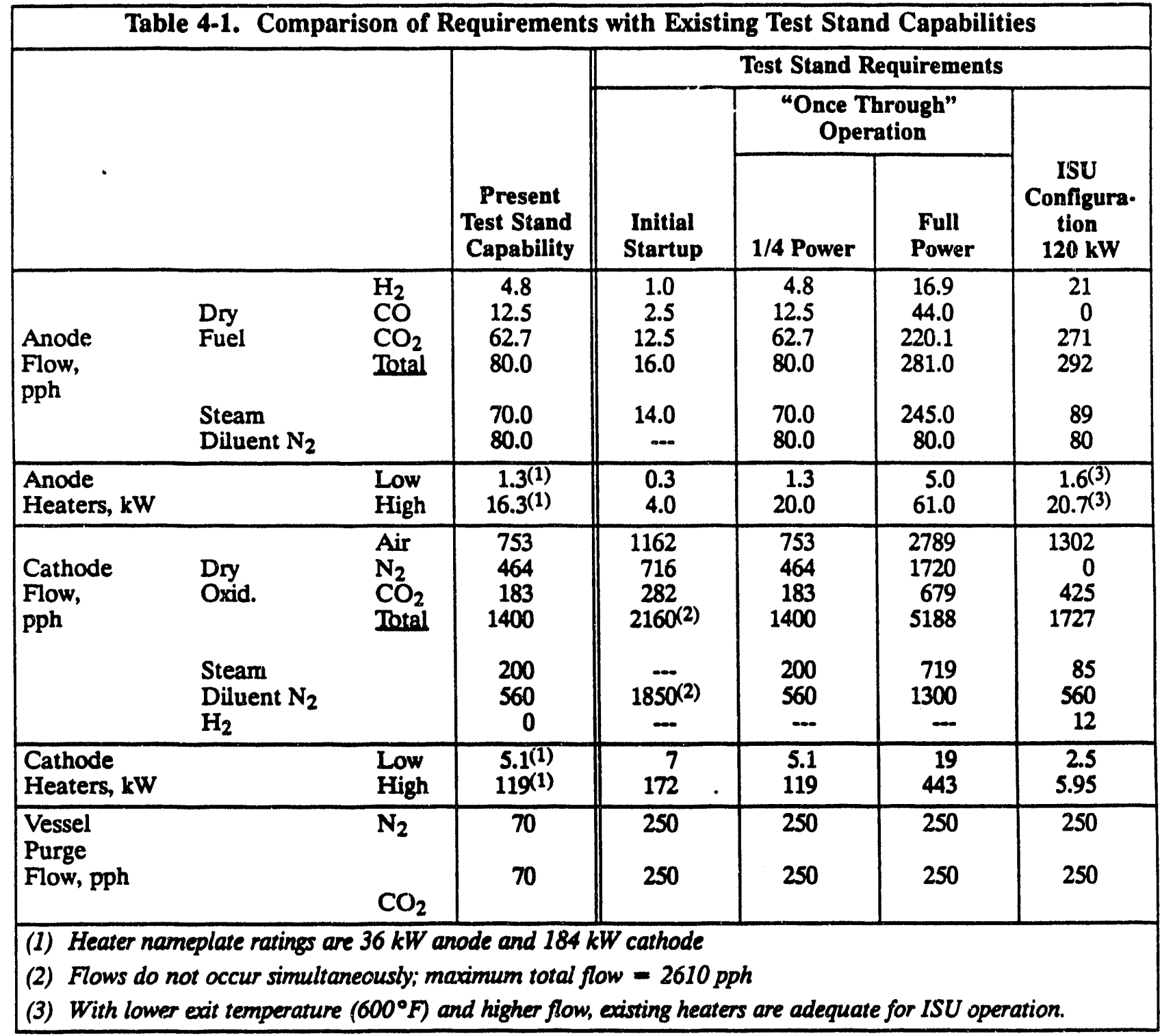

As a result of this analysis, effort was focused on defining an alternative initial conditioning and startup procedure for the 144-cell stack that minimized test stand modification requirements without added risk to the cell stack. The alternative procedure results in requiring the following modifications to the test facility process gases:

- Increase the oxidant-side diluent nitrogen supply to provide a maximum diluted oxidant flow of up to $2160 \mathrm{pph}$.

- Increase the fuel-side supply temperature or increase the heat transfer capability of one or more of the existing heater units. This ensures adequate inlet gas temperature to the stack with allowance for heat loss. 
Additionally, sources of the cathode-side heater losses were identified. These sources, and potential changes to mitigate the losses are as follows:

- Facility bus voltage lower than heater design. The design voltage is 480 volts, but the facility bus is typically lower. This is probably the most significant source of lost heater capacity, representing 25-50 percent of the total loss. This will be mitigated by changes to the facility transformer prior to the start of the test.

- Untuned controllers for several of the heater units, which result in clipping of a portion of the line voltage at maximum settings. The controllers will be tuned prior to the start of the test.

- Heat loss from the surface of the heater units. This effect was calculated to be small, and no modifications are planned.

- Heater degradation from previous use. No modifications are planned.

As a result of the heater investigation, the changes identified above will add $-15-20 \mathrm{~kW}$ heating capability, which will ensure adequate inlet gas temperatures to the stack with allowance for heat loss.

These studies indicated that significant modifications were needed on the cathode oxidant supply side to permit stack conditioning per a revised startup procedure closely paralleling the procedures used in the two previous 20 -cell stacks. Together with other modest modifications, this permitted operation of a stand-alone stack at up to $\sim 1 / 4$ power level. Still further significant modifications were needed to support operation of the ISU at powers up to $120 \mathrm{~kW}$.

Based on the above, it was decided to define a two-step modification approach requiring a reduced front-end level of expenditure to test the stack for integrity and functionality early in the program, followed by additional expenditures on the test stand to be able to demonstrate full ISU capacity and capability. Step A modifies the test facility to support initial startup and conditioning of the stand-alone stack and provides the capability to support subsequent steady-state operation of the stand-alone stack at $-1 / 4$ power $(-30 \mathrm{~kW})$. Step B subsequently modifies the test facility to support restart and steady state operation of the ISU at up to $120 \mathrm{~kW}$. All modifications in Step A are to be consistent with Step B requirements in order to avoid repetitive costs.

For: each phase, the requirements and modifications were identified. These were categorized according to the complete list of systems that are necessary to support the test facility. Figure 4-1 identifies the' test facility systems. For each system, the requirements for each phase were identified and revieved against the existing test facility capability. Assessment of these requirements versus capabilities resulted in a set of modifications for each system by phase. Table 4-2 lists the requirements and modifications for the supply support systems that include the fuel, oxidant, and vessel purge gas systems. Table 4-3 lists the requirements and modifications for the remaining support systems.

One remaining issue was the modification needed to provide emissions abatement during initial conditioning of the stack. This conditioning involves volatilization of the binder material used in tape casting the matrices. These binders are gradually volatilized into several hydrocarbon species during initial stack heatup and carried away with the oxidant-side gas flow used as the source of heat for startup. The larger size of the stack in this program requires changes to the test stand to ensure that the hydrocarbon debinding gases are not exhausted to the atmosphere.

The environmentally acceptable approach for abatement of such gaseous emissions is to destroy the hydrocarbons by complete oxidation to carbon dioxide and water vapor. Two approaches were considered: incineration and catalytic combustion. The former was selected as the preferred approach since it represents standard industry practice and design criteria that ensure complete destruction and are accepted by state and federal environmental agencies. 


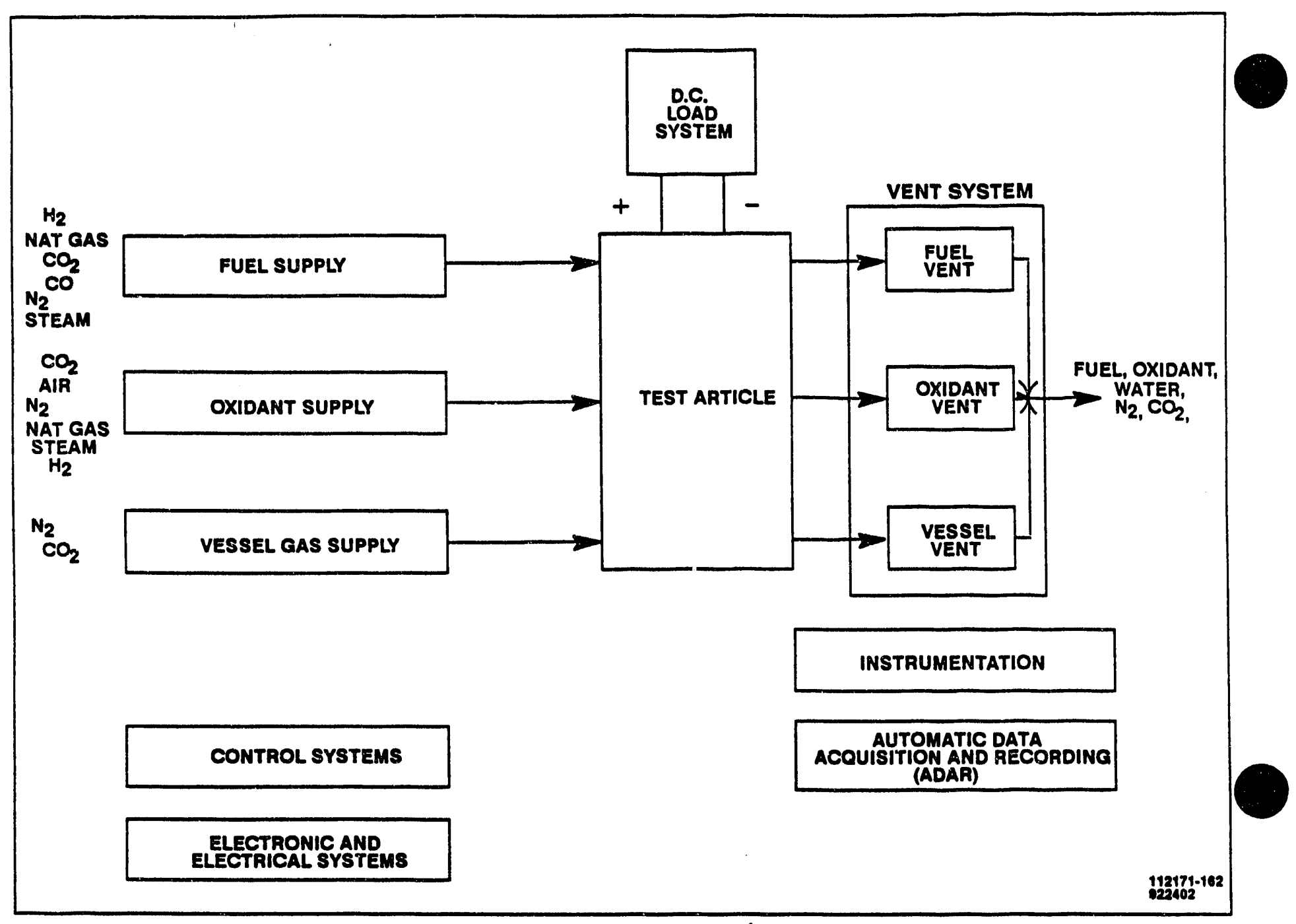

Figure 4-1. X-804 Test Facility Systems 


\begin{tabular}{|c|c|c|}
\hline \multicolumn{3}{|c|}{$\begin{array}{l}\text { Table 4-2. Modification Requirements for } \\
\text { Supply Systems: Fuel, Oxidant, Vessel Gas }\end{array}$} \\
\hline Supply System & \begin{tabular}{|c|} 
Step A \\
\end{tabular} & Step B \\
\hline $\begin{array}{l}\text { Fuel } \\
\text { - Requirements }\end{array}$ & $\begin{array}{l}\text { - Sufficient flow capacity of } \\
\text { all necessary gases } \\
\text { - Improve heat transfer of } 1 \text { or } \\
\text { more heaters for steady-state } \\
\text { operation }\end{array}$ & $\begin{array}{l}\text { - Increase capacity of fuel mix } \\
\text { station by } 4 \mathrm{X} \\
\text { - Increase steam \& } \mathrm{N}_{2} \text { capac- } \\
\text { ity } \\
\text { - Add } \mathrm{CH}_{4} \text { supply to stand }\end{array}$ \\
\hline $\begin{array}{l}\text { - Recommended } \\
\text { Modifications }\end{array}$ & $\begin{array}{l}\text { Modify heaters with } \\
\text { baffling }\end{array}$ & $\begin{array}{l}\text { Mix station - add new as } \\
\text { stand-alone facility } \\
\text { - Test stand - modify for in- } \\
\text { creased flow capacities (fuel } \\
\text { mix, steam, } \mathrm{N}_{2} \text { ) and add } \\
\mathrm{CH}_{4} \text { supply }\end{array}$ \\
\hline $\begin{array}{l}\text { Oxidant } \\
\text { - Requirements }\end{array}$ & $\begin{array}{l}\text { - Improve reliability of oxi- } \\
\text { dant mix station } \\
\text { - Increase } \mathrm{N}_{2} \text { capacity for ini- } \\
\text { tial startup } \\
\text { - Improve voltage to heaters } \\
\text { (See Electrical System, Table } \\
\text { 4-3) }\end{array}$ & $\begin{array}{l}\text { - Increase capacity of oxidant } \\
\text { mix station by } 2 \mathrm{X} \\
\text { - Increase steam capacity of } \\
\text { stand } \\
\text { - Add } \mathrm{CH}_{4}, \mathrm{H}_{2} \text { supply to } \\
\text { stand }\end{array}$ \\
\hline $\begin{array}{l}\text { - Recommended } \\
\text { Modifications }\end{array}$ & $\begin{array}{l}\text { Mix station - add new as } \\
\text { stand-alone facility suffi- } \\
\text { cient for Step B } \\
\text { - Test stand - modify for in- } \\
\text { creased flow capacities (oxi- } \\
\text { dant mix, } \mathrm{N}_{2} \text { ) } \\
\text { Other facilities - new } \mathrm{N}_{2} \text { sup- } \\
\text { ply line }\end{array}$ & $\begin{array}{l}\text { - Test stand } \\
\text { - modify for increased } \\
\text { steam } \\
\text { - add } \mathrm{H}_{2}, \mathrm{CH}_{4} \text { supply } \\
\end{array}$ \\
\hline $\begin{array}{l}\text { Vessel (Purge) Gas } \\
\text { - Requirements }\end{array}$ & - Increase $\mathrm{N}_{2} / \mathrm{CO}_{2}$ capacities & - Same capacities as Step A \\
\hline $\begin{array}{l}\text { Recommended } \\
\text { Modifications }\end{array}$ & $\begin{array}{l}\text { - Test stand - modify for in- } \\
\text { creased } \mathrm{N}_{2} / \mathrm{CO}_{2} \text { capacities }\end{array}$ & - No additional modifications \\
\hline
\end{tabular}




\begin{tabular}{|l|l|l|}
\hline \multicolumn{2}{|c|}{ Table 4-3. Modification Requirements for } \\
Other Systems
\end{tabular}


The requirements for operation of the incinerator, based on the revised startup procedure, exceeded the capabilities of the existing incinerators at IFC. Therefore, an investigation was made to further revise the startup procedure in a manner that reduces the oxidant flow rate to a level that permits utilization of an existing incinerator. Modifications to this incinerator to meet the requirements include extension of the combustion chamber to provide adequate residence time for the oxidant gases, addition of an aspirator-type burner at the base of the unit, and enlargement of the inlet piping to the burner. These modifications are considered minor.

This incinerator also provides insurance for Step B operation of the ISU. Tests of the ISU include several operating modes that are not representative of commercial-product operation, but will be necessary during testing to provide successive low-risk steps toward demonstrating the feasibility and complete functionality of the ISU. One of these test modes could result in significant quantities of $\mathrm{CO}$ exhausting the ISU. The use of the above incinerator during this test mode would ensure that the $\mathrm{CO}$ would be completely burned to $\mathrm{CO}_{2}$.

The design of the Step-A modifications to X-804 test stand was started. Figure 4-2 shows the schedule defining the four month design effort. 


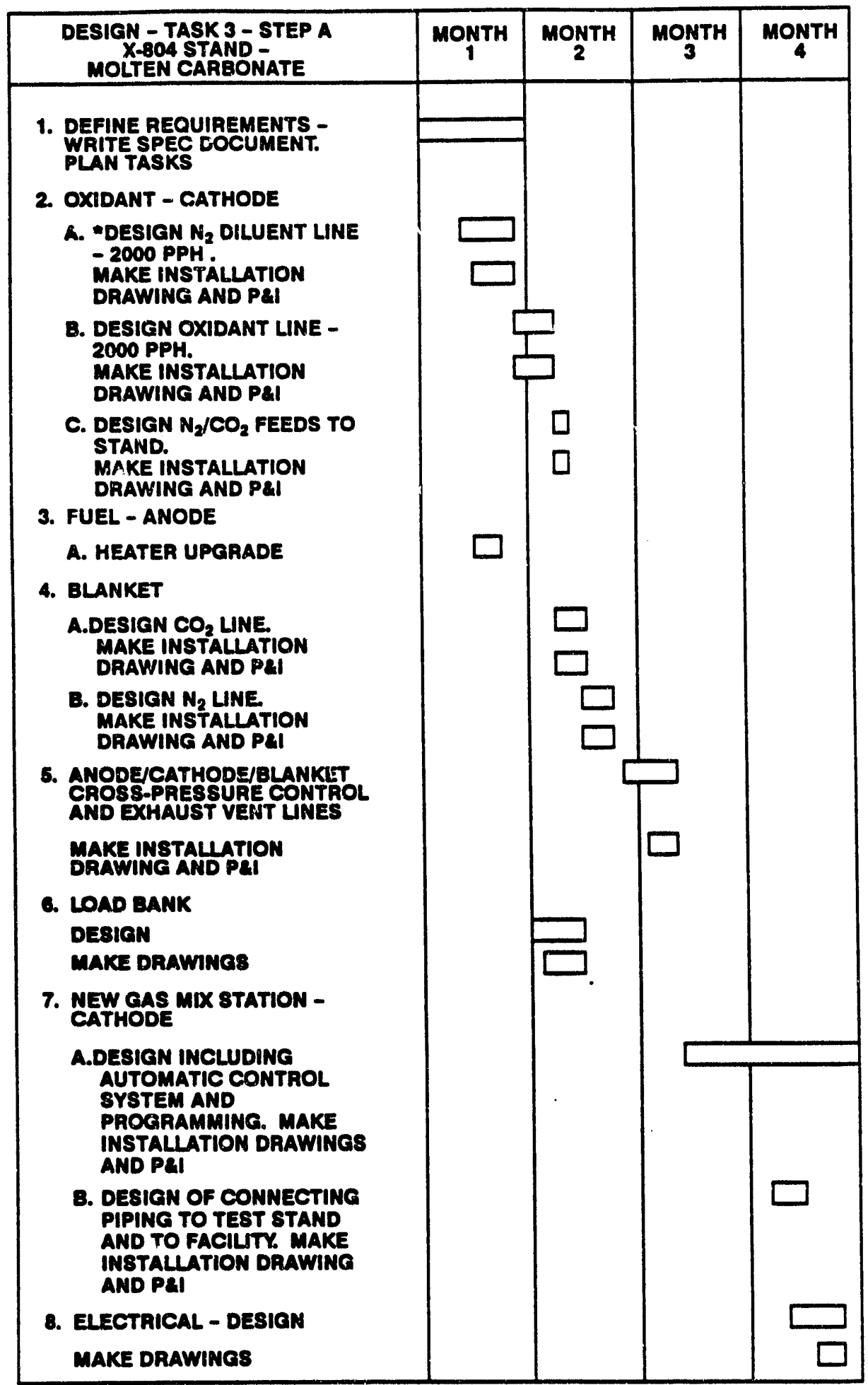

- ML THE DESIGN TASKS INCLUDE SYSTEM DEFINTTON, CALCULATNG SIZES OF LINES, VALVES, AND FLOWMETERS, SELECTION OF COMPONENTS, AND WRITING OF RPO'S.

Figure 4-2. Design Schedule and Subtask Definition 


\section{TASK 5 - REPEAT PART TECHNOLOGY DEVELOPMENT}

\section{Subtask 5.1 Cathode Life}

Objective - The objective of this subtask was to extend the life of molten carbonate fuel cells as affected by cathode dissolution. Electrolyte composition is varied to provide the maximum increase in endurance without adversely affecting performance or cost.

\section{Summary}

Post-test analyses were performed on five $4 \times 4$ inch single cells tested in the previous DOE contract. The data were used to verify the correlation between time-to-short and nickel content of the matrix structure for different cell configurations and electrolyte chemistries, including $\mathrm{Li} / \mathrm{Na}$ carbonate and $\mathrm{Li} / \mathrm{K}$ carbonate with $\mathrm{Ba}$ and $\mathrm{Rb}$ carbonate additives. Nickel content was measured using wet chemistry and electron microprobe scanning.

Much lower nickel content has been found in the matrices of IFC cells compared to those of other MCFC developers. The difference is believed to be due to the higher percentage of lithium carbonate in the electrolyte used by IFC.

\section{Report of Work}

Post-test analyses were conducted on several cells tested under the previous contract to evaluate the effects of cell configuration and electrolyte composition on performance and shorting time due to cathode dissolution. Although much post-test data on matrix nickel content are available on cells of the old IFC design, little data are available for the new design.

The data for the old design are presented, discussed, and correlated in swo publications included in this report as Appendices A and B:

Appendix A - "The Effects of Nickel Oxide Cathode Dissolution on Molten Carbonate Fuel Cell Life" Appendix B - "Variability in Nickel Oxide Cathode Dissolution in Molten Carbonate Fuel Cells"

Table 5.1-1 summarizes the test history and performance of the five cells tested in the previous program which were analyzed for post-test nickel under this contract.

Post-test analyses of matrix nickel were completed for Cell 724 and 730 of the new configuration. These were compared with the nickel content from previous cells of the old design. Both cells of the newer design were found to have about five times as much nickel in the matrix as the older cells after equivalent times. The major difference in these designs relating to nickel oxide dissolution, is that the cells were filled with a lower lithium carbonate/potassium carbonate molar ratio and the consumption of lithium carbonate was higher in the new cell design during the cell testing. A change in electrolyte composition from $72 \mathrm{~m} \%$ lithium carbonate $/ 28 \mathrm{~m} \%$ potassium carbonate to $50 \mathrm{~m} \%$ lithium carbonate $/ 50 \mathrm{~m} \%$ potassium carbonate results in an increase in nickel oxide solubility by a factor of about three or four based on data of Ota ${ }^{(1)}$ and Lee and Shores ${ }^{(2)}$.

(1) Ota, K Mitsushima, S., Kato, K and Kamiya, N., "Solubilities of Metal Oxides in Molten Carbonate," Proceedings of the Second Symposium on Molten Carbonate Fuel Cell Technology, The Electrochem. Soc. Proc. Vol. 90-16, pp 318 to 337, (1990).

(2) Lee, N.K and Shores D.A. "Transport Considerations in the Hot Corrosion of Ni by Molten Alkcali Carbonates," Jl. of the Electrochem. Soc., 137. pp 859 to 871 (1990). 


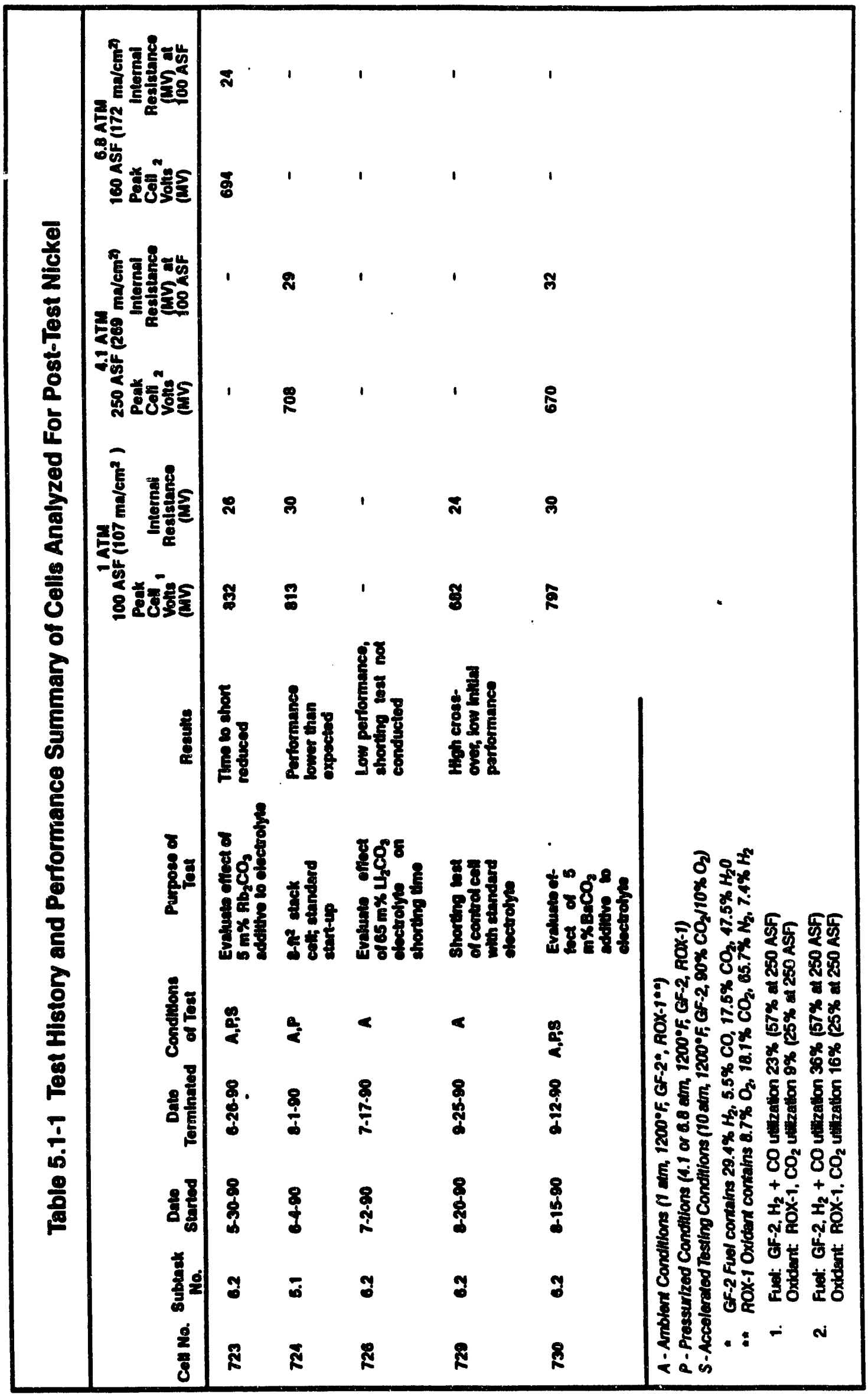


Since obtaining the nickel contents in post-test matrices of Cell 724 and 730 , a survey was made of post-test matrix nickel contents measured by other fuel cell developers. Data from IGT ${ }^{(3)}$ on matrix nickel content were about ten times higher than the old IFC data. Those data were found to be correlated reasonably well by a shorting theory developed at IFC. A comparison of the IGT and IFC data with the predictions of that correlation for $1200^{\circ} \mathrm{F}$ are shown in Figure 5.1-2.

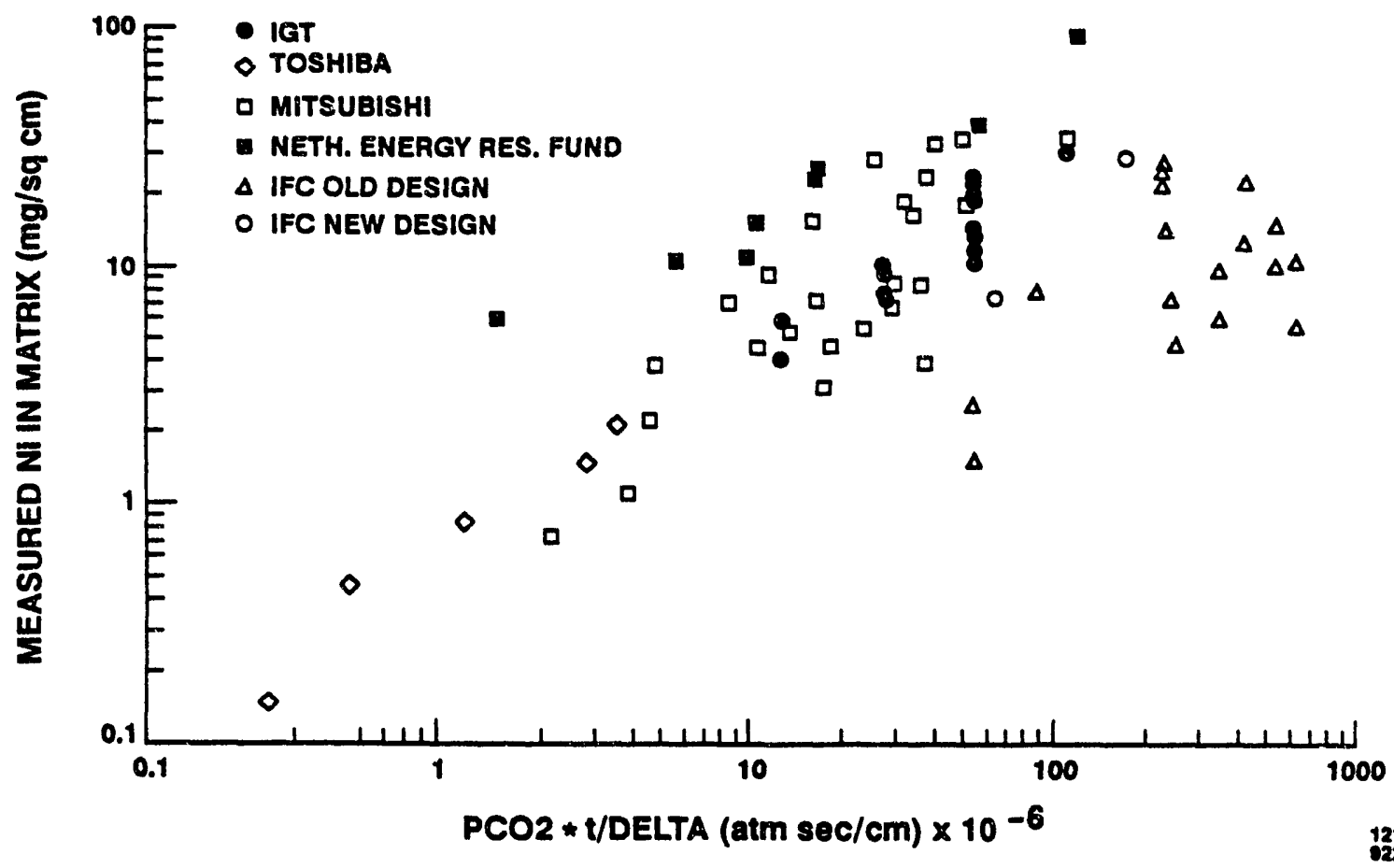

Figure 5.1-1. Experimental Values of Nickel Content in Post-Test Matrices at $1200^{\circ} \mathrm{F}$

Data from tests as long as 10,000 hours were available from Mitsubishi ${ }^{(4)}$ and as shown in Figure 5.1-3 were found to be five times higher than the IFC shorting correlation would predict if the operating current density is assumed to be $150 \mathrm{ma} / \mathrm{sq} \mathrm{cm}$ and the operating pressure one atmosphere (conditions of performance testing). These IGT, Mitsubishi, and Toshiba data ${ }^{(5)}$ have also been added to Figure 5.1-1. Using this correlation, the IGT and Mitsubishi nickel contents were both ten times higher than that of the old IFC design. Toshiba data were found to be 20 times that of the old design.

(3) Shores, D.A., Selman, J.R., and Ong, E.T. "Cathode Degradation, Final Report to Department of Energy, Morgantown Energy Technology Center," Contract DE-AC21-86MC23263 (1989).

(4) Thnaka, T, Saski, A., and Murahashi, T, "Development of Molten Carbonate Fuel Cell Stack at Mitsubishi Electric Corporation," Intersociety Energy Conversion Engineering Conference, 3, pp 1535 to 1540 (1989).

(5) Ogawa, T, Ohzu, H., Murata, K., ant Shirogami, T, "Effect of Alkaline-Earth Carbonates Addition on the Reduction of NiO Cathode Dissolution of Molten Carbonate Fuel Cell," The Electrochem. Soc., Extended Abstracts, 87-2, pp 283 to 284 (1987). 


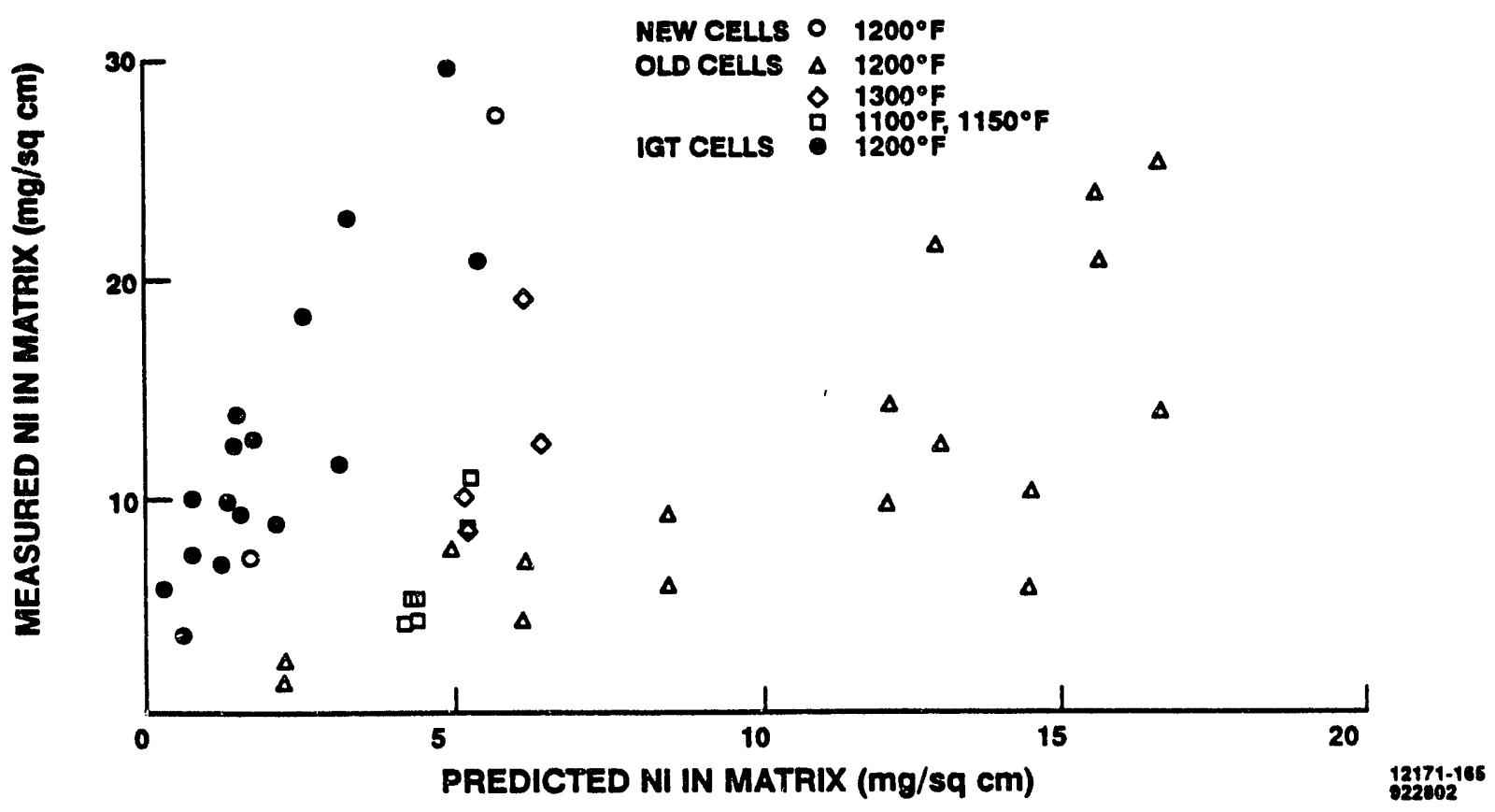

Figure 5.1-2. Comparison of Post-Test Matrix Nickel Content With Predicted Content From Simpler Shorting Theory at $1200^{\circ} \mathrm{F}$

Experimental data on nickel content in post-test matrices from the Netherlands Energy Research Foundation ${ }^{(6)}$ were also compared with data from IFC. The NERF nickel contents were the highest of all the sources, as shown in Figure 5.1-1. Much of the nickel was found close to the cathode. Nickel that close to the cathode may not have been included in the analyses from other sources since they may have considered this nickel to be part of the cathode.

These comparisons indicate that other developers experience about ten times the matrix nickel buildup seen by IFC. No data are available to indicate that this much higher nickel content results in a much higher performance decay rate. Since all developers except IFC use the $62 \mathrm{~m} \%$ lithium carbonate, $38 \mathrm{~m} \%$ potassium carbonate eutectic electrolyte, the lithium rich electrolyte used by IFC may be the reason for this difference. The larger electrolyte volume and the absence of corrosion layers on the anode side of IFC's old cell design both help maintain a higher lithium carbonate content.

(6) Veldhuis, J.B.J., van der Molen, S.E., Makkus, R.C., and Broers, G.H.J., "NiO Cathode Dissolution and Long Term MCFC Operation," Ber. Bunsen - Ges. Phys. Chem., 24, pp 947 to 952 (1990). 


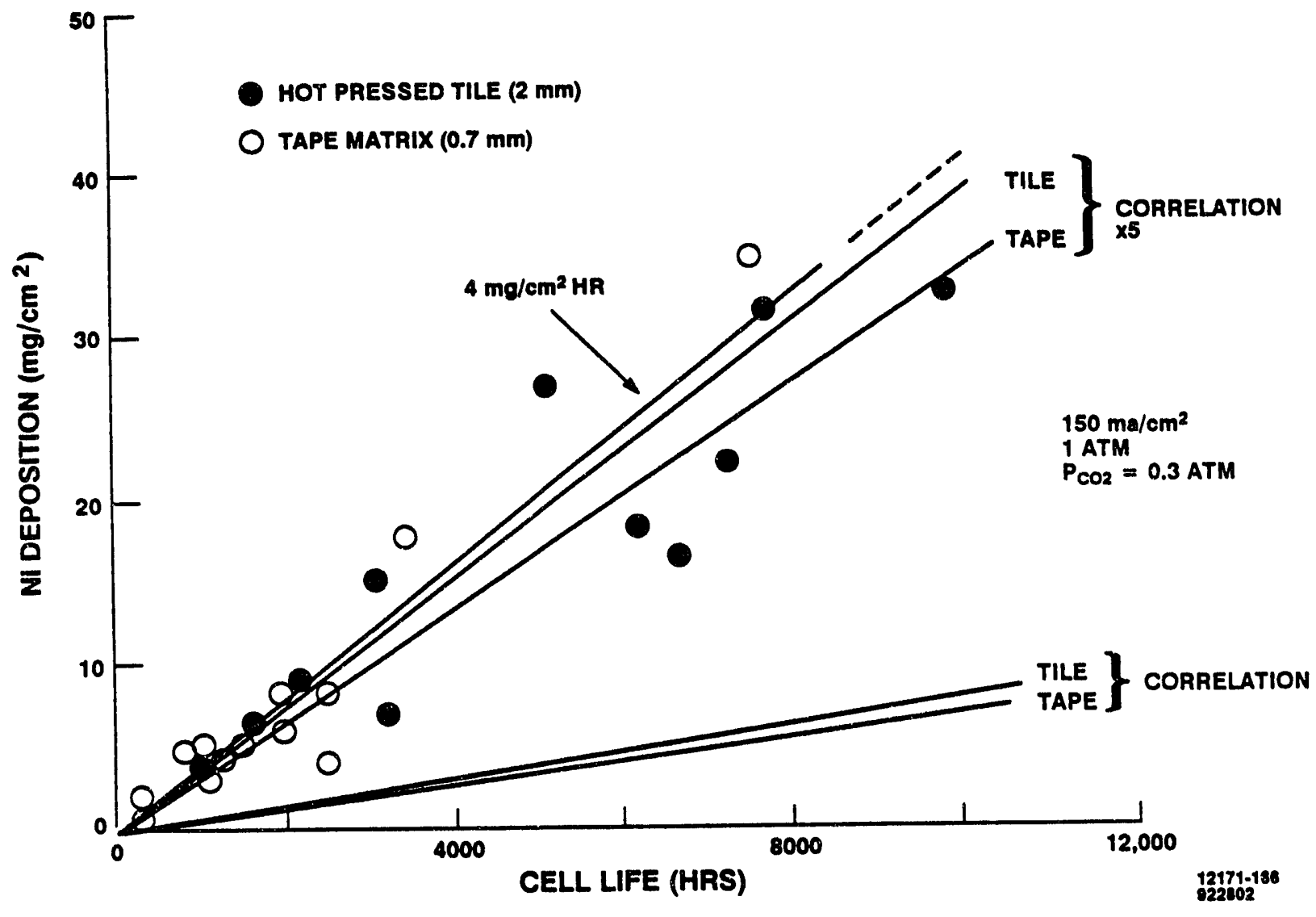

Figure 5.1-3. Nickel Deposited in Tile or Matrix

Cell 729 was tested under the previous contract as a control cell with no electrolyte additive. The build was a standard cell except that the anode was thicker to provide additional electrolyte reservoir volume. The electrolyte was $71.4 \mathrm{~m} \% \mathrm{LiCO}_{3}-28.6 \mathrm{~m} \% \mathrm{~K}_{2} \mathrm{CO}_{3}$. Test duration was 853 hours; 246 hours were under accelerated shorting conditions, 150 psia at $90 \% \mathrm{CO}_{2}-10 \% \mathrm{O}_{2}$.

The cell package separated at the anode-matrix interface during disassembly. Sections of the matrix and cathode were cut from the fuel in-air in and fuel out-air out corners for metallographic examination. Results are summarized in Table 5.1-2.

\begin{tabular}{|l|c|c|}
\hline \multicolumn{2}{|c|}{ Table 5.1-2. Metallographic Examination of Cell 729 } \\
\hline & Fuel In-Air In & Fuel Out-Air Out \\
\hline Matrix thickness (mils) & 19.8 & 17.1 \\
\hline Cathode Thickness: & 15.0 & 8.8 \\
\hline Under current collector (mils) & 27.5 & 25.6 \\
\hline Gas field (mils) & & 0.5 \\
\hline Current Collector Corrosion: & 0.5 & 0.9 \\
\hline Oxide penetration (mils) & 0.7 & \\
\hline Oxide thickness (mils) & & \\
\hline
\end{tabular}


The thickness data indicates that the applied mechanical load was skewed during testing. Nickel deposition appeared to vary based on the contact between the matrix and cathode. Nickel deposition was heaviest in regions under the cathode current collector, where the cathode was compacted and in intimate contact with the matrix. The matrix in regions where the cathode bulged out into the gas flow field was relatively clean, showing primarily a rust-colored deposit adjacent to the cathode. These samples were submitted to the United Technologies Research Center (UTRC) for microprobe analysis. Additional samples were submitted for chemical analysis as a calibration of the microprobe results.

Three separate scans were taken on each metallographic section in $10 \mu$ steps. The scan was extended into the cathode and the nickel intensity in the cathode was used as an internal calibration. The nickel content of each cathode section was calculated using pre-test porosity data and the measured post-test thickness. The microprobe data are summarized in Figures 5.1-4 (Specimen No. 6551 - fuel out-air out) and 5.1-5 (Specimen No. 6552 - fuel in - air in). Data are plotted as cumulative counts for each of the scans and show good uniformity. Nickel content of the matrix was estimated based on the measured $x$-ray intensity relative to the cathode peak. Calculated nickel contents are given in Table 5.1-3.

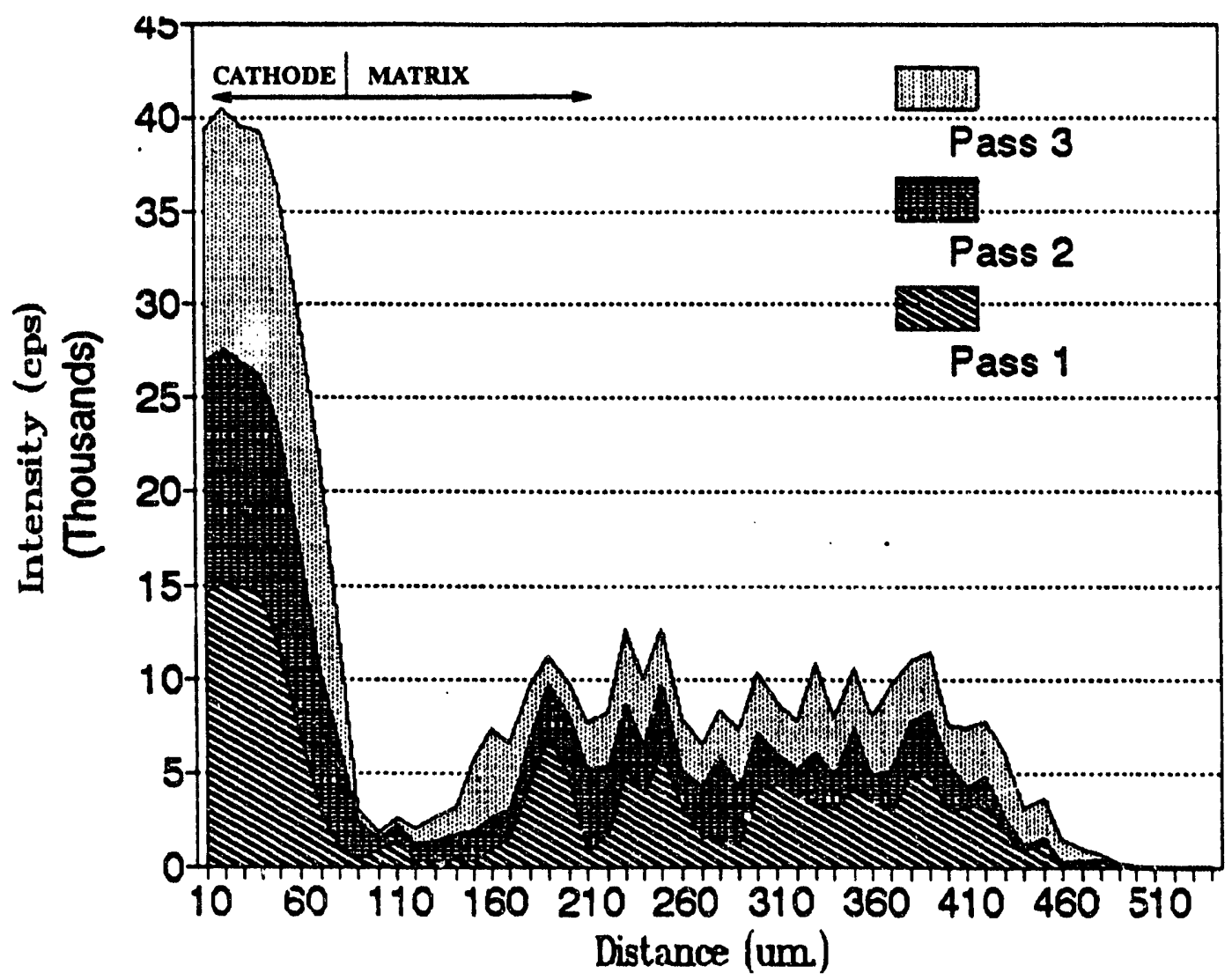

Figure 5.1-4. Cell 729, Specimen No. 6551 - Fuel Out-Air Out 


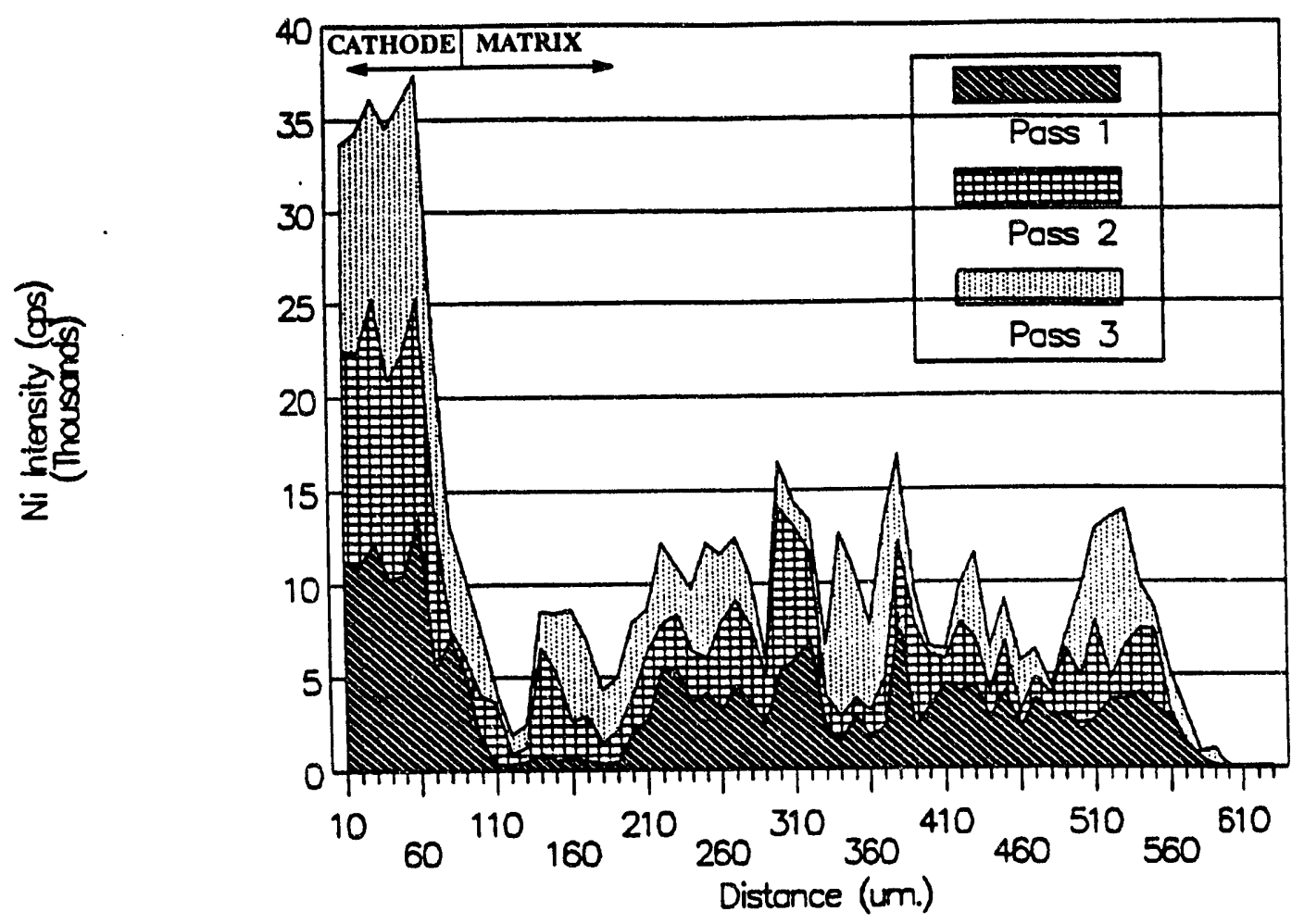

Figure 5.1-5. Cell 729, Specimen No. 6552 - Fuel In-Air In

\begin{tabular}{|l|c|c|}
\hline \multicolumn{3}{|c|}{ Table 5.1-3. Microprobe Characterization of Cell 729 } \\
\hline \multicolumn{1}{|c|}{ Section } & Milligrams Ni/cm ${ }^{2}$ & Grams Ni/cm \\
\hline Fuel out - air out & 22.7 & .522 \\
\hline Fuel in - air in & 28.7 & .570 \\
\hline
\end{tabular}

Chemical analysis of Cell 729 was also completed. Samples of the anode, matrix, and cathode were water-leached to determine electrolyte content at shut down. Lithium, potassium, and carbonate ions were measured independently using a Dionex 2010i ion chromatograph. Data are summarized in Table 5.1-4. With the exception of the anode sample, agreement between the two sets of data was not good. The ranges shown are calculated using the two data sets.

\begin{tabular}{|c|c|c|c|c|}
\hline \multicolumn{5}{|c|}{ Table 5.1-4. Chemical Analysis of Cell 729 } \\
\hline Component & $\begin{array}{c}\text { Electrolyte Fill } \\
(\mathbf{\%})\end{array}$ & $\begin{array}{c}\text { Molar Ratio } \\
\text { Li:K }\end{array}$ & $\begin{array}{c}\text { Post Test Grams } \\
\text { Electrolyte }\end{array}$ & $\begin{array}{c}\text { Initial Grams } \\
\text { Electrolyte }\end{array}$ \\
\hline Anode & 18 & 2.2 & 1.4 & 4.7 \\
\hline Matrix & $73-98$ & $1.9-2.6$ & $4.4-5.9$ & 6.4 \\
\hline Cathode & $50-66$ & $2.0-3.0$ & $1.7-2.3$ & 1.2 \\
\hline & & & $7.5-9.6$ & 12.3 \\
\hline
\end{tabular}


The variation in matrix fill probably reflects variation in compaction of the actual sample analyzed. Based on the electrode fills and duration of the test, no matrix dry.out was expected. The high fill of the cathode suggests some dewetting of the anode. This may have been aided by the crushing of the cathode, forming smaller pores. These data suggest an electrolyte loss rate of 3.2 to 5.6 grams/1000 hours, compared to a "typical" value of 3.1 grams/1000 hours. The performance history of this cell indicated that cathode flooding had occurred. Cell 726 was a test of $65 \mathrm{~m} \% \mathrm{Li}_{2} \mathrm{CO}_{3}-35 \mathrm{~m} \% \mathrm{Na}_{2} \mathrm{CO}_{3}$ electrolyte. The cell was a poor performer; initial cell voltage was $525 \mathrm{mV}$ at $100 \mathrm{ASF}$. Current load was backed off to maintain cell voltage at $\sim 750 \mathrm{mV}$. At 134 hours, the cell was conditioned under MCO-D for one hour. The poor performance was attributed to incomplete melting of the electrolyte, and the cell was heated to $1350^{\circ} \mathrm{F}\left(730^{\circ} \mathrm{C}\right)$ for four hours. The cell still would not hold load at $100 \mathrm{ASF}$, and testing was terminated after 305 hours. Microprobe traces showed essentially no nickel deposited in the matrix, as illustrated in Figure 5.1-6.

Cell 730 was built to evaluate the effect of a $5 \mathrm{~m} \% \mathrm{BaCO}_{3}$ addition to the electrolyte on cathode life. The cell was a slow starter, $664 \mathrm{mV}$ at 100 ASF, but improved gradually over the first week of testing to $\sim 800 \mathrm{mV}$. At 336 hours, the test was placed on accelerated conditions, 150 psia of 90 percent $\mathrm{CO}_{2}$ and 10 percent $\mathrm{O}_{2}$. Nickel shorting was monitored by tracking the open circuit voltage (OCV). The OCV on accelerated conditions was $1066 \mathrm{mV}$ and droppe to $995 \mathrm{mV}$ over 250 hours. Testing was terminated after 652 hours on load ( 250 hours under acc srated conditions).

Representative areas of the matrix were characterized on the electron microprobe. Scans were taken across the matrix in regions where the cathode was compacted under the current collector and in regions where the cathode had extruded into the gas flow field, See Figure 5.1-7.

The traces were extended into the cathode to provide an internal calibration point for nickel content. Nickel in the matrix was estimated based on the ratio of the nickel $x$-ray peaks relative to those from the cathode. Nickel loading in the cathode was calculated based on measured post-test porosity. Results are summarized in Table 5.1-5. The amount of scatter is reasonable given the localized nature of the microprobe measurements. A representative profile in shown in Figure 5.1-8. 


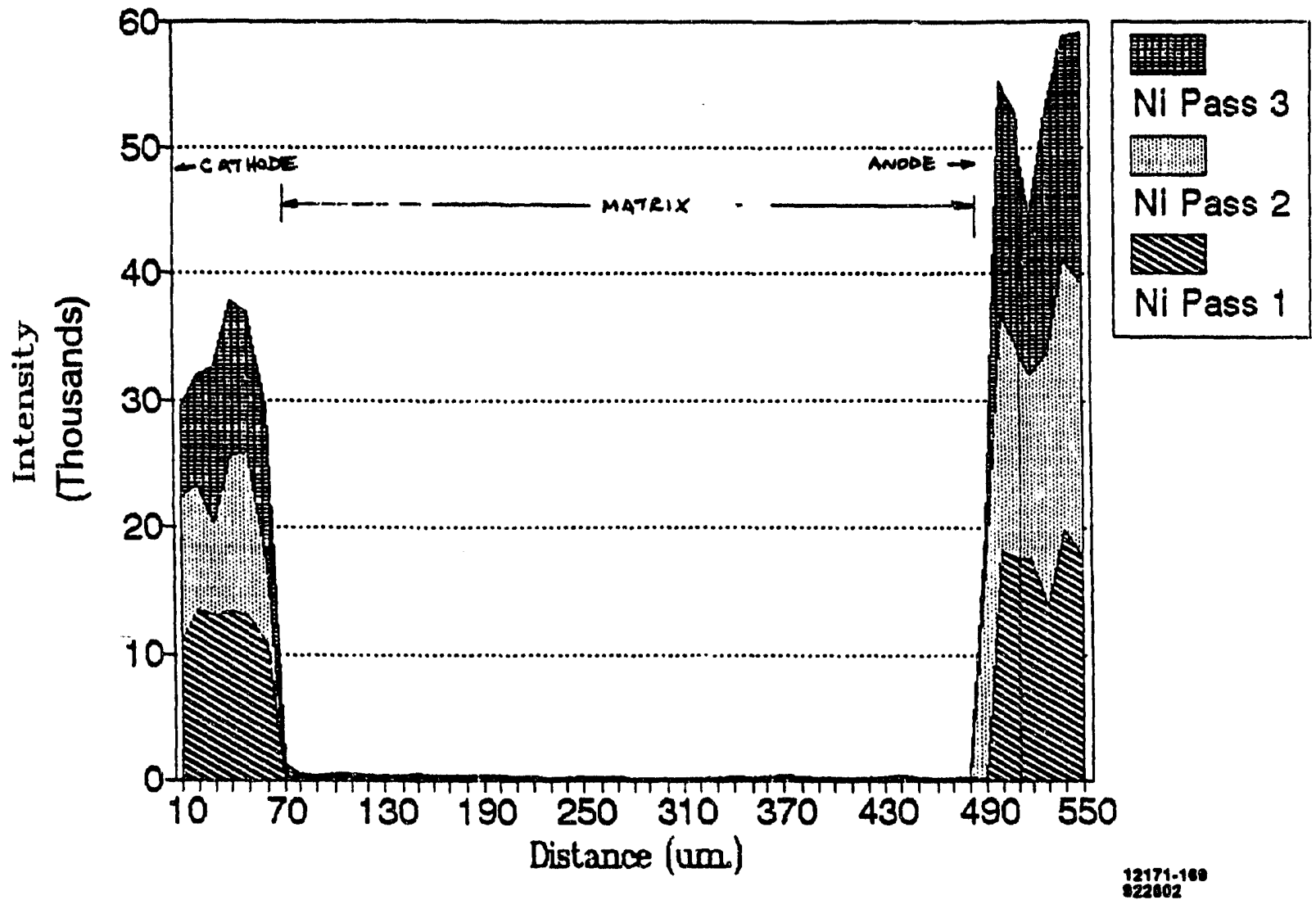

Figure 5.1-6. Cell 726, Cumulative Nickel Profiles for Multiple Passes

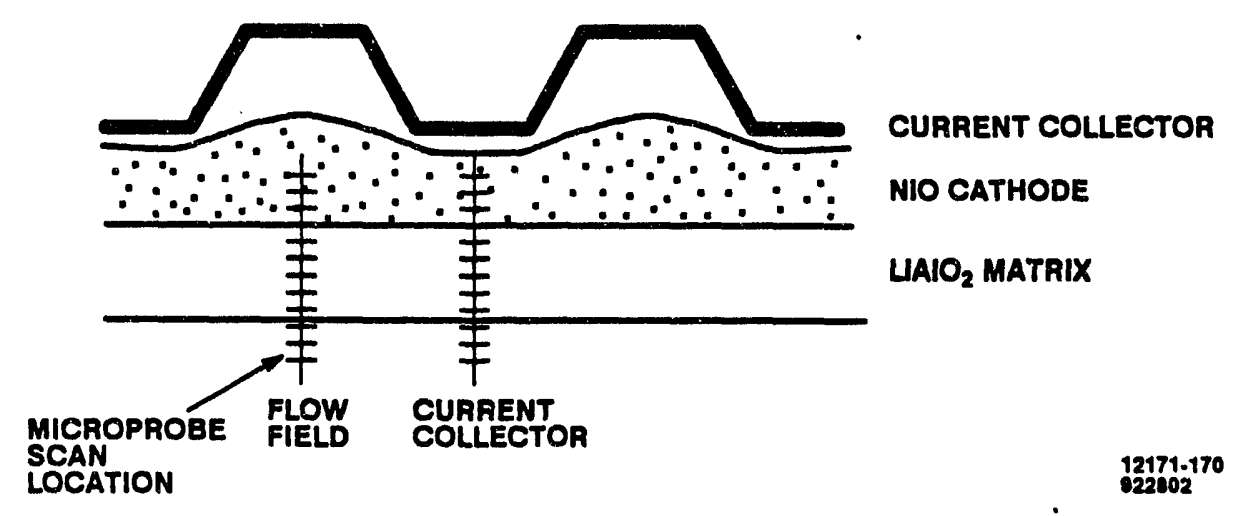

Figure 5.1-7. Microprobe Analysis of Cell 730 Matrix 


\begin{tabular}{|c|c|c|}
\hline \multirow[b]{2}{*}{ Location } & \multicolumn{2}{|c|}{ Nickel Loading } \\
\hline & $\mathrm{gm} / \mathrm{cm}^{3}$ & $\mathrm{mg} / \mathrm{cm}^{2}$ \\
\hline Current collector & 1.04 & 47.0 \\
\hline Flow field & 0.43 & 19.4 \\
\hline Current collector & 0.76 & 34.4 \\
\hline Flow field & 0.94 & 42.5 \\
\hline
\end{tabular}

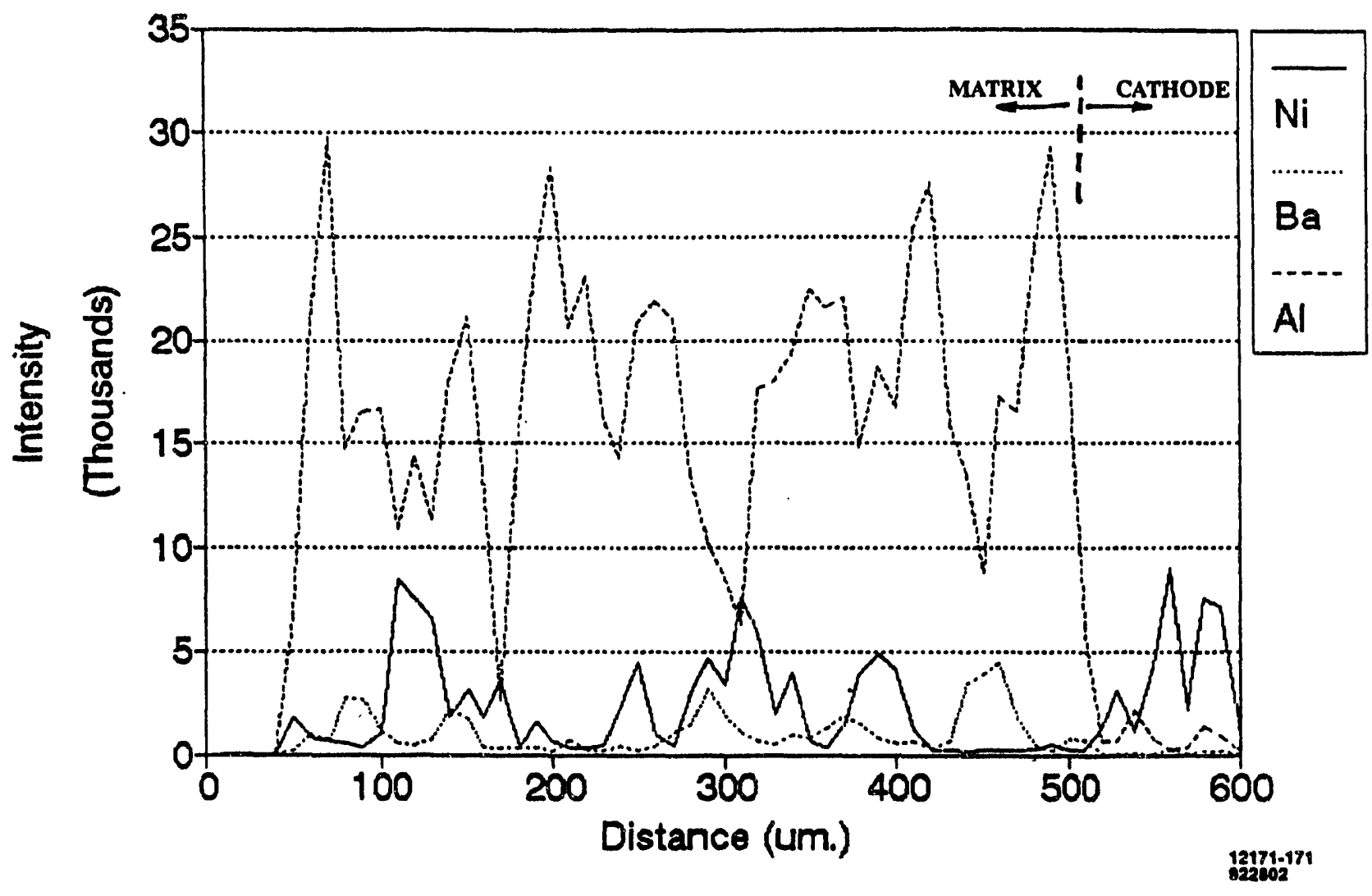

Figure 5.1-8. Elemental Traces from Cell 730 Matrix

Samples of the matrix were washed in $70 \mathrm{v} \%$ acetic acid - acetic and hydride to leach carbonates. The solid residue was analyzed for deposited metals. Results are summarized in Table 5.1-6.

\begin{tabular}{|l|c|}
\hline \multicolumn{2}{|c|}{ Table 5.1-6. Chemical Analysis of Cell 730 Matrix } \\
\hline \multicolumn{1}{|c|}{ Metal } & Concentration, $\mathbf{~ m g} / \mathrm{cm}^{2}$ \\
\hline Nickel & 27.6 \\
\hline Chromium & 3.6 \\
\hline Barium & 2.9 \\
\hline
\end{tabular}


The average nickel content for the microprobe measurements was $35.8 \mathrm{mg} / \mathrm{cm}^{2}$. Agreement with the chemistry results is considered reasonable given the localized nature of the measurements. The level of barium detected in the matrix solids was unexpected. Based on the post-test matrix porosity (estimated from metallographic measurements), the barium content was equivalent to $5 \mathrm{~m} \% \mathrm{BaCO}_{3}$. However, if the barium was present as a carbonate, the acetic acid wash should have dissolved the material. This suggests that the $\mathrm{BaCO}_{3}$ either reacted during testing to form an insoluble compound or precipitated during the acid wash.

Scanning electron microprobe data were obtained on post-test samples of Cell 723 that was tested to determine the effect of $5 \mathrm{~m} \%$ rubidium carbonate on shorting time. The rubidium was added to the cell to prevent nickel oxide from precipitating in the cell matrix near the cathode, thereby, preventing shorting or extending the shorting time. Although at one location no nickel was found in the matrix on the cathode side, at other locations the nickel was nearer the cathode or in the central region of the matrix. At some locations, a rubidium-rich layer existed on the surface of the cathode.

Standard samples were prepared to calibrate the microprobe measurements by pressing $\mathrm{LiAlO}_{2}$ wa. fers with measured amounts of added nickel. Samples were prepared with nominal loadings of 10 and $50 \mathrm{mg} / \mathrm{cm}^{2}$. The standard $\mathrm{LiAlO}_{2}$ wafers were sandwiched between porous nickel plaques of known porosity. Microprobe traces were prepared using the same procedures developed for the analysis of post-test cell sampls.s. Nickel content of the cathode was calculated using the measured porosity. The nickel content of the matrix was calculated based on the weight of nickel added and the measurer volume of the pressed wafer. Microprobe estimates of nickel in the matrix were determined using the calculated loading of the cathodes as an internal calibration and taking the ratio of $x$-ray peaks from the matrix relative to those obtained from the cathode. Results are summarized in Table 5.1-7.

\begin{tabular}{|l|c|c|}
\hline \multicolumn{3}{|c|}{$\begin{array}{l}\text { Table 5.1-7. Comparison of Calculated and } \\
\text { Measured Nickel Loadings in LiA102 Wafers }\end{array}$} \\
\hline Nominal Loading & Calculated & Microprobe \\
\hline $10 \mathrm{mg} / \mathrm{cm}^{2}$ & 9.7 & 17.1 \\
\hline $50 \mathrm{mg} / \mathrm{cm}^{2}$ & $49.5 \cdot$ & 61.7 \\
\hline
\end{tabular}

These results suggest a bias in the reported microprobe data. This anomaly is not yet resolved. 


\section{Subtask 5.2 Single Cell Testing}

Objective - The objective of this subtask was to evaluate the repeat part technology improvements being developed under Task 5 . One or more single cells were to be tested and analyzed to compare their performance against design objectives.

\section{Summary}

A cell was tested using $65 \mathrm{~m} \%$ lithium carbonate, $35 \mathrm{~m} \%$ sodium carbonate electrolyte. Although the initial performance of this cell was good, considerable decay occurred, possibly due to dewetting of the anode. An accelerated shorting test was performed, but the results are considered to be questionable because of crossover present in the cell.

\section{Report Of Work}

Cell 738 was initiated to evaluate the effect of a $65 \mathrm{~m} \% \mathrm{Li}_{2} \mathrm{CO}_{3}-35 \mathrm{~m} \% \mathrm{Na}_{2} \mathrm{CO}_{3}$ electrolyte composition on nickel oxide dissolution and cell shorting. In the previous contract, an electrolyte comprising $70 \mathrm{~m} \% \mathrm{Li}_{2} \mathrm{CO}_{3}-30 \mathrm{~m} \% \mathrm{Na}_{2} \mathrm{CO}_{3}$ was found to extend cell life by 50 percent. However, this electrolyte composition resulted in poor performance below $1200^{\circ} \mathrm{F}$. An electrolyte containing $60 \mathrm{~m} \% \mathrm{Li}_{2} \mathrm{CO}_{3}$ $40 \mathrm{~m} \% \mathrm{Na}_{2} \mathrm{CO}_{3}$ did not result in an increased time to cell shorting, but showed low temperature $\left(<1200^{\circ} \mathrm{F}\right.$ ) performance comparable to standard lithium-potassium compositions. A 65-35 mix was selected as a compromise offering the potential of both increased time to shorting and acceptable low temperature performance.

The test plan is provided in Table 5.2-1. Initial performance was good, $829 \mathrm{mV}$ at 100 ASF under 15 psia of GF-2 fuel and ROX-1 oxidant. Reactant compositions are given in Tables 5.2-2 and 5.2-3. Internal resistance losses were $22 \mathrm{mV}$ at $100 \mathrm{ASF}$. These results compare favorably with standard lithium-potassium cells reported under Subtask 2.2. However, open circuit voltage was depressed by $-3 \mathrm{mV}$ below theoretical. Checks for cell crossover and leakage indicated $15 \mathrm{ccm}$ of crossover and 700 $\mathrm{ccm}$ of overboard oxidant leakage. The high oxidant leakage was evident in diagnostic tests showing a very high oxidant utilization effect. 


\begin{tabular}{|c|c|}
\hline Start-Up & Standard procedure. \\
\hline $0 \cdot 100$ Hours & $\begin{array}{l}1 \text { atm pressure, } 1200 \mathrm{~F} \text { cell temperature } \\
\text { Fuel: GF-2; set flows for } \mathrm{U}\left(\mathrm{H}_{2}+\mathrm{CO}\right)=56.7 \% \text { at } 250 \mathrm{ASF} \text {. } \\
\text { Oxidant: } \mathrm{ROX}-1 \text {; set flows for } \mathrm{U}\left(\mathrm{CO}_{2}\right)=25 \% \text { at } 250 \mathrm{ASF} \text {. } \\
\text { Set load at } 160 \text { ASF. Measure cell voltage, OCV, iR. }\end{array}$ \\
\hline 100 Hours & $\begin{array}{l}\text { Change oxidant to } 3000 \mathrm{ccm} \text { dry MCO-D for one-half hour, return to } \\
\text { ROX-1, wait at least six hours then take diagnostics at highest possible } \\
\text { current density. Return to previous conditions. }\end{array}$ \\
\hline 150 Hours & $\begin{array}{l}\text { Measure cell voltage and iR at } 250 \text { ASF. Check for crossover. Obtain } \\
\text { E-I plots to } 250 \mathrm{ASF} \text { on both GF-2 and lean fuel as the fuels and ROX-1, } \\
\text { ROX-3, and other oxidant mixtures as the oxidants. }\end{array}$ \\
\hline 200 Hours & $\begin{array}{l}\text { Pressurize cell to } 60 \text { psia, set } 250 \text { ASF load and measure cell voltage, } \\
\text { OCV, and iR. Take diagnostics at highest practical current density and } \\
\text { repeat E-I plots including additional oxidant mixtures. Obtain an E-I } \\
\text { plot on lean fuel and ROX-3 at } 1200 \mathrm{~F}, 1100 \mathrm{~F}, 1200 \mathrm{~F}, 1300 \mathrm{~F} \text {, and } 1200 \mathrm{~F} \text {. }\end{array}$ \\
\hline 250 Hours & $\begin{array}{l}\text { Pressurize cell to } 10 \text { atm. and set load at } 160 \text { ASF. Measure OCV, cell } \\
\text { voltage, and iR at } 250 \text { ASF. Obtain E-I plots to } 250 \text { ASF on GF-2 and } \\
\text { lean fuel on ROX-3 oxidant. Change oxidant to } 90 \text { percent carbon diox- } \\
\text { ide/10 percent oxygen and set flows for a carbon dioxide utilization of } 10 \\
\text { percent at } 250 \text { ASF. Change GF-2 fuel flow for a hydrogen plus carbon } \\
\text { monoxide utilization of } 15 \text { percent at } 250 \text { ASF. Set } 160 \text { ASF load and } \\
\text { monitor the OCV. Return to ambient conditions after the OCV drops by } \\
\text { more than } 20 \mathrm{mV} \text {. }\end{array}$ \\
\hline
\end{tabular}

\begin{tabular}{|c|c|c|c|c|c|}
\hline \multicolumn{6}{|c|}{ Table 5.2-2. Fuel Compositions } \\
\hline Mole \% & $\mathbf{H _ { 2 }}$ & CO & $\mathrm{CO}_{2}$ & $\mathrm{H}_{2} \mathrm{O}$ & $\mathbf{N}_{\mathbf{2}}$ \\
\hline GF-2 & 29.4 & 5.5 & 17.5 & 47.6 & 0 \\
\hline Lean Fuel & 6.7 & 4.8 & 33.2 & 24.0 & 31.3 \\
\hline
\end{tabular}

\begin{tabular}{|c|c|c|c|c|c|}
\hline Mole \% & $\mathbf{O}_{2}$ & $\mathrm{CO}_{2}$ & $\mathbf{N}_{2}$ & He & $\mathrm{H}_{2} \mathrm{O}$ \\
\hline ROX-1 & 8.8 & 18.0 & 65.7 & -- & 7.5 \\
\hline ROX-3 & 10.7 & 8.2 & 73.6 & -- & 7.5 \\
\hline ROX-5 & 21.6 & 4.1 & 66.8 & -- & 7.5 \\
\hline ROX-6 & 10.7 & 4.1 & 77.7 & .. & 7.5 \\
\hline $\mathrm{ROX}-\mathrm{He}$ & 8.8 & 18.0 & -- & 65.7 & 7.5 \\
\hline $\mathrm{ROX}-3 / \mathrm{He}$ & 10.7 & 8.2 & - & 73.6 & 7.5 \\
\hline
\end{tabular}

The test was pressurized to $60 \mathrm{psia}$ and additional diagnostic and performance checks were run to determine if the cell shorting test objectives could be met. Deviation of the open circuit voltage from theoretical at pressure remained constant. No serious problems were encountered in controlling the test despite the high overboard leakage. Observed cathode utilization losses dropped from $50 \mathrm{mV}$ at 
15 psia to $11 \mathrm{mV}$ at $60 \mathrm{psia}$, compared to a theoretical value of $6 \mathrm{mV}$. Performance data on various fuel and oxidant mixtures are summarized in Figures 5.2-1 through 5.2-3.

Figure 5.2-1 shows that at high current density, 250 ASF, cell performance under both GF-2 and lean fuel is higher for ROX-3 oxidant gas, which has a lower $\mathrm{CO}_{2}$ content than ROX-1 oxidant. Figure 5.2-2 shows that significant gas-phase diffusional losses are present in the cathode since replacing the nitrogen diluent with helium results in improved performance. Cell polarization, corrected for $\mathrm{iR}$ and utilization losses, was reduced under the helium diluent by 25 to $30 \mathrm{mV}$ at $200 \mathrm{ASF}$.

Figure 5.2-3 shows the performance curves on oxidant mixes with a range of oxygen and carbon dioxide contents. Measured cell polarization data were corrected for theoretical utilization effects. The results were plotted as a function of the log mean carbon dioxide content at a load of 200 ASF in Figure 5.2-4. The minimum polarization occurs at a $\mathrm{CO}_{2}$ content of $<10$ percent in the oxidant with approximately 9 percent oxygen. These data confirm that cells using $\mathrm{Li} / \mathrm{Na}$ electrolytes can be operated on oxidants low in carbon dioxide to extend cathode life, similar to $\mathrm{Li} / \mathrm{K}$ electrolytes. The low $\mathrm{CO}_{2}$ contents extend cathode life by reducing the solubility of nickel oxide in the melt.

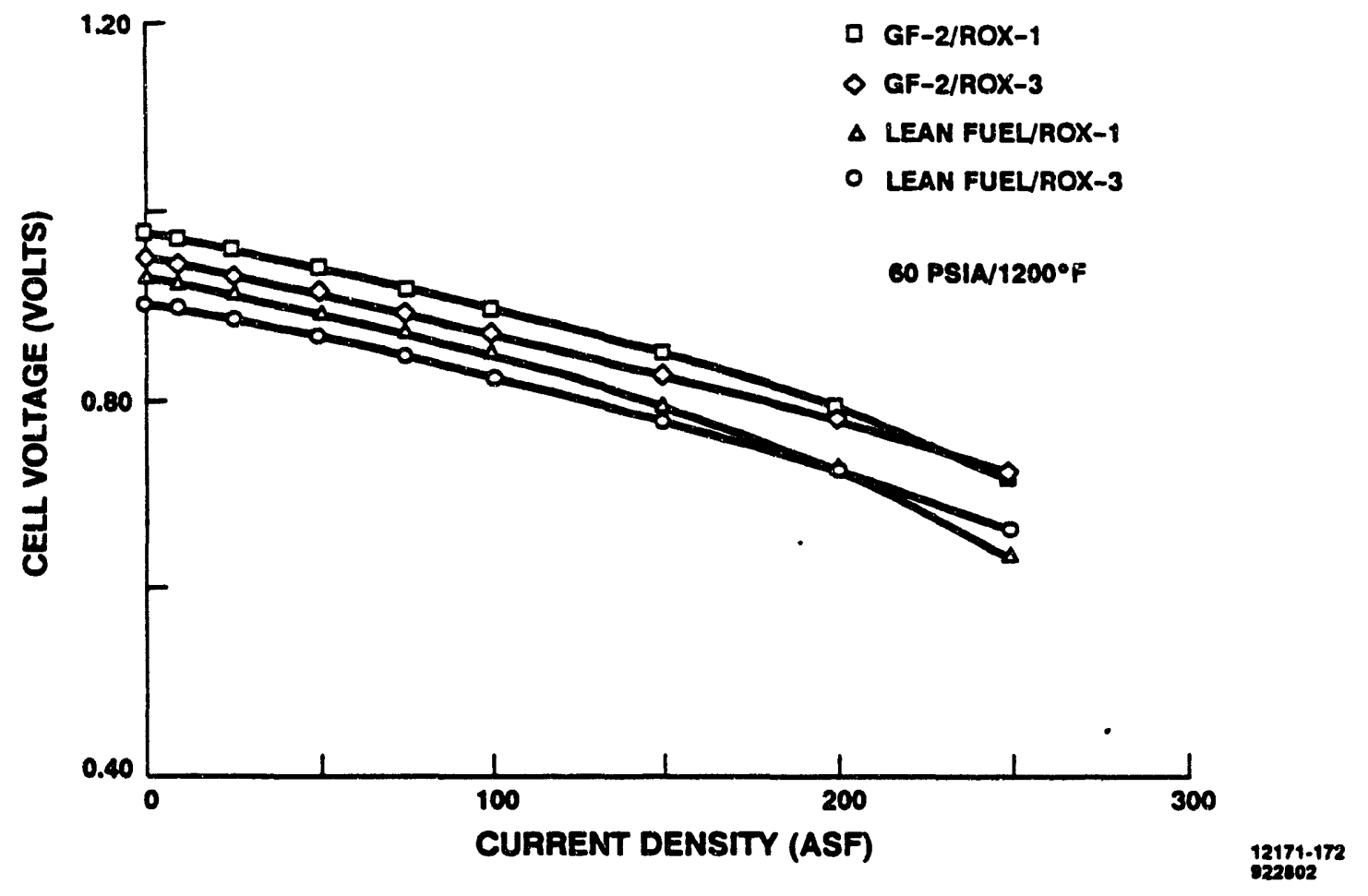

Figure 5.2-1. Effect of Reactant Composition on Initial Performance of Cell 738 


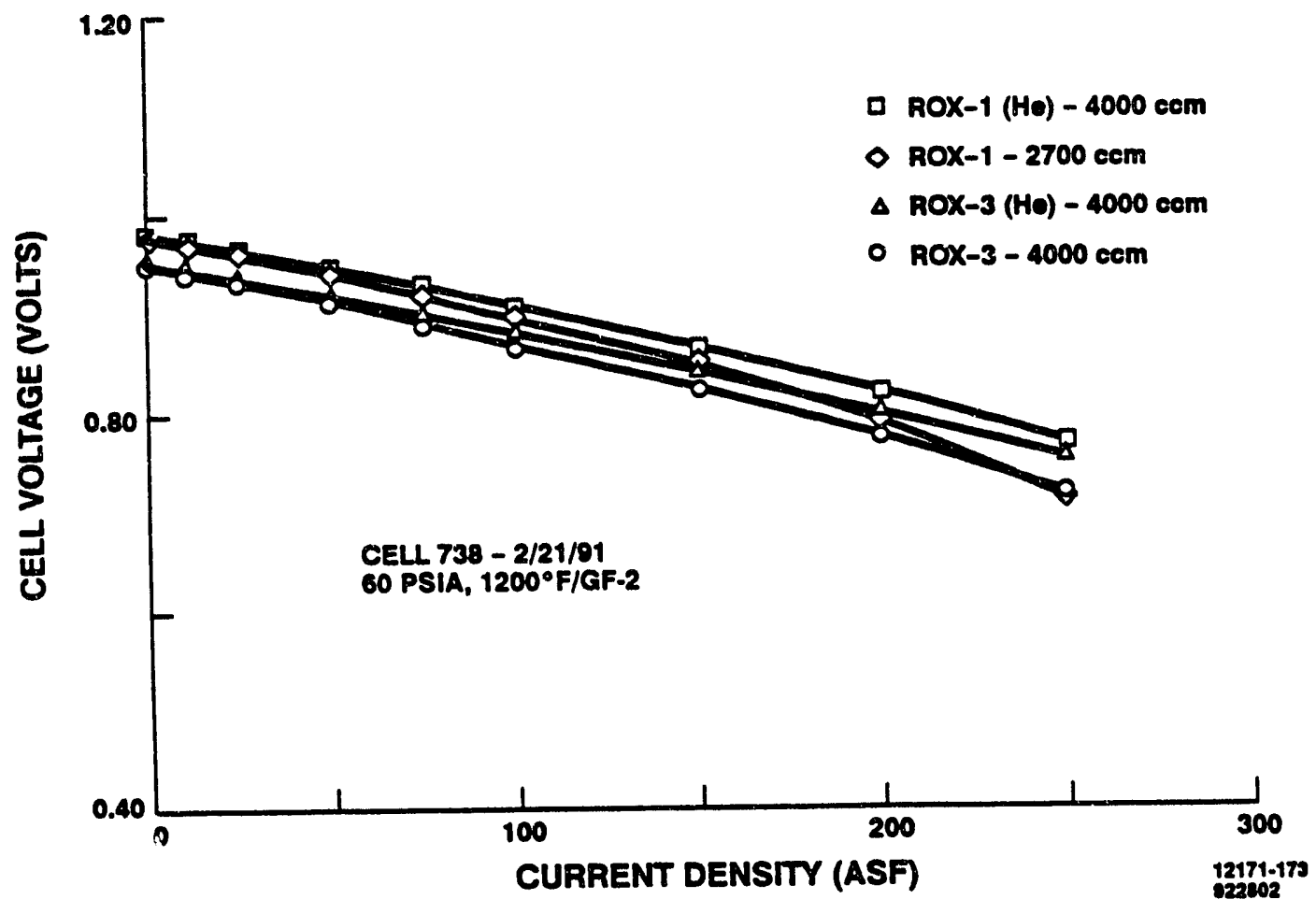

Figure 5.2-2. Effect of Cathode Diluent Type on Initial Performance of Cell 738

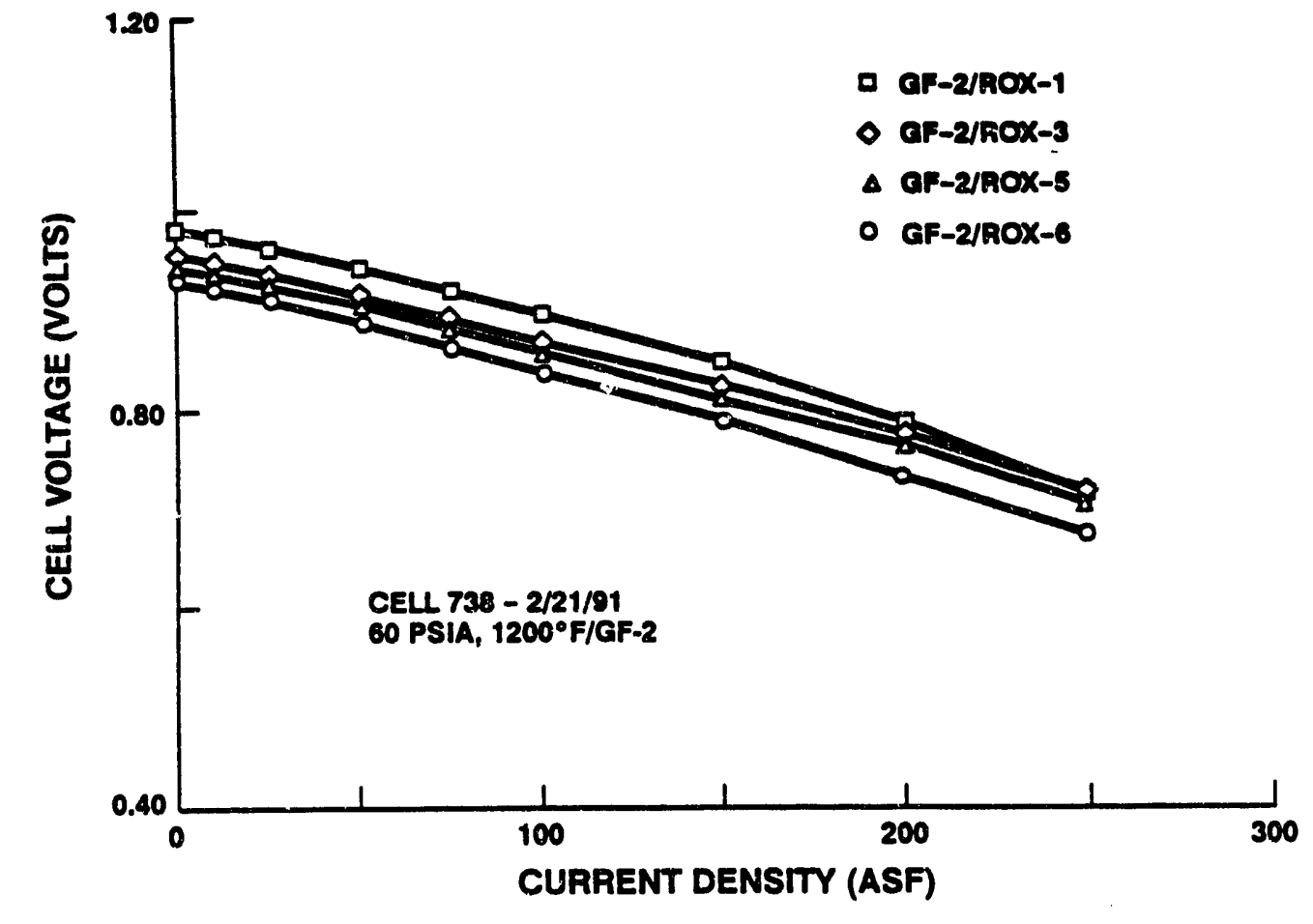

Figure 5.2-3. Effect of Reactant Composition on Initial Performance of Cell 738 


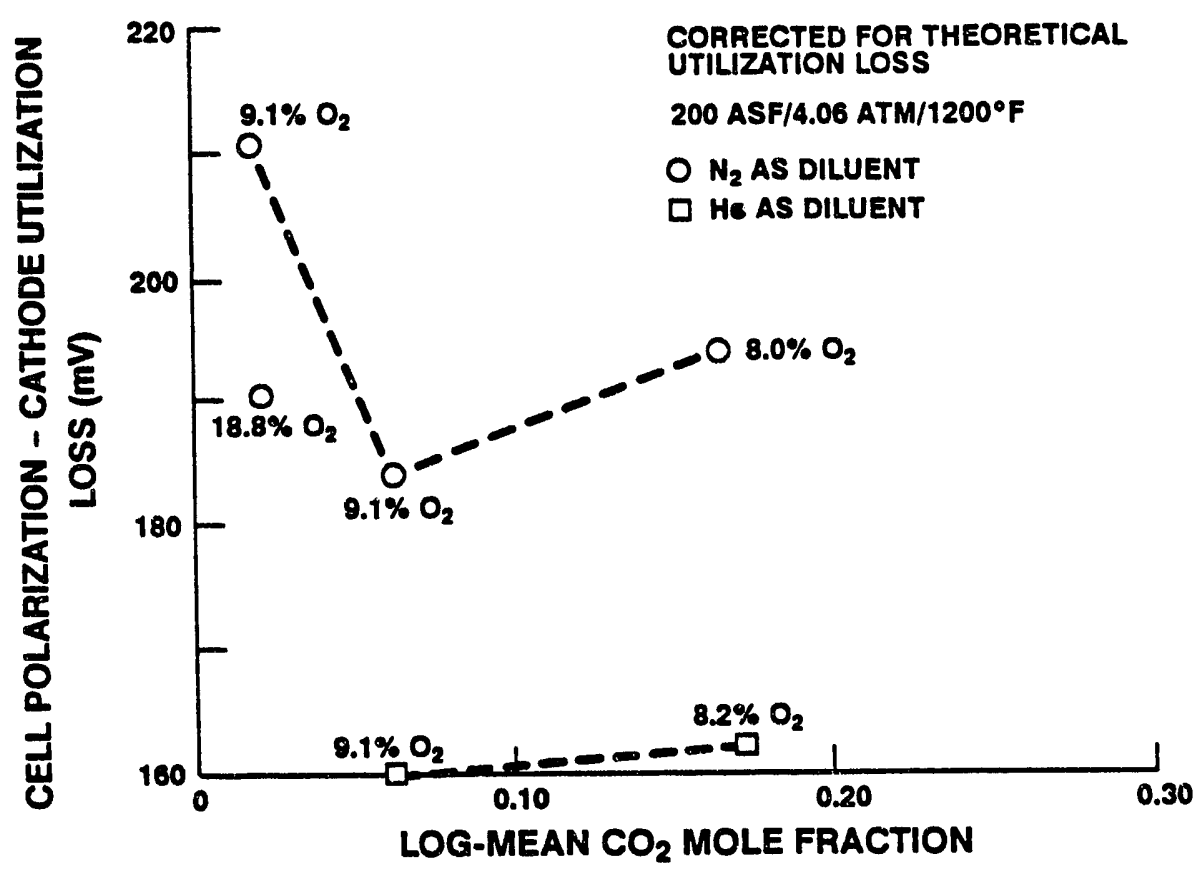

Figure 5.2-4. Effect of Oxidant Composition on Initial Polarization of Cell 738

Testing was performed on Cell 738 to determine the effects of this electrolyte on performance. The initial cell performance level at 60 psia (Figures 5.2-1 through 5.2.3) was good. The internal resistance declined to only $20 \mathrm{mV}$ at 100 ASF, a very low value. However, after a few days of operation, the performance dropped considerably.

Another set of performance data were obtained to help determine the source of this decay. Figure 5.2-5 shows performance data after the performance loss on two different fuels and oxidants. The change in polarization from GF-2 to lean fuel on ROX-3 increased significantly, showing that the anode polarization had increased. The improvement in performance from ROX-1 to ROX-3 increased drastically, implying that the cathode may have flooded. These results may be due to a dewetting of the anode and flooding of the cathode caused by the high contact angle known to occur with $\mathrm{Li} / \mathrm{Na}$ electrolyte. This electrolyte may benefit from an alkaline earth additive to enhance anode wetting $(1)$.

(1) Weewer, R., Vente, J. F., Hemmes, K., and de Wit, J. H. W., "Wetting Behavior of Candidate Molten Carbonate Fuel Cell Anode Materials and Electrolytes", Ber. Bunsenges. Phys. Chem., Vol. 94, pp 967 to 973 (1990). 


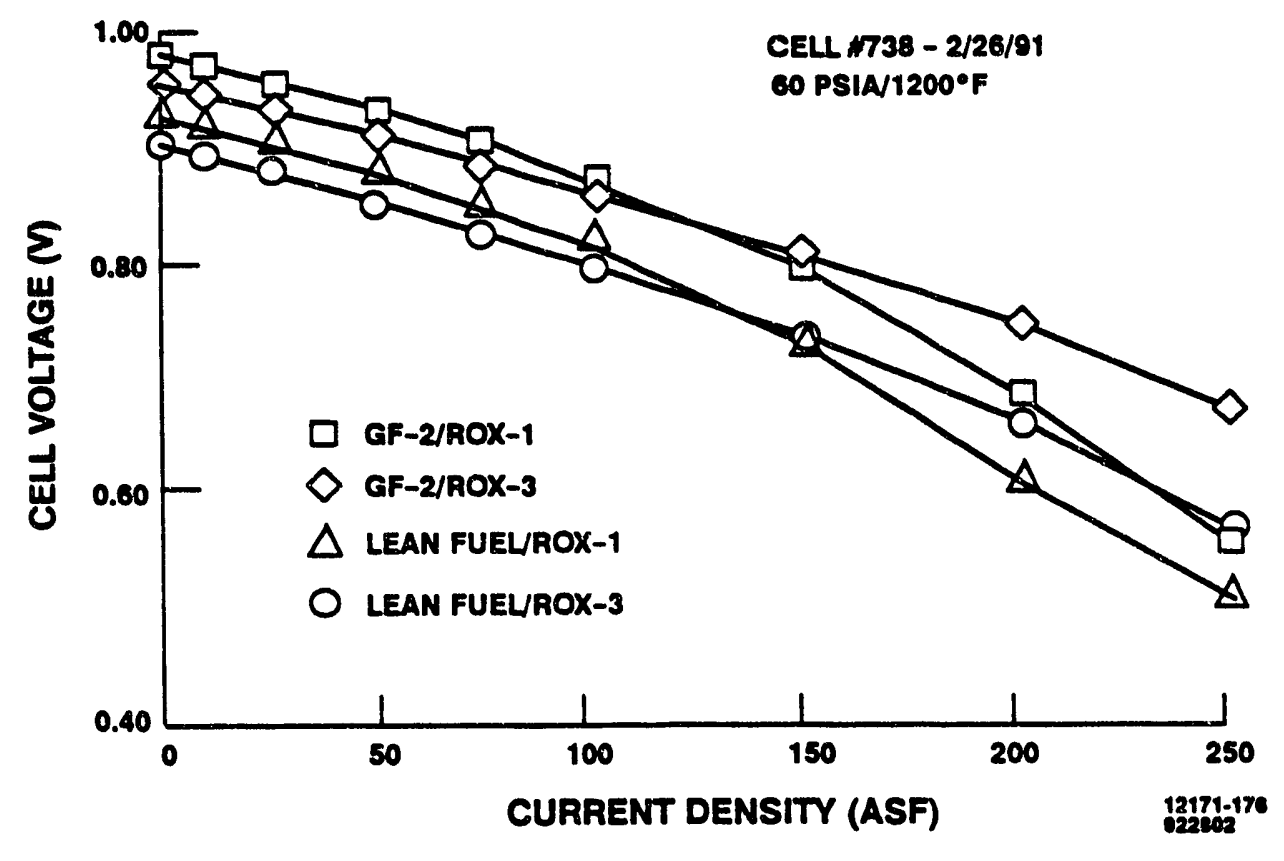

Figure 5.2-5. Effect of Reactant Composition on Performance of Cell 738

Because of the initial crossover found in this cell, it was depressurized and a crossover test performed to determine whether an accelerated shorting test would be worth running. The crossover rate was found to have declined to only three $\mathrm{ccm}$ and the open circuit voltage was near the theoretical value. Because of these positive results, the cell was pressurized to 10 atmospheres for the shorting test. Prior to that test the performance was measured on GF-2 and ROX-1 at 10 atmospheres. The open circuit voltage under these conditions was five millivolts below the theoretical value of 1.001 volts. The cell was then placed on the accelerated oxidant.

As shown in Figure 5.2-6, the cell showed a $10-\mathrm{mV}$ decline in open circuit voltage (the criterion of shorting) in about 120 hours. After correction for other operating conditions using the IFC model, the total effective shorting time becomes 144 hours. This time is only about 45 percent of the anticipated shorting time of a cell using the $72 \mathrm{~m} \%$ lithium carbonate, $28 \mathrm{~m} \%$ potassium carbonate electrolyte. The shorting may have been accelerated by the slight crossover, since the initial open circuit voltage for the shorting test was eight millivolts below the theoretical value of 1.067 volts. 


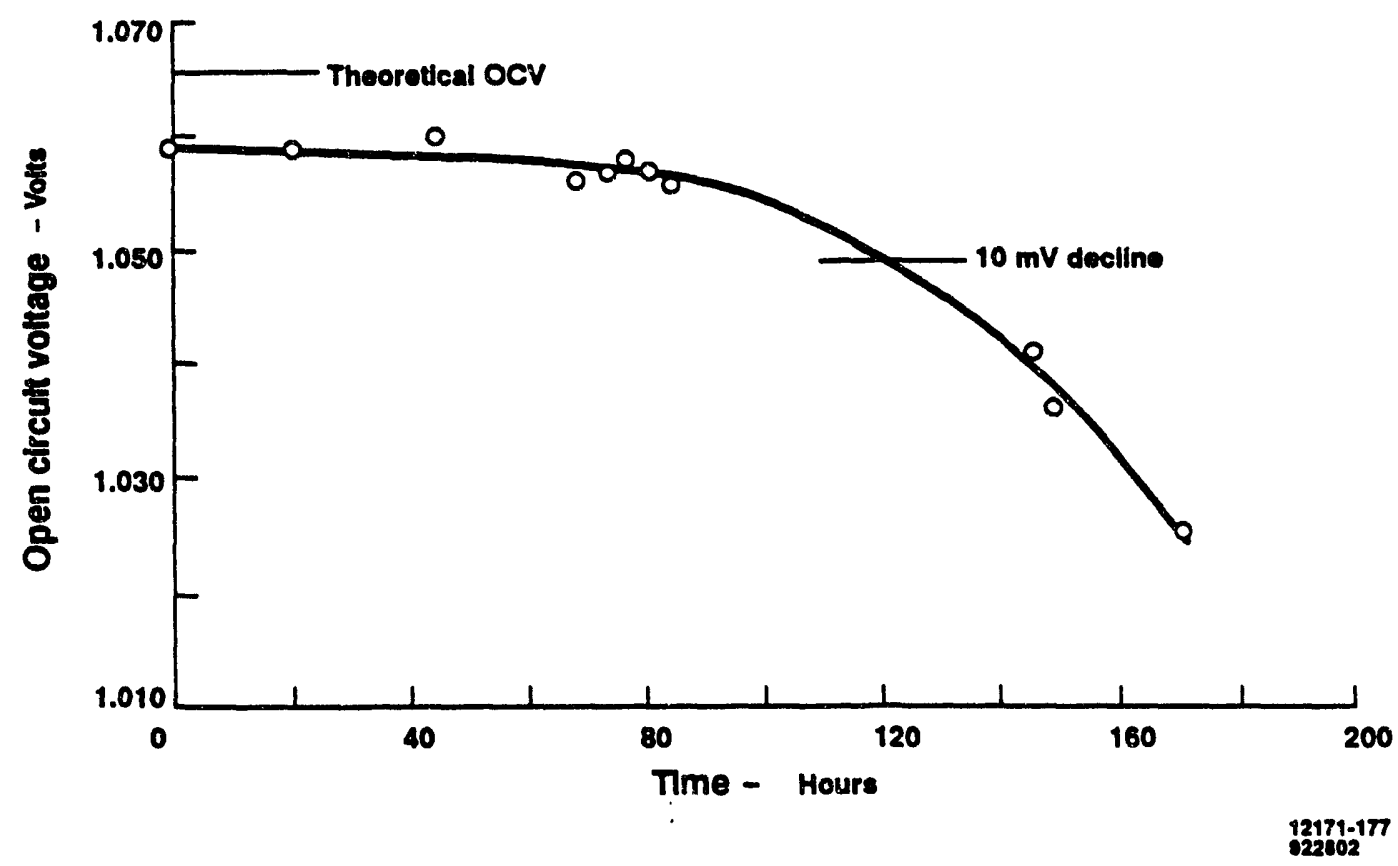

Figure 5.2-6. Open Circuit History of Cell 738 on Accelerated Oxidant

After the shorting test, the performance curve was again determined on GF-2 with ROX-1 and ROX-3 as oxidants as shown in Figure 5.2-7. A performance decay larger than the decline in open circuit voltage was apparent, with the performance on ROX-3 better than that on ROX-1 at 250 ASF. A direct comparison of performance on GF-2 and ROX-1, before and after the shorting test, is shown in Figure 5.2-8. On this oxidant, the performance loss at 250 ASF is three times the decline in open circuit voltage. This increase in polarization is possibly caused by structural degradation of the cathode due to dissolution.

The accelerated shorting test was continued on Cell 738 for another 140 hours to determine the additional performance decay that would result. As shown in Figure 5.2-9, most of the additional decay was found to be due to a further decline in open circuit voltage due to the shorting. Prior to shutdown, the final set of performance data was obtained at atmospheric pressure as shown in Figure 5.2-10. Since the initial open circuit voltage and voltage at 100 ASF were 0.952 and 0.832 volts, respectively, more than half of the performance decay at atmospheric pressure on these reactants was due to the decline in open circuit voltage. 


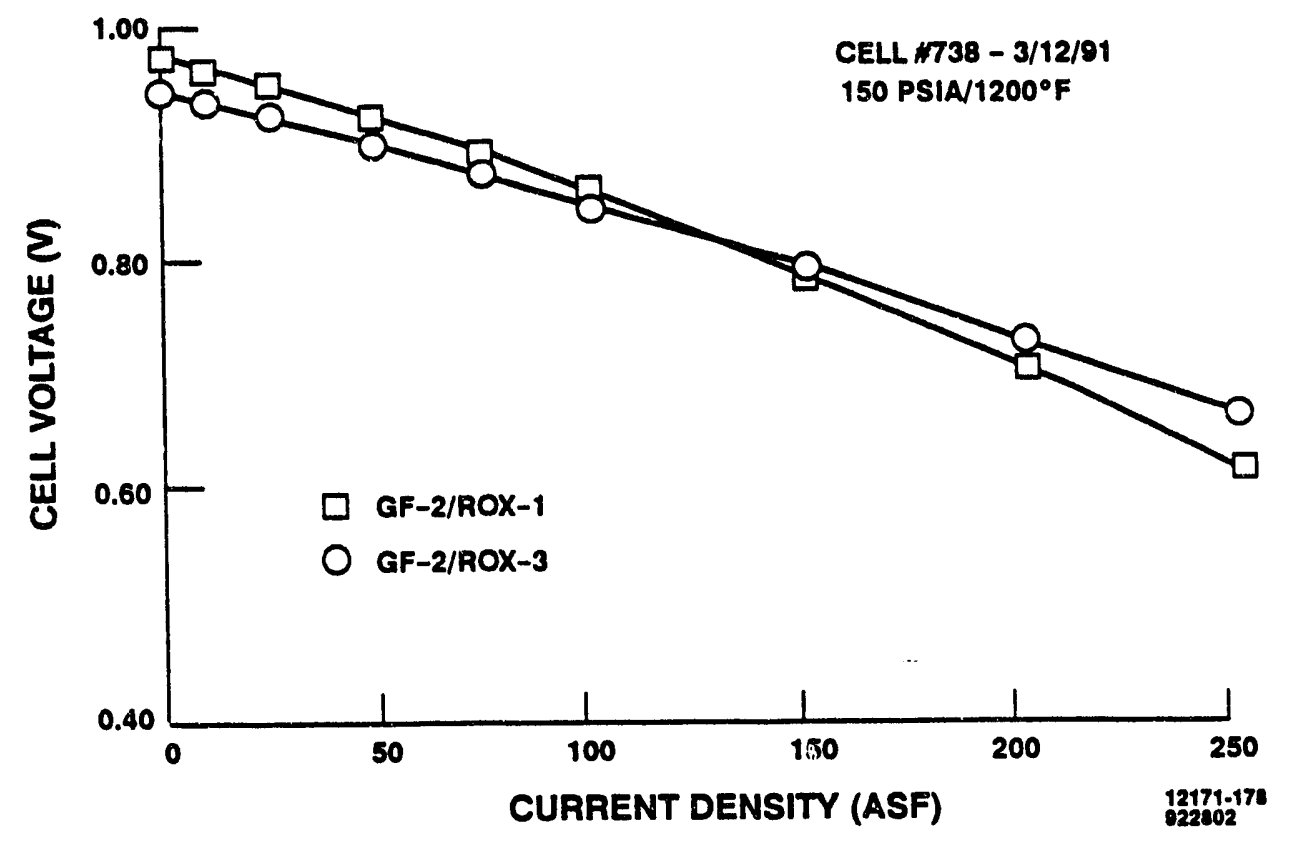

Figure 5.2-7. Effect of Oxidant Composition on Cell Performance

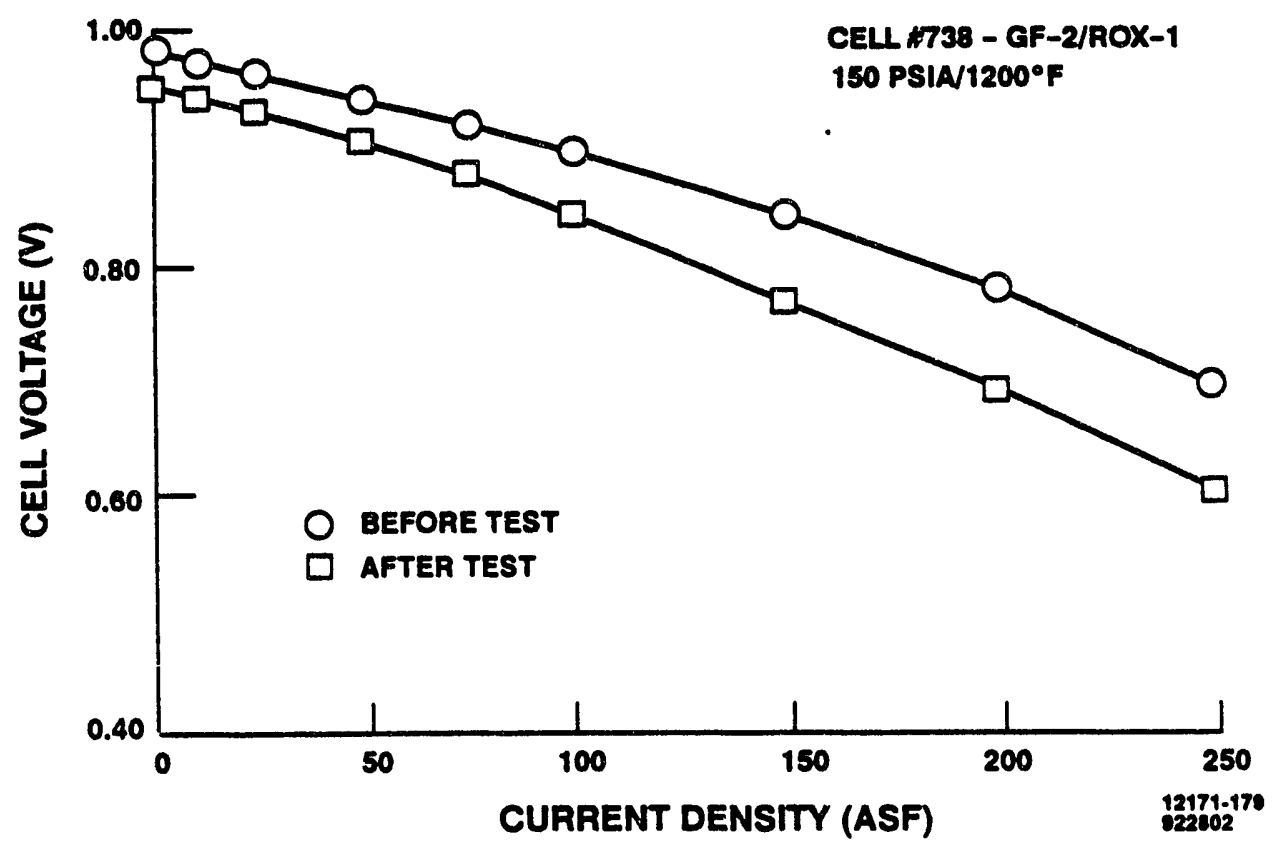

Figure 5.2-8. Effect of Shorting Test on Performance of Cell 738 


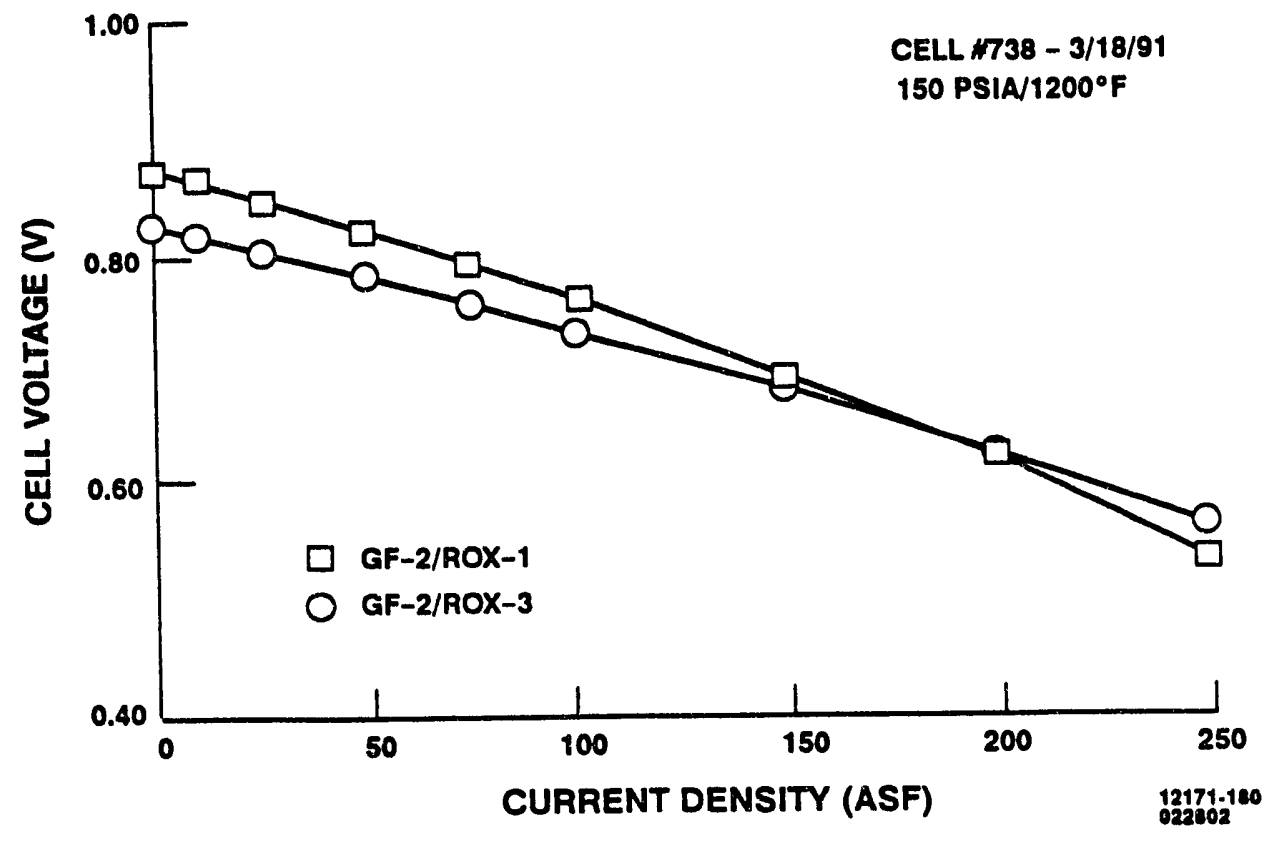

Figure 5.2-9. Effect of Oxidant Composition on Performance of Cell No. 738

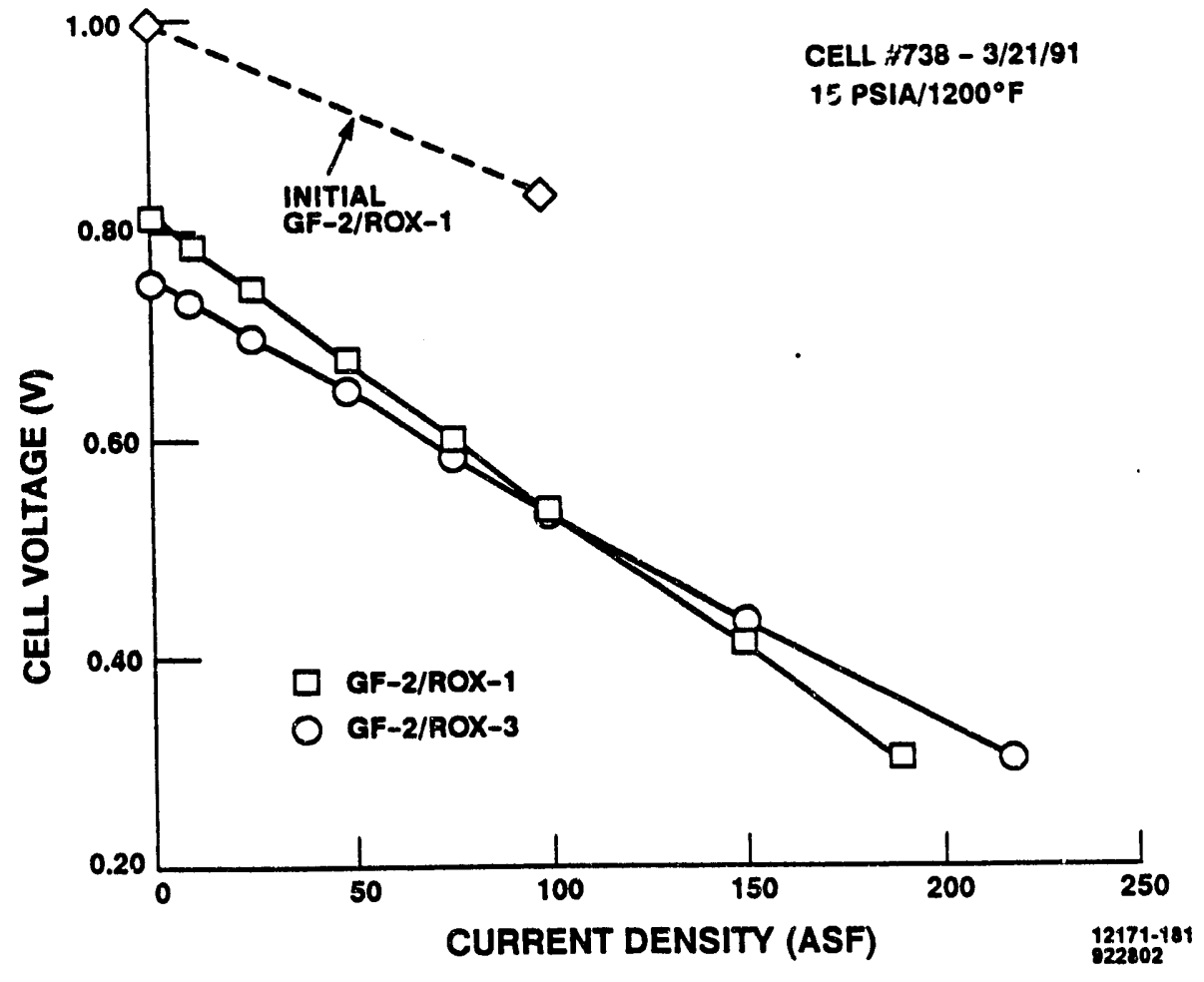

Figure 5.2-10. Effect of Oxidant Composition on Final Performance of Cell 738 
Subtask 5.3 Cathode Cornpatibility Tests

Activity in this task is reported in a separate topical report, FCR-12292. 


\section{APPENDIX A}

THE EFFECTS OF NICKEL OXIDE CATHODE DISSOLUTION ON MOLTEN CARBONATE FUEL CELL LIFE 
The Effects of Nickel Oxide Cathode Dissolution on Molten Carbonate Fuel Cell Iife

\author{
H. R. Kunz and J. พ. Pandolfo \\ International Fuel cells corporation \\ South windsor, CT 06074
}

\title{
ABSTYRACT
}

The dissolution of lithiated nickel oxide cathodes results in a transport of nickel into the fuel cell matrix and can result in an electronic short circuit between the lectrodes. A mathematical model was developed for this process, accounting for the dissolution, diffusion, transference, and convection of nickel. Experimental data on post-test nickel content in matrices and shorting time were found to be correlated by this model, except for a current density effect that was underpredicted. This current density effect is postulated to be caused by cation segregation during cell operation. These results enable the prediction of cathode nickel oxide loss, matrix nickel content, and shorting time as a function of cell design and operating conditions. 


\section{BACKGROUND}

Iithiated nickel oxide cathodes that are presently used in molten carbonate fuel cells have been found to dissolve in the electrolyte and result in the deposition of metallic nickel in the cell matrix.(1) This nickel deposition can result in the formation of an electronically conducting bridge between the electrodes and degrade cell performance. structural deterioration of the cathode can also occur due to loss of material. Because this dissolution is potentially one of the most severe modes of performance decay, numerous experiments have been performed to define the severity of this problem, clarify the mechanisms controlling this process, and evaluate potential solutions.

Subscale cell tests have been performed to determine the effects of cell operating conditions, electrolyte composition, and cell design on the amount of nickel deposited in the matrix. (1) The solubility of nickel oxide has been measured as a function of electrolyte composition, gaseous environment, and temperature.(2-6) Although some variability in these solubilities exists, reasonably good agreement was found for mixtures of lithium carbonate and potassium carbonate near the common fuel cell operating temperature of $650^{\circ} \mathrm{C}$. The primary specie formed in solution when nickel oxide dissolves in the fuel cell is considered to be the $\mathrm{Ni}^{+2}$ ion, since the solubility of nickel oxide was found to be proportional to the HP270 
carbon dioxide partial pressure and independent of the oxygen partial pressure in the range of interest.

Several processes are involved in the migration of nickel from the cathode. These can be categorized into three main steps - dissolution, migration, and deposition. The following sections contain descriptions of these processes.

Dissolution - The kinetics of the dissolution step are unknown. Variation of the carbon dioxide partial pressure and electrolyte potential within the cathode can result in a solubility that varies with location within the cathode. Nickel oxide redistribution within the cathode can then occur as well as migration into the matrix.

yigration - Three mechanisms exist for the migration of nickel into the matrix. First, since the solubility of nickel is virtually zero at the anode potential, a concentration gradient exists that results in the diffusion of nickel ion toward the anode. Secondly, because of the positive charge on the nickel ion, the potential gradient in the cell matrix tends to retard the ion's migration toward the anode. Finally, convection is present because of the flux of carbonate ions toward the anode associated with the fuel cell reactions.(7) The importance of diffusion is discussed in reference (1). Since the solubility increases with the carbon dioxide partial pressure and the diffusion path length increases with matrix thickness, the amount of nickel in the matrix was 
correlated with the product of the carbon dioxide partial pressure and the time divided by the matrix thickness.

Because of the positive charge of the nickel ion, the rate of nickel migration would be expected to be reduced as the current density of the cell increases because of the increasing potential gradient within the matrix. However, the opposite effect was found.(3) Less nickel was found in the matrix after open circuit operation than after a period in which current was flowing. Reference (3) explained this current effect as possibly due to a segregation of the lithium and potassium ions in a cell with current flow and an effect of the electrolyte composition on the nickel oxide solubility. However, data on these phenomena were not available at that time to obtain an appropriate interpretation.

The third migration mechanism, convection, would result in an increase of nickel content in the matrix and a reduced shorting time when the fuel cell is providing current.

Deposition - Nickel can deposit in the matrix either as nickel oxide or metallic nickel depending on the local conditions in the matrix. The solubility of nickel oxide can be exceeded due to gradients in electrolyte composition and carbon dioxide content through the matrix. (2) Nickel oxide has been found to be deposited near the cathode surface.(3) Metallic nickel can plate if the diffusion of the fuel cell reactants into the matrix results in a sufficiently reducing environment. (1) Metallic nickel has been found to have the 
highest concentration typically in the central region of the matrix with some migrating to the anode. The kinetics of these two deposition processes are unknown. Because of the particulate nature of metallic deposits found in matrices, a nucleation process may be important. (1)

Modeling of the migration of nickel has been performed.(1) (9-11) These models have accounted for some of the processes mentioned above and have resulted in some success in correlating data on the amount of nickel deposited in matrices. The present authors performed a series of tests in which the nickel content in the matrices and shorting times were measured. Shorting was defined as the condition at which the open circuit voltage declined by ten millivolts. In these tests, the oxidant composition, fuel composition, matrix thickness, cathode thickness, current density, and temperature were varied. since the solubility of. nickel oxide is proportional to the carbon dioxide partial pressure, shorting time was reduced to abnormally low values by increasing the carbon dioxide pressure in the cathode reactant to as high as 9.9 atmospheres. The suitability of such an accelerated test method was verified.by selecting a few sets of conditions at which the shorting time was extended to as high as 4691 hours.

A model was developed accounting for the dissolution, diffusion, transference and convection processes and compared with the results of these cell tests. This model was found to be partially successful in correlating the cell data on matrix 
nickel content and shorting time. This model and the experimental results are described and discussed in this paper.

\section{THFORY}

The theoretical analysis of nickel migration consists of the application of the continuity equation for the nickel ion to both the cathode and matrix with the requirement that the nickel ion flux and concentration must be equal in these two regions where they bound one another. Because little is known about the dissolution and deposition processes, several simplifying assumptions are made with respect to these processes. These assumptions will be mentioned as they are made in the following description of the theory.

\section{Apolication of continuity sorution to cathode}

An Ion nigrates because of a concentration gradient, a potential gradient, and convection. This migration can be expressed mathematically as:

$$
m=-\frac{D}{\tau} \frac{d c}{d x}+\frac{c z w}{\tau} \frac{d \phi}{d x}+c v
$$

where the symbols are defined in the TABLE OF NONENCLAIURE and the area for ionic migration is the actual electrolyte cross- 
sectional area.

A bulk or convective velocity exists because of the formation of carbonate ions within the cathode and their consumption in the anode. At the cathode-matrix interface, the carbonate ionic current is the total cell current at steady state. This current can be used to calculate the electrolyte velocity (7).

$$
V=\frac{30(I / A)}{P F}
$$

where $I / A$ is the current density based on the actual electrolyte cross-sectional area.

If the carbonate ions are assumed to be generated uniformly through the cathode thickness, this velocity would vary with thickness as:

$$
V=\frac{30(I / A)}{P F}\left(\frac{X}{\delta}\right)
$$

where $x$ is measured from the cathode-gas interface toward the matrix. Such a current distribution within the cathode would result if gas-phase diffusional and lonic resistive losses are relatively small within the cathode.(12) similarly, the potential gradient would vary with depth into the cathode as:

$$
\frac{d \phi}{d x}=(I R)_{c}\left(\frac{x}{\delta^{2}}\right)
$$


where $(I R)_{c}=$ the resistive drop through the cathode if all of the current flowed through the entire thickness.

If relationships from Equations [3] and [4] are used in Equation [1] and the area for diffusion and current flow in $m$ and I/A respectively are converted from actual area to total frontal area,

$$
m=-\frac{D \theta}{\tau} \frac{d c}{d x}+\frac{c z W}{\tau}(I R)_{c} \theta\left(\frac{x}{\delta^{2}}\right)+c\left(\frac{30(I / A)}{p F}\right)\left(\frac{x}{\delta}\right)
$$

where $\theta$ is the fraction of cathode cross-sectional area occupied by electrolyte.

If the rate of dissolution of nickel oxide is assumed to be first order, then

$$
\frac{d m}{d x}=k\left(A_{s}\right)\left(C_{0}-C\right)
$$

Differentiating both sides of Equation [5] and combining with Equation [6],

$$
\begin{aligned}
\frac{d m}{d x}=k\left(A_{s}\right)\left(C_{0}-C\right)=-\frac{D \theta}{\tau} \frac{d^{2} c}{d x^{2}} \\
+\left[\left(\frac{x}{\delta^{2}}\right)\left(\frac{z w(I R)_{c} \theta}{\tau}+\frac{30(I / A) \delta}{\rho F}\right)\right] \frac{d c}{d x} \\
+\left[\frac{I W(I R)_{c} \theta}{\delta^{2} \tau}+\frac{30(I / A)}{P F \delta}\right] c
\end{aligned}
$$

Solving for $\frac{d^{2} c}{d x^{2}}$. 
$\frac{d^{2} c}{d x^{2}}=-\frac{k \tau}{D \theta}\left(A_{S}\right)\left(c_{0}-c\right)+\frac{\tau}{D \theta}\left[\left(\frac{x}{\delta^{2}}\right)\left(\frac{Z w(I R) c \theta}{\tau}+\frac{3 \Delta(I / A) \delta}{\rho F}\right] \frac{d c}{d x}\right.$

$$
+\left[\frac{z w(I R)_{C}}{\delta^{2} D}+\frac{30(I / A) Y}{P F S D \theta}\right] C
$$

The resistive drop (IR)c can be expressed in terms of current density, cathode porosity, and thickness using Archie's equation (13) and noting that the resistive loss through the cell matrix is about 0.02 volts at $0.1 \mathrm{amps} / \mathrm{cm}^{2}$ for $a 0.043 \mathrm{~cm}$ thick matrix.

$$
(I R)_{c}=0.20\left(\frac{I}{A}\right)\left(\frac{S}{S_{m}}\right)\left(\frac{\theta}{\theta_{m}}\right)^{1.75}
$$

The exponent 1.75 is used because a value above the 1.5 predicted by the Bruggeman equation was found to lead to better agreement for porous bodies partially filled with molten carbonate (14).

Equation [8] can be solved for the nickel ion concentration through the cathode in terms of the concentration at the cathode-matrix interface using the boundary conditions:

$$
m=m_{S} \text { AT } x=\delta
$$

and 


$$
\frac{d c}{d x}=0 \text { AT } x=0
$$

The constants in Equation [8] can be estimated. For a 208 filled cathode of 748 porosity,

$$
\theta=0.74(0.20)=0.148
$$

The tortuosity is then,

$$
\tau=\left(\frac{1}{\theta}\right)^{0.75}=4.19
$$

For a nickel oxide surface area of about $1 \mathrm{~m}^{2} / 9$,

$$
\dot{A}_{S}=46,500 \mathrm{~cm}^{-1} \text {. }
$$

The electrolyte density under the present conditions of $650^{\circ} \mathrm{C}$ and $72 \mathrm{mt}$ lithium carbonate, 28 mf potassium carbonate electrolyte is about $1.934 \mathrm{~g} / \mathrm{cm}^{3}$.

Three constants are unknown, the diffusion coefficient of the nickel ion, the mobility of the nickel ion, and the rate constant for the dissolution reaction. The mobility of the nickel ion was assumed to be $2.5 \times 10^{-5} \mathrm{~cm}^{2} /$ volt $\mathrm{sec}$ and the diffusion coefficient and mobility were used as fitting parameters. This value of mobility is discussed later in this report. The diffusion coefficient has been measured for the lithium carbonate, potassium carbonate eutectic electrolyte at 
$640^{\circ} \mathrm{C}$ and found to be $4.89 \times 10^{-5} \mathrm{~cm}^{2} / \mathrm{sec}$

Apolication of the continuity Eouation to the Matrix. The analogous equation to [5] for the matrix is:

$$
m=-\frac{D \theta_{m}}{\tau_{m}} \frac{d c}{d x}+\frac{c z w(I R)_{m} \theta_{m}}{\tau_{m} \delta_{m}}+c\left(\frac{3 D(I / A)}{\rho F}\right)
$$

after noting that the current flow is uniform at its total value through the entire matrix.

From Equation [9],

$$
(I R)_{m}=0.20(I / A)\left(\frac{S_{m}}{0.043}\right)
$$

In the matrix, $m=m$ and is constant.

Rearranging Equations [12] and [13],

$$
\frac{d c}{d x}-\left[\frac{0.20 z w \theta_{m}}{0.043 \tau_{m}}+\frac{30}{p F}\right] \frac{(I / A) \tau_{m}}{D \theta_{m}} c=-\frac{m_{s} \tau_{m}}{D \theta_{m}}
$$

Solving Equation [14] using the boundary condition that $c=0$ at some distance $x=\Delta$ into the matrix from the matrixcathode interface, an equation relating the nickel concentration at that location to the nickel flux can be obtained. 


$$
\frac{C_{s}(I / A)\left[\frac{0.20 z w \theta_{m}}{0.043 \tau_{m}}+\frac{30}{p F}\right]}{1-e^{-K \Delta}}
$$

where $R=\left(\frac{0.20 z w \theta_{m}}{0.043 \delta_{m}}+\frac{30}{p F}\right) \frac{(I / A) \tau_{m}}{D \theta_{m}}$

Here $\theta_{\mu}=0.41$ and $\tau_{m}=(1 / 0.41)^{0.75}=1.95$ and $\Delta=\delta / 2$ based in microprobe studies of post-test matrices. Examples of microprobe results for post-test matrices are shown in Figures 1,2 , and 3 .

The inclusion of the nickel plating process and the deposition of nickel oxide in the matrix were not considered. Two peaks in nickel concentration in the matrix have been experimentally observed in several cases.(3)(15) The peak closer to the cathode has been associated with nickel oxide and that nearer the center of the matrix metallic nickel. Precipitation of nickel oxide may occur because of a segregation of lithium and potassium in the electrolyte, resulting in a solubility gradient through the matrix. A variation of the amount of dissolved carbon dioxide in the electrolyte can also result in a solubility gradient.

Theoretical studies were previously attempted to determine the distribution of nickel concentration through the matrix. In one study, the simultaneous diffusion of the 
gaseous fuel cell reactants through the cell matrix was analyzed under open circuit conditions.(14) The reaction between hydrogen and oxygen was assumed to be in equilibrium because of the presence of nickel in the matrix to act as a catalyst. The water-gas-shift reaction was considered either to be frozen or in equilibrium. Nickel was found to be thermodynamically capable of being plated throughout the entire matrix except for a region near the cathode. The extent of this region was calculated as a function of the cell operating conditions.

In another study (8), the nickel was assumed to plate out in the matrix by the reaction

$$
\mathrm{NiCO}+\mathrm{H}_{2} \rightarrow \mathrm{Ni}+\mathrm{CO}_{2}+\mathrm{H}_{2} \mathrm{O}
$$

Using the rate constant for the plating reaction and the diffusion coefficient of the nickel ion as fitting parameters, an attempt was made to calculate the profiles of nickel deposition as a function of matrix thickness, operating pressure, and reactant compositions in the absence of transference and convection. This study resulted in profiles similar to those measured experimentally including the presence of some nickel reaching the anode. However, general agreement with experimental data was not obtained.

The difficulties encountered in these analyses indicated that the current understanding of the plating process is 
inadequate for modeling.

Equation [8] for the cathode and [15] for the matrix can be solved simultaneously for the flux of nickel from the cathode, $m_{8}$, using the conditions that $c_{8}$ and $m_{8}$ for both equations must match at the cathode-matrix interface.

Simplified Solution Assuming High Rate constant for Dissolution Reaction

If the rate constant for the dissolution reaction is very high, the concentration of nickel at the cathode-matrix interface can be assumed to be the nickel oxide solubility. For this case, an explicit solution for shorting time can be obtained from Equation [15] where $C_{n}$ is then the equilibrium solubility at the cathode.

\section{Calculation of the Time at which Shorting occurs}

As discussed later in this report, the experimental data on the time at which shorting occurs indicates that a certain concentration of nickel may be present in the matrix at the beginning of shorting, which is defined as a 10 millivolt drop in the open circuit voltage. That concentration has an average value of $0.18 \mathrm{~g}$ of nickel per $\mathrm{cm}^{3}$ of matrix volume with a range from 0.08 to $0.27 \mathrm{~g} / \mathrm{cm}^{3}$. The time-to-short is then related to the nickel flux by the equation: 


$$
T T S=\frac{0.18 \mathrm{Sm}}{m_{s}}
$$

using the average value of $0.18 \mathrm{~g} / \mathrm{cm}^{3}$.

\section{Computer solutions}

A computer program was written to simultaneously solve Equations [8] and [15] and calculate the time-to-short using Equation [18]. Another program was written to solve Equation [15] for the simplified solution for a high dissolution rate constant. This program also calculated shorting time for this simplified case. Both programs used a dependence of nickel oxide solubility and carbon dioxide partial pressure sased on published experimental data.(2-5) The solubility for the experimental conditions of $650^{\circ} \mathrm{F}$ temperature and $72 \mathrm{mt}$ lithium carbonate, 28 mf potassium carbonate electrolyte composition was considered to be proportional to carbon dioxide partial pressure and to be equal to $16.2 \mathrm{ppm}$ (wt) at $P_{\mathrm{CO} 2}=1$ atm.

\section{EXPERTYIFNTS}

Two series of experiments were performed, all in benchscale cells of approximately $80 \mathrm{~cm}^{2}$ active area. In the first series, matrix thickness, cathode thickness, current density, 
oxidant composition, fuel composition, and operating temperature were varied. The matrix and cathode thicknesses were varled from that of a standard cell configuration. The matrix of that configuration was nominally $0.043 \mathrm{~cm}$ thick and made by a tape casting process. The cathode of the standard cell was nominally $0.100 \mathrm{~cm}$ thick and oxidized in-situ. In all cases the anode was $0.165 \mathrm{~cm}$ thick, ribbed to provide a gas flow field, and made from chromium stabilized nickel. Operating temperature was varied by $56^{\circ} \mathrm{C}$ above and below the normal temperature of $650^{\circ} \mathrm{C}$. In general, the fuel gas consisted of a simulated gasified coal mixture designated as GF-2. The composition of this gas and other reactants used in this study are listed in Table 1. The variables for each of the cells are listed in Table 2 .

All cells were started and operated at near atmospheric pressure for a few hundred hours until the performance could be adequately documented. A cross-pressure was applied to each cell to determine that little crossover was present. The open circuit voltage was measured and compared to the theoretically calculated value. In general, these two voltages were within a few millivolts of one another, indicating that little crossover or electronic shorting was present between the electrodes at the start of the test.

The cells were placed at the operating conditions of Table 2 and maintained at these conditions until the open circuit voltage declined by $10 \mathrm{mv}$. The open circuit was 
monitored daily and provided a continuous trend with time. Although the $10 \mathrm{mv}$ criterion was arbitrary, once the open circuit voltage declined by this value a further rapid decline ensued. The electronic resistance of each cell was measured as the cell cooled to below the electrolyte solidification temperature on shutdown to ensure that an electronic short was the cause for the decline in open circuit voltage.

After shutdown, the cells were disassembled and inspected for the presence of any observable location at which shorting had occurred. In general, no such indication was present. No indication was generally present for the existence of shorts in the cell edge seal where the matrix extended from the region between the electrodes through the sealing flange. Samples of matrices were removed from the cells and analyzed for nickel content using a scanning electron microprobe.

The second series of tests was performed after the data from the first series were used to obtain a comparison with the theoretical approaches as described in the following section of this report. The variables for this second series are shown in Table 4. In this second series, approaches were investigated to increase the shorting time of cells and provide additional data with respect to the effects of matrix thickness and current density on shorting time. One test was performed to verify that the correlations were applicable to tests that are not accelerated to such a high degree by performing the test at a lower value of cathode carbon dioxide 
partial pressure.

The approaches to increase shorting time consisted of seeding the matrix with nickel particles to provide nucleation sites for nickel plating, removing from the matrix the particulate alumina used to attenuate cracks, and changing the electrolyte composition to alter the solubility of nickel oxide. The electrolyte compositions investigated consisted of 60 mt lithium carbonate/40 mt sodium carbonate, 70 mt lithium carbonate/30 mo sodium carbonate, 5 wts strontium carbonate in 72 mf lithium carbonate/28 mi potassium carbonate, 5 wt? cesium carbonate in 72 mf lithium carbonate/28 mo potassium carbonate and 1 wt rubidium carbonate in 72 mf lithium carbonate/28 mi potassium carbonate. For this series of tests the shorting times were measured but matrix nickel contents are not yet available. For one of the tests using strontium carbonate in the electrolyte, a microprobe scan of strontium across the cell matrix and Auger electron spectroscopy were performed.

\section{BRSUThS}

Examples of the post-test nickel microprobe results from shorted cells are shown in Figures 1, 2, and 3 for samples from Cells No. 489, 507, and 520, respectively. All of these profiles were integrated to obtain the jocal matrix nickel 
content. These nickel contents were found to be dependent upon the in-plane matrix location so two matrix samples were analyzed in general for each cell, resulting in a range of experimental data for matrix nickel content.

The experimental conditions for the first series of tests are presented in Table 2 . Values of matrix nickel content and shorting time for this series are presented in Table 3 . These measured shorting times have been slightly corrected for nickel that was deposited in the matrix when the cell was not at the specific cell operating conditions. This correction was made using Equation [20].

These results indicate that a specific concentration of nickel may be present in the matrix when shorting occurs. The average value for this concentration is about $0.18 \mathrm{~g} / \mathrm{cm}^{3}$. Therefore, calculated values for shorting time for this first test series were obtained using the more complete theory and this average measured nickel concentration in the matrix. A typical diffusion coefficient of $10^{-5} \mathrm{~cm}^{2} / \mathrm{sec}$ was assumed for the nickel ion and the rate constant for the dissolution reaction was determined to be $5 \times 10^{-8} \mathrm{~cm} / \mathrm{sec}$ by fitting the data. These calculated values are also. shown in Table 3. Figure 4 is a comparison of the experimental and calculated values of shorting times.

Since considerable scatter existed in the comparison of the calculated and experimental values, graphs similar to Figure 4 were prepared with each of the variables separately 
delineated to determine how well the effects of these variables were being predicted. If the effect of a variable is not being accurately predicted, the relationship between the calculated and experimental values will be a function of that variable. The effect of matrix thickness is shown to be suitably predicted by the more complete theory in Figure 5 . Osing two plies of matrix to fabricate a given matrix thickness might have some beneficial effect.

The effects of current density (or cathode potential) and operating temperature are compared for the more complete theory in Figures 6 and 7, respectively. The effect of reducing current density to open circuit on extending the shorting time appears to be underpredicted in Figure 6.

The effects of cathode thickness, carbon dioxide pressure, oxidant type, and fuel type are compored in Figures 8 to 11, respectively, for the nore complete theory. The effect of cathode thickness can be seen to be suitably correlated. No effect of fuel type appears to be present within the data scatter. The sam data points that resulted in the apparent poor prediction oil the effect of current density (to open circuit) indicated that this poor agreement could also be caused by an effect of carbon dioxide pressure or oxidant type.

The poor agreemert of the more complete model was assumed to be due to an underprediction of the effect of current density and the fitting parameters of the simpler model 
adjusted to reduce this poor agreement. The fitting parameters were a nickel ion diffusion coefficient of $10^{-6} \mathrm{~cm}^{2} / \mathrm{sec}$ and a shorting concentration in the matrix of $0.146 \mathrm{~g} / \mathrm{cm}^{3}$. The resulting equation for shorting time is:

$\operatorname{TIME}($ HRS $)=\frac{11,600 \delta_{m}\left(1-e^{-266(I / A) \delta_{m}}\right)}{P_{\mathrm{CO}_{2}}(I / A)}$

and for matrix nickel content:

$$
\text { CONTENT }\left(g / \mathrm{cm}^{2}\right)=\frac{0.146\left(S_{\mathrm{m}}\right)(\text { TIME AT CONDITIONS) }}{\text { SHORTING TIME }}
$$

The calculated values of shorting time and matrix nickel contents at the end of the tests using these equations are presented in Table 3. Figure 12 contains a graphical comparison of the measured and calculated values of shorting time using Equation [19].

since the effect of open circuit operation was underpredicted by the more complete model, the experimental data was delineated by current density in Figure 12 , the comparison with the simplified model. In this case a better 
correlation of the open circuit data can be seen. The effects of all the other experimental variables presented in Figures 5 to 11 for the more complete model were very similar for the simpler model. Figure 13 compares the calculated values for the two models for the experimental conditions of the first test series. Only current density can be seen to result in a significant difference.

Figure 14 presents the comparison of matrix nickel contents for the data and simpler model. Included in Figure 14 are data from the first test series and additional data from cells tested under less accelerated conditions and not tested until shorting occurs. The experimental conditions and data for these cells are listed in Table 5.

To determine whether the current density, oxidant carbon dioxide pressure, or oxidant type were the cause for the discrepancies of the more complete model, tests at various current densities were performed in the second series of tests. All of the variables investigated in this series and the results are listed on Table 4, where the experimental shorting times are compared with the values calculated using the simpler model. The experimental increase in shorting time due to open circuit operation was found to be underpredicted by even the simpler model.

This second test series showed no increase in shorting time with increased matrix thickness in one test. The test (Cell No.662) that was performed at lower carbon dioxide 
partial pressure at the cathode to provide a less accelerated condition resulted in a measured shorting time of 2102 hours compared to a predicted value of 1627 hours from the simpler correlation.

The shorting time for a control cell for the cell with the nickel-seeded matrix can be seen to be suitably predicted. The addition of nickel to the matrix reduced the shorting time as if the nickel introduced at the beginning of the test only reduced the amount that must be added to cause shorting. Removing the crack attenuators had no effect. Although changing the electrolyte to $60 \mathrm{mf}$ lithium carbonate/40 mi sodium carbonate and adding 1 wto rubidium carbonate had little effect, the change to $70 \mathrm{mr}$ lithium carbonate/30 mf sodium carbonate had a significant beneficial effect by increasing the shorting time to about 50 * above similar cells in the second test series using $72 \mathrm{mf}$ lithium carbonate, $28 \mathrm{mf}$ potassium carbonate electrolyte.

The addition of 5 wtf strontium carbonate or 5 wt? cesium carbonate to the 72 mf lithium carbonate, 28 mo potassium carbonate electrolyte were found to reduce shorting time.

A comparison of the effects of current density with the simplified theory is shown in Figure 15 for both. the $72 \mathrm{~m} \%$ lithium carbonate, 28 motassium carbonate electrolyte and the electrolyte containing 5 wt? strontium carbonate. Although the effect of open circuit operation is underpredicted, as mentioned above, the measured effect of current density is 
similar to the predicted trend above about $100 \mathrm{ma} / \mathrm{cm}^{2}$ for both of these electrolyises.

\section{DISCUSSION}

The present study shows that the shorting of cells due to nickel oxide cathode dissolution is more complicated than considered in the derived models. Figure 14 shows that the average nickel content through the matrix varies greatly with in-plane matrix location. Figures 1 to 3 show that the nickel content also varies significantly and irregularly through the matrix. These effects are associated with the particulate nature of the deposited nickel and probably also the variations in matrix properties. For example, the very low value of $3.3 \mathrm{mg} / \mathrm{cm}^{2}$ for Cell No. 520 occurred at a location where large pores were present in the matrix on the cathode side, resulting in little nickel deposition probably because of the presence of oxidant.

Average values of matrix nickel content obtained from multiple microprobe scans and shorting times are more predictable. Effects of some cell features and operating parameters appear to be well predicted within the data scatter. Equation [19] predicts the shorting time of all tests 
in the first series with a mean error of 30 with a standard deviation of $37 \%$. For the second test series, the mean error with this equation is 5 with a standard deviation of 46 \% The effects that are best predicted are those of the matrix thickness, cathode thickness, oxidant carbon dioxide pressure, and oxidant composition. Fuel composition and temperature appear to have little effect on shorting time. The prediction of the effect of carbon dioxide pressure is very significant since it indicates that the acceleration of the process by increasing carbon dioxide pressure is appropriate.

However, discrepancies are evident that show that the shorting phenomenon is not well understood. within the apparent data scatter of the more complete model, the effect of open circuit operation was found to be underpredicted based on the results of the first test series, as shown in Figure 6.

A second effect, that of a possible increase in shorting time with two-ply matrices, is also suggested. Figure 5 shows this trend for the data of the first test series. Cell No.627, No.636, and No.662 of the second test series all used two-ply matrices and resulted in measured shorting times that exceeded the predicted values from Equation [19] by $24 \%, 22 \%$, and 25 \%, respectively.

The effect of current density cannot be accurately predicted with the present models using realistic values of the fitting parameters. Figure 6 shows that the effect of current density can be predicted at 0.108 and $0.172 \mathrm{amps} / \mathrm{cm}^{2}$ 
using a value of the correct order of magnitude, $10^{-5} \mathrm{~cm}^{2} / \mathrm{sec}$, for the diffusion coefficient of the nickel ion. However, at open circuit, nickel lons migrate due only to diffusion, and the use of this value of diffusion coefficient results in much too low a predicted shorting time. The simpler model uses a diffusion coefficient unrealistically low $\left(10^{-6} \mathrm{~cm}^{2} / \mathrm{sec}\right)$ to bring the open circuit data for the first test series into better agreement (Figure 12). However, even this low a diffusion coefficient underpredicts the effect of current density in the second test series (Figure 15).

For operating current densities, transference and convection also contribute to the migration of nickel ions in the models. The mobility of the nickel ion was set at a low value to result in most of the effect of current density being caused by convection. This value of mobility $2.5 \times 10^{-5}$ $\mathrm{cm}^{2} /$ volt sec is smaller than would be expected based on the measured diffusion coefficient of $4.89 \times 10^{-5} \mathrm{~cm}^{2} / \mathrm{sec}$ for slightly different conditions if the mobility is calculated using the Nernst-Einstein equation. This latter value would be $6.15 \times 10^{-4} \mathrm{~cm}^{2} /$ volt sec. The low value $2.5 \times 10^{-5} \mathrm{~cm}^{2} / \mathrm{sec}$. is approximately twice the value that results using the fitted value of diffusion coefficient of $10^{-6} \mathrm{~cm}^{2} / \mathrm{sec}$ used with the simpler model. More experimental data are needed on the diffusion coefficient and mobility of the nickel ion. Such low values as used in these models would be somewhat surprising, however. It is interesting to note that the effect 
of current density is not poorly estimated at operating current densities if diffusion and transference are completely neglected in the simpler model, resulting in no fitting parameters.

If the convective velocity is being calculated correctly, the effect of current density appears to be caused by factors not included in the models. A phenomenon that results when current flows and is not included in the model is the possible segregation of the lithium and potassium ions across the cell. For lithium contents below about 72m: lithium carbonate, the potassium ion is more mobile than the lithium ion and tends to segregate toward the cathode. (16)(17) This segregation results in an increased solubility of nickel in the cathode and a declining nickel oxide solubility as the nickel ion migrates from the cathode through the matrix. This solubility gradient could result in a precipitation of nickel oxide near the cathode. Cells tested using the $62 \mathrm{~m} /$ lithium carbonate eutectic have shown dual nickel peaks in the matrix, one near the cathode, presumably due to nickel oxide, and the other in the central matrix region due to metallic nickel. (3)

This electrolyte segregation would not be expected for a cell that contains $72 \mathrm{~m}$ lithium carbonate as in the present study. However, this $72 \mathrm{mt}$ composition is a calculated value based on a higher amount of lithium carbonate at cell filling and an assumed lithium carbonate consumption by corrosion and lithiation reactions with cell components. If more lithium 
carbonate was consumed than anticipated, cation segregation could occur and the current density effect be enhanced.

This supposition is supported by the shorting times measured using strontium carbonate as an additive. A small concentration of strontium oxide has been found to reduce the solubility of nickel oxide in the lithium carbonate, potassium carbonate eutectic.(4) Alkaline earth additives, such as strontium carbonate, have been found to reduce the post-test nickel content in matrices.(15)(18) However, in this study, shorting time was found to be reduced. The effect of current density with this additive is similar to that found without strontium carbonate (Figure 16).

An electron microprobe analysis was performed on Cell No. 637, one of the cells that evaluated the effect of strontium carbonate. This cell was shut down while maintaining a current flowing to try to preserve any electrolyte concentration gradients. The results showed that segregation of strontium occurred toward the anode.(19) A reduced concentration of strontium in the cathode would reduce the beneficial effect of strontium in lowering nickel oxide mobility. Also, as nickel ions migrate, from the cathode, they would enter regions of lower solubility, favoring the precipitation of nickel oxide. Auger electron spectroscopy indicates that part of the nickel in the matrix is in the form of nickel oxide. This segregation of the additive could explain the reduced shorting time. 
of all of the electrolyte compositions, only the 70m? lithium carbonate, 30m\% sodium carbonate electrolyte resulted in an increase in shorting time. This beneficial effect can be caused by the reduced solubility of nickel oxide in the electrolyte due to the replacement of potassium carbonate by sodium carbonate, and the reduction of solubility with increasing lithium carbonate content. Iess electrolyte segregation may also be occurring for this electrolyte compared to the 60mt Iithium carbonate, $40 \mathrm{mt}$ sodium carbonate mixture.

Unfortunately, the 70m, lithium carbonate mixture resulted in very poor tolerance to operating at temperatures below $650^{\circ} \mathrm{C}$. Before the shorting test was performed, the cell voltage of Cell No.654 increased only slightly from 0.780 volts to 0.805 volts at atmospheric pressure and 0.108 amps/ $\mathrm{Cm}^{2}$ on $\mathrm{GF}-2$ and $\mathrm{ROX}-1$ reactants as the temperature was increased from $650^{\circ} \mathrm{C}$ to $704^{\circ} \mathrm{C}$. However, on reducing the temperature from $650^{\circ} \mathrm{C}$ to $593^{\circ} \mathrm{C}$, the voltage dropped to 0.420 volts. After the shorting test was performed, the performance level increased from 0.724 volts at $650^{\circ} \mathrm{C}$ to 0.755 volts at $704^{\circ} \mathrm{C}$. At $593^{\circ} \mathrm{C}$, the voltage dropped to 0.530 volts.

The drop in cell performance is larger than the 10mv decline in open circuit voltage at $650^{\circ} \mathrm{C}$. This increased performance loss at current density is typical of all cells that shorted and is probably related to structural changes in the cathode due to dissolution. The amount of nickel that 
causes shorting is only about $0.18 \mathrm{~g} / \mathrm{cc}$ in the cell matrix. This is only about two percent of the matrix volume and represents a loss of about $4 \%$ of the nickel from the cathode. The performance loss when the cell temperature is reduced from $650^{\circ} \mathrm{C}$ to $593^{\circ} \mathrm{C}$ is less after the shorting test possibly because of the reduced lithium content in the electrolyte due to corrosion and lithiation reactions. The sensitivity to temperature before the shorting test is probably related to the operation of the cell at a temperature near the electrolyte solidification point.

The effect of electrolyte composition and possible composition gradients indicate that the shorting time of a cell may be very dependent on the cell design. Changes in component materials will affect the consumption of lithium carbonate by corrosion reactions. The anode, cathode, and matrix thicknesses and properties will affect the electrolyte content and hence composition changes. The matrix thickness will also affect the severity of any composition variations through the matrix. The shorting results in the present study would therefore not be quantitatively applicable to other cell designs and materials.

Figure 16 shows the shorting times that would be expected at various operating conditions using the simpler model. For a cell operating at atmospheric pressure and $0.269 \mathrm{amps} / \mathrm{cm}^{2}$ with a $0.043 \mathrm{~cm}$ thick matrix, shorting would be expected in 27,000 hours when operating with an oxidant relatively-low in 
carbon dioxide, $7 \mathrm{~m}$. This time is increased to about 44,000 hours with a performance penalty by increasing the matrix thickness to $0.086 \mathrm{~cm}$.

For stack operation at three atmospheres pressure, which is desirable to increase stack performance and reduce the stack and power plant cost compared to ambient pressure operation, the shorting times with $0.043 \mathrm{~cm}$ and $0.086 \mathrm{~cm}$ matrices are reduced to about 10,000 hours and 16,000 hours, respectively. Increases in shorting time can be obtained by an additional increase in the matrix thickness and by lowering the carbon dioxide pressure and current density. These changes would also result in a performance penalty offsetting some of the benefits associated with pressurized operation in the absence of cathode dissolution restrictions.

\section{CONCLOSIONS}

The dissolution of nickel oxide cathodes can result in electrode shorting and cathode performance degradation, and severely restrict the life of molten carbonate fuel cells. The time at which shorting occurs depends on the cell design, electrolyte composition, and operating conditions of the cell. For the design and electrolyte composition of this study, the effects of operating conditions and matrix thickness can be estimated using the semiempirical Equation [19].

Deficiencies exist concerning the understanding of the 
factors controlling cathode dissolution. Although Equation [19] was theoretically developed, the fitting parameters used are not realistic. The effect of current density on shorting time is underpredicted by this equation. Also, an importance of matrix homogeneity appears to be present. This importance has not been explained or quantified. The effect of cathode dissolution on cathode performance has not been treated.

For near atmospheric pressure operation, a life of 40,000 hours is predicted to be possible without shorting by suitable cell design and operating conditions with some performance penalty compared to operation without cathode dissolution restrictions. For pressurized operation, which results in a reduction in stack and power plant cost, long life is also predicted to be achievable, but with further changes in cell design and operating conditions that would result in a performance penalty compared to pressurized operation without cathode dissolution restrictions.

The composition of the electrolyte can affect cell shorting time. However, the effects of electrolyte composition cannot be predicted from changes in nickel oxide solubility with electrolyte composition since composition gradients may occur in the cell. These gradients may change the solubility of nickel oxide in the cathode and result in a precipitation of nickel in the matrix as nickel oxide as well as metallic nickel. Because of the consumption of lithium carbonate in cells due to corrosion and lithiation reactions, the 
composition of the electrolyte changes with time, modifying the dissolution process.

Acknowledgements - The authors thank the Department of Energy for support received under Contract No. DE-AC21-87MC23270, the Electric Power Research Institute under Research Project 10854, and the Gas Research Institute under Contract No. 5081-3440528. 


\section{REFERENCES}

1. Vogel, W.M., Bregoli, L.J., Kunz, H.R., and Smith, S.W., "stability of Nio Cathodes in Molten Carbonate Fuel Cells," The Electrochem. Soc., Proc. 84-13, 443-451 (1984) .

2. Ota, K. Shinjo, T., Kamiya, N., "Solubility of: Nickel oxide in Molten Carbonates I," Denki Kagaku Oyubi Kogyo Butsuri Kayaku 1987, 55(4), 323-6 (Japan).

3. Baumgartner, C.E., "Solubility and Transport of NiO Cathodes in Molten Carbonate Fuel Cells," J. Am. Ceram. Soc., 69, No. 2, 162-168 (1986).

4. Doyan, J.D., Gilbert, T., Davies, G., and Paetisch, I., mNio Solubility in Mixed Alkali/Alkaline Earth Carbonates," J. Electrochem. Soc., 134, 3035 (21987).

5. Yuh, E. Y. and Pigeaud, A., "Determination of: Optimum Electrolyte Composition," Energy Research Co:poration Final Report on DOE Contract No. DE-AC21-B6MC23264 (1989) - 
6. Lee, L. N., and Shores, D. A., "Transport Considerations in the Hot Corrosion of $\mathrm{Ni}$ by Molten Alkali Carbonates," J. Electrochem. Soc., 137, No. 3, 859-871 (1990).

7. Kunz, H. R., "Transport of Electrolyte in Molten Carbonate Fuel Cells," J. Electrochem. Soc., 134, No. 1, 105-113 (1987).

8. "Evaluation of Natural Gas Molten Carbonate Power Plants", prepared by Power Systems Division of United Technologies Corporation, Final Technical Report on Gas Research Institute Contract No. 5081-344-0528 (1985).

9. Shores, D. A., Selman, J. R., and Ong., O. T., "Cathode Degradation". Final Report on DOE Contract DE-AC21-

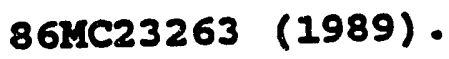

10. Veldhuis, J. B. J., Makkus, R. C., Van Der Molen, S. B., and Broers, G. H. J., "NiO Cathode Dissolution and Long Term MCFC operation", Submitted to: Berichte Der Bunsengesellschaft Fur Physicalische Chemie, ECN-RX-90027 (1990).

11. "Molten Carbonate Fuel Cell Technology Improvement," International Fuel Cells Topical Report on DOE Contract No. DC-AC21-87MC23270, FCR-10823 (1990). 
12. Kunz, H. R., and Murphy, I. A., "The Effect of Oxidant Composition on the Performance of Molten Carbonate Fuel Cells", J. Electrochem. Soc., 135, No. 5, 1124-1131 (1988).

13. Merideth, A. E., and Tobias, C. พ. in, "Advances in Electrochemistry and Electrochemical Engineering," Vol. 2, C. W. Tobias, Editor, P. 15, Interscience, New York (1966) •

14. "Development of Improved Holten Carbonate Fuel Cell Technology," Prepared by Power Systens Division of United Technologies Corporation, Final Report on Electric Power Research Project 1085-4 (1983).

15. Ogawa, T., Oozu, B., Murata, R., and Shirogami, T., neduction of NiO Cathode Ioss in Molten Carbonate Fuel Cell with the Addition of Alkaline-Earth Carbonates," Denki Kagaku, 58, No. 4, 336-340 (1990).

16. Kunz, H. R., "Binary Electrolyte for Molten Carbonate Fuel Cells," U.S. Patent Number 4,591,538, May 27, 1986.

17. Yang, C., Takagi, R., Rawamura, R., and Okada, I., Electrochim. Acta, 32, 1607-1611 (1987). 
18. "Molten Carbonate Fuel Cell Development, "Final Report of Energy Research Corporation to the U. S. Department of Energy on Contracts DE-AC21-76ET11304, DE-AC03-76ET11304, EY-76-CO3-1196, and E-(04-3) 1196 (1987)

19. Kunz, H. R., and Bregoli, L. J., "Ionic Migration in Molten Carbonate Fuel Cells", The Electrochem. Soc., Proc. $90-2,221-222$ (1990) 


\section{TABIEE OF NOMENCIATURE}

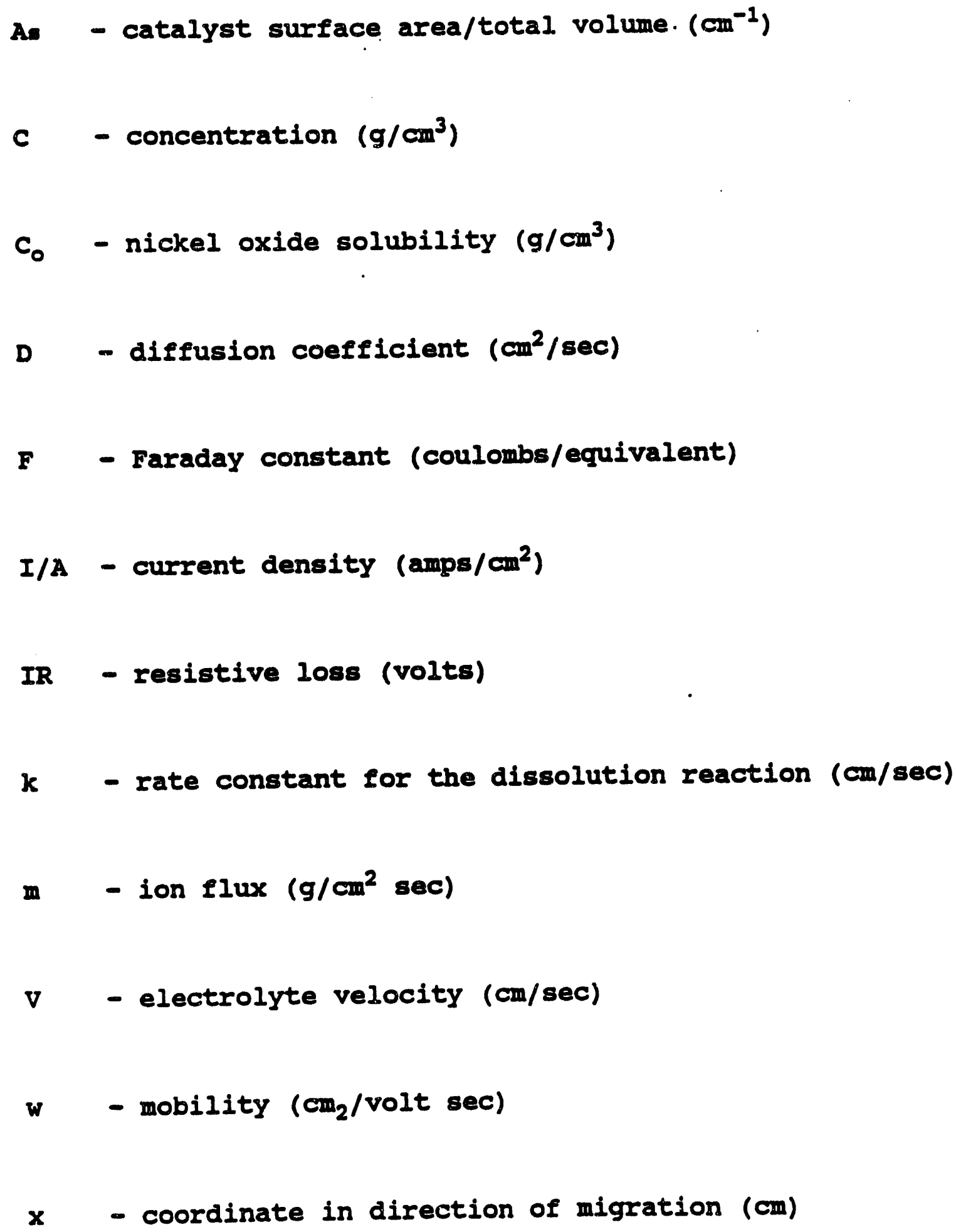


- valence

$\delta$ - cathode thickness (cm)

$\delta_{m}$ - matrix thickness (cm)

- - fraction of cathode cross-sectional area occupied by electrolyte

$\theta_{\mathrm{m}} \quad$ - matrix porosity

$\rho \quad-$ electrolyte density $\left(\mathrm{g} / \mathrm{cm}^{3}\right)$

$\tau \quad$ - tortuosit:y

$\tau_{m}$ - matrix tortuosity 
Table 1 - Test Gas Compositions and Utilizations

Fuel Gas

Designation

Oxidant Gas Designation

ROX-1

AOX-2

AOX -3

AOX -4

MCOD

WF-1

WF-2

\begin{tabular}{rrrrr}
\multicolumn{5}{c}{ Percentt } \\
\hline$H_{2}$ & CO & \multicolumn{1}{c}{$\mathrm{CO}_{2}$} & $\mathrm{~B}_{2} \mathrm{O}$ & $\frac{\text { Otilization }}{\left(\mathrm{H}_{2}+c 0\right)}$ \\
& & & & 56.78 \\
27.2 & 4.4 & 16.5 & 51.9 & 56.78 \\
29.5 & 5.5 & 17.5 & 47.5 & 19.78 \\
3.7 & 2.3 & 51.8 & 42.1 & \\
13.3 & 5.7 & 36.8 & 44.2 & 19.78
\end{tabular}

13.3

2.3

5.7

Percent

$\begin{array}{lllll}\Omega_{2} & \mathrm{CO}_{2} & \mathrm{~N}_{2} & \mathrm{H}_{2} \mathrm{O} & \frac{\text { Dtilization }}{\left(\mathrm{CO}_{2}\right)}\end{array}$

$\begin{array}{rcccc}9.1 & 18.1 & 65.1 & 7.7 & 30.0 \% \\ 9.9 & 89.9 & - & 0.2 & 5.5 \% \\ 13.6 & 31.9 & 54.3 & 0.2 & 15.6 \% \\ 1.0 & 98.8 & - & 0.2 & <9.08 \\ 33.3 & 66.7 & - & - & -\end{array}$

* Note: In shift equilibrium at $650^{\circ} \mathrm{C}$ 


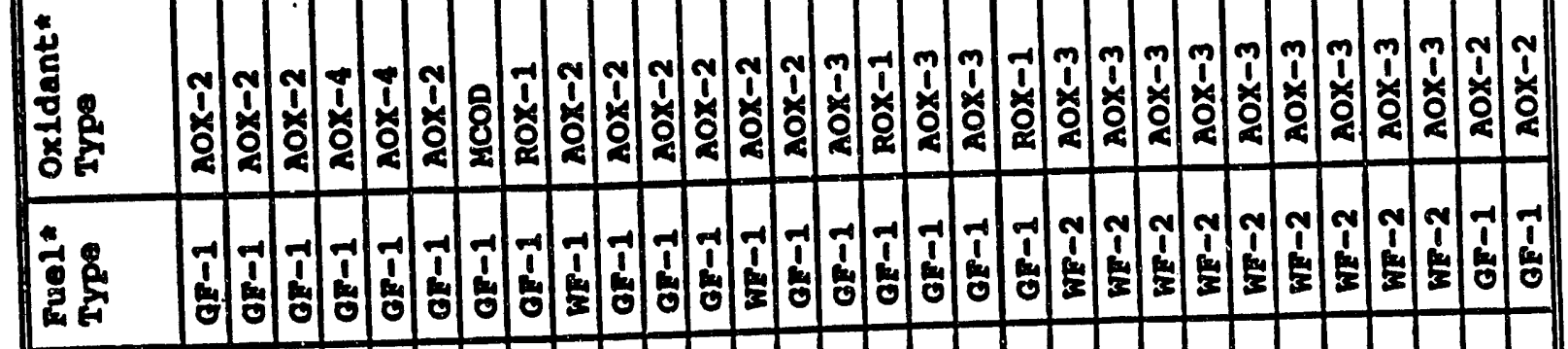

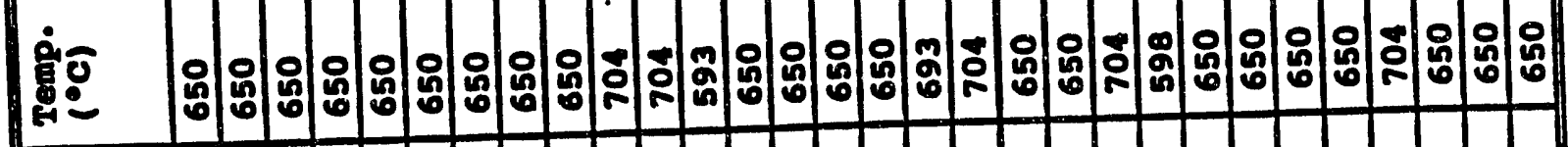

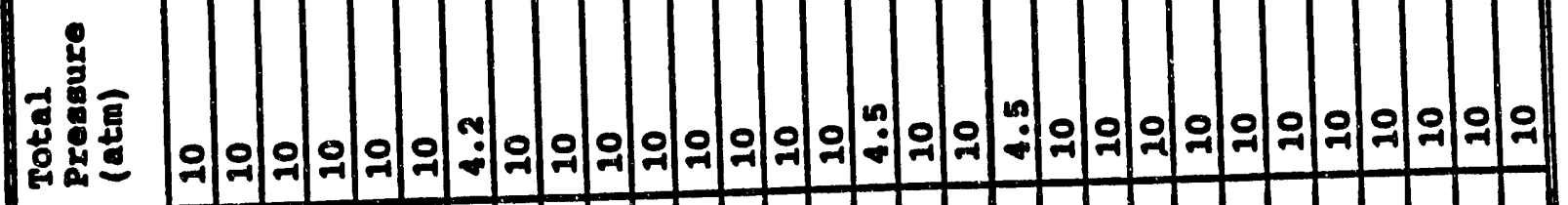

N

:

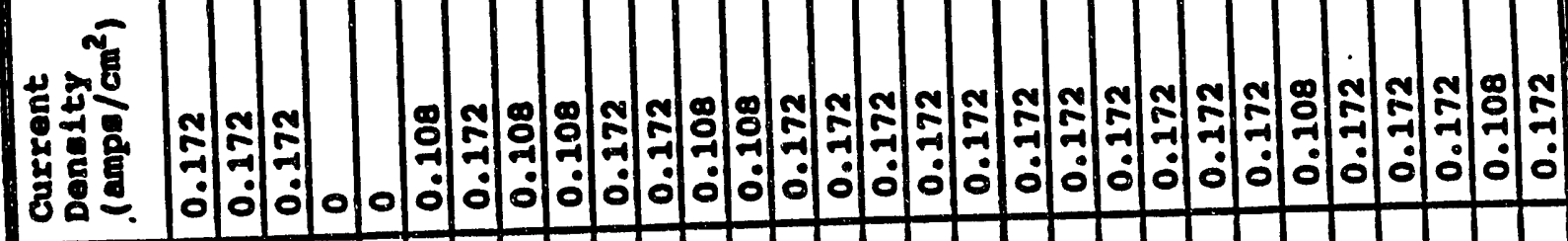

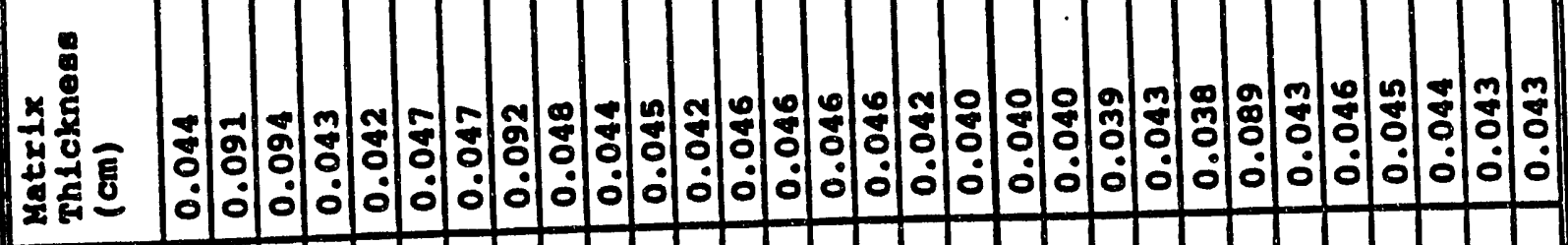

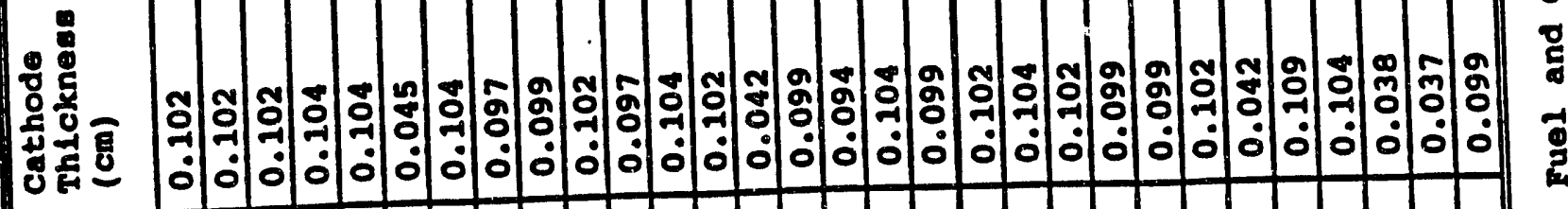

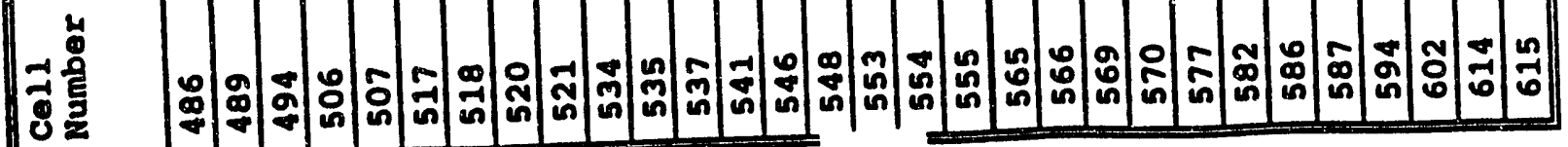




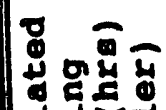

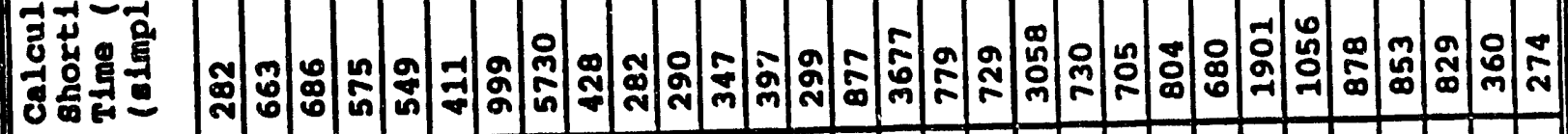

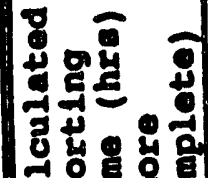

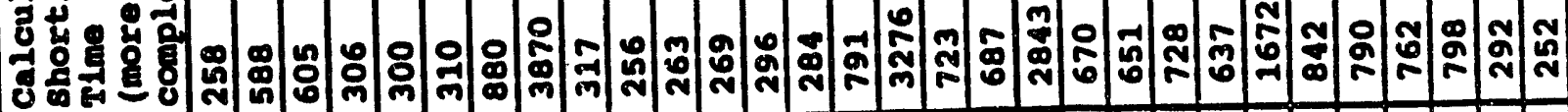

$8 g$

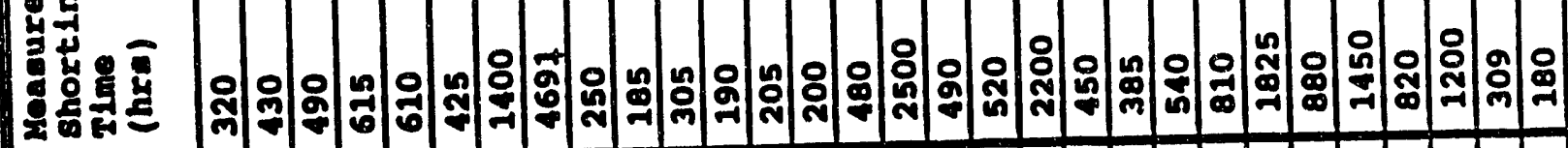

苟

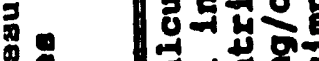

욱

$+8$

兽

疍量

훈도

\&

목

1 in

in ไै

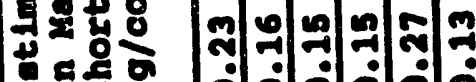

ต동 o

-

울

$+3$

म्षै土

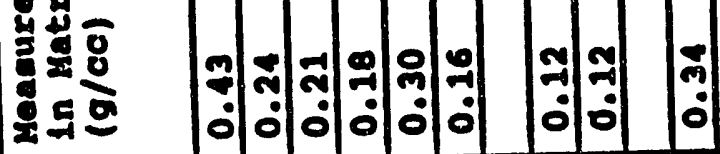

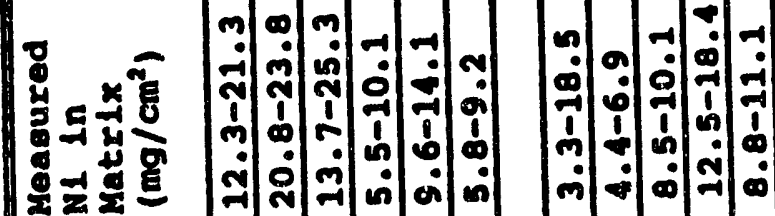

跣

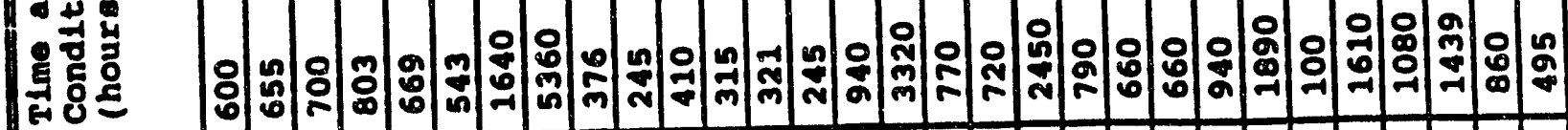

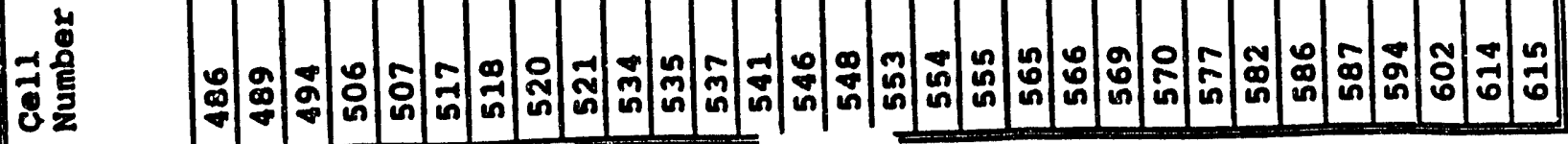




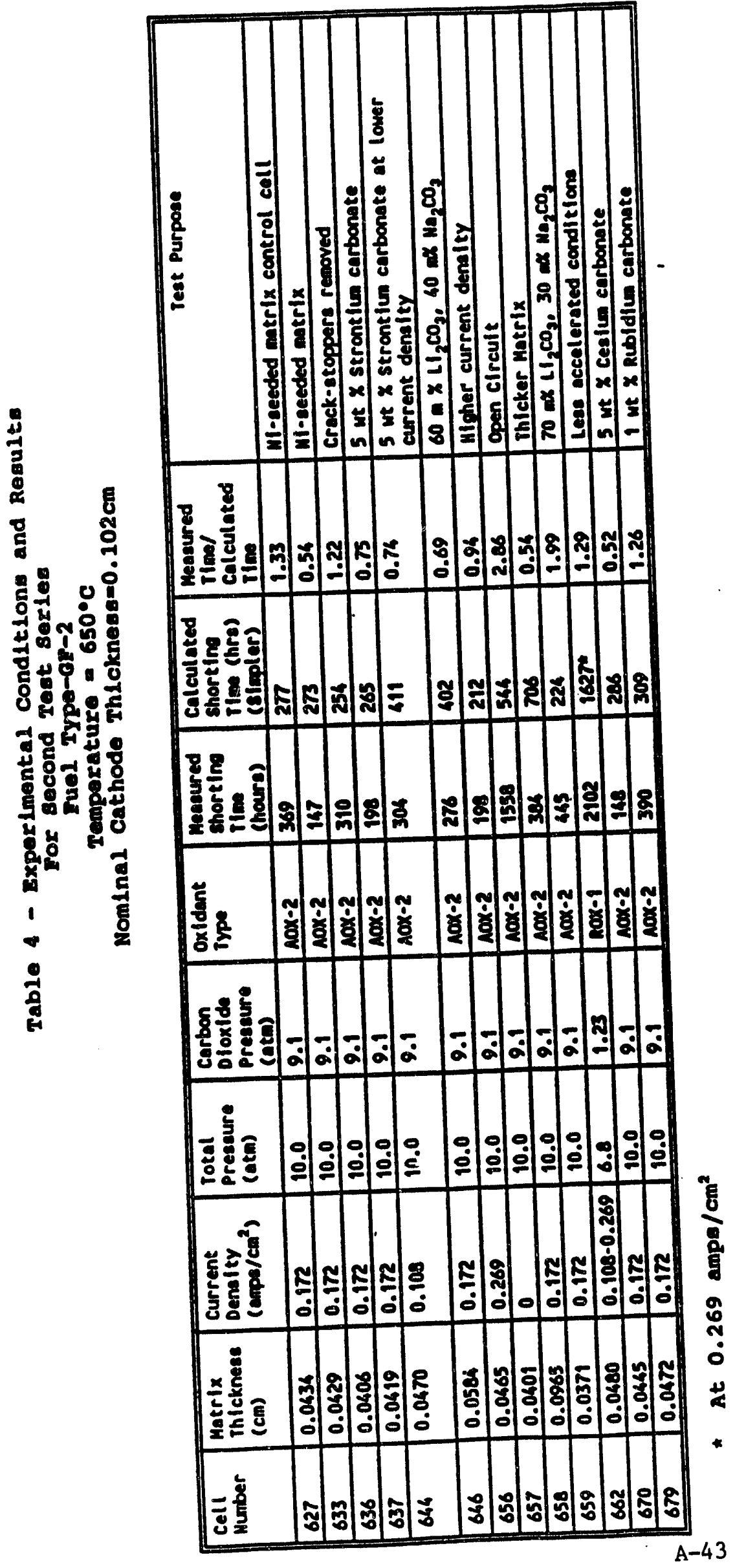




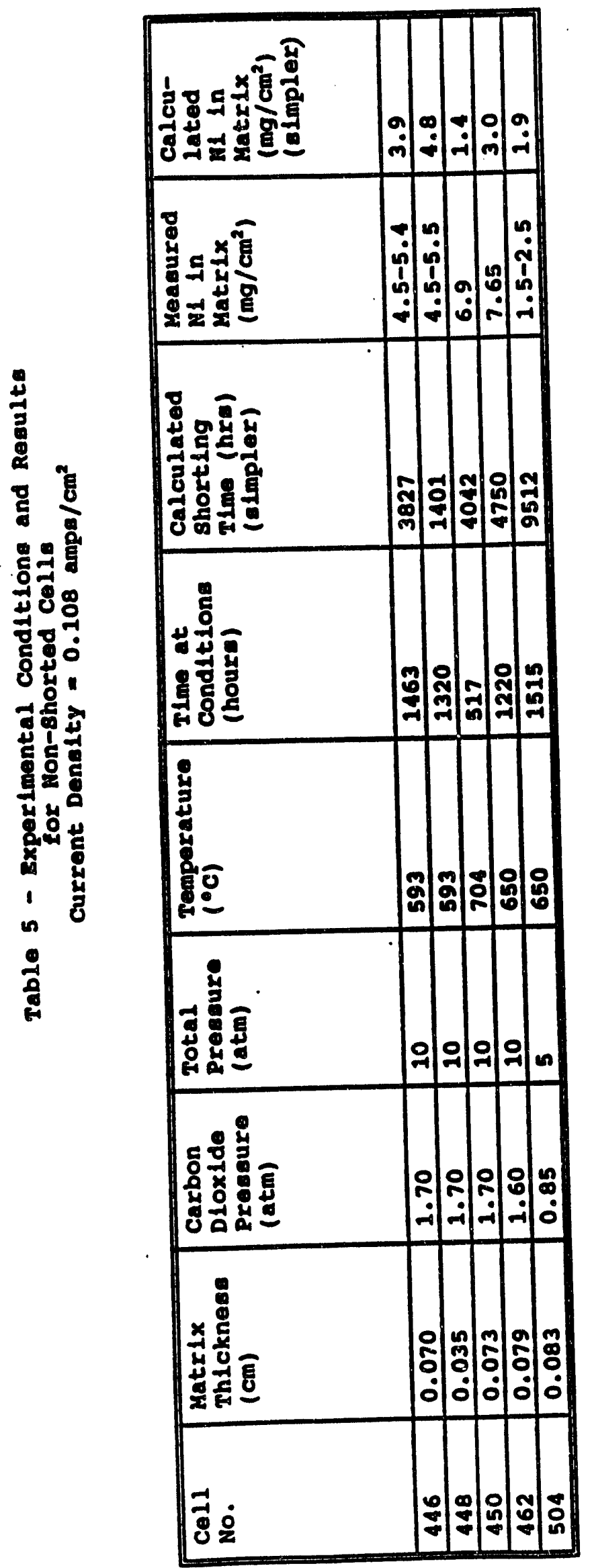




\section{Iist of Fiqures}

Figure 1

Microprobe Nickel Scan Through Cell No. 489 Matrix

Figure 2

Microprobe Nickel Scan Through Cell No. 507 Matrix

Figure 3

Microprobe Nickel scan Through Cell No. 520 Matrix

Figure 4

Comparison of More Complete Model With Data on shorting

Figure 5

Comparison of More Complete Model with Data on Shorting Showing Effect of Matrix

Figure 6

Comparison of More Complete Model With Data on Shorting showing Effect of Current Density

Figure 7

Comparison of More Complete Model With Data on Shorting showing Effect of Temperature

Figure 8 Comparison of More Complete Model With Data on Shorting showing Effect of Cathode Thickness 
Figure 9

Figure 10

Figure 11

Figure 12

Figure 13

Figure 14

Figure 15

Figure 16
Comparison of More Complete Model With Data on Shorting Showing Effect of $\mathrm{CO}_{2}$ Pressure

Comparison of More Complete Model with Data on Shorting Showing Effect of Oxidant Type

Comparison of More Complete Model with Data on Shorting Showing Effect of Fuel Type

Comparison of Simpler Model with Data on shorting

Comparison of Calculated Results of Two Models Showing The Effect of Current Density

Comparison of Simpler Model With Data on Matrix Nickel Content

Effect of Current Density on Shorting Time Estimated Shorting Time Using Simpler Model 


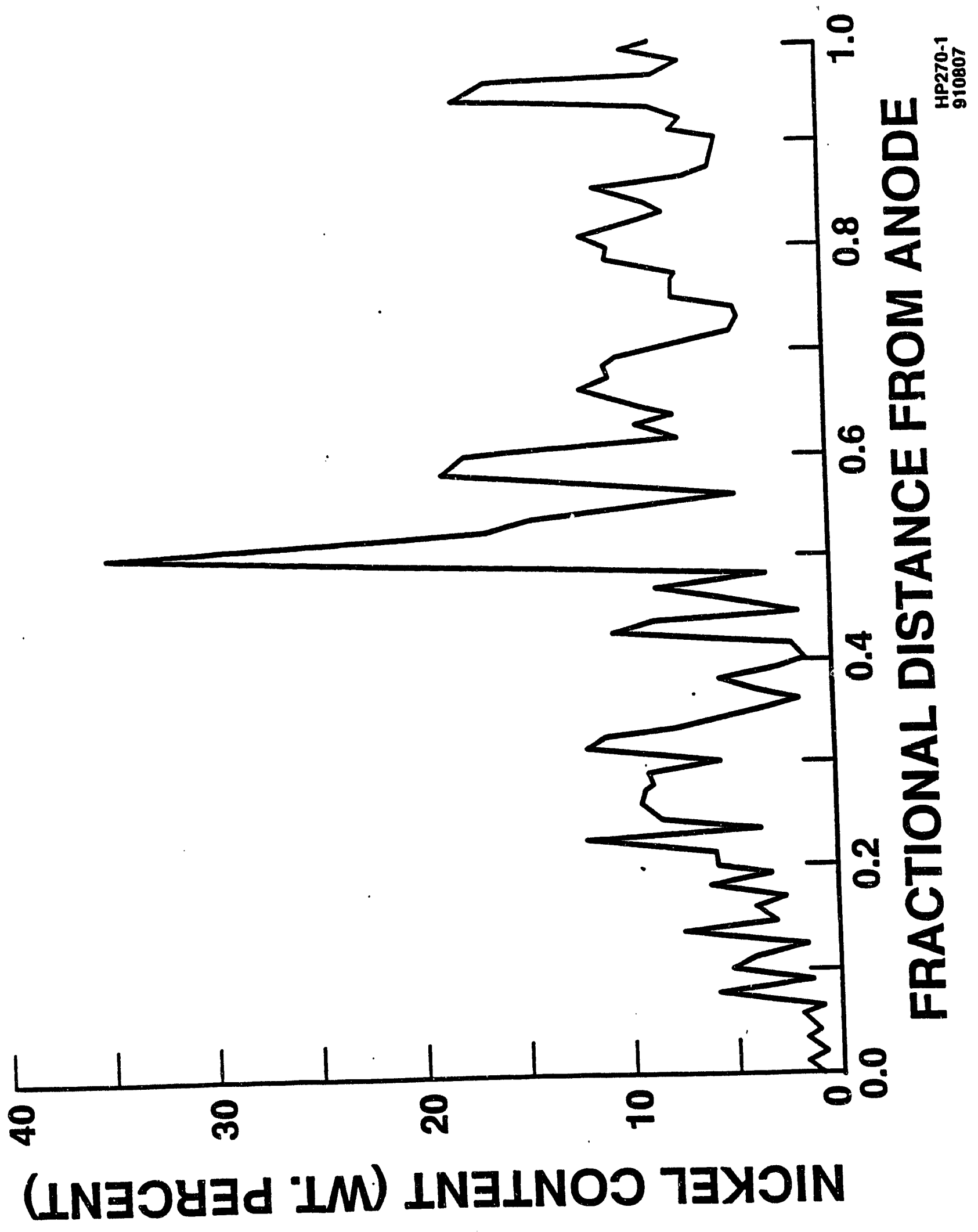




$$
\text { Figure }
$$
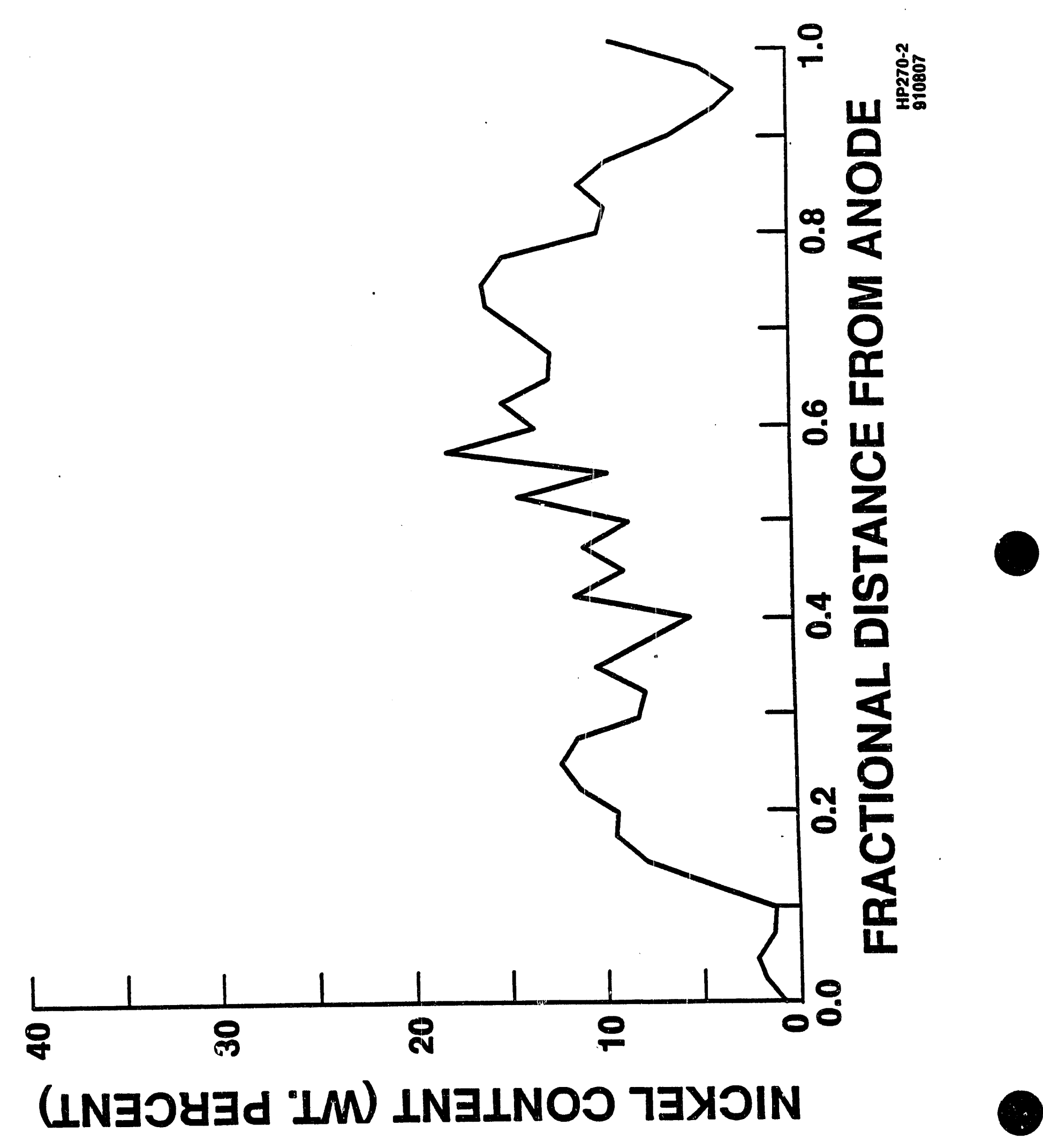


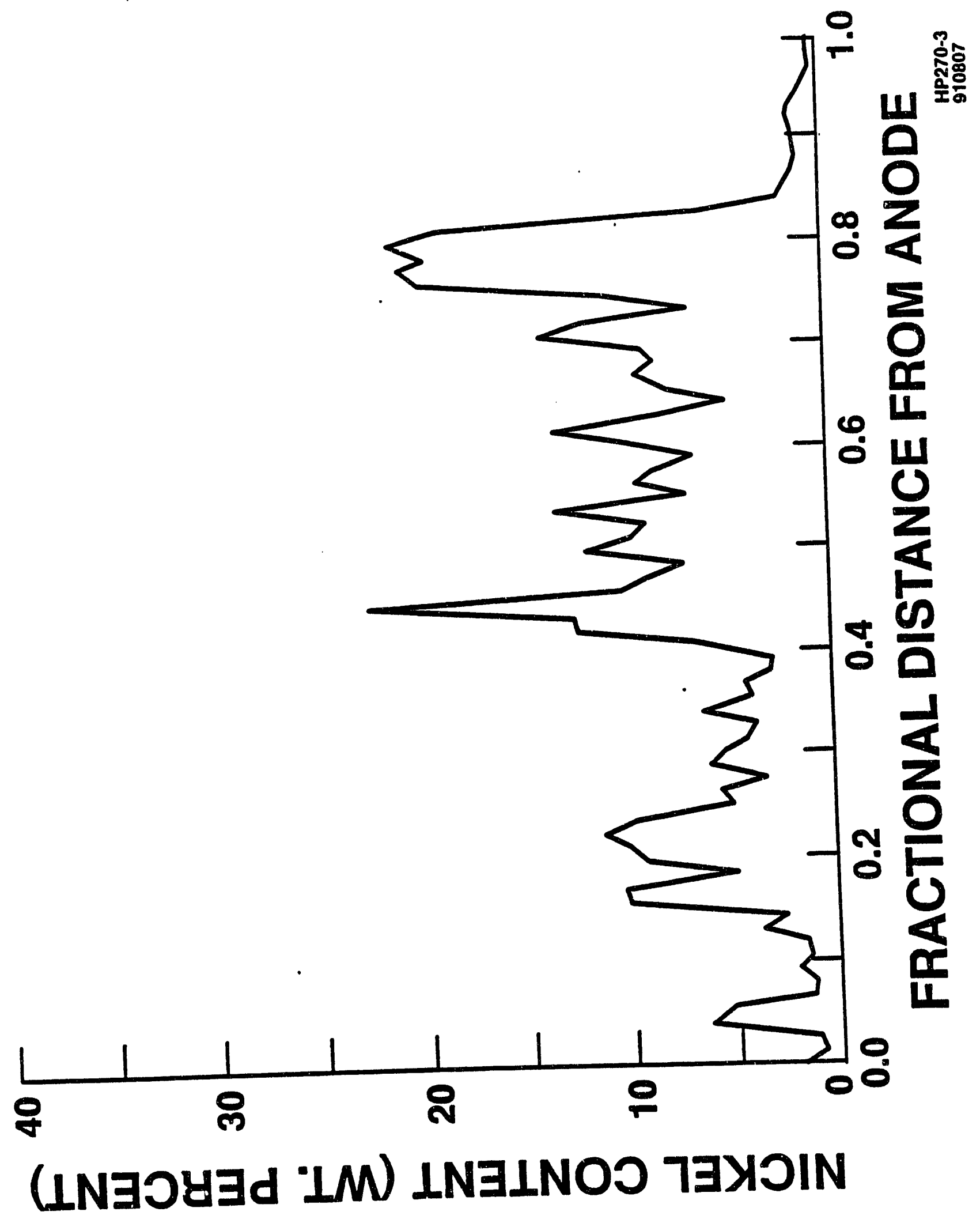




$$
\text { Figur }=4
$$

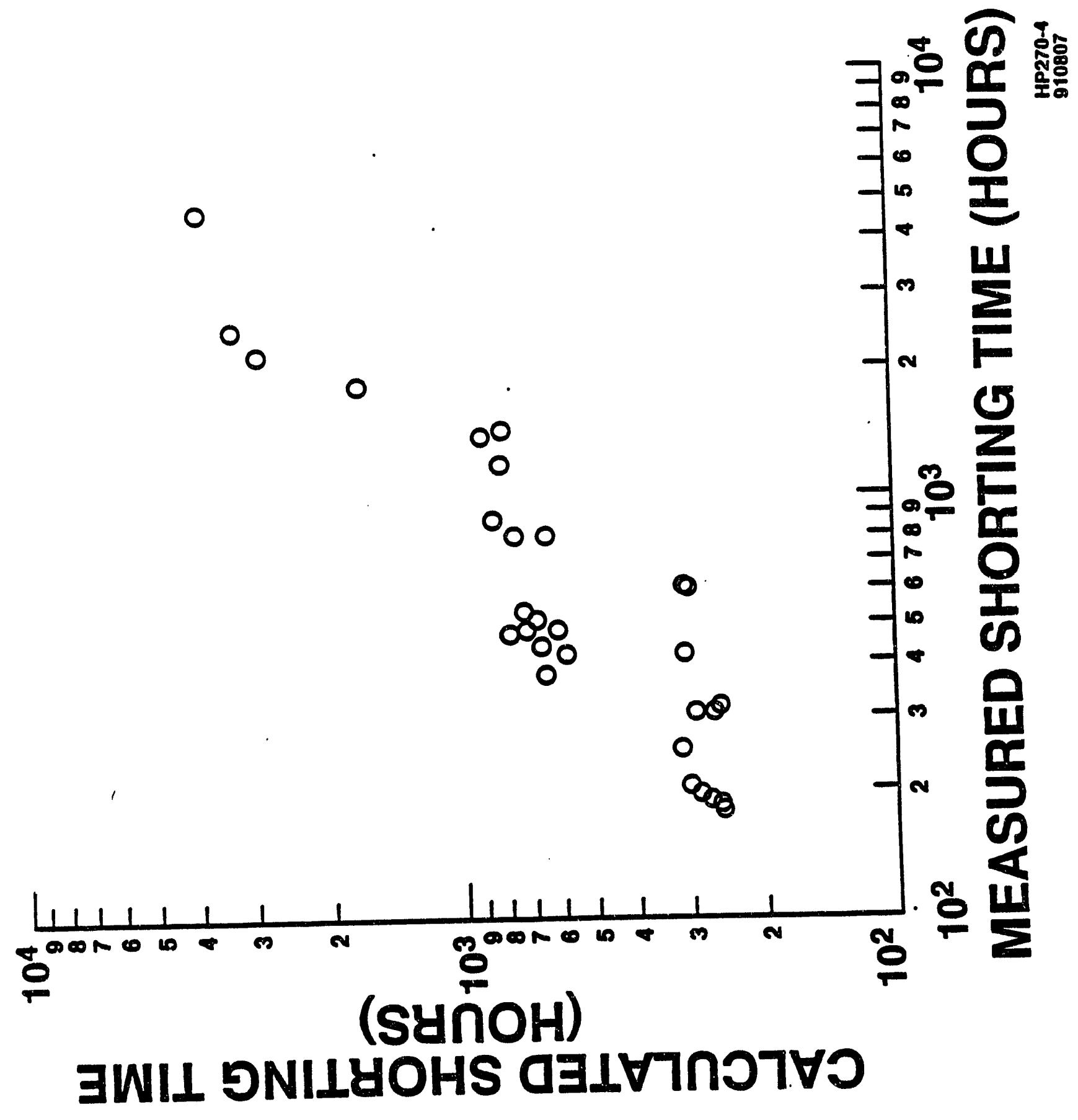


Figure=

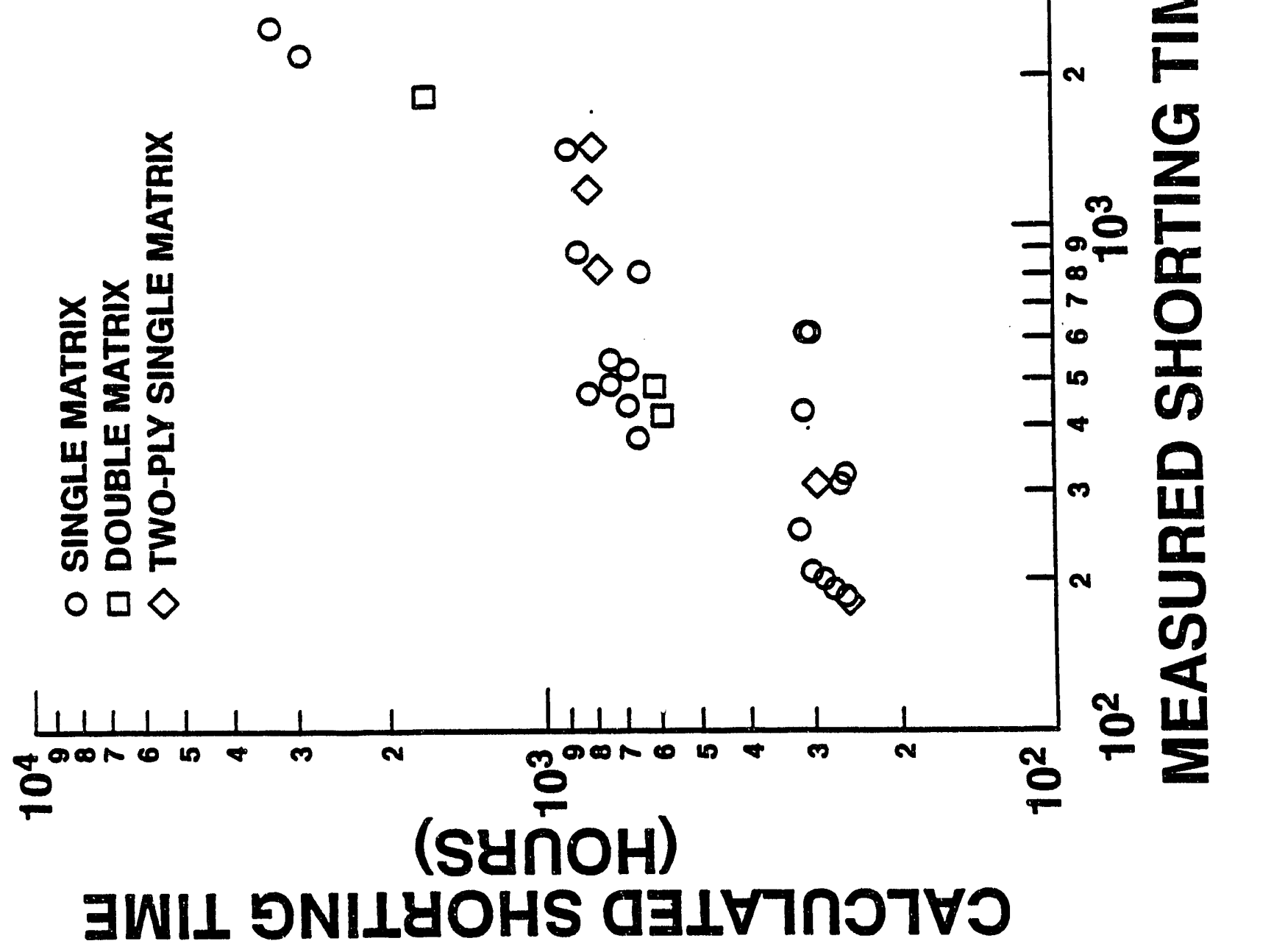


Figure 6

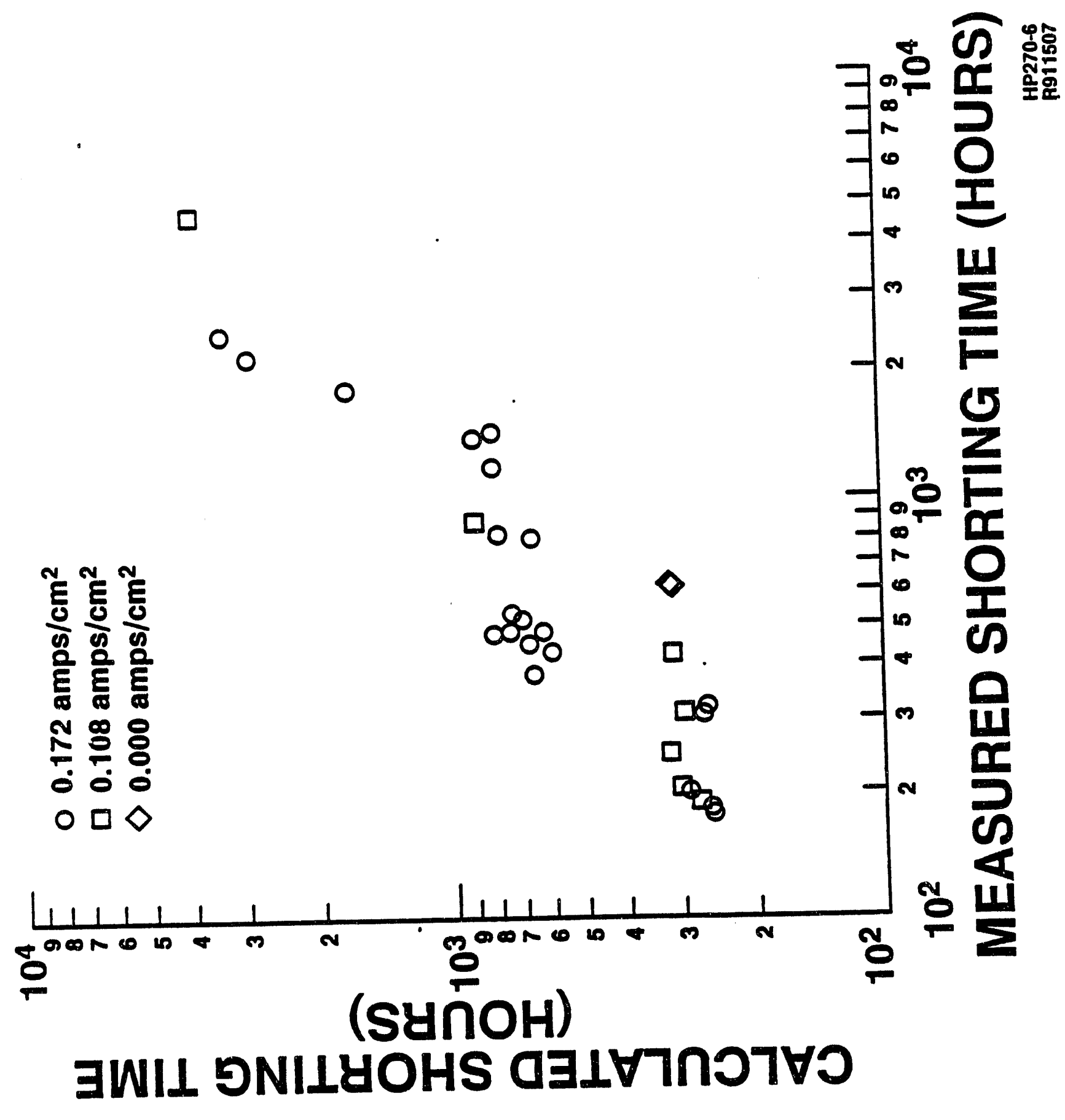




$$
\text { Figure }
$$

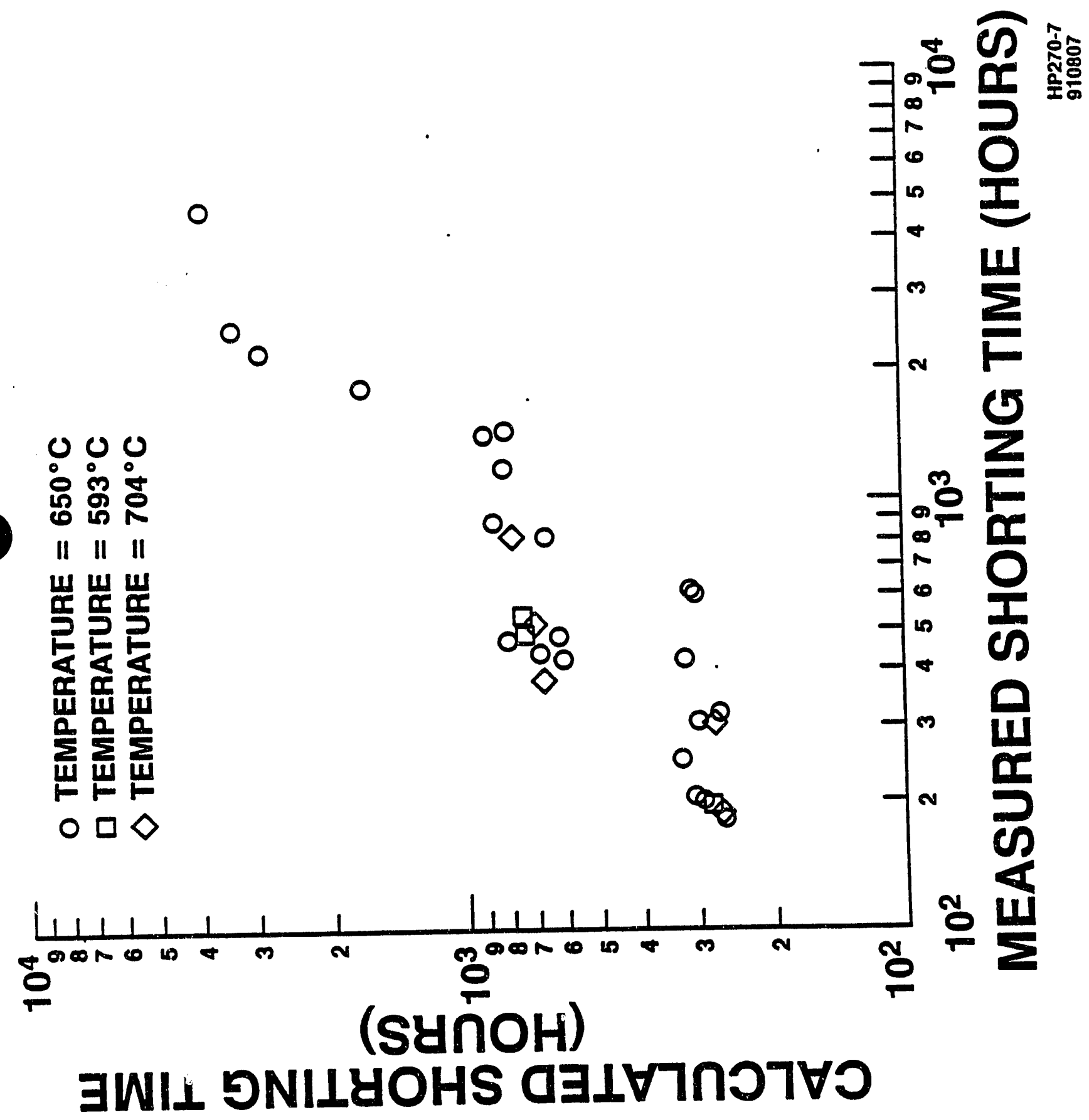




$$
\text { Figure } 8
$$

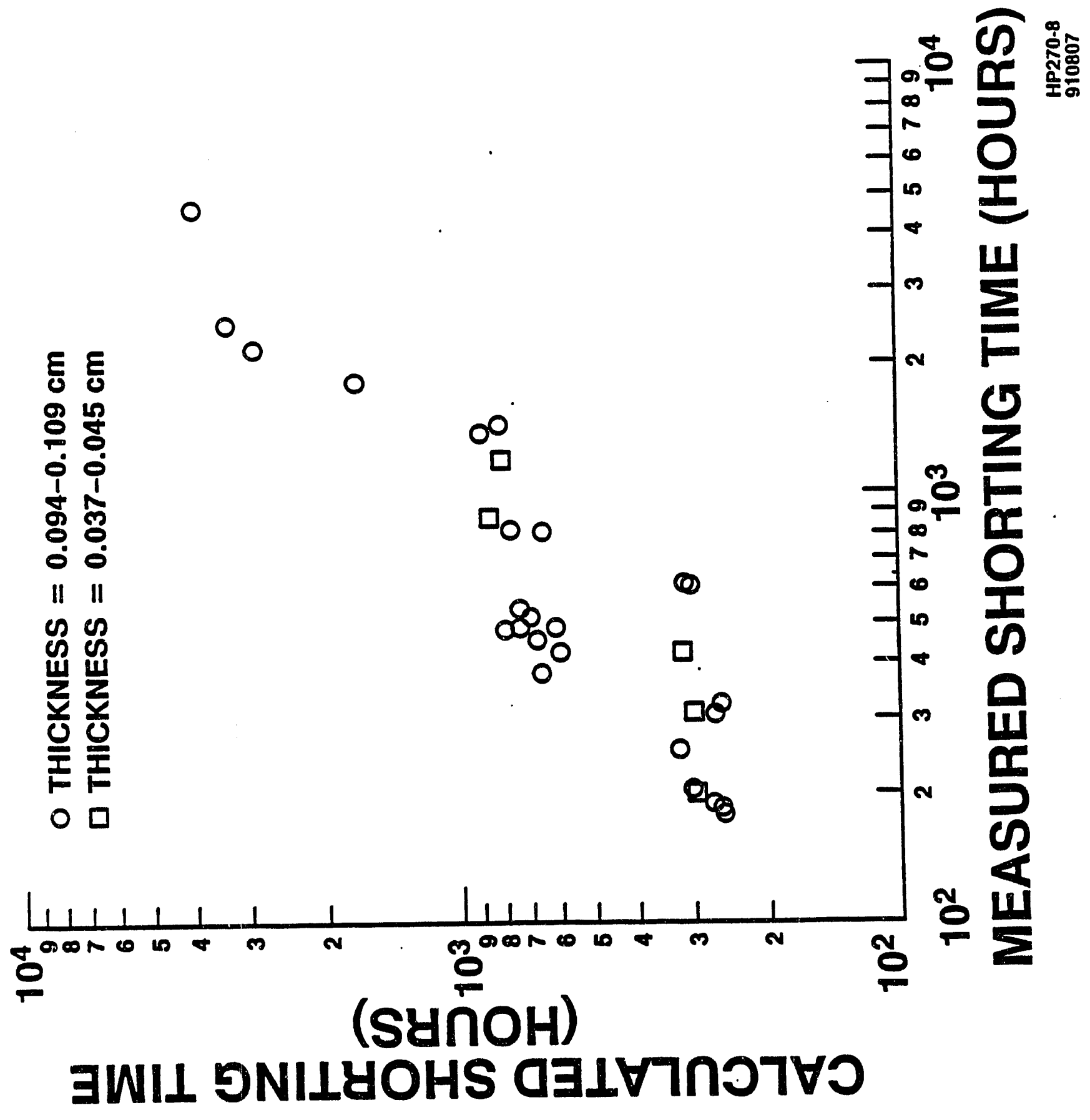




$$
\text { Figure }
$$

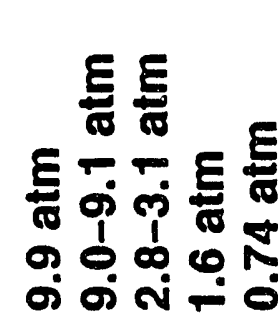

|| || || || ||

山山山ш山

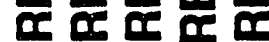

๘

ผ

III II II II

$\alpha \tilde{\alpha} \boldsymbol{\alpha} \alpha$

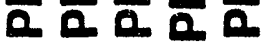

กิ์ พิ์

ช0 000

$0 \square \diamond \triangleleft$ $\diamond$

(1)

多

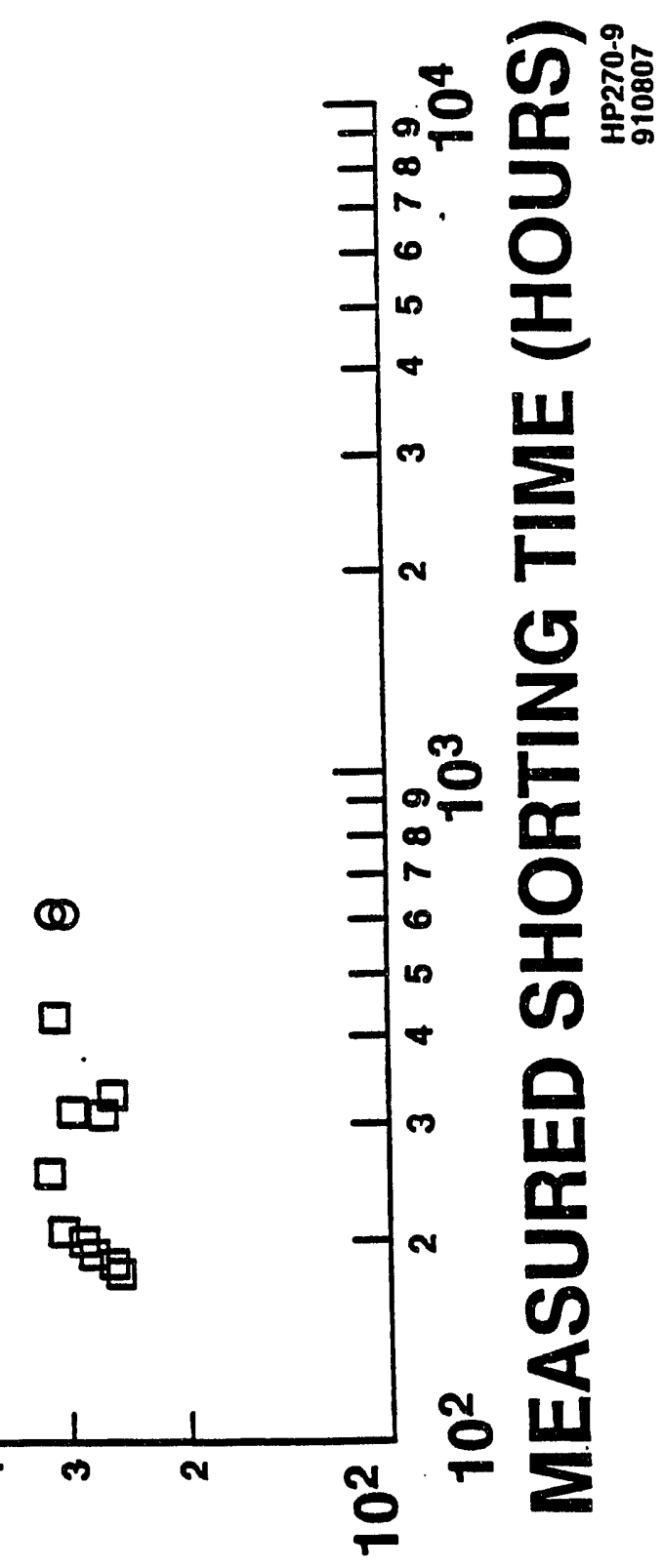

(Syก̃oH)

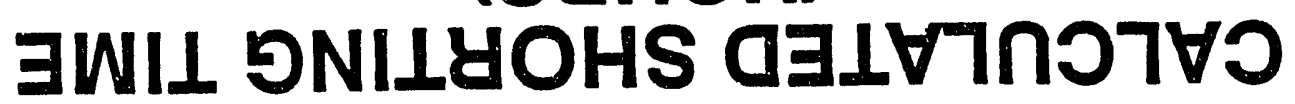




$$
\text { Figure } 10
$$

$\checkmark$

$\checkmark$
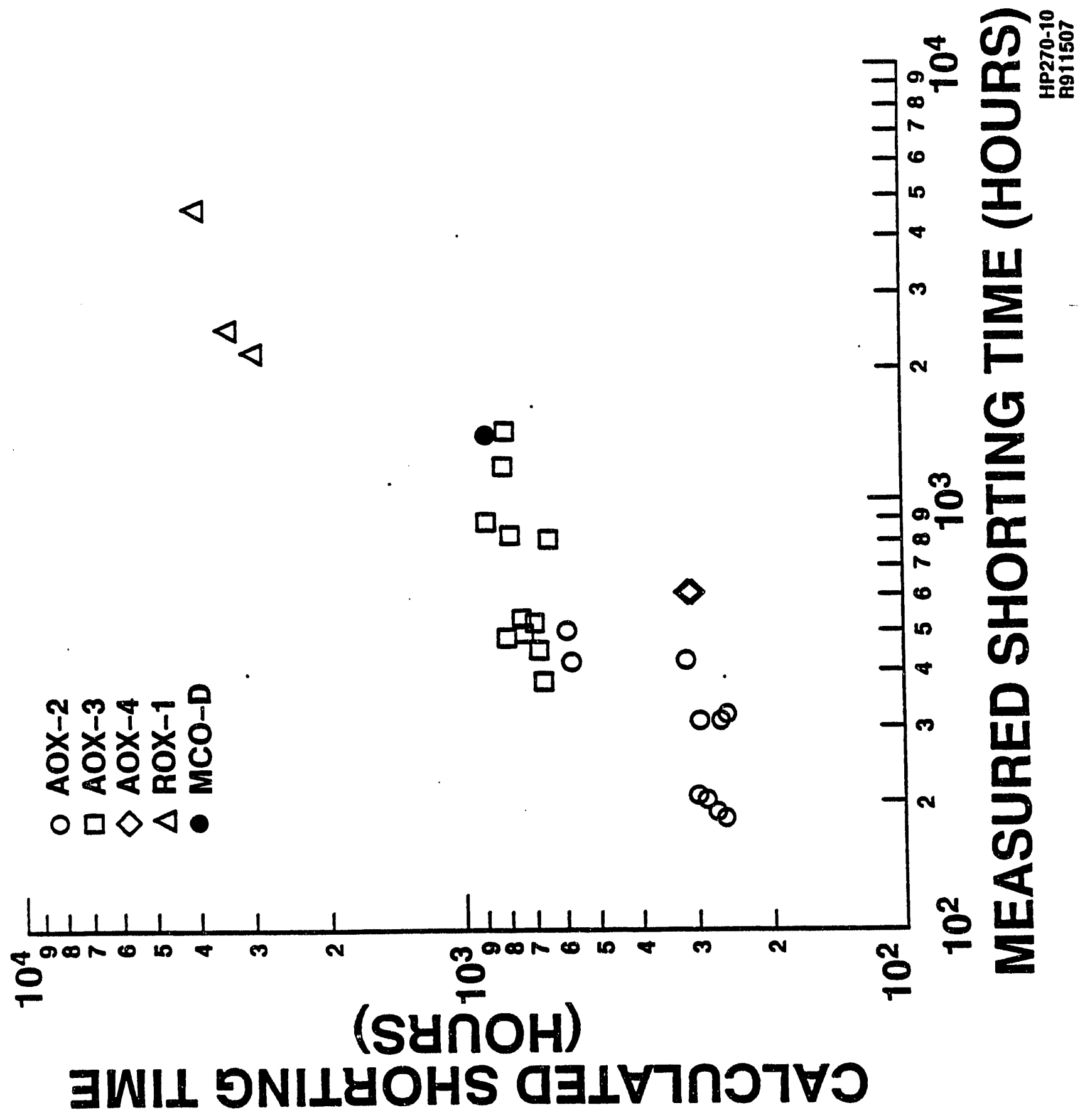

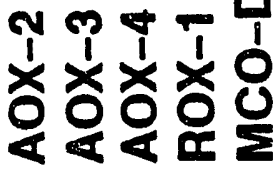

$\square \square \square$ 


$$
\text { Figure } 11
$$

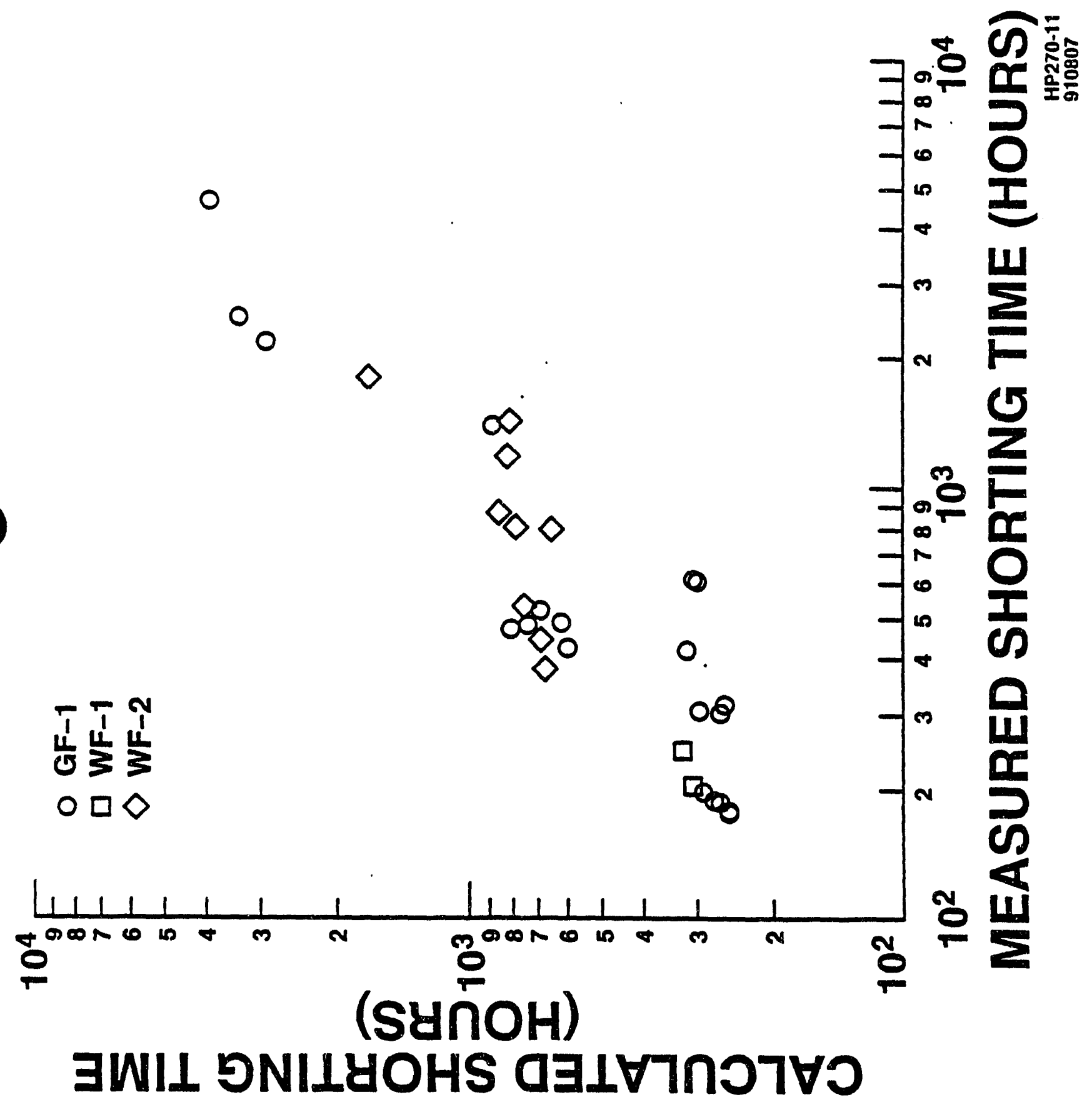




$$
\text { Figure } 1 \geq
$$

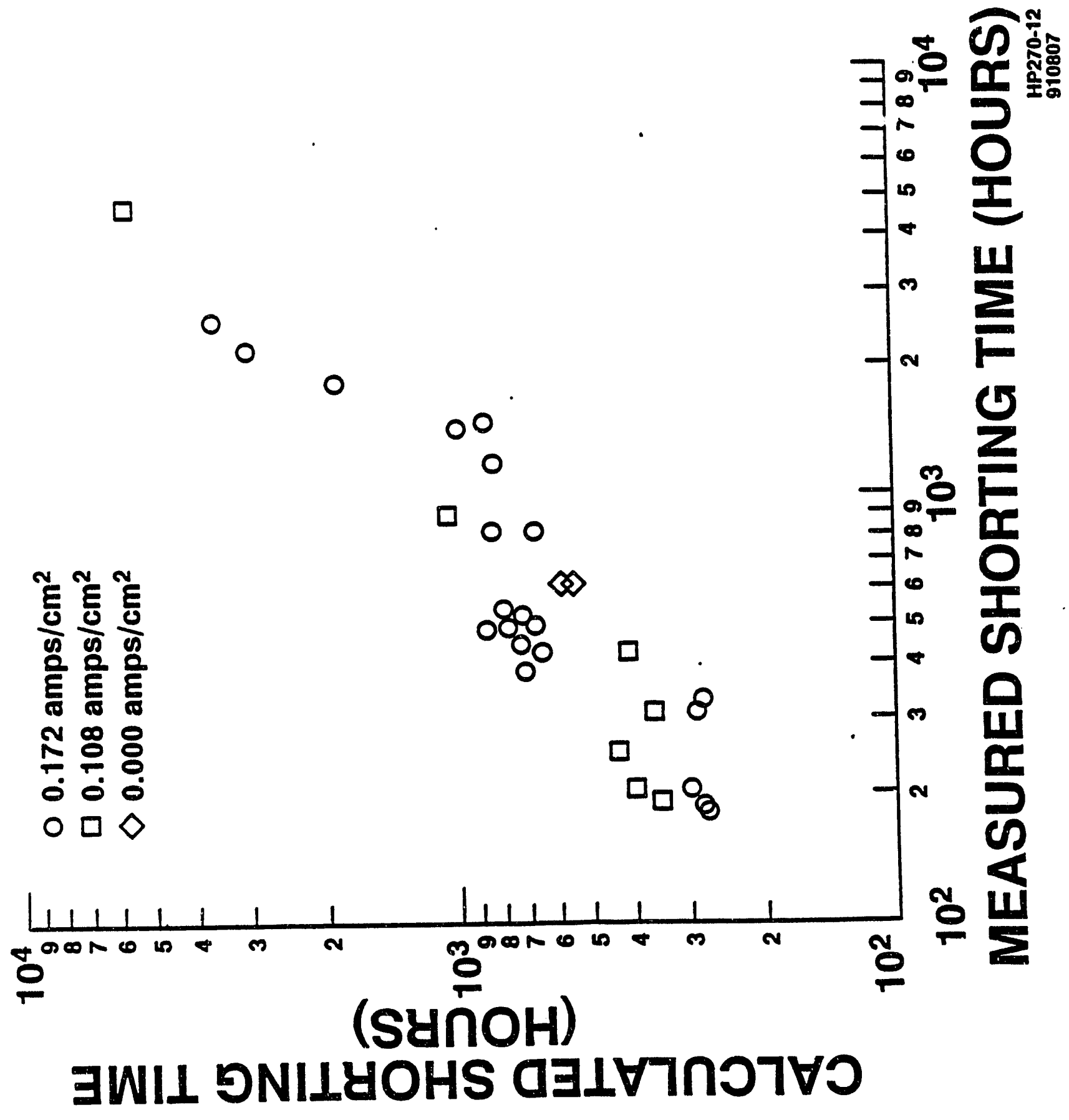


Figure $1 \Xi$

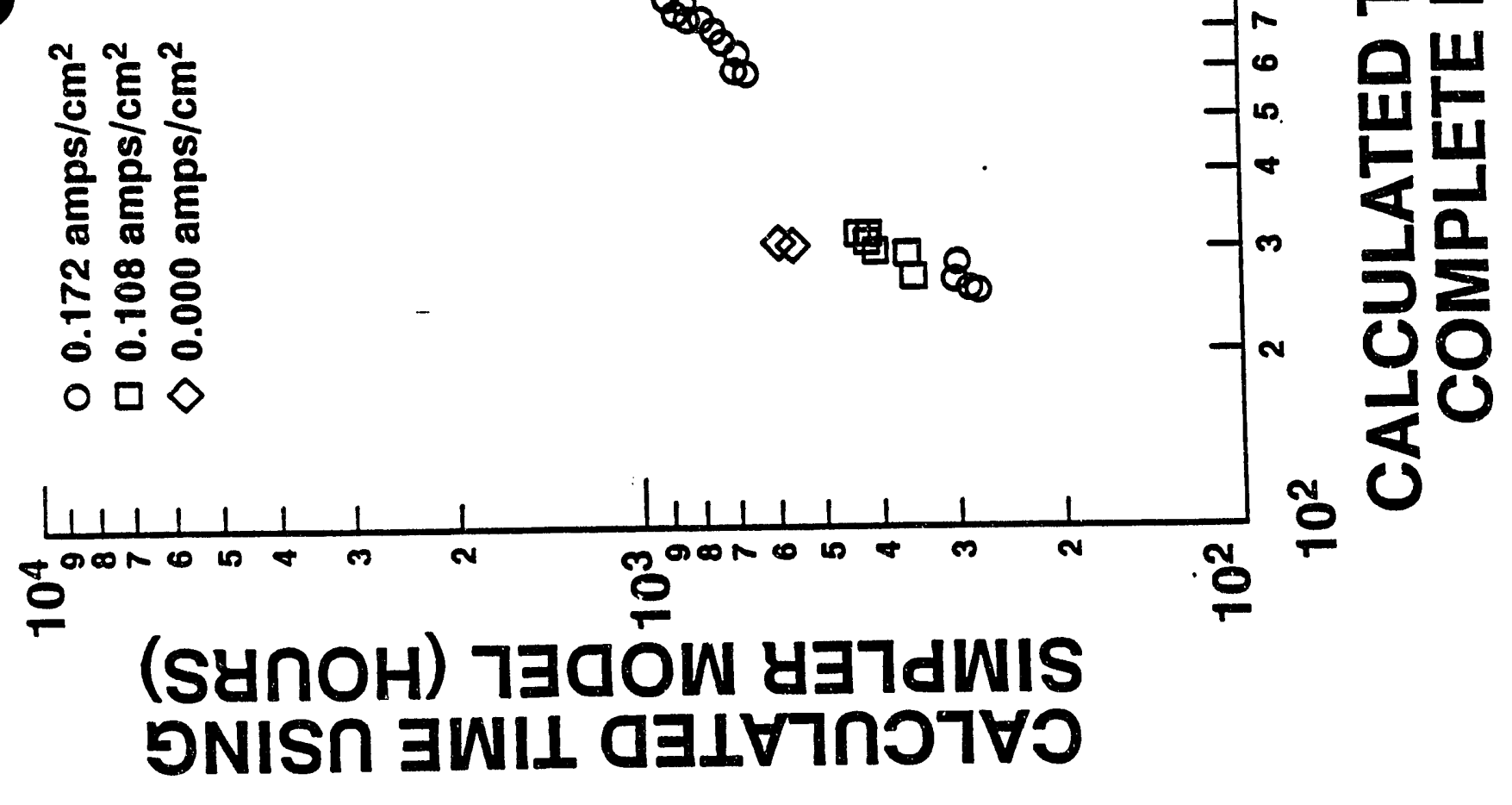




$$
\text { Figure } 14
$$

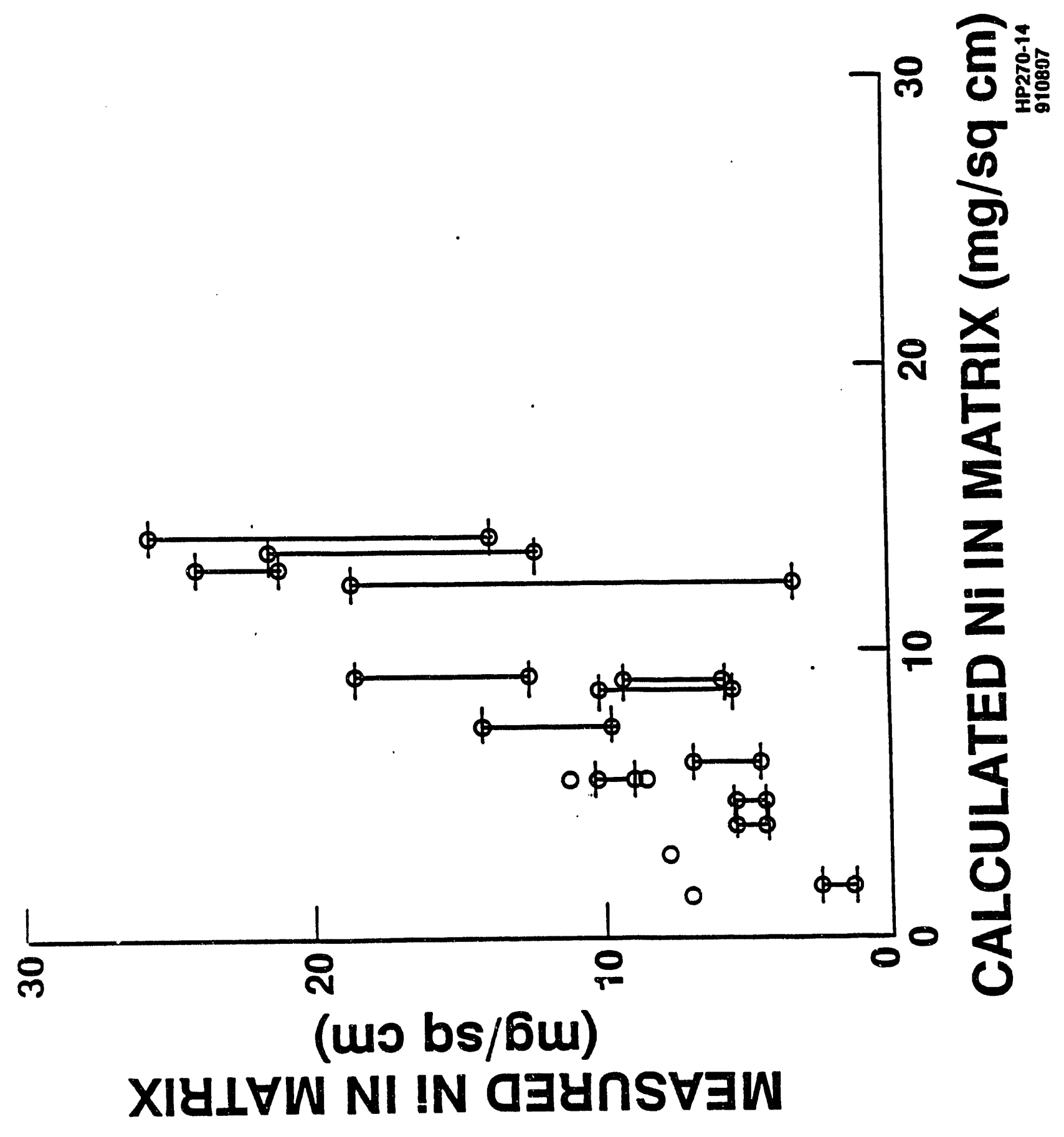


Figure $1 \equiv$

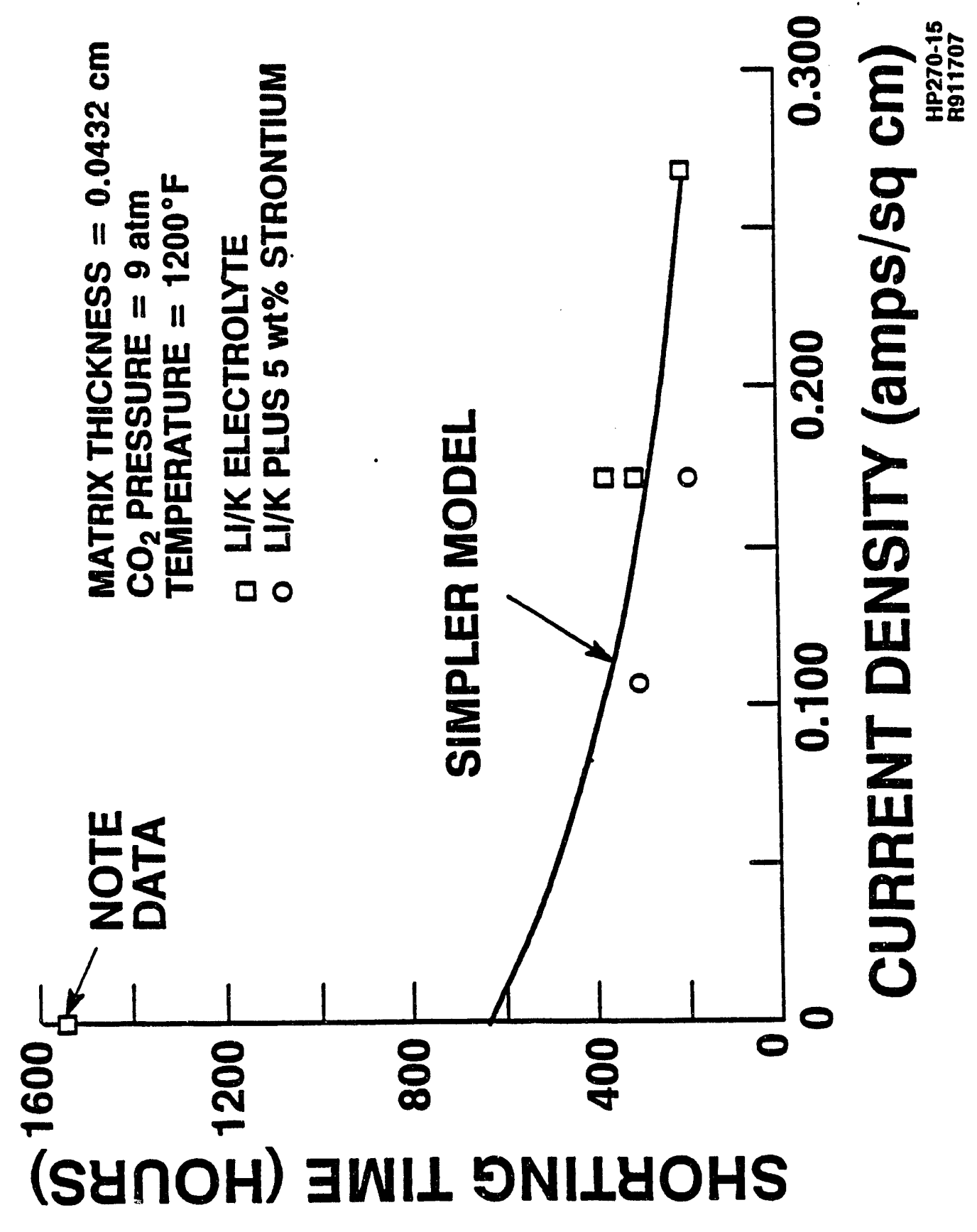




$$
\text { Figure } 16
$$

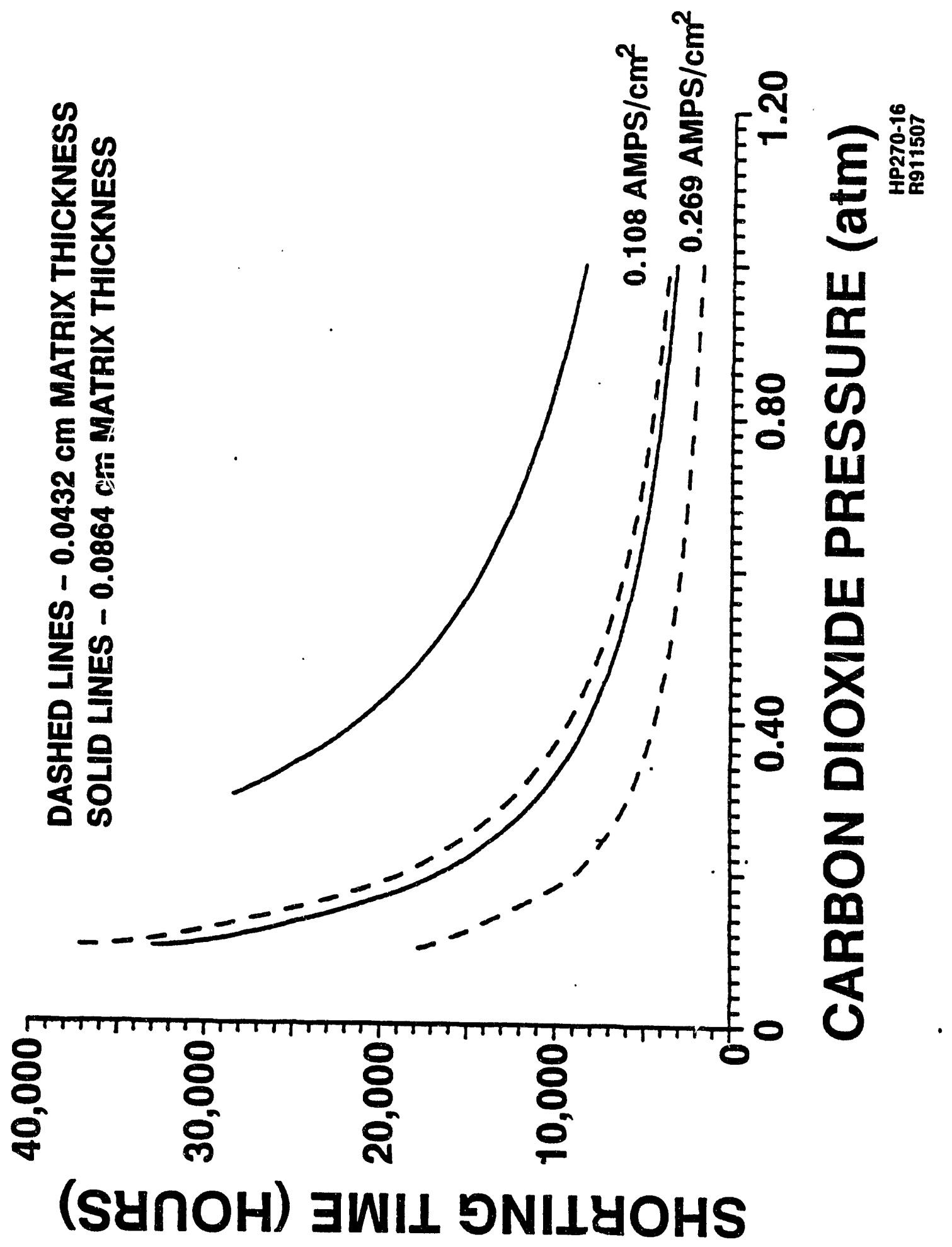




\section{APPENDIX B}

VARIABILITY IN NICKEL OXIDE CATHODE DISSOLUTION IN MOLTEN CARBONATE FUEL CELLS 
Variability in Nickel Oxide Cathode

Dissolution in Molten Carbonate Fuel Cells

\author{
H. R. Kunz \\ International Fuel Cells Corporation \\ South Windsor, CT 06074
}

\title{
SUMMARY
}

Asurvey was made of experimental data on the nickel content in post-test matrices of fuel cells using mixtures of lithium carbonate and potassium carbonate as the electrolyte. Each of the sets of experimental data was found to show similar trends of nickel content with experimental operating conditions. Hlowever, the levels of nickel content were found to vary by a factor of about 20 between the extremes. This large variability is suspected to be caused by differences in cell design and electrolyte composition.

\section{BACKGROUND}

Lithiated nickel oxide cathodes that are presently used in molten carbonate fuel cells have been found to dissolve in the electrolyte and result in the deposition of metallic nickel in the cell matrix (1) This nickel deposition can result in an electronically conducting bridge between the electrodes and degrade cell performance. Structural deterioration of the cathode can also occur due to loss of material. Because this dissolution is potentially one of the most severe modes of performance decay, numerous experiments have been performed to define the severity of this problem, clarify the mechanisms controlling this process, and evaluate potential solutions.

Subscale cell tests' have been performed to determine the effects of cell operating conditions, electrolyte composition, and cell design on the amount of nickel oxide deposited in the matrix ${ }^{(1-n)}$ The solubility of nickel oxide has been measured as a function of electrolyte composition, gaseous environment, and temperature.(8-12) Although some variability in these solubilities exists, reasonably good agreement was found for mixtures of lithium carbonate and potassium carbonate near the common fuel cell operating temperature of $650^{\circ} \mathrm{C}$. The primary specie formed in solution when nickel oxide dissolves in the fuel cell is considered to be the $\mathrm{Ni}^{+2}$ ion, since the solubility of nickel oxide was found to be proportional tc the carbon dioxide partial pressure and independent of the oxygen partial pressure in the range of interest.

\section{MECHANISMS}

Several processes are involved in the migration of nickel from the cathode. These can be categorized into three main steps - dissolution, migration, and deposition. The following sections contain descriptions of these processes. 
Dissolution - The kinetics of the dissolution step are unknown. Variation of the carbon dioxide partial pressure and electrolyte potential within the cathode can result in a solubility that varies with location within the cathode. Nickel oxide redistribution within the cathode can then occur as well as migration into the matrix.

Migration - Three mechanisms exist for the migration of nickel into the matrix. First, since the solubility of nickel is virtually zero at the anode potential, a concentration gradient exists that results in the diffusion of nickel ion toward the anode. Secondly, because of the positive charge on the nickel ion, the potential gradient in the cell matrix tends to retard the ion's migration toward the anode. Finally, convection is present because of the flux of carbonate ions toward the anode associated with the fuel cell reactions. ${ }^{(13)}$

The importance of diffusion is discussed in Reference (1). Since the solubility increases with the carbon dioxide partial pressure and the diffusion path length increases with matrix thickness, the amount of nickel in the matrix was correlated with the product of the carbon dioxide partial pressure and the time divided by the matrix thickness.

Because of the positive charge of the nickel ion, the rate of nickel migration would be expected to be reduced as the current density of the cell increases. However, the opposite effect was found.(9) Less nickel was found in the matrix after open circuit operation than after a period in which current was flowing; and the time at which shorting occurred in a cell was found to decrease as the current increased. Reference (9) explained this current effect as possibly due to a segregation of the lithium and potassium ions in a cell with current flow and an effect of the electrolyte composition on the nickel oxide solubility. However, data on these phenomena were not available at the time to obtain an appropriate interpretation.

The third migration mechanism, convection, would result in an increase of nickel content in the matrix and a reduced shorting time when the fuel cell is providing current.

Peposition - Nickel can deposit in the matrix either as nickel oxide or metallic nickel depending on the local conditions in the matrix. The solubility of nickel oxide can be exceeded due to gradients in electrolyte composition and carbon dioxide content through the matrix. ${ }^{(8)}$ Nickel oxide has been found to be deposited near the cathode surface. (9) Metallic nickel can plate out if the diffusion of the fuel cell reactants into the matrix results in a sufficiently reducing environment.(1) Metallic nickel has been found to have the highest concentration typically in the central region of the matrix with some migrating all the way to the anode. ${ }^{(14)}$ The kinetics of these two deposition processes are unknown. Because of the particulate nature of metallic deposits found in matrices, a nucleation process may be important.(1) 


\section{MODELING}

Modeling of the migration of nickel has been performed. $(1,2,4,15)$ These models have resulted in some success in correlating data on the amount of nickel deposited in matrices. The model of Reference (2) accounted for the dissolution, diffusion, transference and convection processes and was compared with cell data on both matrix nickel content and shorting time.

The experimental data used in the development of this model were cbtained using bench-scale cells of approximately $80 \mathrm{~cm}^{2}$ active area in two series of tests. (2) In the first series, matrix thickness, cathode thickness, current density, operating temperature,oxidant composition and fuel composition were varied. The tests were accelerated by operating the cells at elevated pressures using oxidants high in carbon dioxide content, as high as 9.9 atmospheres. The validity of such an accelerated test method was checked by selecting a few sets of conditions at which the shorting time was extended to as long as 4691 hours.

All cells were started and operated at near atmospheric pressure for a few hundred hours until the performance could be adequately documented. The open circuit voltage was measured and compared to the theoretically calculated value. In general, these two voltages were within a few millivolts of one another, indicating that little reactant crossover or electronic shorting was present between the electrodes at the start of the test.

The cells were set at the operating conditions of the accelerated test and maintained at these conditions until the open circuit voltage declined by $10 \mathrm{mV}$. The open circuit voltage was monitored daily and provided a continuous trend with time. When the open circuit voltage declined by $10 \mathrm{mV}$, the cell was assumed to have developed an internal electronic short circuit through the matrix. Although the $10 \mathrm{mV}$ criterion was arbitrary, once the open circuit voltage declined by this amount a further rapid decline ensued. The electronic resistance of each cell was measured as the cell cooled to below the electrolyte solidification temperature on shutdown to ensure that an electronic short was the cause for the decline in open circuit voltage. Samples of matrices were removed from the cells and analyzed for nickel content through the matrix using a scanning electron microprobe, in general at two in-plane matrix locations.

A comparison of the experimental data on shorting time with theoretical predictions using the model of Reference (2) is shown in Figure 1. These predictions use a diffusion coefficient of $10^{-5} \mathrm{~cm}^{2} / \mathrm{sec}$ for the nickel ion and a dissolution rate constant of $5 \times 18^{-8} \mathrm{~cm} / \mathrm{sec}$ for nickel oxide. The effects of matrix thickness, cathode thickness, and cathode oxidant composition on shorting time at a current density of $0.172 \mathrm{amps} /$ $\mathrm{cm}^{2}$ were found to be predicted with a mean error of 17 percent and a standard devi- 
ation of the error of 34 percent. No effects of temperature and fuel composition were found. Although the trend of increasing shorting time with decreasing current density was present in both the data and theory, the experimental increase was much larger than the predicted.

To obtain a better comparison with respect to the effect of current density, semiempirical equations for matrix nickel content and shorting time were developed assuming that the dissolution reaction occurred very quickly. These equations are:

$$
\text { Shorting Time }(h r s)=\frac{11,600\left(d_{m}\right)\left(1-e^{-266 d_{m}(I / A)}\right)}{P_{C_{2}}(I / A)}
$$

for the shorting time and

$$
\text { Content }\left(\mathrm{g} / \mathrm{cm}^{2}\right) \frac{0.146\left(\mathrm{~d}_{\mathrm{m}}\right) \text { (Time at Conditions) }}{\text { Shorting Time }}
$$

for the matrix nickel content. In these equations, $d_{m}$ is the matrix thickness in centimeters, $\mathbf{I} / \mathrm{A}$ is the current density in amperes per square centimeter, and $\mathrm{PCO}_{2}$ is the carbon dioxide partial pressure at the cathode in atmospheres.

The comparison of the results of Equation [1] with the experimental data is shown in Figure 2. Equation [1] was found to result in a mean error of 30 percent with a standard deviation of 37 percent for all of the experimental data, including the effect of current density. A.comparison of the predictions of equation [2] with the data on matrix nickel content is shown in Figure 3. A large variation of nickel content with in-plane matrix location resulted in a high degree of scatter.

The second series of tests was performed to obtain additional comparisons with the theoretical approaches. In this second series, the data were obtained with respect to the effect of matrix thickness and current density on shorting time. One test was performed to verify that the correlations were applicable to tests that are not accelerated to such a high degree by performing the test at a lower value of cathode carbon dioxide partial pressure. For this series, the average error of Equation [1] was -15 percent with a standard deviation of 15 percent if the data obtained at open circuit and with a thicker matrix are not included. In this test series doubling the matrix thickness had little effect on shorting time. The effect of current density continued to be underpredicted as shown in Figure 4, notably with respect to the shorting time at zero current (i.e., open circuit) conditions. Data with $5 \mathrm{wt} \%$ strontium carbonate added to the electrolyte have been included in this figure to provide additiunai data on the 
effect of current density. For the less accelerated test, the measured shorting time was 2102 hours compared to a predicted time from Equation [1] of 1627 hours.

\section{DATA COMPARISONS}

This report describes attempts to apply the model of Reference (2) and Equations [1] and [2] to additional data found in the literature. Data on nickel content in matrices have been reported by several molten carbonate fuel cell developers. ${ }^{(3-7)}$ No new experimental data on shorting time were found. For much of the experimental data, the conditions at which the tests were performed were not defined completely enough to allow comparison of the data with the predicted values from the model of Reference (2) or Equation [2]. No attempt was made to evaluate the experimental techniques used.

The data presented in Reference (5) were complete enough to enable a comparison with results predicted by Equation [2] if the current density and carbon dioxide pressure at the cathode are considered to be the nominal values presented. A comparison of the data from Reference (5) with the predictions from Equation [2] are shown in Figure 5. The matrix nickel contents from Reference (5) were found to be about six times the predicted levels. The effect of matrix thickness, however, was found to be predicted as was the linear increase in nickel content with time.

The data from Reference (4) was complete enough for comparisons to be made both with Equation [2] and the model of Reference (2). The comparison with predicted values from Equation [2] is presented in Figure 6. Again, the measured values are about six times the predicted levels. When the comparison with the model of Reference (2) was made, the solubility of nickel oxide in the electrolyte was increased to account for the different electrolyte composition used in Reference (2) compared to Reference (4). While Reference (2) used an electrolyte composition high in lithium content such that mixture of $72 \mathrm{~m} \%$ lithium carbonate, $28 \mathrm{~m} \%$ potassium carbonate would result after lithium consumption by cell components, Reference (4) used the $62 \mathrm{~m} \%$ lithium carbonate, $38 \mathrm{~m} \%$ potassium carbonate eutectic. The data of Ota, et. al. ${ }^{(8)}$ on nickel oxide solubility was used to make this adjustment. This comparison is shown in Figure 7. The ratio of the experimental to predicted values was reduced from the factor of around six to about two.

In the other references where comparisons with the model or Equation [2] could not be made, a data comparison was made using the older correlation of Reference (1) in which the matrix nickel content was correlated with a parameter that consisted of the product of carbon dioxide pressure and time divided by the matrix thickness. This comparison is shown in Figure 8. Although this correlation resulted in considerable scatter for each set of data, a large variation was clearly apparent between the 
results of these different sources. In the extreme case, the matrix nickel content was about 20 times the values shown in Reference (1).

\section{DISCUSSION}

A large variation in matrix nickel content exists among the data of the references investigated. All of the data other than those in References (1) and (2) were obtained at near atmospheric pressure and $650^{\circ} \mathrm{C}$ operating temperature using the $62 \mathrm{m \%}$ lithium carbonate, $38 \mathrm{~m} \%$ potassium carbonate eutectic as the electrolyte. An adjustment of the nickel oxide solubility to correct for this difference in electrolyte composition was shown in Figure 7 to account for much of the disagreement between the model of Reference (2) and the data of Reference (4).

Since lithium carbonate is consumed by various reactions within a cell, comparisons of both Equation [2] and the model of Reference (2) were made with the data of Reference (4) assuming that the eutectic electrolyte had been depleted of lithium carbonate by these reactions to result in a $50 \mathrm{~m} \%$ lithium carbonate, $50 \mathrm{~m} \%$ potassium carbonate mixture. The results of these comparisons are shown in Figures 9 and 10, respectively. Although considerable scatter still exists, the magnitude of the correction implies that the change in electrolyte composition may be the cause for the difference in matrix nickel contents between References (2) and (4). The comparison with the model in Figure 10 resulted in a mean error of 24 percent with a standard deviation of 20 percent. The scatter in the data of matrix nickel content in Figure 9 is much less than that in Figure 3 because the matrix nickel content was measured in larger matrix samples using atomic absorption in Reference (4) rather than at specific locations using an electron microprobe as in Reference (2).

Figure 9 shows an overprediction of the effect of current density for Equation [2], whereas Figure 10 shows a better prediction of the effect of current density. The significance of increased current density in reducing shorting time is more important for the data of Reference (2) than the data of Reference (4).

Electrolyte composition can affect more than just the solubility of nickel oxide. It can also affect the mechanism of nickel oxide dissolution because the mobilities of the lithium and potassium ions are a function of electrolyte composition. For the 62 $\mathrm{m} \%$ lithium carbonate, $38 \mathrm{~m} \%$ potassium carbonate eutectic, the potassium ion is more mobile than the lithium ion. Potassium would, therefore, tend to segregate in the cathode and increase the solubility of nickel oxide. As nickel ions migrate from the cathode toward the anode, the solubility of nickel oxide would decline and nickel oxide could precipitate ${ }^{(2)}$.

The differences in the results may also be due to differences in the cell designs because they can affect the change in electrolyte composition with time. For the different

HP-269 
designs, the amount of lithium carbonate and potassium carbonate salts depends on the anode, cathode, and matrix thicknesses. The consumption of lithium carbonate by corrosion and lithiation reactions also depends on the cell design because the extent and type of sheet metal components, the cathode thickness, and other possible factors are involved.

Because of the large variation in matrix nickel content, the decay rate of cell performance due to cathode dissolution would be expected to vary widely as well.

Although some features of nickel oxide dissolution are predictable with reasonable accuracy, many unknowns remain. These are not only the effects of cell design and electrolyte composition but also the effects of factors such as matrix properties and shutdown-restart cycles. The fact that the fitting parameters in the model and Equation [2] were not at the anticipated levels are an indication that all of the important mechanisms have not been modeled. The significance of the loss of nickel oxide from the cathode on its performance has not been defined.

\section{CONCLUSIONS}

The amount of nickel found in fuel cell matrices at comparable operating conditions varies by a factor of about 20 among the various fuel cell developers. This variation can be rationalized by the model of Reference (2) to be caused by differences in cell design and electrolyte composition. Such a wide variation would be expected to result in large variations of cell performance decay.

\section{ACKONOWLEDGEMENT}

The author thanks the Department of Energy for support received under Contract Number DE AC21-92MC27393. 


\section{REFERENCES}

(1) Vogel, W. M., Bregoli, L. J., Kunz, H. R., and Smith, S. W., "Stability of NiO Cath-

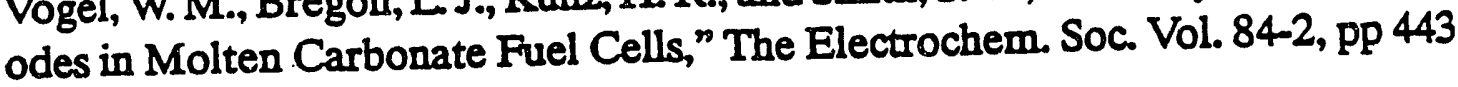
to 451 (1984)

(2) Kunz, H. R. And Pandolfo, J. W., "The Effects of Nickel Oxide Cathode Dissolution on Molten Carbonate Fuel Cell Life," Submitted for publication in the II. of the Electrochem. Soc.

(3) Ogawa, T., Ohgu, H. Murata, K., and Shirogami, T, "Effect of Alkaline-Earth Carbonate Addition on the Reduction of $\mathrm{NiO}$ Cathode Dissolution of Molten Carbonate Fuel Cell," The Electrochem. Soc. Vol. 87-2, pp 283 (1987)

(4) Shores, D. A., Selman, J. R., and Ong, E. T., "Cathode Degradation," Final Report of Institute of Gas Technology to Department of Energy, Morgantown Energy Technology Center under Contract No. DE-AC21-86 MC23263 (1989)

(5) Tanaka, T, Sasaki, A, and Murahasi, "Development of Molten Carbonate Fuel Cell Stack at Mitsubishi Electric Corporation, "24th Intersociety Energy Conversion Engineering Conference, Vol. 3, pp. 1535 to 1540 (1989)

(6) Paetsch, L. (Program Manager), "Molten Carbonate Fuel Cell Development," Final Report of Energy Researcin Corporation on Department of Energy Contract Numbers DE-AC21-76ET 11304, DE-AC03-76ET 11304, EY-76-(03-1196), and E-(04-3) 1196. (1987)

(7) Veldhuis, J. B., J., van der Molen, I. B., Makkus, R. C., and Broers, G. H. J., "NiO Cathode Dissolution and Long Term MCFC Operation," Ber. Bunsenges., Phys. Chem., Vol. 94, pp 947 to 952 (1990)

(8) Ota, K, Sinjo, T. and Kamita, N., "Solubility of Nickel Oxide in Molten Carbonates," Denki Kagaku Oyubi Kogyo Butsuri Kayaku 1987, 55(4), 323-6 (Japan)

(9) Baumgartner, C. E., "Solubility and Transport of NiO Cathodes in Molten Carbonate Fuel Cells," J. Am. Ceram. Soc., 69 , No. 2, 162-168 (1986)

(10)'Doyan, J. D., Gilbert, T., Davies, G., and Paetsch, L, "NiO Solubility in Mixed Alkali/Alkaline Earth Carbonates," J. Electrochemical Society, 134, 3035 (1987).

(11) Yuh, E. Y. and Pigeaud, A., "Determination of Optimum Electrolyte Composition," Energy Research Corporation Final Report on DOE Contract No. DEAC21-86MC23264 (1989)

(12) Lee, L N., and Shores, D. A. "Transport Considerations in the Hot Corrosion of Ni by Molten Alkali Carbonates," Л. of the Electrochem. Soc., 137, No. 3 , 859-871 (1990). 
(13) Kunz, H. R., "Transport of Electrolyte in Molten Carbonate Fuel Cells," Jl of the Electrochem. Soc., 134. No. 1, 105-113 (1987).

(14) "Evaluation of Natural Gas Molten Carbonate Power Plants", prepared by Power Systems Division of United Technologies Corporation, Final Technical Report on Gas Research Institute Contract No. 5081-344-0528 (1985).

(15) Veldhuis, J. B. J., Makkus, R. C., Van Der Molen, S. B., and Broers, G. H. J., "NiO Cathode Dissolution and Long Term MCFC Operation," Submitted to: Berichte Der Bunsengesellschaft Fur Physicalische Chemie, ECN-RX-90-027 (1990).

; 

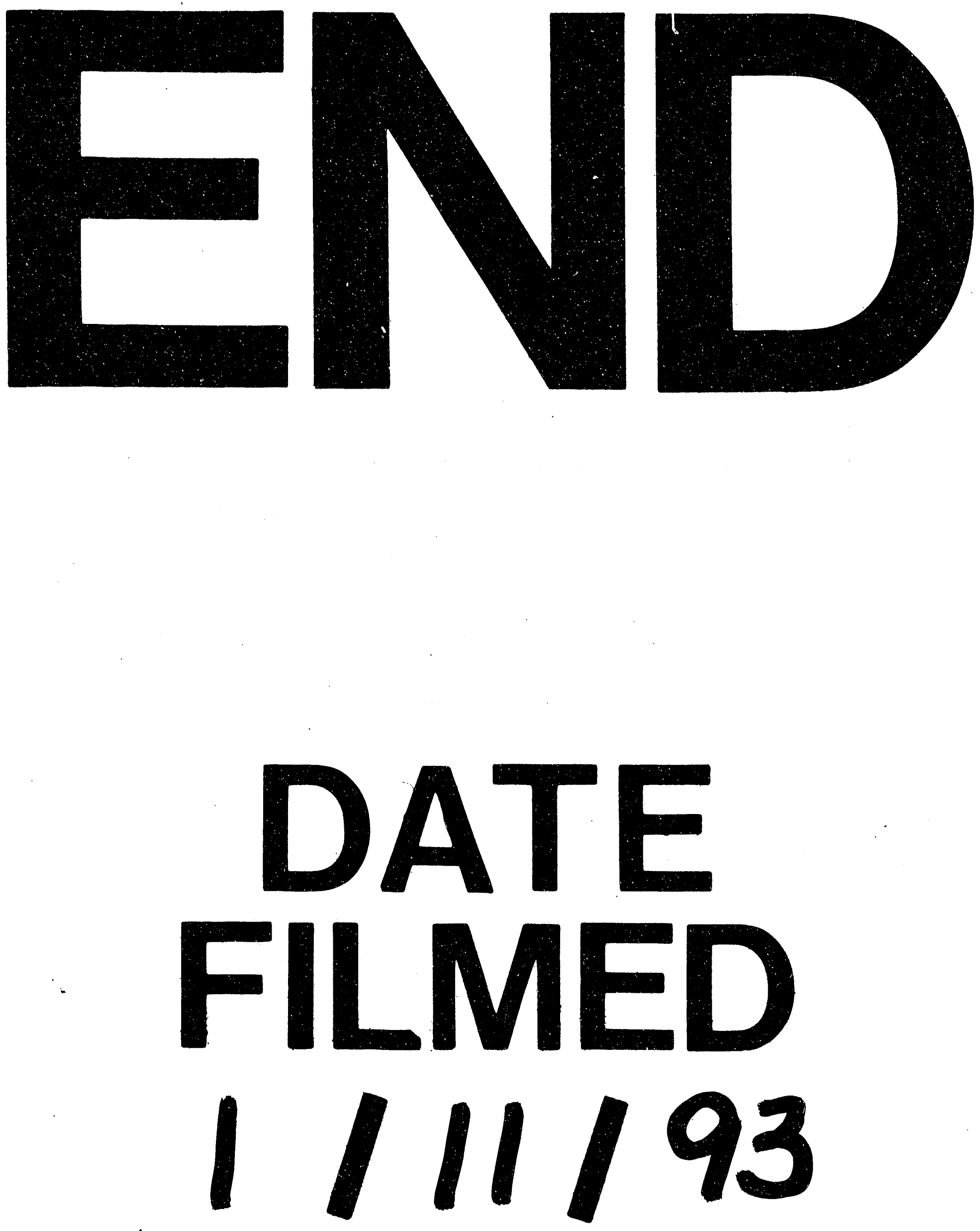